EDGARD BORGES MALTA

\title{
MÉTODOS E PROCESSOS PARA A ANÁLISE EXPERIMENTAL DE SISTEMAS OCEÂNICOS DE PRODUÇÃO DE PETRÓLEO E GÁS
}

Dissertação apresentada à Escola Politécnica da Universidade de São Paulo para obtenção do Título de Mestre em Engenharia Naval. 

EDGARD BORGES MALTA

\section{MÉTODOS E PROCESSOS PARA A ANÁLISE EXPERIMENTAL DE SISTEMAS OCEÂNICOS DE PRODUÇÃO DE PETRÓLEO E GÁS}

Dissertação apresentada à Escola Politécnica da Universidade de São Paulo para obtenção do Título de Mestre em Engenharia Naval.

Área de concentração:

Engenharia Naval

Orientador:

Prof. Dr. André Luís Condino Fujarra 


\section{Ficha Catalográfica}

\section{MALTA, EDGARD BORGES}

MÉTODOS E PROCESSOS PARA A ANÁLISE EXPERIMENTAL DE SISTEMAS OCEÂNICOS DE PRODUÇÃO DE PETRÓLEO E GÁS. São Paulo, 2010. 188 p.

Dissertação (Mestrado) - Escola Politécnica da Universidade de São Paulo. Departamento de Engenharia Naval e Oceânica.

1. Engenharia naval e oceânica. 2. Dinâmica das estruturas. 3. Análise experimental de estruturas. I. Universidade de São Paulo. Escola Politécnica. Departamento de Engenharia Naval e Oceânica. II. t. 
Obrigado a toda a minha família que me apóia em todos os momentos da minha vida. Principalmente a Alice, por toda ajuda e paciência. 



\section{Agradecimentos}

Ao professor André Fujarra, pela orientação, pela paciência e pelo constante estímulo transmitido durante todo o trabalho. Ao professor Kazuo Nishimoto pela oportunidade de trabalhar nesses últimos sete anos junto ao TPN - Tanque de Provas Numérico, o que me auxiliou tanto na graduação, quanto na conclusão do presente programa de mestrado. Também agradeço aos professores que me guiaram nos desafios proporcionados pelos projetos dos quais participei. Aos funcionários do IPT, que me auxiliaram durante a execução dos ensaios. Aos que auxiliaram na realização do ensaio: Daniel Prata, Felipe Rateiro e Rodrigo Amarante . Aos que ajudaram na revisão da dissertação: Fabio Tadao, Fernando Luz, Guilherme Feitosa, Rafael Watai, Rodolfo Gonçalves e Fabiano Rampazzo. E, por fim, a todos amigos com os quais dividi bons e maus momentos durante os últimos anos. 



\section{Resumo}

O aumento na complexidade das operações de sistemas de produção de petróleo e gás no mar é um fato concreto. Atualmente, a necessidade de avaliar o comportamento no mar destes sistemas requer a compreensão de fenômenos, até então, pouco explorados e que tornam imprescindível uma investigação apoiada em experimentos com modelos reduzidos.

Resultados obtidos em tanques de provas, por sua vez, requerem metodologias que contam com a experiência do pesquisador e que, em muitos casos, não são encontradas de maneira detalhada o suficiente na literatura. Ou seja, muitas destas metodologias normalmente são encontradas, no entanto, não em nível para que pesquisadores iniciantes desenvolvam atividades experimentais minimamente pertinentes às eventuais tomadas de decisão ou confrontação com outras linhas de abordagem como a analítica e/ou a numérica.

Portanto, é exatamente neste contexto que se insere a presente dissertação de mestrado, buscando descrever em detalhes a teoria e prática envolvida nos procedimentos experimentais para o estudo de comportamento no mar típico de uma plataforma padrão, perfeitamente adaptáveis a outras geometrias mais complexas de sistemas navais e oceânicos. Esses procedimentos envolvem desde o planejamento dos ensaios necessários, passando pelos cuidados durante sua execução, culminando nos métodos de análise dos resultados e formas usuais de documentação.

Para facilitar o processo de compreensão, além do próprio texto, este trabalho também contemplou a construção de uma ferramenta matemática dedicada à condução das atividades acima, destacando-se a avaliação e obtenção de parâmetros a partir de ensaios de decaimento e o levantamento expedito das curvas de resposta em ondas regulares, transientes e irregulares.

Palavras chave: Comportamento no mar, ensaios em tanque de provas, modelos em escala reduzida, procedimentos e análises de sistemas flutuantes, ferramenta matemática dedicada. 



\section{Abstract}

The increasing complexity of offshore system operations for oil and gas production is a reality. Currently, the need to evaluate the seakeeping of these systems requires understanding some phenomena not yet explored and, for that reason, researches using experiments with small scale models become indispensable.

Results obtained in model basins require methodologies that rely on the researcher's experience and, most of the time, they are not found detailed enough in the literature. When many of these methodologies are usually found, however, they are not ready for beginner researchers to develop experimental activities minimally relevant to any decision and/or confrontation with other lines, such as the analytical and/or numerical approaches.

Therefore, the context of this dissertation describes in detail the theory and involved practice in an experimental procedure for the study of seakeeping of a standard platform, perfectly adaptable to other complex geometries and naval systems. These procedures involve the planning of the necessary tests, through the care during their execution, culminating in the methods of result analyses and usual forms of documentation.

In order to facilitate the process of understanding, the construction of a dedicated mathematical tool to conduct the activities described above is provided, emphasizing the assessment and quick obtaining parameters from decay tests, curves response in regular and transient waves, among many others.

Key-Words: Seakeeping, model test, scale models, procedures and analyses of floating units, dedicated mathematical tool. 



\section{Sumário}

Lista de Abreviaturas

Lista de Símbolos

Lista de Figuras

Lista de Tabelas

\section{Prefácio}

1 Delineamento do Problema 1

1.1 Introdução . . . . . . . . . . . . . . . . . . . . . . . . 2

1.2 Objetivos . . . . . . . . . . . . . . . . . . . . . 8

1.3 Abordagem Experimental Típica . . . . . . . . . . . . . . . . 9

2 Experimentos em Tanque de Provas $\quad 15$

2.1 Tanques de Provas . . . . . . . . . . . . . . . . 16

2.2 Modelo em Escala . . . . . . . . . . . . . . . . . . . . . . 19

2.2.1 Unidade Flutuante . . . . . . . . . . . . . . . . . 20

2.2.2 Linhas de Amarração e Risers . . . . . . . . . . . . . . . 25

2.3 Aquisição de Dados . . . . . . . . . . . . . . . . . . . . . . . . 29

2.4 Condições Ambientais . . . . . . . . . . . . . . . . . . 32

2.5 Análise de Sinais . . . . . . . . . . . . . . . . . . 36

2.5.1 Análise de Decaimento . . . . . . . . . . . . . . . 37

2.5.2 Análise de RAO . . . . . . . . . . . . . . . . . 43 
2.5.3 Análise de Excitações aleatórias . . . . . . . . . . . . . . . . . . . . 49

2.5.4 Método de Decomposição Empírica . . . . . . . . . . . . . . . . 51

2.6 Pré-Testes . . . . . . . . . . . . . . . . . . . . 54

2.6 .1 Teste de Inclinação . . . . . . . . . . . . . . . . . . . . . . 55

2.6.2 Teste de Decaimento . . . . . . . . . . . . . . 56

2.6.3 Metodologia do Teste de Decaimento . . . . . . . . . . . . 56

2.6.4 Ordem dos Testes de Decaimento . . . . . . . . . . . . . . . 60

2.6.5 Análises e Resultados do Teste de Decaimento . . . . . . . . . . . . 61

2.7 Ensaios de Comportamento em Ondas . . . . . . . . . . . . . . 66

2.7.1 Metodologia do Ensaio em Ondas . . . . . . . . . . . . . . . 66

2.7.2 Ordem de Execução dos Ensaios . . . . . . . . . . . . . . . . . . . 69

2.7.3 Análises e Resultados . . . . . . . . . . . . . . . . . . . . . . . 70

2.7.4 Ensaio em Ondas Transientes _. . . . . . . . . . . . . . . . . 71

2.7.5 Ensaio em Ondas Regulares . . . . . . . . . . . . . . . . . 71

2.7.6 Ensaio em Ondas Irregulares . . . . . . . . . . . . . . . . . . . 72

3 Consolidação $\quad 83$

3.1 Normas dos Ensaios . . . . . . . . . . . . . . . . . . . . . 84

3.2 Documentação Padrão . . . . . . . . . . . . . . . . . . . . 86

3.3 Comparações Experimentais e Numéricas . . . . . . . . . . . . . . . . . 88

3.4 Conclusões e Recomendações . . . . . . . . . . . . . . . . . . . . . . . . . . 91

$\begin{array}{ll}\text { Referências } & 93\end{array}$

Anexo A - Características dos Tanques de Provas $\quad 95$

A.1 Características Gerais dos Tanques Nacionais . . . . . . . . . . . . . . . 95

A.2 Tanque do Instituto de Pesquisas Tecnológicas do Estado de SP . . . . . . 95

A.3 Laboratório de Tecnologia Oceânica - LabOceano . . . . . . . . . . . . . . 96 
A.4 Tanque do Departamento de Engenharia Naval e Oceânica da USP . . . . 98

A.5 Calibrador Hidrodinâmico - TPN f . . . . . . . . . . . . . . . 98

A.6 Características de Tanques no Mundo . . . . . . . . . . . . . . . . 100

$\begin{array}{ll}\text { Anexo B - Sistemas Oceânicos } & 107\end{array}$

B.1 Floating, Production, Storage and Offloading - FPSO . . . . . . . . . . 107

B.2 Semi-submersíveis . . . . . . . . . . . . . . . . . . . 108

B.3 Tension Leg Platform - TLP . . . . . . . . . . . . . . . 109

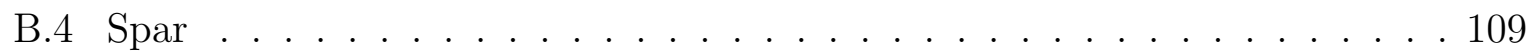

B.5 Monocolunas . . . . . . . . . . . . . . . . . . . . . . 110

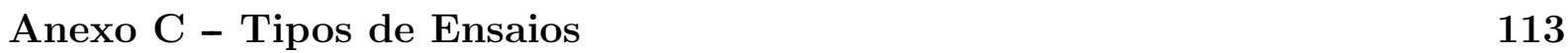

$\begin{array}{ll}\text { Anexo D - Tipos de Instrumentação } & 115\end{array}$

Apêndice I - Modelagem Analítica e Numérica $\quad 119$

Apêndice II - Estabilidade Básica $\quad 123$

Apêndice III - Estatística Básica $\quad 125$

Apêndice IV - Análise de Incertezas $\quad 127$

Apêndice V - Filtragem de Sinais $\quad 129$

Apêndice VI - Rotinas dos Ensaios 131

VI.1 Rotinas de Planejamento dos Ensaios . . . . . . . . . . . . . . . . 131

VI.2 Rotinas de Tratamento de Dados . . . . . . . . . . . . . . . . . . 139

VI.3 Rotinas de Análise . . . . . . . . . . . . . . . . . . . . . . . 146

VI.4 Rotinas de Documentação . . . . . . . . . . . . . . . . . . . . 177

Apêndice VII - Parâmetros em Escala 185 
Apêndice VIII - Propriedades de Alguns Sólidos 


\section{Lista de Abreviaturas}

CH-TPN - Calibrador Hidrodinâmico do Tanque de Provas Numérico.

CFD - Computational Fluid Dynamics.

DENO - Departamento de Engenharia Naval e Oceânica da Universidade de São Paulo.

EMD - Empirical Mode Decomposition.

FFT - Fast Fourier Transform.

FPSO - Floating, Production, Storage and Offloading unit.

IMF - Intrinsic mode functions.

IPT - Instituto de Pesquisas Tecnológicas da Estado de São Paulo.

ITTC - International Towing Tank Conference.

JONSWAP - Joint North Sea Wave Project.

KG - Altura do centro de massa da unidade flutuante com relação à quilha.

NMRI - National Maritime Research Institute.

PIV - Particle Image Velocimetry.

PM - Pierson-Moskowitz spectrum.

PMM - Planar Motion Mechanism.

RAO - Response Amplitude Operator.

RMS - Root-mean-square.

RDT - Random Decrement Technique.

TDP - Touch Down Point. 
TLP - Tension Leg Platform.

TPN - Tanque de Provas Numérico da Universidade de São Paulo.

VIM - Vortex-induced motions - Movimentos induzidos pela emissão de vórtices.

VIV - Vortex-induced vibrations - Vibrações induzidas pela emissão de vórtices. 


\section{Lista de Símbolos}

$a$

A

$A_{W L}$

B

$B_{2}$

$B_{E}$

C

f

$F_{1 i}$

$F_{2 i}$

$F_{c}$

$F_{l}$

$F_{v}$

$g$

G

H

$H_{s}$

$I_{x x}, I_{y y}$ e $I_{z z}$

$I_{W L}$

$k$

$K B$

$K G$

$K_{x x}$

$m$

$m_{n}$

$M$

$M_{\text {rest }}$

$p(x)$

$S_{x x}(f)$

$S_{x y}(f)$
Amplitude de onda.

Matriz de massa adicional.

Área de Linha d'água.

Matriz de amortecimento potencial.

Matriz de amortecimento quadrático potencial.

Matriz de amortecimento externo linear.

Matriz de restauração.

Frequência em Hz.

Força de onda de primeira ordem para o grau de liberdade $i$.

Força de onda de segunda ordem para o grau de liberdade $i$.

Força de correnteza.

Força de linhas.

Força de vento.

Aceleração da gravidade.

Função de grupo de onda.

Altura de onda.

Altura significativa de onda.

Inércias de roll, pitch e yaw.

Inércia de linha d'água

Número de onda ou relação de dispersão.

Altura do centro de carena.

Altura do centro de massa.

Raio de giração em torno do eixo $\mathrm{x}$.

Massa.

Momentos espectrais.

Matriz de massa.

Momento restaurador.

Função densidade de probabilidade.

Auto espectro de onda.

Espectro cruzado de onda e registro y. 


\begin{tabular}{|c|c|}
\hline$S_{y y}(f)$ & Auto espectro do registro y. \\
\hline$T$ & Período de onda. \\
\hline$T_{p}$ & Período de pico. \\
\hline$T_{z}$ & Período entre zeros ascendentes. \\
\hline$T_{c}$ & Período entre cristas. \\
\hline$T_{r}$ & Tempo total de amostragem do sinal. \\
\hline$u$ & Incerteza na medida. \\
\hline$u_{c}$ & Incerteza acumulada. \\
\hline$x_{i}$ & Movimento no grau de liberdade $i$. \\
\hline$X_{k}$ & Amplitude de oscilação. \\
\hline$\delta(n)$ & Fase da onda $n$ \\
\hline$\Delta t$ & Intervalo de aquisição do sinal. \\
\hline$\Delta$ & Deslocamento em massa, $\Delta=\rho \nabla$. \\
\hline$\eta$ & Elevação de onda. \\
\hline$\gamma$ & Parâmetro de amplificação do pico do espectro JONSWAP. \\
\hline$\Gamma(f)$ & Função de coerência. \\
\hline$\nabla$ & Volume submerso. \\
\hline$\omega$ & Frequência angular em $\mathrm{rad} / \mathrm{s}$. \\
\hline$\phi$ & Campo potencial. \\
\hline$\zeta$ & Coeficiente de amortecimento linear. \\
\hline$\rho$ & Massa específica da água. \\
\hline$\sigma$ & Desvio padrão. \\
\hline$\tau$ & Parâmetro de forma do espectro JONSWAP. \\
\hline$\tau_{t}$ & Tensão torcional. \\
\hline
\end{tabular}




\section{Lista de Figuras}

1.1 Tipos de Sistemas Flutuantes [Clauss, 2007] . . . . . . . . . . . 3

$1.2 \quad$ Modelos em escala reduzida de Froude . . . . . . . . . . . . . . . . . 4

1.3 Diagrama de planejamento de ensaios para sistemas oceânicos (traduzido de $[$ Chakrabarti, 1994]) . . . . . . . . . . . . . . . . . . . 11

1.4 Arranjo do ensaio realizado para investigação do efeito dos risers na dinâmica do sistema flutuante $[$ Rateiro, 2010] . . . . . . . . . . . . 12

1.5 Planejamento do ensaio considerando o efeito de linhas na dinâmica das unidades flutuantes . . . . . . . . . . . . . . . . . . . . . . 13

2.1 Tipos de tanques de provas . . . . . . . . . . . 17

2.2 Processo de calibração dos modelos . . . . . . . . . . . . . . . . . . . 19

2.3 Marcação de um modelo em mesa de desempeno . . . . . . . . . . . . 20

2.4 Verificação do centro de massa da unidade ITTC-SR192 . . . . . . . . . 21

2.5 Verificação do nivelamento do modelo em teste bifilar . . . . . . . . . . . 21

2.6 Esboço das distâncias utilizadas para determinação do KG . . . . . . . . 22

2.7 Verificação com balança de precisão de todas as massas do modelo $\quad$ . . 23

2.8 Exemplo de teste bifilar . . . . . . . . . . . . . . . . . . . 23

2.9 Instrumentos de medida utilizados durante o teste bifilar . . . . . . . 25

2.10 Exemplo de um arranjo do sistema de amarração . . . . . . . . . . . . 26

2.11 Modelo de linhas de riser . . . . . . . . . . . . . . . . 26

2.12 Visão do ângulo de saída das linha de ancoragem . . . . . . . . . . . 27

2.13 Arranjo das linhas em ensaio com fundo falso . . . . . . . . . . . 27

2.14 Fundo falso utilizado para ensaio de linhas . . . . . . . . . . . . . . 28

2.15 Medida de rigidez flexional e axial da linha . . . . . . . . . . . 28 
2.16 Modelo de linhas de amarração . . . . . . . . . . . . . . . . . . . 28

2.17 Exemplo de ondógrafo para medir elevação de onda . . . . . . . . . . . . 30

2.18 Exemplo de curva de calibração de um ondógrafo . . . . . . . . . . . . 30

2.19 Célula de carga utilizada na medida de tração das linhas . . . . . . . . . 30

2.20 Anel de carga . . . . . . . . . . . . . . . . . . . . . 31

2.21 Câmeras de infra-vermelho para a aquisição por imagem . . . . . . . . . 31

2.22 Câmeras submersas . . . . . . . . . . . . . . . . . . . . 31

2.23 Exemplo de verificação de mar irregular . . . . . . . . . . . . . . . . . 35

2.24 Procedimento de análise de decaimento . . . . . . . . . . . . . . . . 39

2.25 Sinal teórico com período de $10 \mathrm{~s}, \zeta=5 \%$ e $X_{0}=1 \ldots \ldots$. . . . 40

2.26 Regressões para o coeficiente de amortecimento do sinal da Figura 2.25 . 40

2.27 Simulações numéricas para o sinal da Figura 2.25 . . . . . . . . . . . . . 41

2.28 Sinal teórico com período de $10 \mathrm{~s}, \zeta=5 \%, X_{0}=1$ e $B_{2} /(M+A)=0.05 . \quad 42$

2.29 Regressões para o coeficiente de amortecimento do sinal da Figura 2.28 . 42

2.30 Simulações numéricas para o sinal da Figura 2.28 . . . . . . . . . . . . . 43

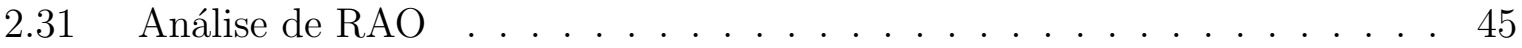

2.32 Sinais harmônicos com defasagem de 30 graus e respectivos espectros . 46

2.33 Avaliação do RAO entre dois sinais harmônicos com defasagem de 30 graus 46

2.34 Avaliação do RAO entre dois sinais harmônicos com defasagem de 30 graus através da transformada de Hilbert . . . . . . . . . . . . . . . 47

2.35 Sinal de reposta em onda transiente . . . . . . . . . . . . . . 48

2.36 Avaliação do RAO do sinal de reposta em onda transiente da Figura 2.3548

2.37 Procedimento de análise através da RDT . . . . . . . . . . . . . 49

2.38 Sinal aleatório com pontos inicias dos segmentos através do método RDT 50

2.39 Série de decaimento obtida através da média dos segmentos do sinal da Figura $2.38 \ldots \ldots \ldots$. . . . . . . . . . . . . . . . . 50

2.40 Procedimento de análise através de EMD . . . . . . . . . . . . . . . 52 
2.41 Espectro de Hibert-Huang para a série de decaimento da Figura 2.25 . . 53

2.42 Espectro de Hibert-Huang para a onda transiente da Figura 2.35 . . . . 53

2.43 Etapas de realização dos pré-testes . . . . . . . . . . . . . . . 54

2.44 Exemplo de análise linear de decaimento . . . . . . . . . . . . . 58

2.45 Série temporal de um teste de decaimento de roll com as linhas de risers, apresentando valores extremos e zeros ascendentes . . . . . . . . . . 60

2.46 Análise de um ensaio de decaimento de roll com as linhas de risers, através da regressão $2.23 \ldots \ldots$. . . . . . . . . . . . . . . 61

2.47 Teste de decaimento de sway para a condição sem linhas de risers . . . . 62

2.48 Teste de decaimento de sway para a condição com linhas de risers . . . 63

2.49 Ensaio de decaimento de roll com linhas de risers sem correnteza . . . . 64

2.50 Ensaio de decaimento de roll com linhas de risers com correnteza . . . . 65

2.51 Informações relevantes obtidas em cada tipo de onda . . . . . . . . . . 67

2.52 RAO obtido a partir de testes em ondas transientes e regulares . . . . . 68

2.53 Espectro do movimento de sway em mar irregular . . . . . . . . . . . . . 69

2.54 Ordem de execução dos ensaios . . . . . . . . . . . . . . . . . . . 70

2.55 Série temporal da onda transiente longa . . . . . . . . . . . . . . . 71

2.56 Série temporal da onda transiente curta . . . . . . . . . . . . . . 72

2.57 Exemplo de curva de RAO de onda transiente . . . . . . . . . . . . . 73

2.58 Exemplo de curva de RAO de sway em onda regular . . . . . . . . . . . 74

2.59 Exemplo de curva de RAO de heave em onda regular . . . . . . . . . . . 75

2.60 Exemplo de curva de RAO de roll em onda regular . . . . . . . . . . . . 76

2.61 Série temporal dos movimentos no ensaio em mar irregular . . . . . . . . 77

2.62 Série temporal dos movimentos no ensaio em mar irregular com correnteza 78

2.63 RAO dos movimentos no ensaio em mar irregular com e sem correnteza . 79

2.64 Espectro de Hilbert-Huang para o movimento de roll no ensaio em mar irregular com correnteza . . . . . . . . . . . . . . . . . 80 
2.65 Espectro de Hilbert-Huang para o movimento de roll no ensaio em mar irregular sem correnteza . . . . . . . . . . . . . . . . . . 80

2.66 Espectro de Hilbert-Huang para o movimento de roll no ensaio em mar irregular com correnteza comparado com o espectro de Fourier . . . . . . 81

2.67 Espectro de Hilbert-Huang para o movimento de roll para o ensaio em mar irregular com correnteza . . . . . . . . . . . . . . . . . 81

2.68 RDT para o movimento de roll no ensaio em mar irregular sem correnteza e sem risers . . . . . . . . . . . . . . . . . . . . . . 82

2.69 RDT para o movimento de roll no ensaio em mar irregular sem correnteza e com risers . . . . . . . . . . . . . . . . . . . . . . . . . 82

3.1 Balanço entre incertezas do modelo físico e modelo numérico truncado $[\mathrm{ITTC}, 2008 \mathrm{~b}] \ldots \ldots \ldots \ldots$

3.2 Características e propriedades avaliadas em cada modelo numérico . . . 89

3.3 Comparação entre níveis de amortecimento para a calibração dos modelos numéricos . . . . . . . . . . . . . . . . . . . . . . 990

A.1 Carro de reboque no tanque do IPT . . . . . . . . . . . . . 96

A.2 Construção de modelo no tanque de provas do IPT . . . . . . . . . . . . 97

A.3 Carro do sistema PMM f . . . . . . . . . . . . . . . . . . 98

A.4 Laboratório de Tecnologia Oceânica - LabOceano . . . . . . . . . . . . . 99

A.5 Dimensões principais do tanque de provas DENO-USP . . . . . . . . . 100

A.6 Dimensões principais do atenuador de ondas DENO-USP . . . . . . . . . 100

A.7 Capacidade de geração de ondas do CH-TPN . . . . . . . . . . . . . 101

A.8 Sistema de Oscilação Forçada . . . . . . . . . . . . . . . . . . . . 103

A.9 Sala de Visualização . . . . . . . . . . . . . . . . . . . . . 103

A.10 David Taylor - Deep Sea Basin . . . . . . . . . . . . . . . . . . . . . 104

A.11 Exemplo da oficina de modelo do Tanque David Taylor . . . . . . . . . . 104

A.12 NMRI Japão - Deep Sea Basin - [Malta et al., 2009] . . . . . . . . . . . . 105

A.13 Visão geral de montagem de ensaio com tendões . . . . . . . . . . . . . 105 
A.14 Balança de inércia do Offshore Model Basin [Chakrabarti, 1987] . . . 106

B.1 Comparação entre ressonância dos sistemas e espectros de mar . . . . . . 107

B.2 P-50 - Sistema do tipo FPSO . . . . . . . . . . . . . 108

B.3 P-36 e P52 exemplos de sistemas do tipo semisubmersível . . . . . . . . 109

B.4 Seastar - Sistema do tipo TLP . . . . . . . . . . . . . . . . 110

B.5 Exemplos de sistemas do tipo spar . . . . . . . . . . . . . . 111

B.6 Moonpool, saia e praia de uma monocoluna . . . . . . . . . . . . . 111

B.7 Exemplo de um sistema do tipo monocoluna . . . . . . . . . . . . . . 112

D.1 Imagem utilizada na aquisição do TDP de um modelo de riser . . . . . . 116

D.2 Exemplo de campo de velocidades através de um análise de PIV . . . . . 116

D.3 Medidor de pressão . . . . . . . . . . . . . . . . . . . 117

D.4 Exemplo de rate gyro para medida de velocidade angular . . . . . . . . 117

I.1 Graus de liberdade dos sistemas flututantes . . . . . . . . . . . . . 119

I.2 Condições de contorno do modelo potencial . . . . . . . . . . . . . . . 120 



\section{Lista de Tabelas}

1.1 Matriz de ensaio definida após o planejamento dos ensaios . . . . . . . . . 14

2.1 Determinação do centro de massa do modelo . . . . . . . . . . . . . . . . . 22

2.2 Resultados do teste bifilar . . . . . . . . . . . . . . . . . . . 24

2.3 Relações entre águas rasas e profundas [Chakrabarti, 1987] . . . . . . . . . 32

2.4 Determinação da altura metacêntrica . . . . . . . . . . . . . . . . 56

2.5 Comparação dos parâmetros estatísticos com e sem a presença da correnteza 76

3.1 Tolerâncias para ondas regulares e irregulares [Chakrabarti, 1987] . . . . . 84

A.1 Dimensões do tanque do IPT f . . . . . . . . . . . . . . . 96

A.2 Dimensões do tanque do LabOceano . . . . . . . . . . . . . . . . . . . 97

A.3 Dimensões do Calibrador Hidrodinâmico ～. . . . . . . . . . . . . . . . . . . 99

A.4 Principais característica dos tanques no mundo . . . . . . . . . . . . 102

V.1 Faixa de frequência na escala do modelo . . . . . . . . . . . . . . . 129

VII.1Parâmetros em escala . . . . . . . . . . . . . . . . 186

VIII.1Propriedades de alguns sólidos . . . . . . . . . . . . . . 187 



\section{Prefácio}

As referências sobre os aspectos importantes que envolvem os principais ensaios em tanques de provas para avaliação do comportamento no mar de sistemas flutuantes possuem a descrição dos fenômenos sem apresentar todo o procedimento do ensaio.

Os procedimentos aqui descritos envolvem desde o planejamento dos ensaios, passando por alguns cuidados durante a sua execução, até os métodos de análise dos dados. Adicionalmente, as informações importantes e relevantes para a documentação dos experimentos estão brevemente descritas.

Essa dissertação de mestrado, além de apresentar os procedimentos e metodologias, envolvidas nos ensaios em tanque de provas, também apresenta algumas ferramentas numéricas especialmente criadas para auxiliar e automatizar as tarefas desde o planejamento, passando pela preparação, execução, análise, e finalmente, a documentação padrão dos experimentos dos sistemas flutuantes. Estas ferramentas irão auxiliar diretamente o desenvolvimento dos ensaios no Calibrador Hidrodinâmico do Tanque de Provas Numérico, como ainda servir de material de referência aos pesquisadores que trabalham em laboratórios que realizam esses tipos de ensaios.

A estrutura do texto tem como objetivo adicional evitar que o leitor tenha que buscar na literatura disponível toda a teoria necessária à compreensão básica dos experimentos. Portanto, ao longo de poucas páginas pode-se obter informações importantes dessas referências, teorias e resultados. Além disso, o procedimento é sempre apresentado em conjunto com aplicações advindas de um experimento típico, convenientemente selecionado.

Primeiramente, na parte de delineamento do problema, uma descrição breve dos aspectos gerais da produção de petróleo e gás no mar, com uma descrição dos ensaios a serem realizados para avaliação de sistemas flutuantes, é apresentada no Capítulo 1.1. Por sua vez, os objetivos do estudo são sedimentados no Capítulo 1.2. Em seguida, Capítulo 1.3, são apresentadas as etapas que envolvem um ensaio no tanque de provas, desde a definição da escala até a documentação dos experimentos.

Com relação aos experimentos em si, a metodologia de cada ensaio é descrita, iniciando 
com as informações sobre o tanque de provas utilizado no Capítulo 2.1.

No Capítulo 2.2, a construção e a calibração dos modelos em escala reduzida, com os procedimentos que precedem o ajuste de lastro e os pré-testes, são utilizadas para verificar características como altura metacêntrica e períodos naturais. Neste capítulo, também são apresentados os cuidados durante a calibração do modelo das linhas de ancoragem e modelos de risers. Em seguida, os equipamentos de aquisição de dados utilizados são descritos no Capítulo 2.3.

Alguns dos cuidados que envolvem a representação das condições ambientais e como são verificadas as suas características, para assim garantir que as mesmas atendam aos critérios estatísticos, estão no Capítulo 2.4.

No Capítulo 2.5, as análises dos sinais do ensaio com os tratamentos utilizados como filtragem, transformação da escala do modelo para real, em conjunto com as rotinas que foram criadas para cada operação.

No Capítulo 2.6, destacam-se as avaliações em ensaios de decaimentos, onde são obtidos coeficientes de massa adicional, de amortecimentos lineares e quadráticos; os ensaios para a obtenção das curvas de resposta em ondas regulares e transientes, além da avaliação do sistema flutuante em condição de mar, ou ondas irregulares.

No Capítulo 2.7, os procedimentos de cada ensaio estão descritos, desde os ensaios em ondas regulares até os ensaios que combinam a incidência de onda e correnteza simultaneamente.

Com a consolidação dos ensaios, as normas que regulam os ensaios apresentados ao longo dessa dissertação são brevemente descritas no Capítulo 3.1, bem como as informações que devem estar presentes na documentação dos ensaios para a consolidação dos resultados estão no Capítulo 3.2 .

No Capítulo 3.3 encontra-se uma descrição geral dos modelos numéricos e como as comparações com os resultados experimentais auxiliam na sua calibração. Por fim, algumas conclusões e recomendações estão presentes no Capítulo 3.4.

Importante destacar que alguns dos procedimentos foram colocados na forma de rotinas para auxiliar o processo de análise e preparação do relatório do experimento. Todas as rotinas desenvolvidas são apresentadas no Apêndices VI. 
1 Delineamento do Problema 


\subsection{Introdução}

A busca por fontes de energia é um dos maiores desafios do homem e os produtos mais importantes da matriz energética atual são os derivados de petróleo. Contudo, a exploração do petróleo não é uma tarefa simples, quer seja por motivos técnicos, sociais, econômicos ou mesmo ambientais. Um bom exemplo é o caso do Oriente Médio, onde apesar da facilidade de extração devido aos poços estarem próximos à superfície, guerras pelo controle dos reservatórios acabaram dificultando a exploração em várias oportunidades ao longo da história.

No Brasil, por outro lado, as dificuldades são em sua grande maioria de ordem técnico-econômica e se concentram predominantemente na exploração em alto mar, embora existam pequenas explorações terrestres, não menos complicadas como aquelas na bacia de Urucu, marcadas por discussões sobre problemas ambientais e de preservação da Amazônia.

Independente das dificuldades técnico-econômicas, a exploração em alto mar ainda tem se mostrado uma ótima solução e, considerando a necessidade constante por novas reservas, vem sendo intensamente praticada a partir de unidades flutuantes operando em águas cada vez mais profundas, o que acaba por aumentar o desafio dos projetos de pesquisa e desenvolvimento neste segmento.

Em grande parte, os desafios relacionados com a produção de petróleo e gás no mar geralmente são operações processadas em condições ambientais adversas, onde os principais agentes ambientais (onda, correnteza e vento) atuam de forma severa. Além das embarcações de apoio, são necessárias unidades de produção, normalmente plataformas, que podem apresentar diversas formas e tipos, utilizadas conforme as necessidades e características da área de operação, tema extensamente discutido em [Clauss, 2007].

Dentre os principais tipos de plataforma, destacam-se as plataformas fixas, as auto-elevatórias e as flutuantes. Este último grupo apresenta, ainda, uma grande diversidade de formas e capacidades operacionais, dentre as quais: as unidades FPSO, que possuem formas de navio; as plataformas semi-submersíveis, as plataformas spar e, mais recentemente, o conceito das monocolunas. No Anexo B são apresentados alguns detalhes das principais unidades flutuantes.

Independente da geometria, as unidades flutuantes sofrem movimentações devido à ação das ondas, correntezas e ventos, com possibilidade de danificar os subsistemas 


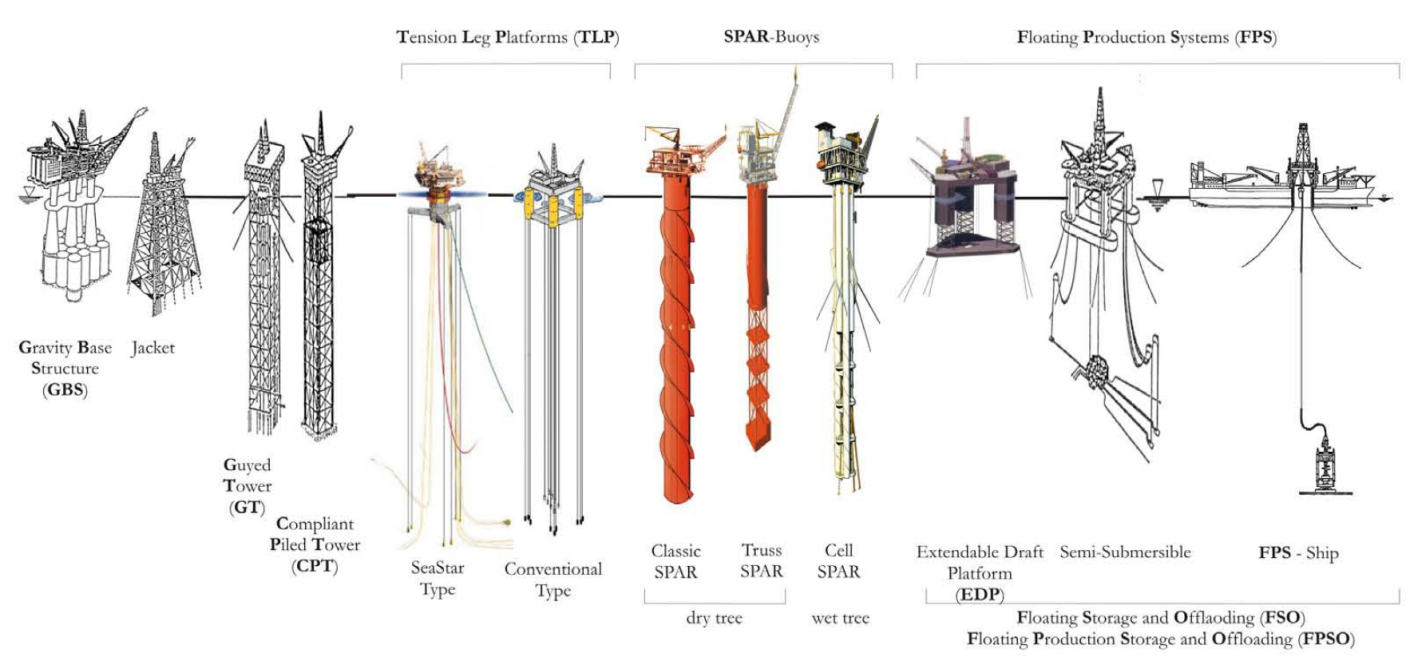

Figura 1.1: Tipos de Sistemas Flutuantes [Clauss, 2007]

lançados em direção aos poços localizados no leito do oceano. Por esse motivo, torna-se indispensável que essas unidades se mantenham posicionadas na superfície, dentro de um raio de ancoragem que atenda aos requisitos de movimento ditados pelos equipamentos de convés e também submersos. Neste sentido, dois tipos de sistema são responsáveis pelo posicionamento das unidades flutuantes: o sistema de ancoragem convencional e o sistema de posicionamento dinâmico.

O sistema de ancoragem convencional é constituído por âncoras e amarras ${ }^{1}$, atuando como molas que produzem restauração capaz de garantir a posição de interesse, mesmo sob a ação dos agentes ambientais.

Por outro lado, no sistema de posicionamento dinâmico não existe ligação física entre a plataforma e o fundo do mar, exceto pela eventual presença de equipamentos de perfuração no caso de plataforma do tipo sonda. Sensores acústicos determinam a deriva com relação a uma posição de interesse pré-estabelecida e propulsores controlados por computador a restauram constantemente.

Os efeitos do mar nos sistemas flutuantes descritos acima são alvo de pesquisas até hoje. Contudo, conforme apresentado em [Chakrabarti, 1994], as primeiras descobertas sobre como modelar os fenômenos de mecânica dos fluidos pertinentes à engenharia naval dizem respeito aos trabalhos realizados por Osborne Reynolds e William Froude, respectivamente responsáveis por desenvolver os critérios para a consideração de efeitos viscosos e inerciais. Posteriormente, apareceram nomes como Lamb, Stokes, Boussinesq, entre outros.

\footnotetext{
${ }^{1}$ As amarras são compostas por correntes e cabos de aço ou poliéster.
} 


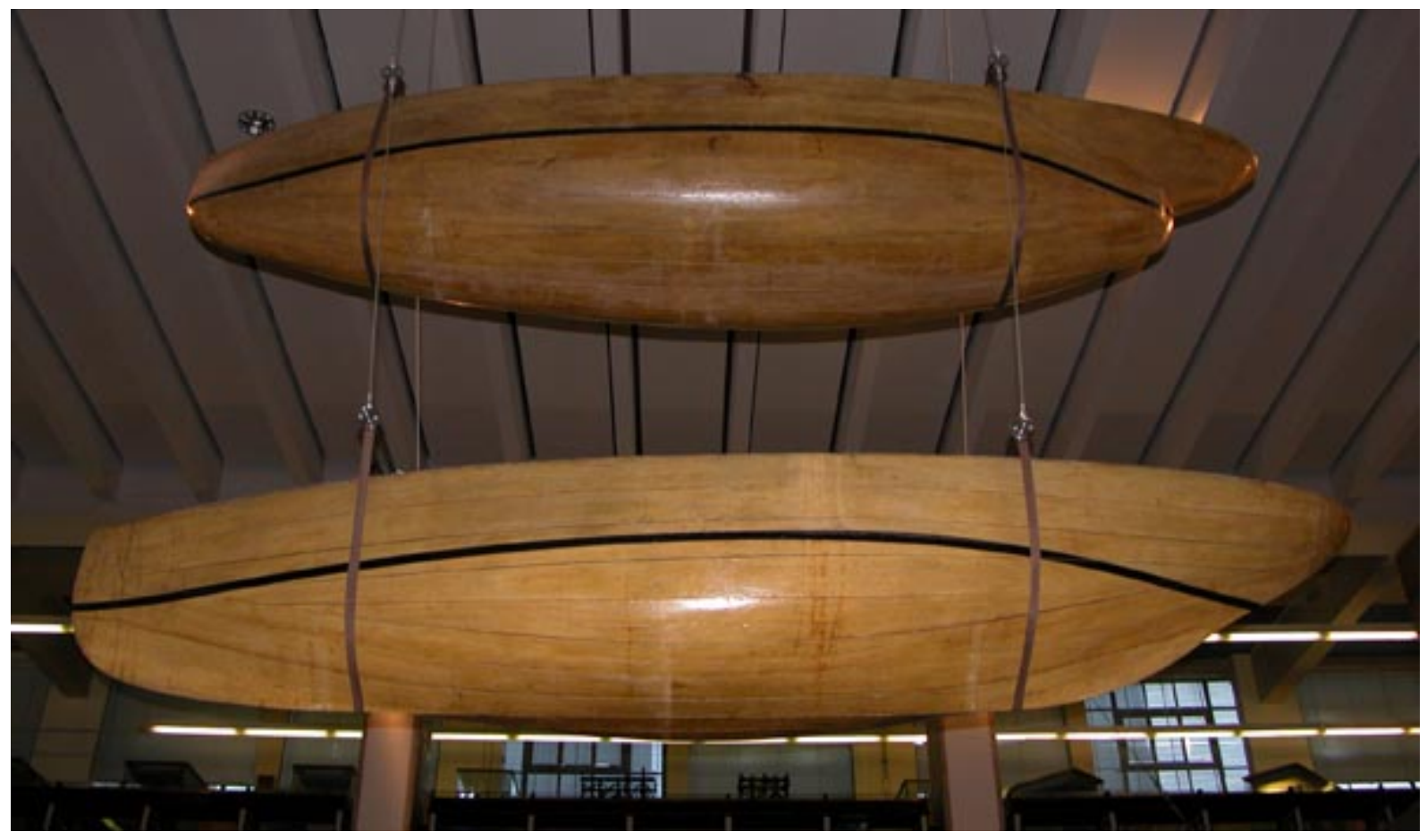

Figura 1.2: Modelos em escala reduzida de Froude

Embora Reynolds (1842-1912) fosse um investigador de muitos fenômenos físicos, destacou-se por ser um dos primeiros a discutir sobre os efeitos da escala na propulsão marinha e por realizar pesquisas hidrodinâmicas. Enquanto explorava os resultados aparentemente discrepantes dos experimentos sobre perda de carga de Poiseuille e Darcy, Reynolds argumentou que, enquanto as forças viscosas tendem a produzir estabilidade, as forças inerciais tendem a causar instabilidade. Desta forma, a mudança de um tipo de movimento para outro se deve à relação entre essas forças e, portanto, ocorreria em algum valor critico dessa relação, conhecida como número de Reynolds.

Por outro lado, Froude (1810-1879) iniciou suas investigações propondo a idéia de uma quilha para a atenuação do movimento de jogo do navio. Sua primeira publicação discutia sobre esse movimento, o qual julgou ser de grande importância no estudo das formas do casco. Em 1870, iniciou uma série de experimentos para estudar a resistência de embarcações utilizando um tanque de reboque. Mais tarde, em 1876, a British Association organizou um comitê, tendo Froude como um dos membros incumbidos de estudar propulsão, estabilidade e comportamento em ondas de navios. Assim, foi utilizado um conjunto de modelos, de 3, 6 e 12 pés, para auxiliar no equacionamento da resistência ao avanço. Uma imagem desses modelos pode ser vista na Figura 1.2 expostos no Museu de Ciências de Londres.

Os experimentos de Froude levaram a seguinte proposição: "In fact, we are thus 
brought to the scale of comparison which was just now enunciated, that the entire resistance of a ship and a similar model are as the cube of their respective dimensions if their velocities are as the square roots of their dimensions". Ou seja, as forças de resistência do navio e de seu modelo estarão em uma relação de escala ao cubo, se suas velocidades estiverem na raiz desta mesma escala. No Apêndice VII são apresentadas as relações entre os principais parâmetros envolvidos nos ensaios típicos e as respectivas relações com a escala definida segundo a Lei de Froude.

Nos estudos de sistemas oceânicos de exploração de petróleo descritos nessa dissertação, o número de Reynolds e a Lei de Froude são utilizados em ensaios de arrasto e de comportamento em ondas na definição das escalas para os modelos. No entanto, para ensaios típicos de sistemas oceânicos sujeitos à ação de ondas, sabe-se que os modelos são ajustados apenas pela Lei de Froude e que a compatibilidade dos números de Reynolds se faz de maneira artificial através da utilização de elementos de excitação de turbulência, em princípio, capazes de emular no modelo regimes de escoamento semelhantes aos observados no protótipo.

Ainda no cenário das investigações experimentais sobre a dinâmica de sistemas oceânicos, é importante deixar claro que não só os fenômenos não conhecidos devem ser estudados, mas também fenômenos de natureza tipicamente não-linear, onde a abordagem experimental se associa à teórica em busca de uma maior compreensão das situações reais de operação no mar.

Portanto, em primeira instância, os experimentos em tanques de provas ainda são ferramentas confiáveis e amplamente aplicadas na reprodução mais realística de situações extremas de operação dos novos sistemas flutuantes. Resultados experimentais são utilizados para a calibração de modelos matemáticos ou comprovação de sua capacidade preditiva. Além disso, devido à necessidade de se projetar sistemas de produção de petróleo e gás com formas cada vez mais otimizadas, os procedimentos e os resultados obtidos em tanques de provas tornam-se ferramentas indispensáveis na pesquisa e desenvolvimento de tais formas.

Em se tratando das infra-estruturas disponíveis, os experimentos podem ser conduzidos em diferentes tipos de tanques, a depender das investigações pretendidas. Cada infra-estrutura conta com uma habilidade específica para um determinado grupo de experimentos. Assim, existem tanques oceânicos, tanques de reboque, tanques de reboque com gelo, tanques de águas rasas e, ainda, canais de circulação.

Como exemplo, ensaios de sistemas flutuantes em ondas são melhores representados 
nos tanques oceânicos. Estes tanques possuem a capacidade de geração de ondas multidirecionais, eventualmente com a absorção ativa, o que amplia em muito os tempos de ensaio, pois diminui a reflexão das ondas que novamente incidiriam sobre a região dos testes.

Isto não significa que ensaios de comportamento em ondas de sistemas flutuantes não possam ser realizados em outros tipos de infra-estrutura além das oceânicas. Por exemplo, existem tanques de reboque que podem investigar este tipo de comportamento, como é o caso do tanque de provas do Instituto de Pesquisas Tecnológicas do Estado de São Paulo (IPT), onde, ao invés de representar a velocidade de avanço de embarcações, o reboque representa a correnteza em plataformas. Assim, os tanques de reboque podem realizar outras classes de ensaios, como por exemplo, aquelas focadas na observação do fenômeno de movimentos induzida pelos emissão de vórtices (VIM - Vortex-induced Motion), conduzidos por [Fujarra et al., 2009], ou aqueles preocupados com a avaliação dos comportamentos de segunda ordem em ondas, conduzidos por [Simos et al., 2008], ambos realizados no IPT.

De qualquer forma, independente da infra-estrutura adotada, sabe-se que os ensaios de comportamento no mar de sistemas flutuantes são caracterizados por um conjunto de testes típicos: os ensaios de calibração (inclinação e ajustes de lastro), ensaios de decaimento, ensaios em ondas regulares e ensaios em ondas irregulares.

Além disso, face ao enorme número de parâmetros e variáveis envolvidas, os ensaios precisam ser projetados com relação à escala do modelo, à instrumentação e à qualidade dos resultados pretendidos. Isto se faz com o auxílio de análises de incerteza, principalmente em se tratando de ensaios nunca desenvolvidos anteriormente. Para ensaios padrões, tais análises podem ser eventualmente suprimidas, desde que haja acúmulo de conhecimento suficiente que permita tal tomada de decisão.

Neste contexto, o foco do estudo aqui apresentado é a abordagem experimental típica de análises do comportamento no mar de sistemas flutuantes, descrevendo em detalhes seus principais métodos e processos de execução. Cumpre mencionar que um estudo numérico foi desenvolvido em conjunto, apresentado em [Rateiro, 2010], como parte de um programa paralelo de mestrado.

As principais referências utilizadas e que discorrem a respeito dos principais aspectos relacionados com ensaios de comportamento no mar de sistema flutuantes são brevemente discutidas abaixo.

Em [Newman, 1982] encontra-se uma boa discussão quanto à modelagem dos 
principais fenômenos. Em [Chakrabarti, 1994], a descrição dos procedimentos de ensaio é feita em detalhes. Outra referência importante utilizada é o [SNAME, 1984], onde são apresentados assuntos relacionados com a arquitetura naval, inclusive com resultados experimentais. [Faltinsen, 1990] também apresenta de maneira didática uma boa discussão dos vários fenômenos de interesse.

Vale lembrar ao leitor que, conforme apresentado anteriormente, muitos assuntos discutidos nestas referências são apresentados em momento oportuno ao longo dos próximos capítulos deste texto. 


\subsection{Objetivos}

O objetivo principal deste texto é apresentar em detalhes os métodos e processos utilizados na análise experimental típica do comportamento no mar de um sistema oceânico com foco na avaliação da influência de riser $^{2}$. Como elemento de apoio à melhor compreensão das práticas aqui apresentadas e discutidas, também foram geradas algumas ferramentas numéricas que poderão ser utilizada na realização de ensaios futuros. De antemão é importante deixar claro que, embora tenham sido baseadas em um tipo de ensaio específico, muitas das atividades mais adiante apresentadas são passíveis de adaptações e aplicação em outros experimentos.

\footnotetext{
${ }^{2}$ Risers são dutos para a exploração e produção de petróleo que transferem o óleo dos poços até a planta de processo, podendo ser rígidos ou flexíveis.
} 


\subsection{Abordagem Experimental Típica}

O processo de análise experimental do comportamento no mar de um sistema oceânico começa com a idealização do problema e o levantamento das hipóteses que permitam a construção de um modelo matemático. Em alguns casos, a criação desse modelo é tão complexa que a realização de experimentos em escala reduzida, capazes de reproduzir a dinâmica do sistema em estudo, torna-se necessária.

Geralmente, estes experimentos em escala reduzida são conduzidos em tanques de prova. Os principais benefícios da realização de um experimento em tanque de prova são: a validação de valores de projeto, a possibilidade de trabalhar com problemas de difícil resolução analítica, a obtenção de coeficientes empíricos, a comprovação de técnicas analíticas, a verificação de operações oceânicas, a avaliação de efeitos de ordem elevada e a investigação de efeitos imprevisíveis ou inesperados.

Em geral, a investigação experimental busca responder as seguintes questões: Qual o problema e/ou qual a questão a ser respondida? Qual a física envolvida? O que deve ser medido? Quais as variáveis devem ser controladas? Qual a precisão que será necessária? Qual instrumentação deve ser usada? Quais experimentos podem solucionar o problema? Quais as dificuldades e dúvidas podem ser antecipadas? Qual será a matriz de ensaio? Qual o custo e tempo dos ensaios? Como a informação será armazenada e analisada? Quais as técnicas utilizadas na análise? Como o resultado será utilizado? Qual a melhor maneira de apresentar os resultados?

Concomitantemente, sabe-se que nos projetos de sistemas flutuantes para exploração e produção de petróleo, alguns experimentos são indispensáveis. Dado o alto custo para a realização desses experimentos, estes devem ser realizados de maneira eficiente, de tal forma que seus resultados forneçam o melhor entendimento do problema estudado.

Com isso em mente, o planejamento de um experimento é uma das primeiras etapas, devendo contemplar os seguintes aspectos: A escolha da escala a ser utilizada e as implicações envolvidas nessa escolha; A própria escolha do tanque de provas; O método de construção do modelo; A representação de todas as condições ambientais importantes, atentando para o atendimento das normas e critérios referentes ao estudo pretendido.

No caso de experimentos associados ao desenvolvimento de novos sistemas oceânicos, o início do planejamento experimental deve coincidir com o próprio projeto dos mesmos.

Além de diminuir o custo, outra justificativa para o planejamento esta relacionada ao fato de que o número de condições ambientais agindo sobre os sistemas flutuantes pode 
trazer uma quantidade de dados inviável de ser analisada em tempo hábil.

Com base nestes aspectos, busca-se que o experimento não seja uma mera aquisição de dados, mas um conjunto de tarefas planejadas e coordenadas com o objetivo final de avaliar de maneira precisa e eficiente o problema em questão.

Ainda que não completamente desenvolvidos, os modelos matemáticos auxiliam qualitativamente na antecipação de alguns efeitos inesperados. Além disso, de acordo com [Coleman \& Steele, 1999], a análise das incertezas é uma ferramenta importante no planejamento de experimentos e auxilia na economia de tempo.

O planejamento pode ser dividido em etapas, conforme descrito em [Chakrabarti, 1994], sinteticamente apresentadas no diagrama da Figura 1.3. Os próximos parágrafos tecem comentários a respeito dessas etapas.

Um dos critérios mais importantes para o sucesso de um experimento diz respeito à escolha da escala de redução, pois os parâmetros que serão avaliados devem ser bem determinados e permitir a medida das grandezas de interesse, sem que sejam afetadas pela escolha feita. Definida a escala, deve-se verificar quais tanques de prova estão habilitados e se as infra-estruturas disponíveis atendem as necessidades do experimento.

O passo seguinte é a construção do modelo, muitas vezes a etapa mais demorada, pois envolve um grande número de tarefas e recursos materiais e humanos. Além disso, na maioria das vezes, deve contemplar facilidades para o ajuste de lastro e instalação da instrumentação. Por este motivo, sugere-se considerá-la em paralelo a outras etapas do experimento, particularmente com relação às calibrações da instrumentação necessária e das condições ambientais na escala do modelo, principalmente as ondas.

Ainda com relação à construção dos modelos, esta pode ser feita a partir de diversos materiais, dentre os quais, os mais frequentes são: a madeira, o alumínio, o ferro, a fibra de vidro, os plásticos e a cera. Na Figura A.11 do Anexo A, é apresentada uma imagem de uma oficina convencional de construção de modelos do tanque David Taylor, típica da década de cinquenta. Atualmente, novas tecnologias de construção têm auxiliado a obtenção de modelos mais precisos, com fabricação mais rápida a partir de infra-estruturas mais modernas como aquela atualmente encontrada no IPT, dotada de equipamentos automatizados e metrologia de precisão, ver Figura A.2 também no Anexo A. 


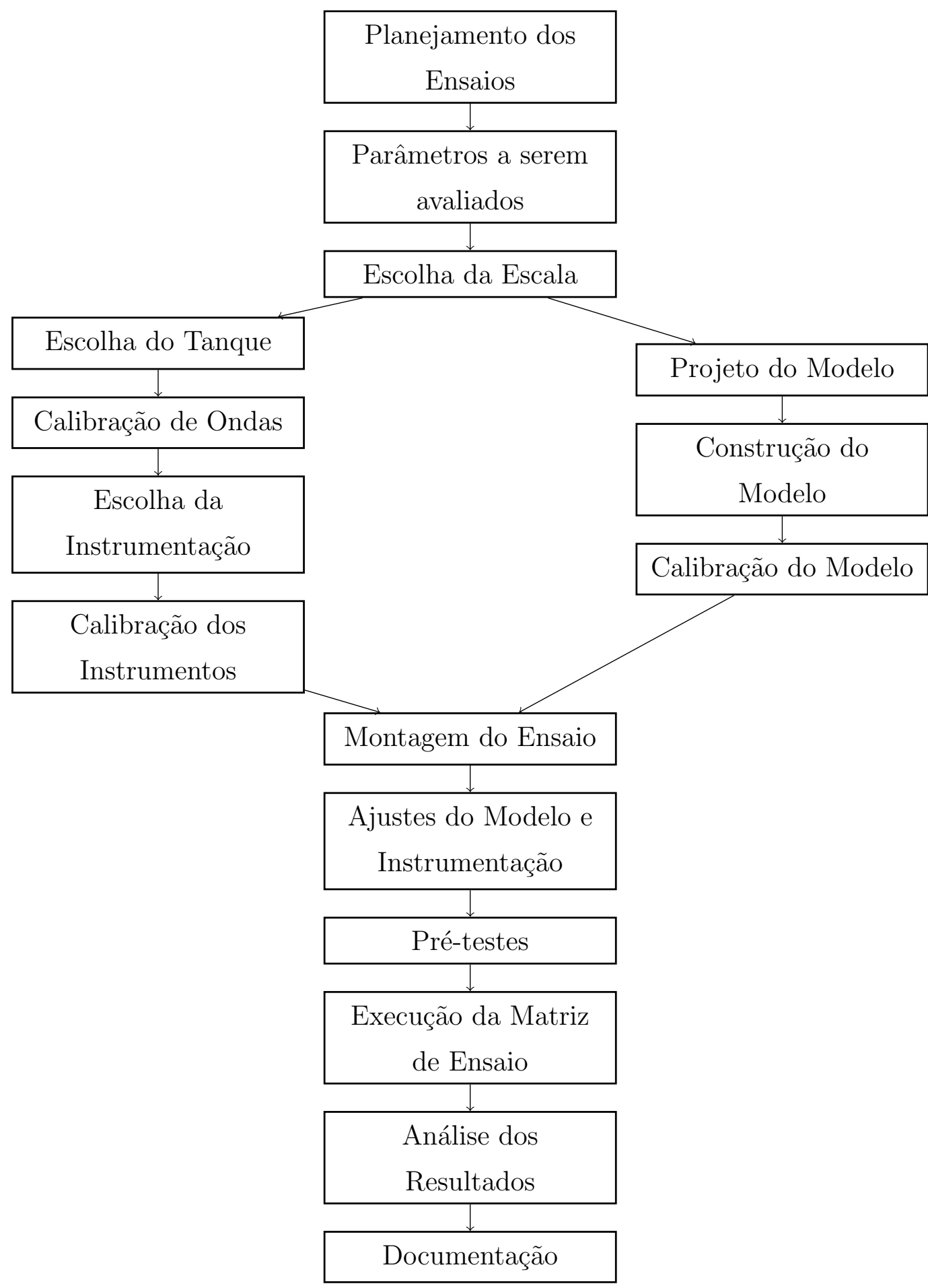

Figura 1.3: Diagrama de planejamento de ensaios para sistemas oceânicos (traduzido de [Chakrabarti, 1994])

No tocante à instrumentação, esta deve ser verificada, e eventualmente calibrada, antes que o modelo seja instalado no tanque de provas. Obviamente, uma nova etapa de calibração deve acontecer com todo o arranjo experimental instalado. Para a calibração de ondas deve-se desconsiderar a presença do modelo, como forma de garantir que as ondas calibradas não contenham efeitos associados à interação modelo/fluido. 
Ainda de acordo com a Figura 1.3, os próximos passos são a montagem do ensaio, alguns pré-testes de verificação, a execução dos ensaios planejados e posterior análise e documentação.

Todas as idéias desenvolvidas anteriormente foram mais aplicadas ao estudo experimental do comportamento no mar de um modelo padronizado (ITTC-SR192) (ver Figura 1.4). Este experimento foi planejado de maneira a contemplar os efeitos das linhas na dinâmica da unidade flutuante devido às ondas e correnteza. Um modelo numérico foi construído no $\mathrm{TPN}^{3}$ e auxiliou no processo de planejamento do experimento.

Um diagrama detalhado para o planejamento desses experimentos é apresentado na Figura 1.5. Neste caso, existem algumas diferenças com relação às etapas propostas em [Chakrabarti, 1994]. A principal diferença diz respeito à escolha do tanque de provas, pois no estudo em questão, o tanque de provas do IPT foi previamente definido (ver Anexo A.2).

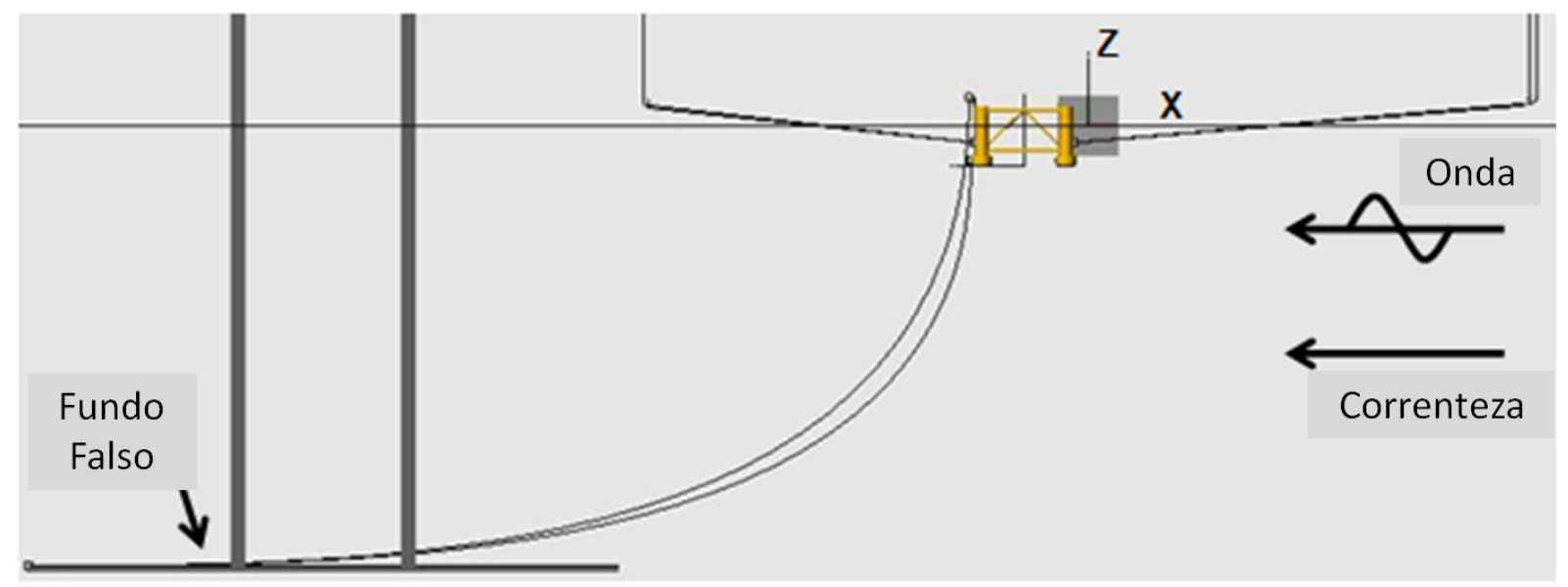

Figura 1.4: Arranjo do ensaio realizado para investigação do efeito dos risers na dinâmica do sistema flutuante [Rateiro, 2010]

Após o levantamento das dimensões do tanque do IPT, junto com o arranjo do carro de reboque, um modelo numérico foi construído no TPN para auxiliar o dimensionamento do sistema de amarração e risers. Nessa etapa foram dimensionadas as molas que representassem em escala o sistema de amarração e limitassem a deriva da unidade, de tal forma que o equipamento óptico de medição monitorasse plenamente a dinâmica da mesma ${ }^{4}$. A partir do sistema composto pela unidade flutuante, amarração

\footnotetext{
${ }^{3} \mathrm{O}$ modelo numérico do TPN é baseado em simulações no domínio do tempo, que contemplam a dinâmica acoplada das linhas e unidade flutuante.

${ }^{4}$ Ver descrição sobre o sistema de aquisição no capítulo 2.3 .
} 


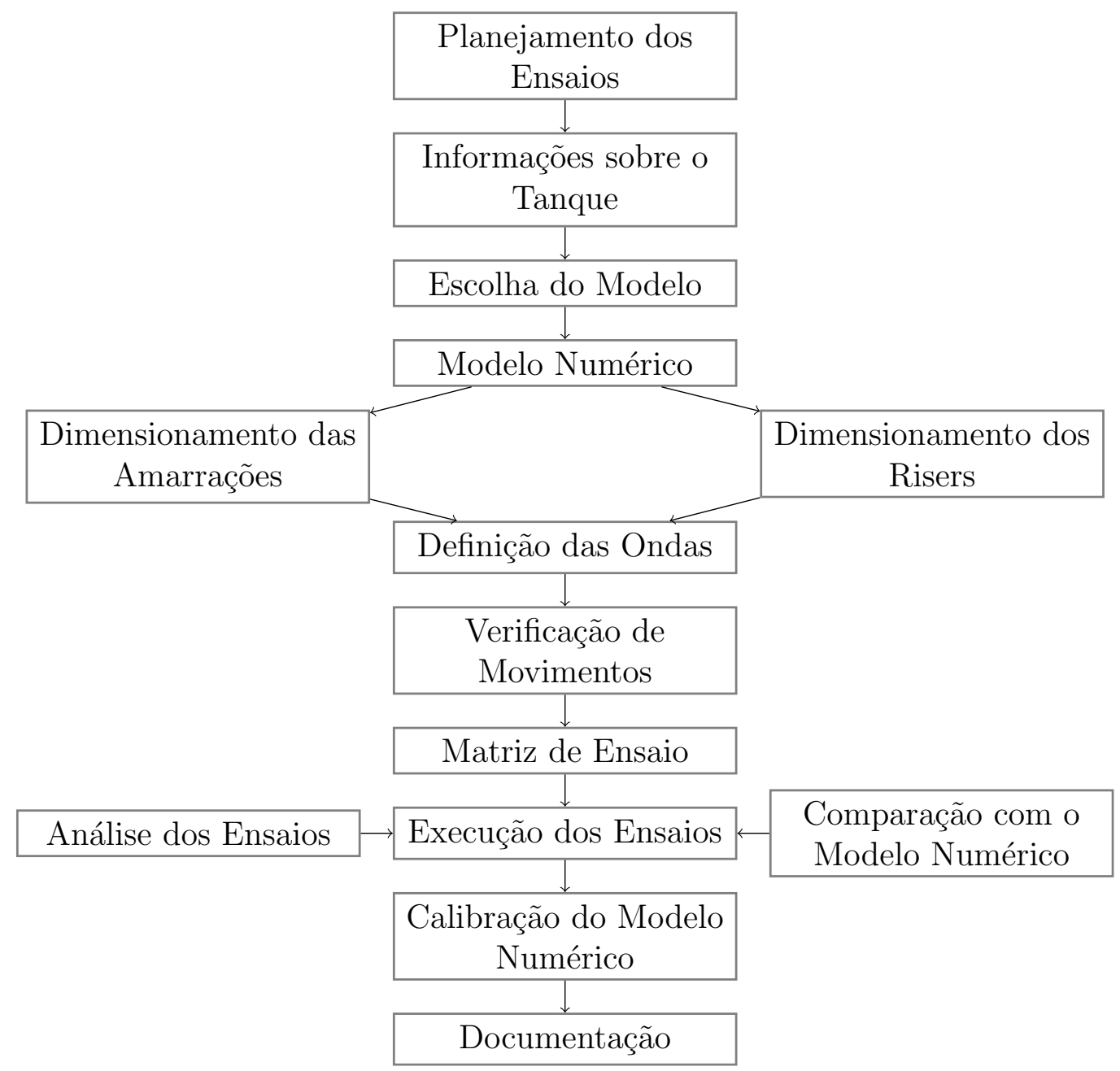

Figura 1.5: Planejamento do ensaio considerando o efeito de linhas na dinâmica das unidades flutuantes

e risers, foram caracterizadas as condições ambientais. Também foi definida a velocidade de correnteza, neste caso, representada pelo reboque do modelo através do carro dinamométrico.

Com o ajuste dos principais parâmetros, foi definida uma matriz de ensaio contemplando: testes de decaimento e incidência de ondas, com e sem a presença da correnteza (ver Tabela 1.1).

Simultaneamente à execução da matriz de ensaio, os resultados de amortecimento e RAO, obtidos através de rotinas de análise desenvolvidas no contexto deste trabalho, foram comparados com resultados numéricos do TPN. Finalmente, foi realizada a documentação dos resultados, última etapa descrita na Figura 1.5. 
Tabela 1.1: Matriz de ensaio definida após o planejamento dos ensaios

\begin{tabular}{|c|c|c|c|c|}
\hline Pré-testes & Ondas Transientes & & Ondas Regulares & Ondas Irregulares \\
\hline $\begin{array}{l}\text { Teste de inclinação sem } \\
\text { risers ( } 5 \text { pontos) }\end{array}$ & $\begin{array}{l}\text { Transiente Curto } \\
\text { risers }\end{array}$ & sem & 12 ondas sem risers & 4 ondas sem risers \\
\hline $\begin{array}{l}\text { Decaimento de Sway sem } \\
\text { risers }(3 \mathrm{x})\end{array}$ & $\begin{array}{l}\text { Transiente Longo } \\
\text { risers }\end{array}$ & sem & $\begin{array}{l}12 \text { ondas sem risers com } \\
\text { correnteza }\end{array}$ & $\begin{array}{l}4 \text { ondas sem risers com } \\
\text { correnteza }\end{array}$ \\
\hline $\begin{array}{l}\text { Decaimento de Heave sem } \\
\text { risers }(3 \mathrm{x})\end{array}$ & $\begin{array}{l}\text { Transiente Curto } \\
\text { risers com correnteza }\end{array}$ & sem & 12 ondas com risers & 4 ondas com risers \\
\hline $\begin{array}{l}\text { Decaimento de Roll sem } \\
\text { risers }(3 \mathrm{x})\end{array}$ & $\begin{array}{l}\text { Transiente Longo } \\
\text { risers com correnteza }\end{array}$ & sem & $\begin{array}{l}12 \text { ondas com risers com } \\
\text { correnteza }\end{array}$ & $\begin{array}{l}4 \text { ondas com risers com } \\
\text { correnteza }\end{array}$ \\
\hline $\begin{array}{l}\text { Dec. de Sway sem risers } \\
\text { com correnteza }(3 \mathrm{x})\end{array}$ & $\begin{array}{l}\text { Transiente Curto } \\
\text { risers }\end{array}$ & com & & \\
\hline $\begin{array}{l}\text { Dec. de Heave sem risers } \\
\text { com correnteza }(3 \mathrm{x})\end{array}$ & $\begin{array}{l}\text { Transiente Longo } \\
\text { risers }\end{array}$ & com & & \\
\hline $\begin{array}{l}\text { Dec. de Roll sem risers } \\
\text { com correnteza }(3 \mathrm{x})\end{array}$ & $\begin{array}{l}\text { Transiente Curto } \\
\text { risers com correnteza }\end{array}$ & com & & \\
\hline $\begin{array}{l}\text { Teste de inclinação com } \\
\text { risers ( } 5 \text { pontos) }\end{array}$ & $\begin{array}{l}\text { Transiente Longo } \\
\text { risers com correnteza }\end{array}$ & com & & \\
\hline \multicolumn{5}{|l|}{$\begin{array}{l}\text { Dec. de Sway com risers } \\
(3 \mathrm{x})\end{array}$} \\
\hline \multicolumn{5}{|l|}{$\begin{array}{l}\text { Dec. de Heave com risers } \\
(3 \mathrm{x})\end{array}$} \\
\hline \multicolumn{5}{|l|}{$\begin{array}{l}\text { Dec. de Roll com risers } \\
(3 \mathrm{x})\end{array}$} \\
\hline \multicolumn{5}{|l|}{$\begin{array}{l}\text { Dec. de Sway com risers } \\
\text { com correnteza }(3 \mathrm{x})\end{array}$} \\
\hline \multicolumn{5}{|l|}{$\begin{array}{l}\text { Dec. de Heave com risers } \\
\text { com correnteza }(3 \mathrm{x})\end{array}$} \\
\hline $\begin{array}{l}\text { Dec. de Roll com risers } \\
\text { com correnteza }(3 \mathrm{x})\end{array}$ & & & & \\
\hline
\end{tabular}

A próxima parte deste texto descreve em detalhes cada um dos principais elementos envolvidos em um experimento típico em tanque de provas. Esses elementos são apresentados de uma maneira mais abrangente e, posteriormente, adequados ao problema experimental de exemplo, no caso, o estudo em escala reduzida da dinâmica da unidade flutuante (ITTC-SR192) acoplada a linhas de risers. 
2 Experimentos em Tanque de Provas 


\subsection{Tanques de Provas}

O objetivo de um tanque de provas é simular as condições ambientais presentes em altomar: onda, vento e correnteza.

Alguns dos limitantes que devem ser considerados durante a execução de ensaios de sistemas flutuantes são as dimensões e infra-estrutura dos tanques de provas. Por esse motivo, as condições capazes de serem reproduzidas em cada tanque estão diretamente relacionadas às características dos mesmos.

No Anexo A são apresentadas as características de alguns dos tanques atualmente existentes no mundo e os experimentos possíveis de serem realizados em cada um deles. Alguns dos tipos de tanques de provas mostrados na Figura 2.1 serão descritos abaixo.

Tanques de reboque caracterizam-se por apresentarem comprimentos muito maiores que a largura. Nestes, os modelos são fixados a um carro dinamométrico e rebocados de maneira a representar a velocidade de avanço, correnteza ou mesmo vento. Em geral estes tanques são utilizados para testes de embarcações a fim de avaliar a resistência ao avanço e obter seus coeficientes de forma. Esses modelos podem ser testados em baixa velocidade, onde os parâmetros viscosos são predominantes, ou em alta velocidade, onde a radiação de onda e efeitos de planeio são avaliados.

Outro dispositivo passível de ser encontrado em tanques de reboque é o sistema de PMM (Planar Motion Mechanism) que possibilita a avaliação dos coeficientes de arrasto em diferentes incidências de correnteza (aproamento) e dos coeficientes de manobrabilidade ${ }^{1}$.

Essas avaliações podem ser realizadas para modelos de embarcações e plataformas de petróleo, além da avaliação de coeficientes hidrodinâmicos de torpedos, âncoras, válvulas submersas e outras formas que necessitam de informações acerca de sua dinâmica devido à ação de ondas ou correnteza.

Por outro lado, tanques de reboque apresentam limitações devido à profundidade e à largura dos mesmos. Estas restrições impedem a realização de testes para a representação de arranjos submarinos, por exemplo sistema de ancoragem; além do problema de reflexão de ondas nas paredes dos tanques e blocagem. Outro inconveniente é necessidade de o modelo precisar ser reposicionado, caso seja previsto o estudo de comportamento em ondas/correnteza sob diferentes aproamentos. Ainda assim, prefere-se a utilização de tanques de reboque para os ensaios com correnteza devido ao baixo nível de turbulência,

\footnotetext{
${ }^{1} \mathrm{Em}$ alguns tanques de reboque essas mesmas avaliações podem ser realizadas com a presença de gelo.
} 


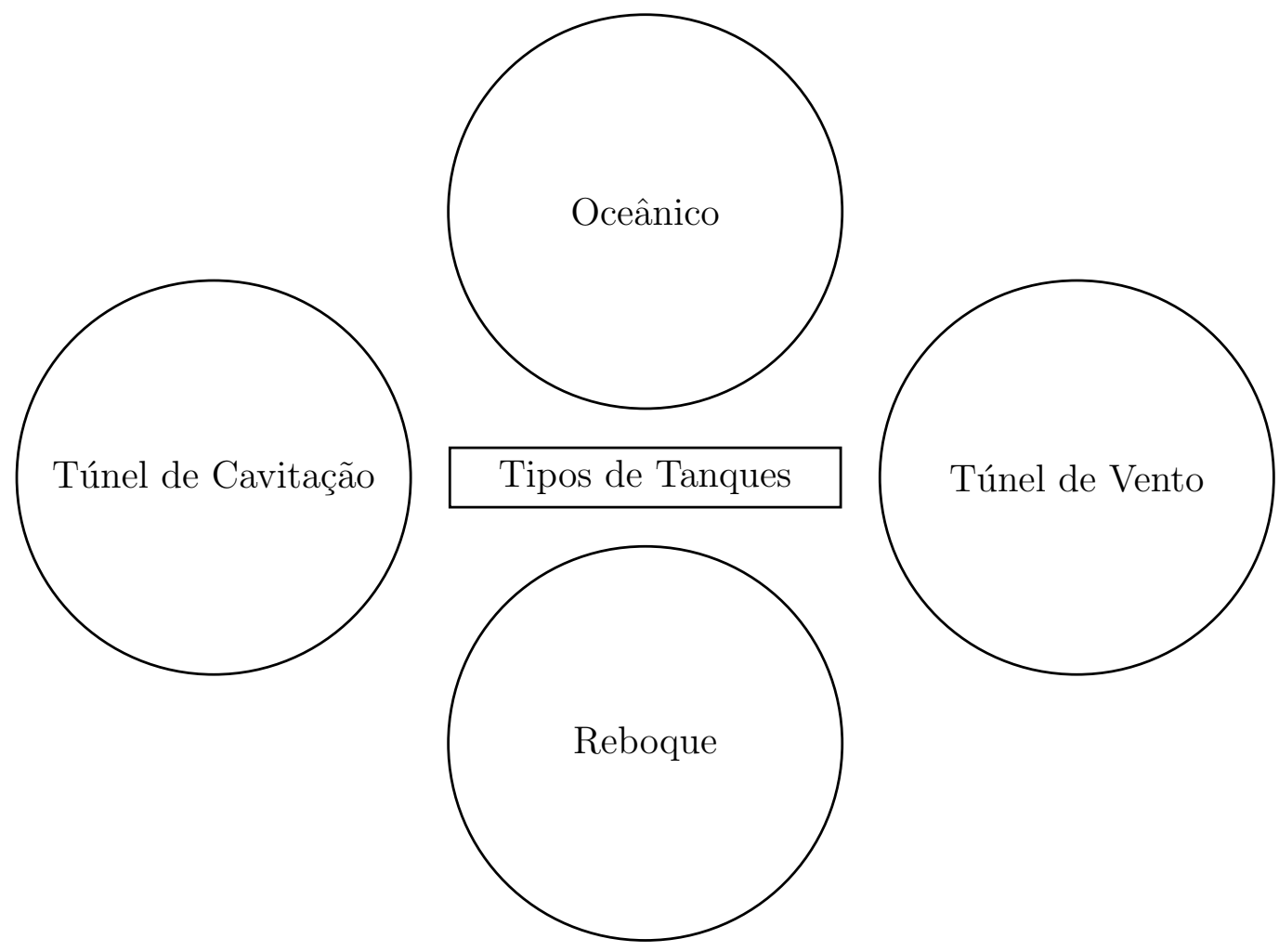

Figura 2.1: Tipos de tanques de provas

quando comparado com outros tipos de tanques de provas apresentados abaixo.

Tanques oceânicos possuem comprimento e largura de dimensões similares. Em geral, possuem grandes profundidades e/ou a possibilidade da variação desta através de um fundo móvel. Esses tanques possuem a capacidade de geração de onda, vento e correnteza. A geração e absorção de ondas multidirecionais possibilita o estudo de condições de mar mais realísticas, sem a necessidade de alterar a posição do modelo para diferentes aproamentos. A absorção de ondas pode ser dividida em passiva ou ativa. No caso de absorção passiva são utilizadas praias nas extremidades dos tanques de provas para que a menor energia possível retorne para a posição onde o ensaio está sendo realizado. No caso de absorção ativa os próprios geradores absorvem as ondas radiadas e difratadas pelo modelo.

Alguns tanques oceânicos são equipados com Rotating $\mathrm{Arm}^{2}$ que possibilita ensaios de manobrabilidade, ou avaliação de coeficientes de arrasto, como os PMM nos tanque de reboque. Esses braços mecânicos permitem o controle dos movimentos e a aquisição das forças nos seis graus de liberdade dos modelos.

Outros tipos de tanques de provas são os túneis de cavitação e os canais de circulação

\footnotetext{
${ }^{2}$ Estruturas instaladas no centro do tanque de provas capaz de impor movimento com uma frequência angular específica.
} 
que, diferentemente dos tanques de reboque, usam o movimento do fluído para representar o escoamento e as escalas dos modelos nestes tanques são bem menores. A diferença entre túnel de cavitação e canal de circulação é que o último trabalha com a presença de superfície livre. Normalmente são ensaiados propulsores para a verificação de cavitação e ruídos, cilindros rígidos e flexíveis para verificação de vibração induzida por vórtices e, estruturas submarinas para a determinação de coeficientes de arrasto.

Os túneis de vento são utilizados para a avaliação dos carregamentos aerodinâmicos, ou seja, forças e momentos devido ao vento nas superestruturas das plataformas ou embarcações. Outros ensaios realizados nos túneis de vento são os estudos de dispersão de gases, como os casos de vazamento em plantas de processo. Os túneis de vento são equipados com a possibilidade de visualização do fluxo de ar para altos números de Reynolds.

O tanque de provas utilizado para avaliação da influência dos risers na dinâmica da unidade, foco do presente trabalho, foi o tanque de reboque do IPT. Mais informações sobre o tanque do IPT são apresentadas no Anexo A.2. 


\subsection{Modelo em Escala}

Nesse capítulo serão discutidos alguns pontos sobre a calibração de modelos em escala reduzida para as análises de sistemas oceânicos.

Para os ensaios em tanque de provas, os modelos em escala podem ser representações das unidades flutuantes e/ou dos sistemas conectados a elas, como as linhas de amarração, risers, umbilicais, entre outras.

Para modelos de unidades flutuantes avaliados com relação ao comportamento em ondas, são calibrados parâmetros dimensionais e inerciais. No caso de modelos de linhas em geral, coeficientes de rigidez axial e flexional também devem ser verificados, para que esses modelos representem os seus protótipos.

Para realização do ajuste dos modelos não existe apenas uma maneira isolada de calibração, por isso os procedimentos aqui apresentados foram os testados na realização do ensaio da plataforma ITTC-SR192 com linhas de amarração e risers. O diagrama da Figura 2.2 apresenta os processos de calibração utilizados nesse ensaio.

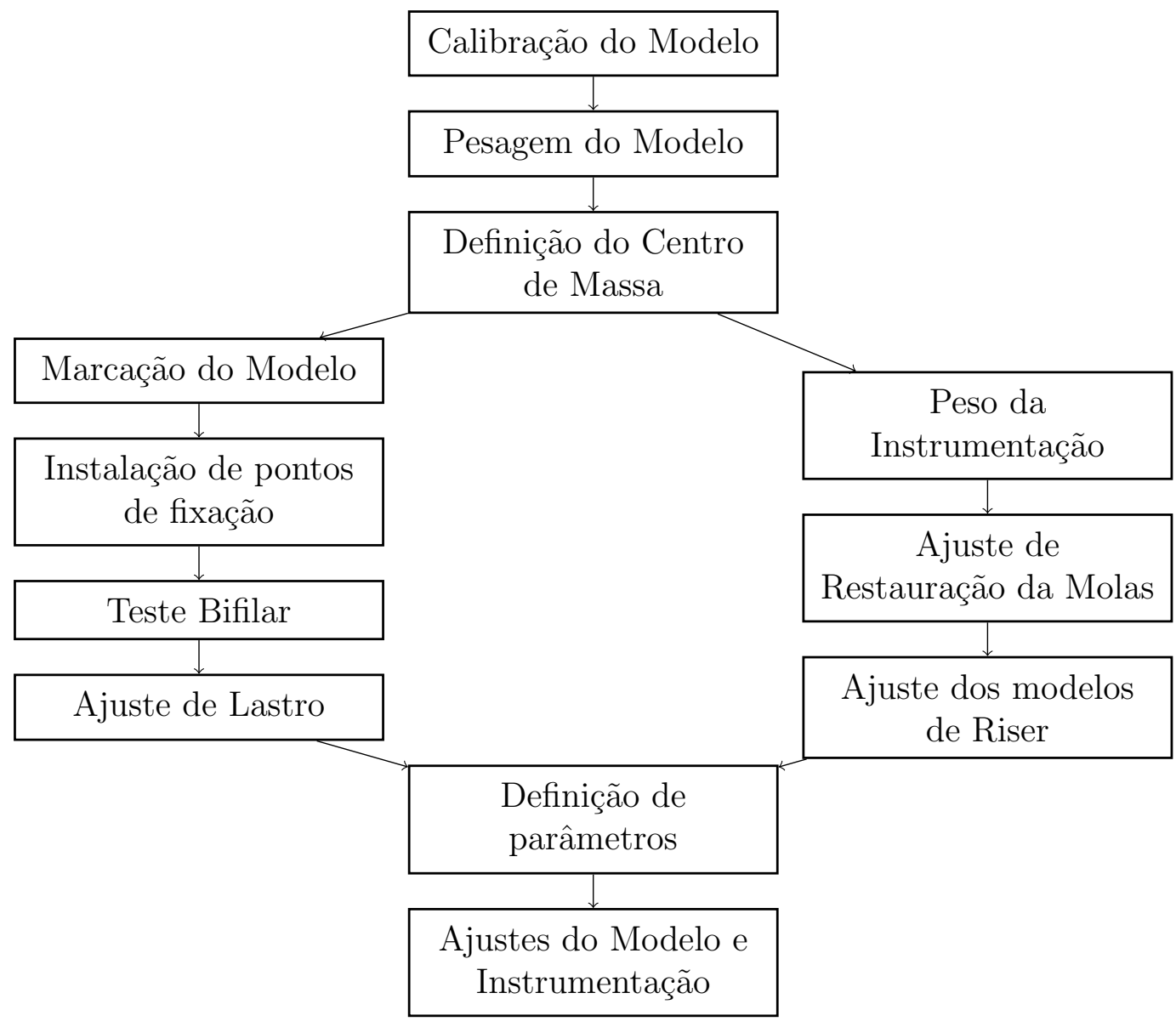

Figura 2.2: Processo de calibração dos modelos 


\subsubsection{Unidade Flutuante}

A calibração dos modelos de unidades flutuantes é realizada para a avaliação da dinâmica do sistema, sendo assim, posição, movimentos, acelerações em alguns pontos, borda-livre, água no convés, pressões e demais parâmetros necessários para determinar o comportamento no mar dessas unidades são os resultados experimentais analisados.

As propriedades do modelo devem estar em escala com relação ao protótipo (ver Apêndice VII). As principais propriedades são massa, inércia, posição do centro de massa, altura metacêntrica e períodos naturais.

Dentre os procedimentos de calibração, além de verificações dimensionais e massas através de balanças, destacam-se os procedimentos de determinação de centro de massa, teste bifilar para determinar inércias próprias e o arranjo de lastro.

O arranjo de lastro é realizado utilizando-se massas extras, comumente chamadas de lastro, cujas características inercias são conhecidas. Estas massas são alocadas em pontos específicos, de forma que a massa total, a inércia e centro de massa do protótipo seja recuperado.

Na Figura 2.3 é apresentada uma das primeiras etapas antes da calibração de um modelo envolvendo além da verificação das medidas, a marcação de calados e posições de referência.

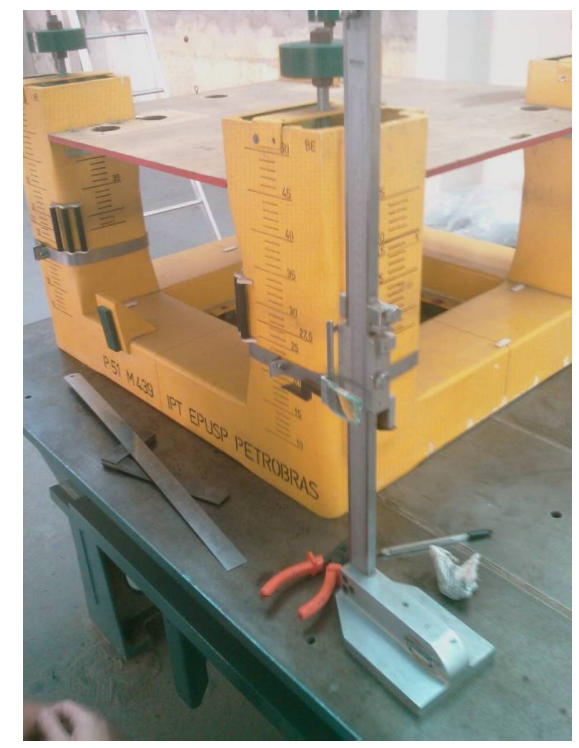

Figura 2.3: Marcação de um modelo em mesa de desempeno

Após a verificação da massa total do modelo, facilmente medida por uma balança com fundo de escala coerente, uma das possibilidades para a determinação do centro de massa 
é apoiar o modelo, conforme apresentado na Figura 2.4.

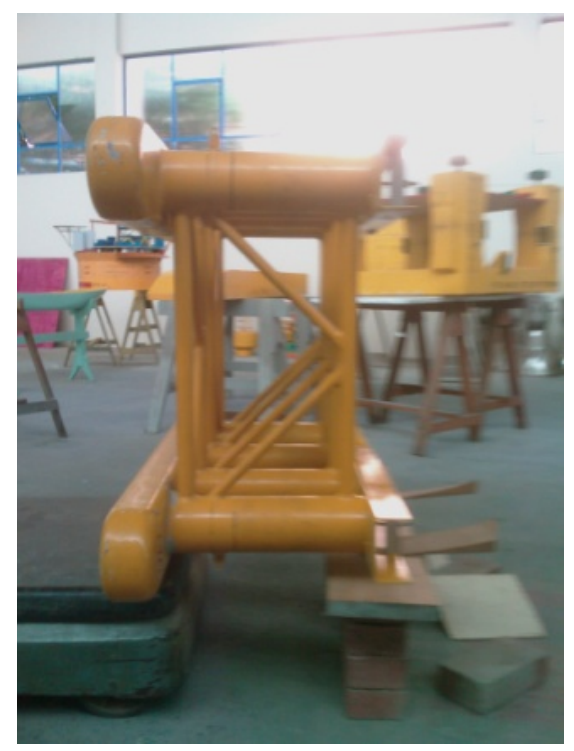

Figura 2.4: Verificação do centro de massa da unidade ITTC-SR192

Um dos cuidados durante as medidas é garantir que o modelo esteja bem nivelado. Uma cunha sobre um dos apoios auxiliou a variação da altura do modelo conforme mostrado na Figura 2.5.

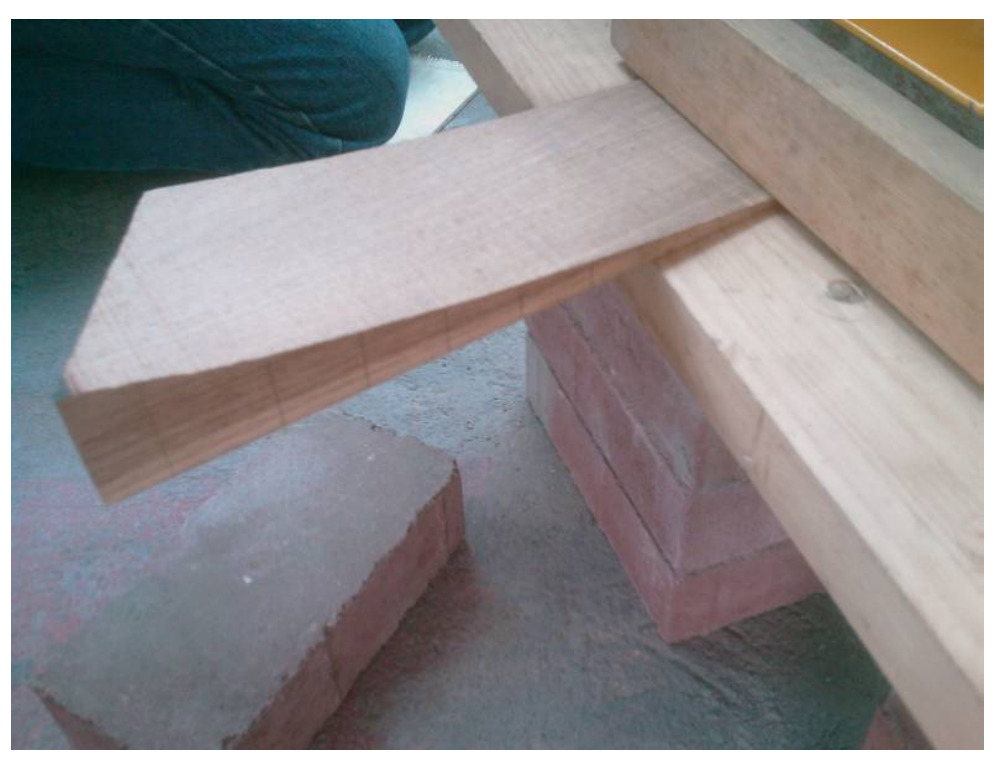

Figura 2.5: Verificação do nivelamento do modelo em teste bifilar

Sabendo que a soma das forças e dos momentos devem ser nulos, como mostrado na Figura 2.6, o centro de massa do modelo é definido conforme apresentado na Tabela 2.1.

Após a determinação do KG do modelo sem lastro, o ajuste de lastro deve ser realizado para que todas as propriedades do modelo estejam ajustadas em escala. Nessa fase, 


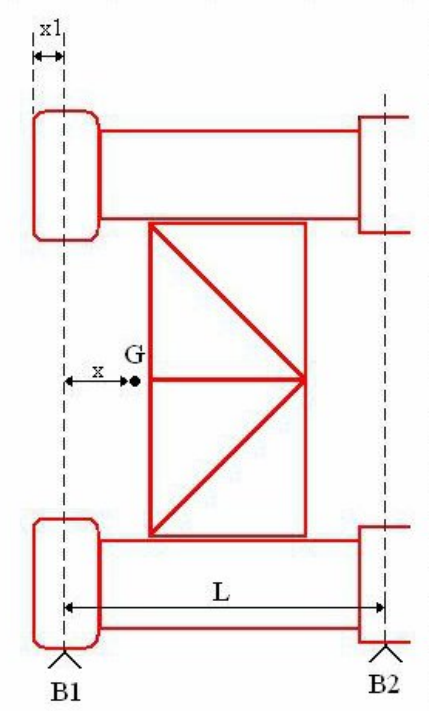

Figura 2.6: Esboço das distâncias utilizadas para determinação do KG

Tabela 2.1: Determinação do centro de massa do modelo

\begin{tabular}{lcc}
\hline Massa total & 31,1 & $\mathrm{~kg}$ \\
\hline Distância do fundo para a faca & 15,5 & $\mathrm{~mm}$ \\
\hline Distância do convés para a faca & 1,0 & $\mathrm{~mm}$ \\
\hline Distância entre as facas & 440,0 & $\mathrm{~mm}$ \\
\hline Massa durante o teste de KG & 21,8 & $\mathrm{~kg}$ \\
\hline XCG & 308,42 & $\mathrm{~mm}$ \\
\hline Pontal & 455,5 & $\mathrm{~mm}$ \\
\hline KG & 147,08 & $\mathrm{~mm}$ \\
\hline
\end{tabular}

todas as massas que serão anexadas ao modelo devem ser consideradas, assim como a instrumentação e estruturas auxiliares (ver Figura 2.7), além dos lastros.

Para o ajuste de lastro, outras propriedades como a inércia também devem ser avaliadas. O teste bifilar é realizado para se obter os parâmetros de inércia do modelo. Esse teste é realizado para posterior calibração da inércia do modelo através de lastros. Durante o procedimento da determinação de inércia, primeiro pendura-se o modelo por dois fios de comprimentos iguais (conhecidos) e paralelos ao eixo que se quer obter a inércia, geralmente um eixo de simetria do modelo. Depois, deve-se conhecer a distância entre esses fios, devendo ser constante ao longo destes, ou seja, fios paralelos. Com a aplicação de um binário no modelo, mede-se o período de oscilação, passo que é repetido algumas vezes para obter-se a média do período de oscilação. No ensaio bifilar, pode-se aumentar a precisão aumentando o comprimento dos cabos que suspendem o modelo. 


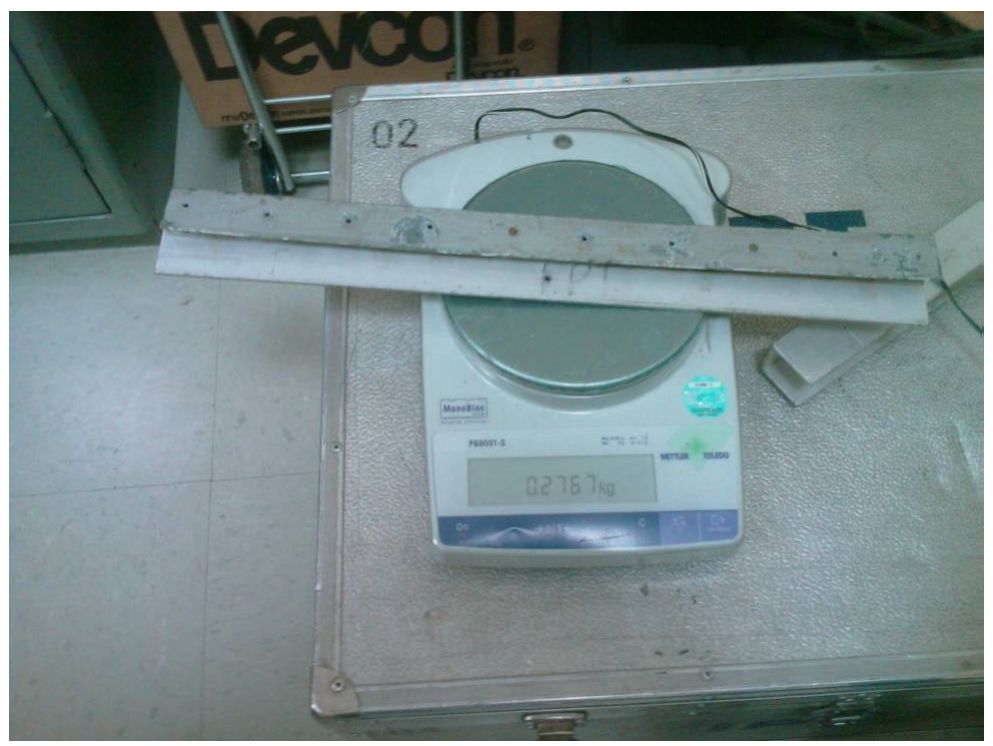

Figura 2.7: Verificação com balança de precisão de todas as massas do modelo

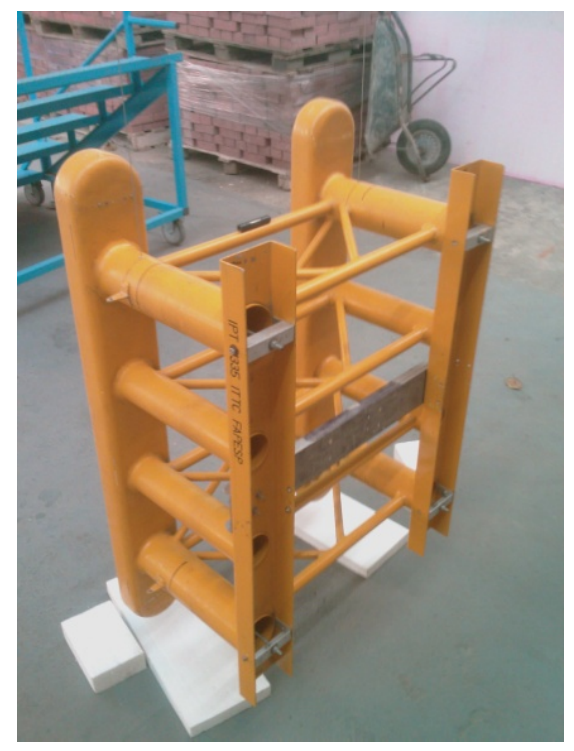

Figura 2.8: Exemplo de teste bifilar

Após a cronometragem das oscilações do modelo, a inércia pode ser calculada como apresentado na Tabela 2.2 .

Para obter o raio de giração é usada a equação 2.1 .

$$
K_{x x}=\frac{T a}{2 \pi} \sqrt{\frac{g}{L}}
$$

Com o valor do raio de giração utiliza-se a equação 2.2 para obtenção da inércia.

$$
I_{x x}=m K_{x x}{ }^{2}
$$


Tabela 2.2: Resultados do teste bifilar

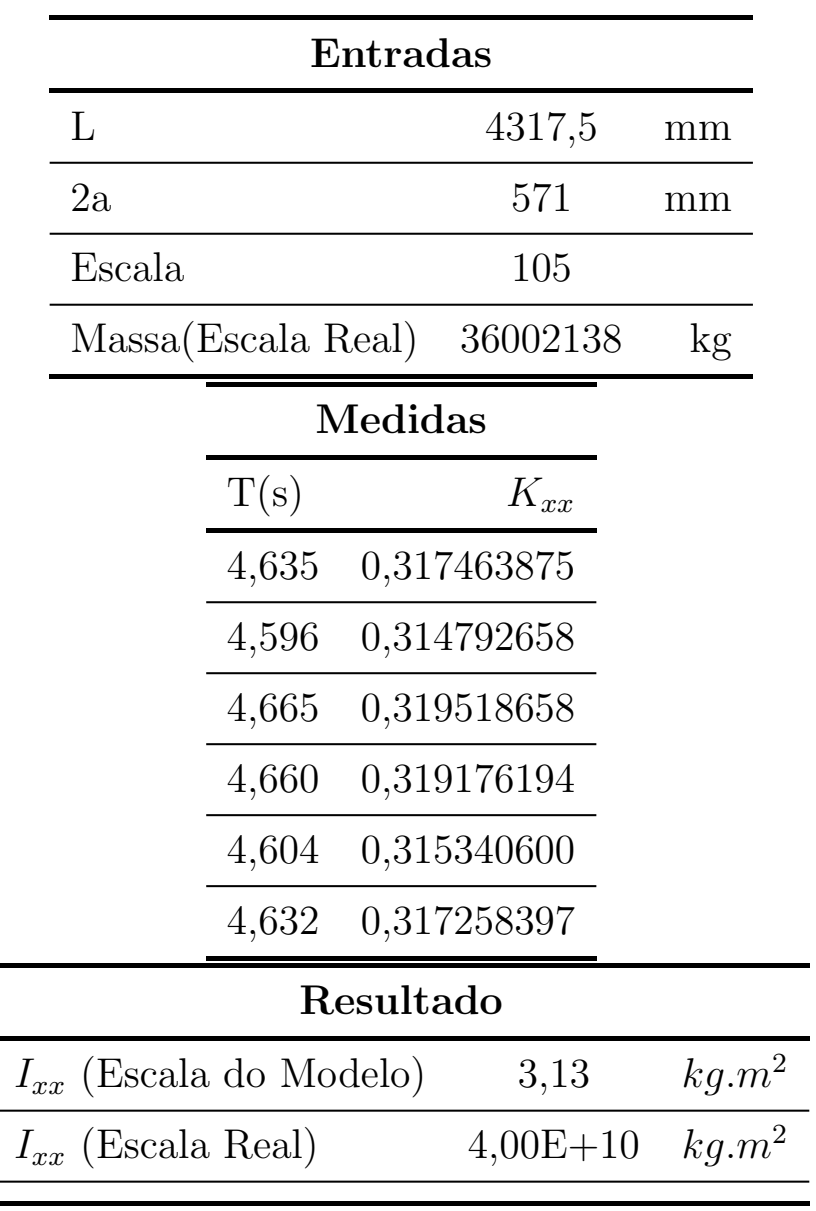




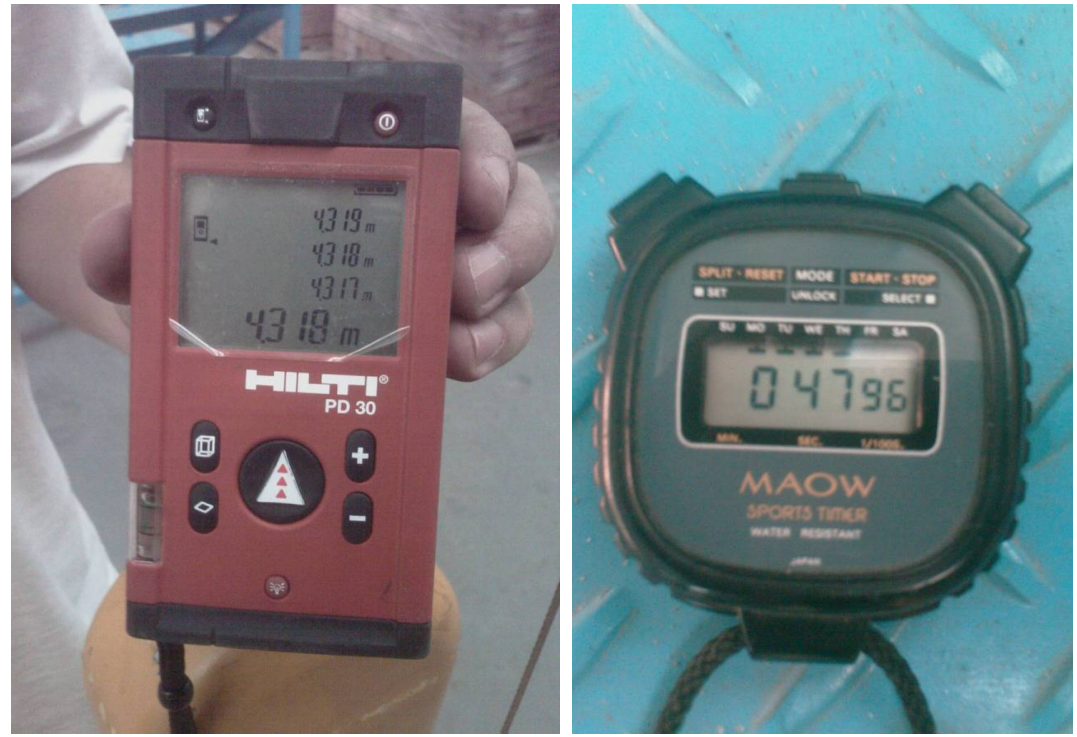

Figura 2.9: Instrumentos de medida utilizados durante o teste bifilar

Com a inércia do modelo sem lastro determinada, deve-se ajustar tanto o centro de massa quanto a inércia com a adição de lastros. É recomendado que sejam utilizados lastros padronizados, onde a sua inércia própria e massa foram bem determinadas. No caso de lastros comuns, pode-se usar as informações do Apêndice VIII para realizar o balanço de massas e inércias.

Outra maneira para a avaliação da inércia própria de um modelo é através de uma balança de inércia como mostrado na Figura A.14.

\subsubsection{Linhas de Amarração e Risers}

Nesse item estão descritos alguns cuidados com relação aos modelos de linhas de ancoragem e risers. Um exemplo das variáveis do arranjo utilizado para o sistema de amarração e risers é apresentado na Figura 2.10.

No caso dos risers, representados por mangueiras de silicone (ver Figura 2.11), a propriedade importante que deve ser verificada são os ângulos de saída das linhas como mostrado na Figura 2.12.

Também deve ser verificada a posição do TDP, conforme mostrado na Figura 2.13.

No caso do IPT, para uma simulação com o efeito de correnteza, é necessária a criação de um fundo o falso, de tal forma que todo o sistema possa ser arrastado pelo carro dinamométrico (ver Figura 2.14).

O modelo do riser deve ter a tensão axial e flexional verificadas, conforme apresentado 


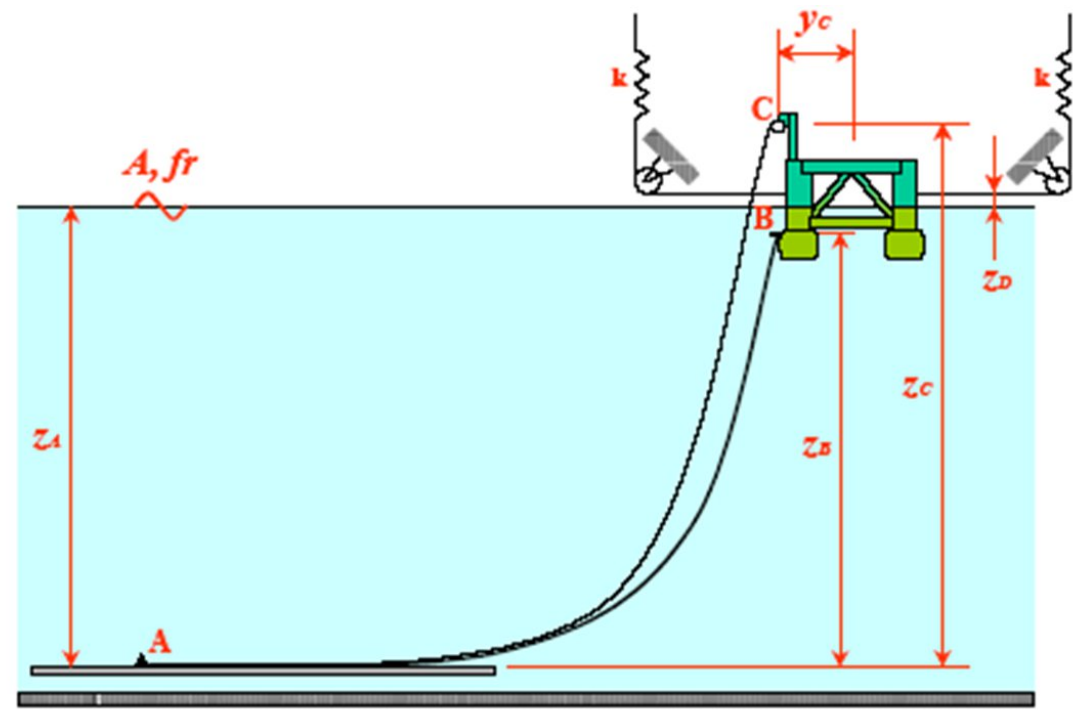

Figura 2.10: Exemplo de um arranjo do sistema de amarração

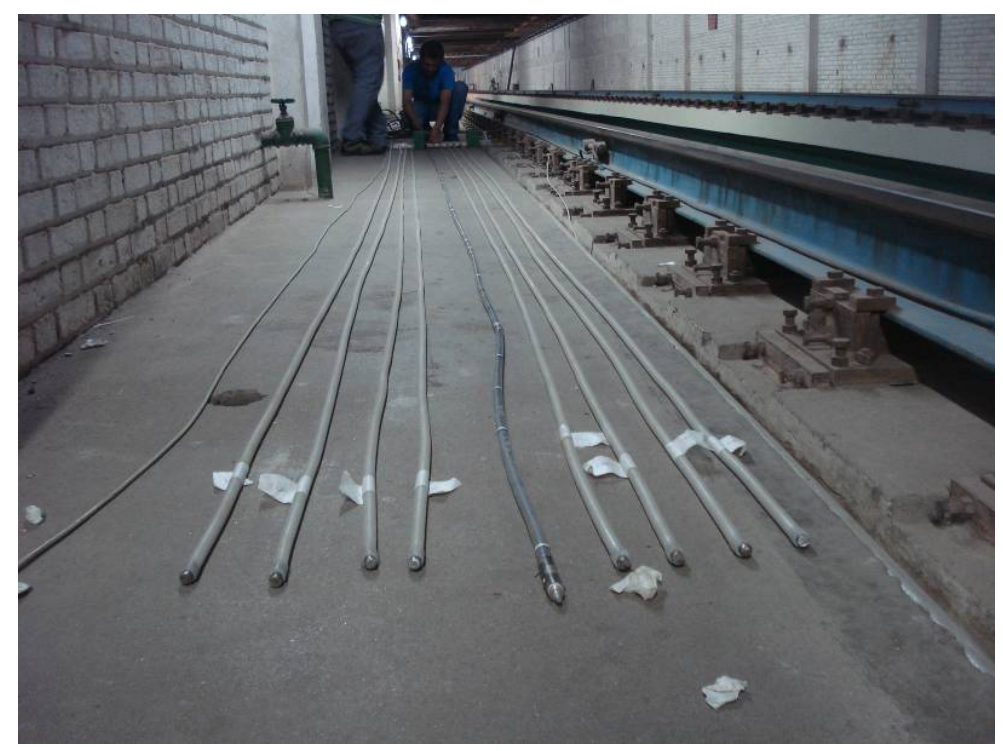

Figura 2.11: Modelo de linhas de riser

na Figura 2.15 .

Os modelos de linhas de amarração são normalmente representados através de cabos e molas. Com o ajuste da rigidez das molas, o sistema deve possuir a mesma restauração equivalente às linhas de ancoragem da escala real.

O arranjo de molas deve ser dimensionado de forma que essas não alterem as características do modelo. Para tanto, alguns cuidados devem ser tomados: evitar que as molas sejam muito pesadas e que o formato não se altere para diferentes carregamentos, evitando não-linearidades indesejáveis durante a execução dos ensaios. O cálculo das molas pode ser realizado conforme apresentado no procedimento abaixo. 


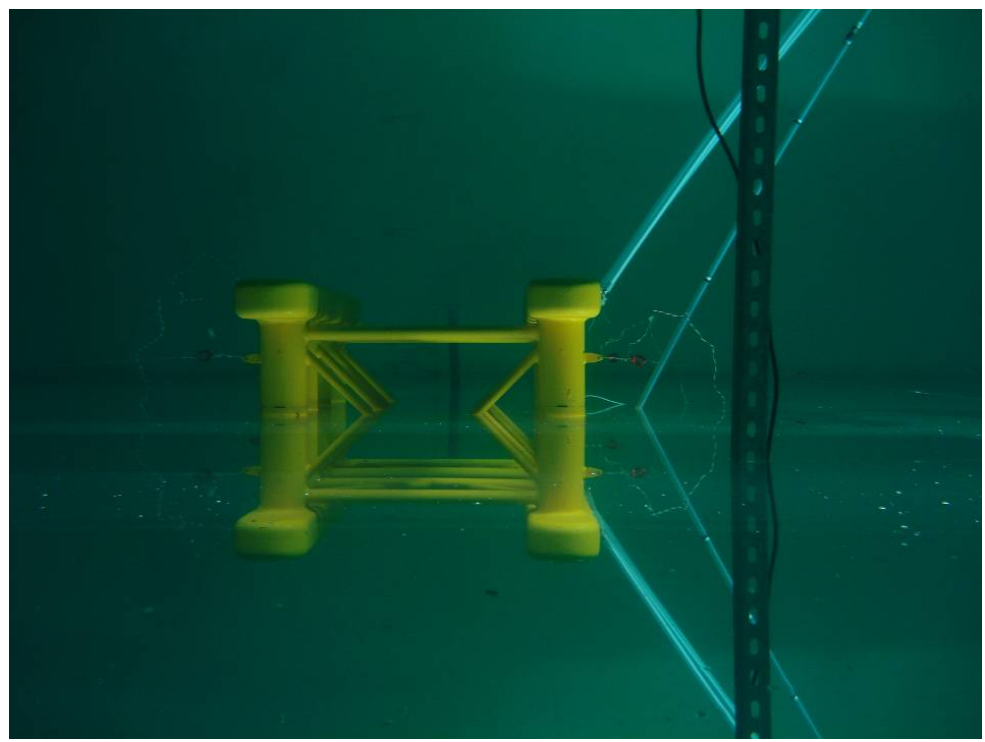

Figura 2.12: Visão do ângulo de saída das linha de ancoragem

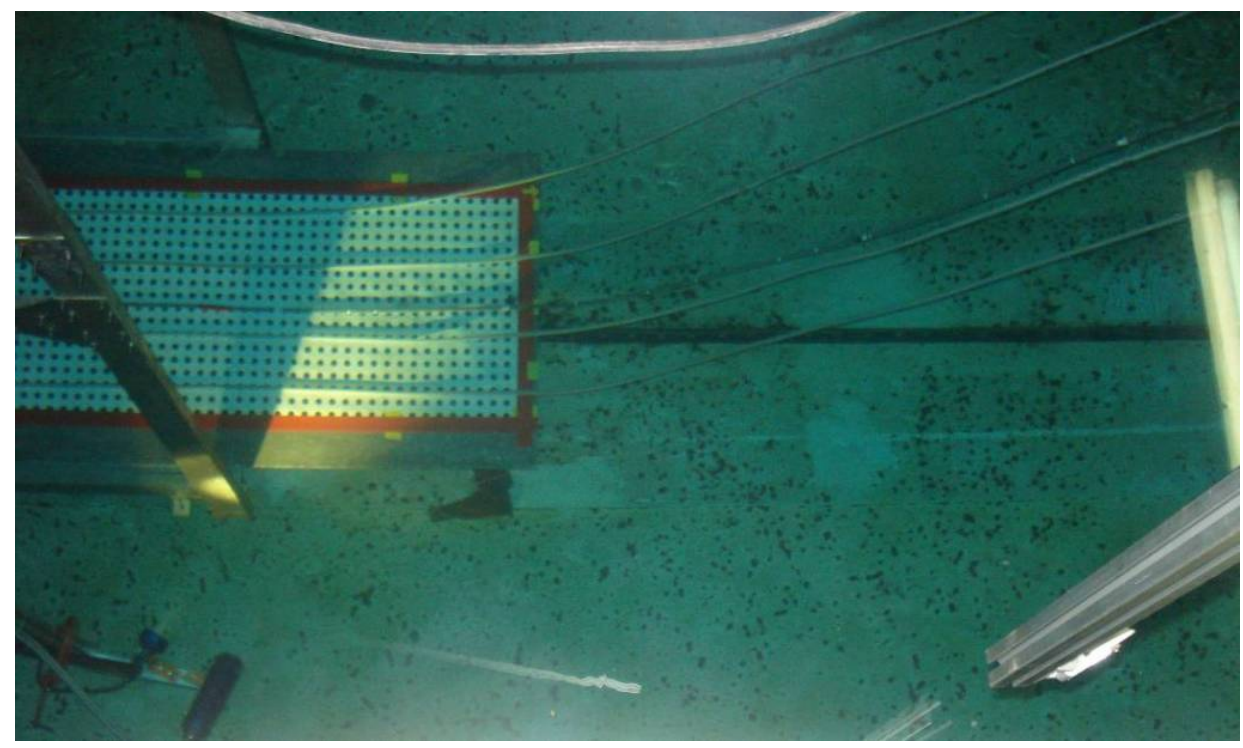

Figura 2.13: Arranjo das linhas em ensaio com fundo falso

Dependendo do material, do diâmetro da espira e do arame, a mola suporta uma tensão torsional máxima, como mostrado na equação 2.4. Através do cálculo da flecha para cada carregamento, é possível determinar qual a restauração da mola e ajustá-la para a escala do modelo.

$$
\begin{gathered}
\text { flech } a=\frac{4 \pi n r^{2} \tau_{t}}{d G} \\
\tau_{t}=\frac{16 P r}{\pi d^{3}}
\end{gathered}
$$




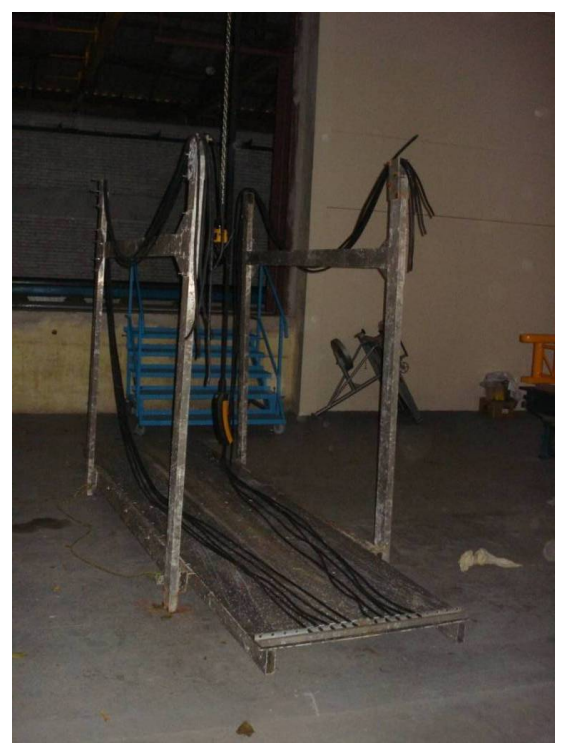

Figura 2.14: Fundo falso utilizado para ensaio de linhas

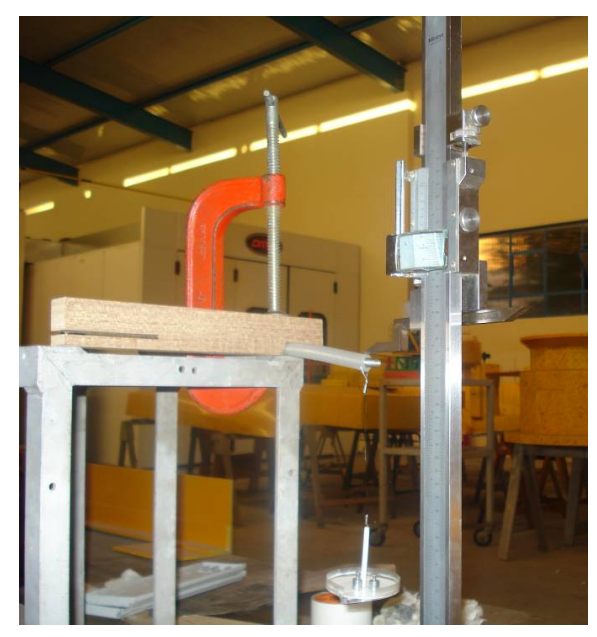

Figura 2.15: Medida de rigidez flexional e axial da linha

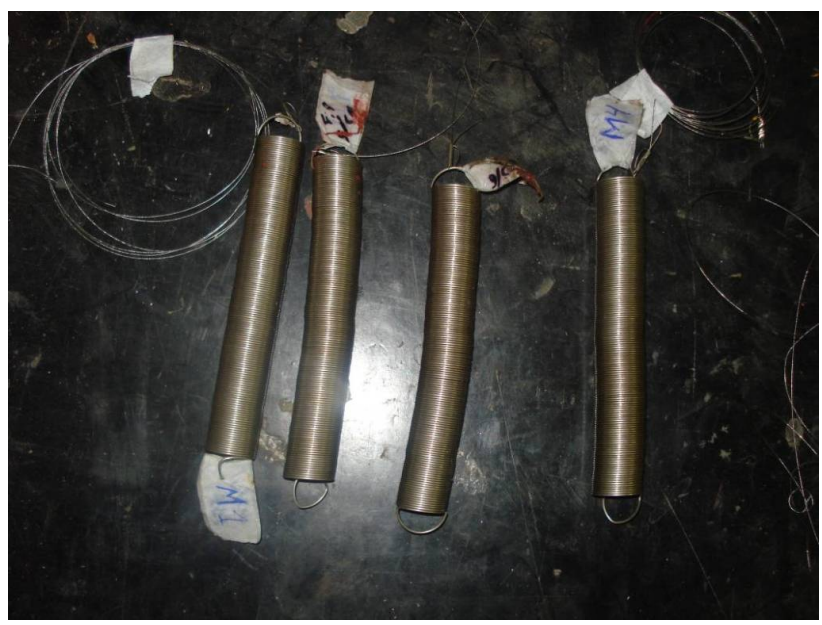

Figura 2.16: Modelo de linhas de amarração 


\subsection{Aquisição de Dados}

Nesse capítulo estão descritos os equipamentos de medição utilizados no ensaio de estudo neste texto. Outros dispositivos de aquisição estão apresentados no Anexo D.

A aquisição de dados é feita através de equipamentos capazes de medirem as variáveis de estudo. Os primeiros equipamentos de medição utilizados na área naval foram as massas suspensas por roldanas e cabos ligados a modelos para contrapor a força de resistência. Atualmente, a aquisição de dados é feita através de transdutores, amplificadores, filtros e placas do tipo $\mathrm{A} / \mathrm{D}^{3}$ para computadores.

Conforme apresentado em [Chakrabarti, 1994], os principais equipamentos de medição são: ondógrafos, potenciômetros lineares e angulares, acelerômetros, medidores de pressão, células de carga, sistema óptico ${ }^{4}$ e medidores de velocidade.

Os ondógrafos são utilizados para a aquisição da elevação da superfície livre em alguns pontos da mesma. Nas Figuras 2.17 e 2.18 é apresentada uma curva de calibração de um ondógrafo utilizado em um ensaio no tanque de provas do DENO.

A célula de carga é um dispositivo eletromecânico que, em geral, mede a deformação de um corpo e a transforma em uma saída de tensão. O sinal em microvolts é alterado proporcionalmente à medida que aplica-se uma carga em sua estrutura física. Esta célula é constituída por um ou mais extensômetros, ligados em um circuito denominado ponte de Wheatstone, um exemplo de célula de carga é apresentado na Figura 2.19. Outro dispositivo utilizado para a medida de cargas, é o chamado anel de carga, que por ser bem leve e a prova d'água é utilizado diretamente no modelo (ver Figura 2.20).

Para a aquisição da posição no tempo do modelo, são utilizadas duas ou mais câmeras de emissão e recepção infra-vermelho que, através das imagens capturadas, calcula a posição 3D de alvos no modelo (ver Figura 2.21). Os movimentos dos seis graus de liberdade são transferidos em tempo real através de uma conexão TCP-IP.

Para os sistemas submersos, como por exemplo os modelos dos risers, foram utilizadas câmeras convencionais a prova d'água (ver Figura 2.22).

\footnotetext{
${ }^{3}$ As placas A/D são utilizadas para conversão dos sinas analógicos em digitais, ou seja, converter sinais de voltagem dos equipamentos de medição para valores numéricos de engenharia.

${ }^{4}$ QUALISYS
} 


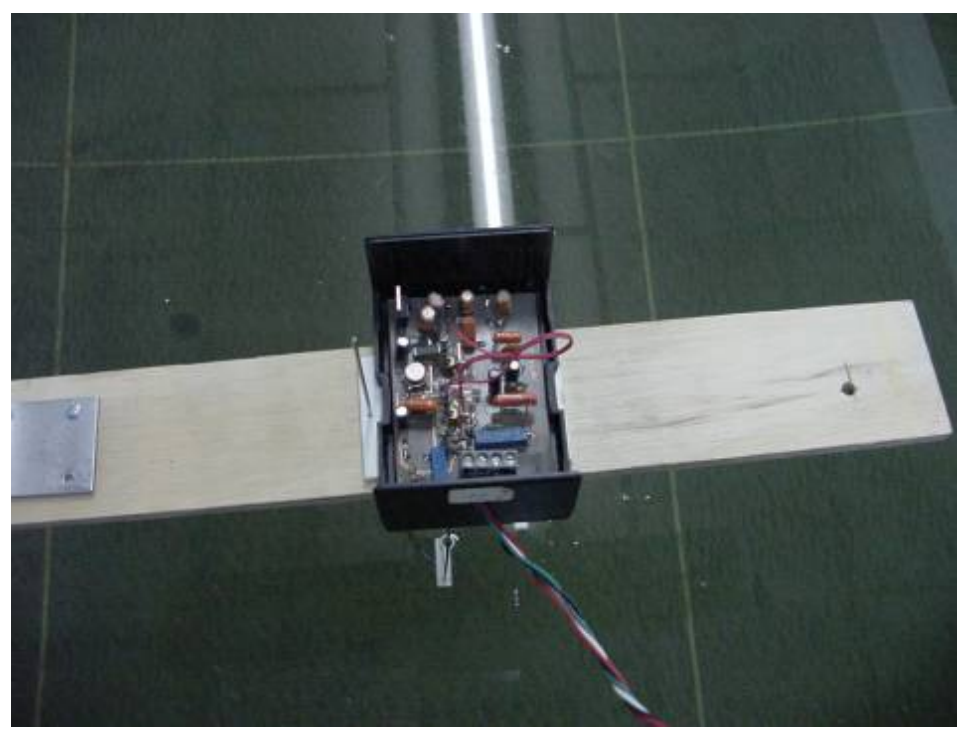

Figura 2.17: Exemplo de ondógrafo para medir elevação de onda

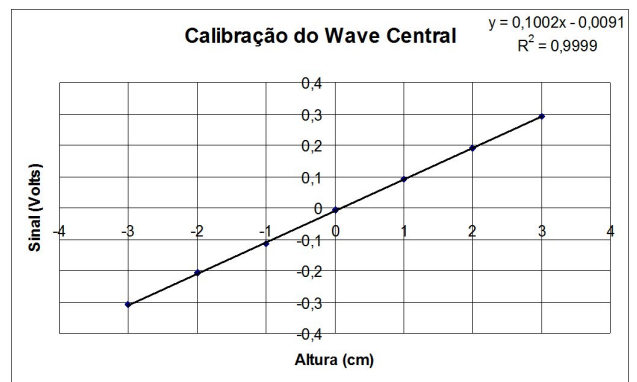

Figura 2.18: Exemplo de curva de calibração de um ondógrafo

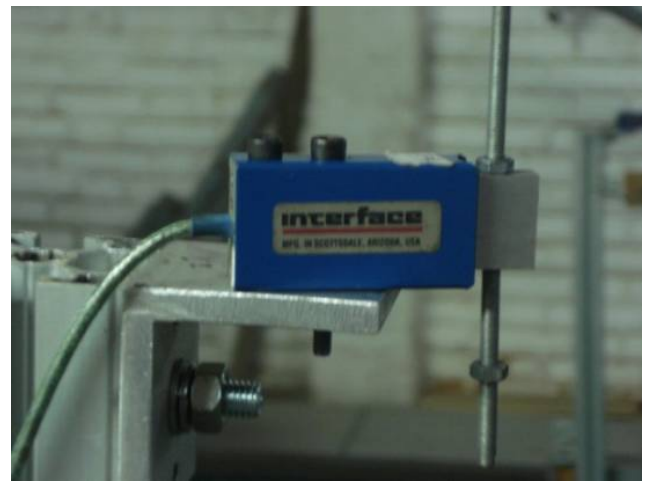

Figura 2.19: Célula de carga utilizada na medida de tração das linhas 


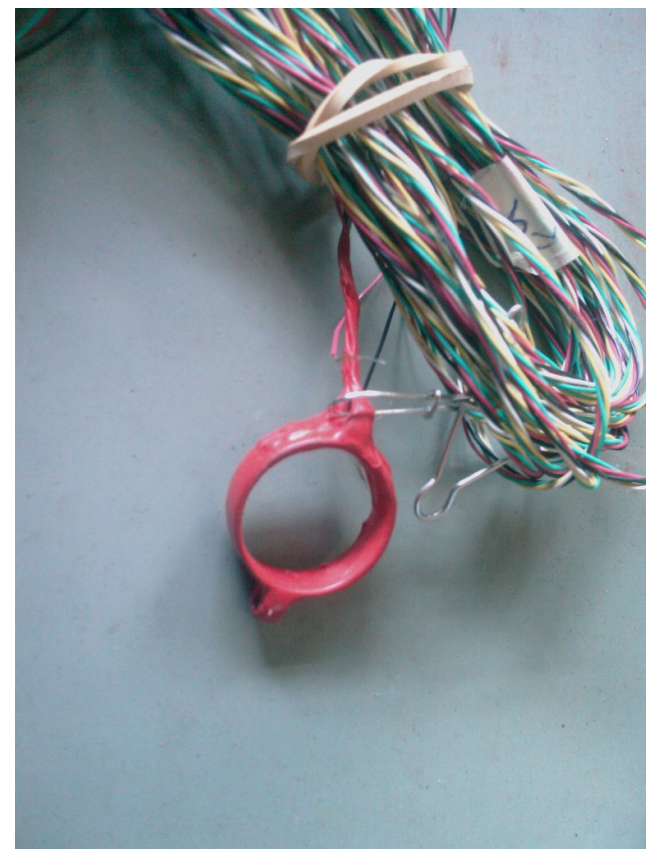

Figura 2.20: Anel de carga

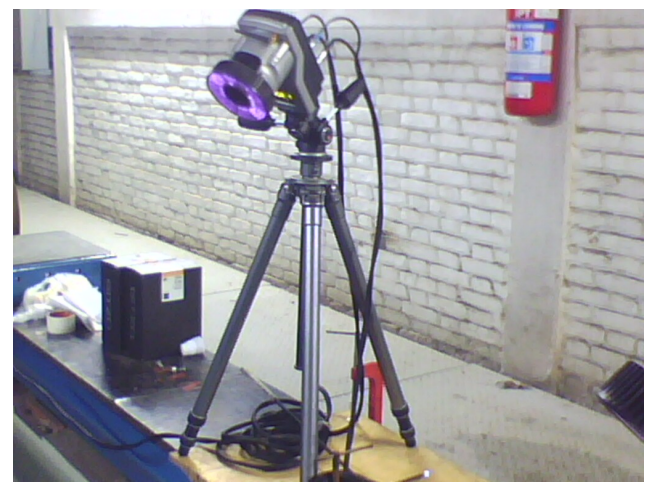

Figura 2.21: Câmeras de infra-vermelho para a aquisição por imagem

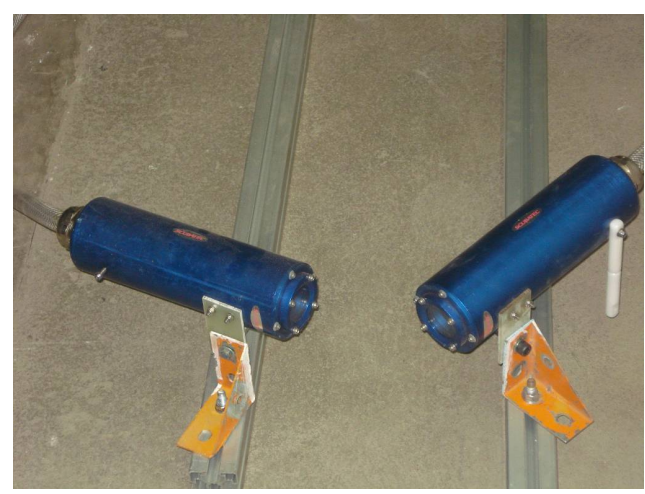

Figura 2.22: Câmeras submersas 


\subsection{Condições Ambientais}

As condições ambientais impostas aos modelos de sistemas oceânicos podem ser compostas por correnteza, onda e/ou vento. Através das informações meteorológicas do local onde serão instalados estes sistemas, a relação entre os parâmetros que definem cada agente são obtidos para diferentes períodos de retorno ${ }^{5}$.

A calibração das condições ambientais deve ser realizada sem a presença do modelo, pois assim os efeitos de difração e radiação de ondas da unidade flutuante não interferem na avaliação da elevação de onda. Mesmo assim, existem reflexões das próprias paredes do tanque e, por esse motivo, as séries temporais são divididas para que cada série possua as características da condição desejada e um tempo total que atenda os critérios apresentados abaixo. Posteriormente, essas séries são analisadas em conjunto para a obtenção dos seus parâmetros estatísticos.

O tipo de geração de ondas depende das instalações dos tanques de provas, como discutido no Capítulo 2.1, e por esse motivo, as calibrações das condições ambientais devem ser realizadas de acordo com as características de cada gerador. Além disso, as ondas podem ser divididas em regulares, irregulares, (unidirecionais ou multidirecionais) e representar águas rasas ou profundas. Na Tabela 2.3 estão apresentadas algumas características para a definição do tipo de onda.

Tabela 2.3: Relações entre águas rasas e profundas [Chakrabarti, 1987]

\begin{tabular}{lrr}
\hline Aproximações & Critério & Comprimento de Ondas \\
\hline Águas Profundas & $d / L>\frac{1}{2}$ & $L=g T^{2} / 2 \pi$ \\
Águas Rasas & $d / L<\frac{1}{20}$ & $L=T \sqrt{g d}$ \\
\hline
\end{tabular}

No experimento em questão foram utilizadas ondas unidirecionais representando águas profundas. Para ondas regulares deve ser garantido uma amplitude e frequência constantes, além de atender o critério da Tabela 2.3. Nas amplitudes das ondas existe também a verificação da declividade, para garantir que estas ondas não quebrem durante os ensaios. A amplitude não deve ser maior do que $7 \%$ seu comprimento. Contudo para que a onda seja considerada linear, sua amplitude deve ser no máximo $4 \%$ do comprimento. No caso das ondas irregulares essas representações são feitas através de

\footnotetext{
${ }^{5} \mathrm{O}$ período de retorno define o período de pico e altura significativa para ondas, perfil de velocidades para vento e correnteza de projeto. Normalmente são considerados os períodos de retorno anuais, centenários ou até milenares.
} 
espectros teóricos, dentre os quais, os mais comuns são os espectros do tipo Pierson-Moskovitz (PM) e JOSNWAP(Joint North Sea Wave Project) ${ }^{6}$. As formulações básicas para cada tipo de espectro, baseado em [Chakrabarti, 1987], estão apresentadas na equações 2.5 e 2.6, respectivamente.Ambas incorporadas à rotina seaspectrum, desenvolvida no presente trabalho.

$$
S\left(\omega, \omega_{0}, \sigma\right)=5 \sigma^{2} \frac{\omega^{-5}}{\omega_{0}^{-4}} \exp \left(-1.25\left(\omega / \omega_{0}\right)^{-4}\right)
$$

Onde $\omega_{0}=2 \pi / T_{p}$ e $\sigma=H_{s} / 4$.

O espectro do tipo JONSWAP é uma derivação do espectro PM.

$$
S\left(\omega, \omega_{0}, \sigma, \gamma, \tau\right)=5 \sigma^{2} \frac{\omega^{-5}}{\omega_{0}^{-4}} \exp \left(-1.25\left(\omega / \omega_{0}\right)^{-} 4\right) \gamma^{\exp \left(\frac{\left(\omega-\omega_{0}\right)^{2}}{2 \tau^{2} \omega_{0}^{2}}\right)}
$$

Onde $\gamma$ é o parâmetro de amplificação de pico do espectro e $\tau$ o parâmetro de forma ${ }^{7}$.

A primeira verificação da calibração das condições ambientais é com relação aos espectros teóricos apresentados acima. No entanto, também são realizadas verificações estatísticas das elevações e amplitudes das ondas. As elevações devem respeitar a distribuição Gaussiana e as amplitudes a distribuição de Rayleigh. Além disso, devem ser verificados os parâmetros da série temporal comparados com os momentos espectrais, conforme as relações apresentadas no Apêndice III.

Além do espectro teórico de primeira ordem, deve ser verificado o espectro de segunda ordem ou função de grupo de ondas, definido na equação 2.7.

$$
G(\omega)=8 \int S(\mu) S(\mu+\omega) d \mu
$$

Nos movimentos de primeira ordem a excitação de ondas é causada pela energia presente no espectro de primeira ordem. De modo geral, movimentos de segunda ordem são excitações que se manifestam nas regiões ressonantes de movimento. Por esse motivo, a excitação que causa os efeitos de segunda ordem não é devida a energia do espectro de primeira ordem diretamente. Desta forma deve-se avaliar a contribuição da excitação do mar na suas diferenças ou somas de frequência. A comparação entre os espectros teórico

\footnotetext{
${ }^{6}$ Os espectros PM e JONSWAP são utilizados para representação de condições de mar plenamente desenvolvidas e não-desenvolvidas, respectivamente. Os mares desenvolvidos são aqueles em que os seus parâmetros estatísticos estão definidos, enquanto os não-desenvolvidos representam condições que a não linearidade das ondas é importante, como no caso de condições de furacão

${ }^{7}$ Os valores de $\tau$ são geralmente fixos com valores de 0,07 para $\omega \leq \omega_{0}$ e 0,09 para $\omega>\omega_{0}$.
} 
e experimental de primeira ordem pode ser visualmente coerente. Contudo, o espectro de segunda ordem deve ser verificado, pois distorções nas amplitudes da onda são elevadas ao quadrado, podendo assim causar movimentos incoerentes.

Como os ensaios realizados deste trabalho foram executados com onda e correnteza, todos os parâmetros acima descritos tiveram que ser calibrados duas vezes. Nos ensaios com correnteza as ondas geradas foram corrigidas para que o período de encontro com o modelo fosse coerente com o estipulado.

Na Figura 2.23, é apresentada a calibração das ondas irregulares geradas através da rotina caracteristicasonda. 

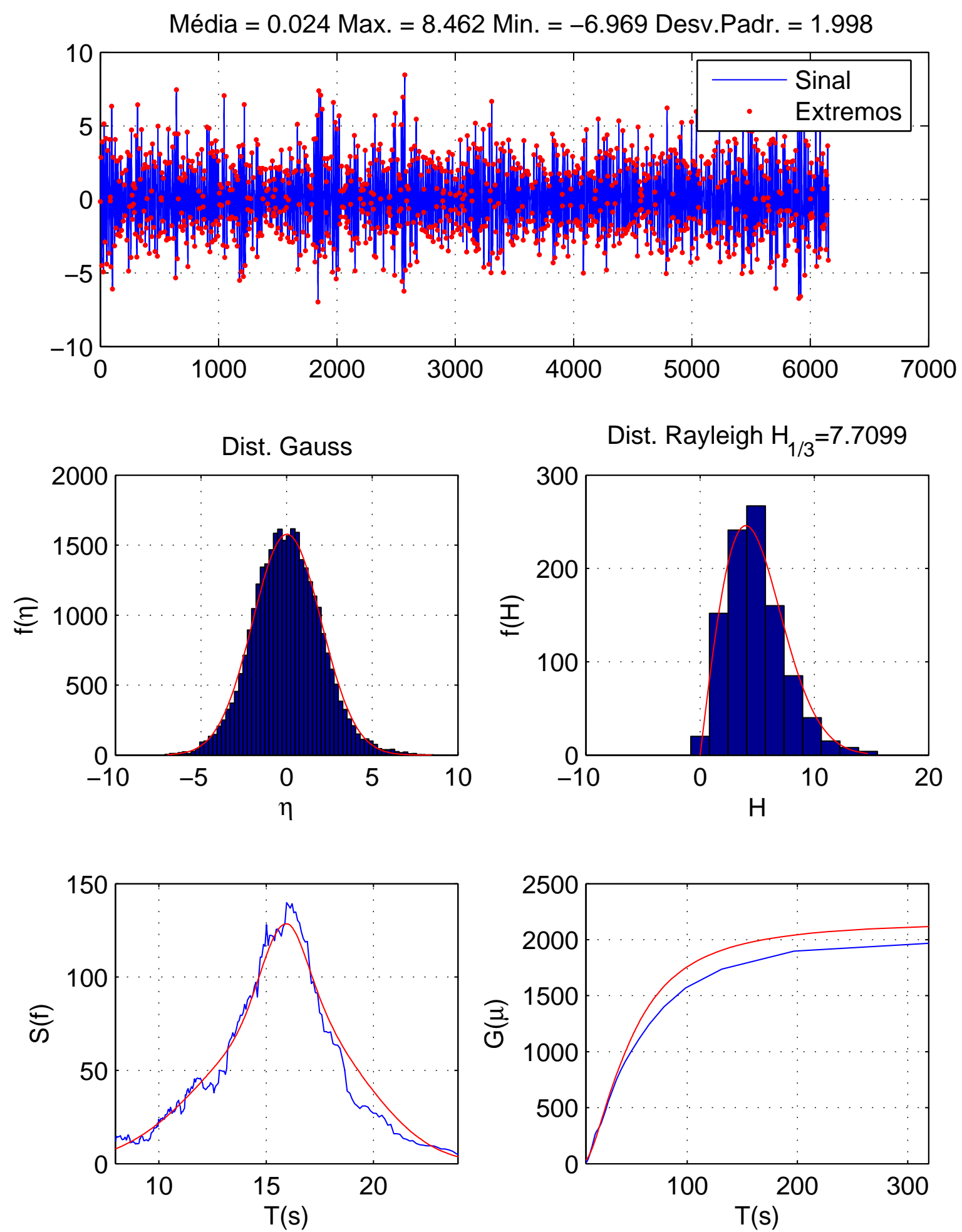

Sinal Desv.Padr. $=1.97 \mathrm{Hs}=7.88 \mathrm{Tp}=15.95 \mathrm{~T} 2=12.28 \mathrm{~T} 4=7.705 \mathrm{e}=0.7785$

Teórico Desv.Padr. $=1.993 \mathrm{Hs}=7.973 \mathrm{Tp}=15.95 \mathrm{~T} 2=12 \mathrm{~T} 4=8.498$ e $=0.7062$

Figura 2.23: Exemplo de verificação de mar irregular 


\subsection{Análise de Sinais}

A análise de experimentos envolve diversas operações sobre os sinais adquiridos. Com exemplos destas operações podem ser citadas: a filtragem de ruídos, o ajuste de escalas, o corte de regiões de interesse, a verificação de máximos e mínimos, o ajuste de média e o cálculo de parâmetros estatísticos, entre outras.

Praticamente todas estas operações são utilizadas em análises de experimentos oceânicos típicos, podendo ser encontradas em programas comerciais. No entanto, conhecer exatamente quais são as técnicas de análise utilizadas e, além disso, ter a possibilidade de construir procedimentos específicos, são dois aspectos que acabam motivando a criação de programas de análise próprios.

Por esse motivo, algumas rotinas mais adiante apresentadas foram especificamente desenvolvidas em ambiente MatLab ${ }^{\circledR}$ para o apoio às práticas experimentais discutidas ao longo deste texto. Estas rotinas podem ser divididas nos seguintes grupos:

- Rotinas para carregamento e adequação dos sinais brutos;

- Rotinas de tratamento dos sinais;

- Rotinas de análise propriamente ditas;

- Rotinas de apresentação e documentação dos resultados.

Uma vantagem de se contar com um programa de análise expedito e dedicado às atividades experimentais pretendidas diz respeito à possibilidade praticamente simultânea de se avaliar a qualidade dos mesmos, reduzindo a possibilidade de perdas de informação e, eventualmente, equívocos experimentais. Por esse motivo, quanto mais rápida a análise dos dados coletado, menor o risco da necessidade de repetição de alguma etapa da matriz de ensaio ou, ainda, a necessidade de uma reformulação do arranjo experimental. Durante o processo de pré-análise devem ser verificados principalmente problemas relacionados com ruídos acentuados ou falhas na aquisição. Além disso, quando pertinente, alguns parâmetros podem ser obtidos e comparados com aqueles advindos das simulações numéricas de apoio, procedimento que pode contribuir ainda mais para a qualidade do experimento. Portanto, as ferramentas de análise configuram-se como um elemento indispensável ao processo experimental como um todo.

Há que se comentar um aspecto adicional. Alguns experimentos têm um caráter de investigação qualitativa e, desta forma, contam com poucos instrumentos de medição. 
Um bom exemplo são os pré-testes utilizados para verificar as propriedades dos modelos ou os testes que envolvem a verificação de apenas um grau de liberdade com o objetivo de avaliar um movimento específico durante as análises iniciais de um projeto conceitual ao qual o experimento como um todo esteja associado.

Conforme mencionado, um conjunto de rotinas foi desenvolvido para apoiar as discussões deste texto. Estas rotinas buscaram atender as seguintes demandas do experimento:

- Análise dos decaimentos;

- Análises espectrais em geral;

- Análise dos RAO's;

- Análises específicas de oscilações aleatórias.

Existe, no entanto, um grupo de rotinas desenvolvido para a análise automatizada final dos sistemas flutuantes considerando um grande número de condições ambientais e de carregamento ensaiadas. Obviamente, este grupo de rotinas se vale daquelas anteriormente apresentadas e são encontradas no Apêndice VI.3.

No presente capítulo são apresentados os procedimentos que deram origem às rotinas mais adiante testadas para as análises dos experimentos apresentados nos Capítulos 2.6 e 2.7. Estes procedimentos são descritos na forma de diagramas que detalham as várias etapas envolvidas em cada tipo de análise e permitem uma avaliação da sua aplicabilidade, além dos seus respectivos parâmetros de entrada e saída. No apêndice V são discutidos alguns pontos com relação ao tratamento de sinais.

\subsubsection{Análise de Decaimento}

Na rotina de análise de decaimento, o sinal (registro temporal) não requer um tratamento de filtragem, apesar desta opção se mostrar disponível.

Para a obtenção dos resultados, é necessário apenas o corte do sinal no intervalo que vai do instante próximo ao início do decaimento até o instante onde as oscilações deixam de ser apreciáveis. Destaca-se que na região próxima ao final do decaimento é importante evitar que perturbações sejam reconhecidas como amplitudes.

Recomenda-se, ainda, zerar o valor médio do sinal, obtido a partir da condição de repouso anterior à imposição da condição inicial do decaimento. Há situações, no entanto, 
em que o sinal registrado não contém a situação de repouso inicial. Para estes casos, um valor médio com base nos instantes centrais do sinal é utilizado.

Além disso, é importante lembrar que o procedimento sugerido não deve deteriorar as características do sinal, principalmente com relação às amplitudes ciclo a ciclo, e que quanto maior o número de oscilações registradas, melhor a estimativa dos parâmetros de interesse (valores de amortecimento e frequência ou período).

A partir do sinal com média nula, a identificação dos valores extremos pode ser realizada após a identificação dos instantes com ordenada nula. Estes valores extremos são utilizados tanto para a obtenção dos decrementos, quanto para a estimativa do período amortecido do sinal. Mesmo em sinais com ruído moderado, o método sugerido apresenta bons resultados, pois para a obtenção dos valores extremos é utilizado máximo entre dois zeros consecutivos. Outra opção para encontrar os extremos seria determinar os instantes em que a derivada do sinal apresente valores nulos. Este último procedimento, no entanto, pode incorrer em resultados pouco confiáveis quando tratar de sinais com ruído.

O primeiro e o último extremos são descartados para evitar que a condição inicial ou final do sinal seja considerada como um valor extremo. Em seguida, o cálculo dos decrementos logarítmicos e dos coeficientes de amortecimento para cada amplitude média nos sucessivos ciclos identificados é feito como mostrado na equação 2.18. A rotina desenvolvida e que deu origem à Figura 2.24 mostra os valores considerados como extremos e zeros, permitindo a avaliação de coerência. Caso alguns pontos se mostrem incoerentes, torna-se necessária uma nova seleção de intervalo de interesse ou mesmo a filtragem prévia do sinal de decaimento. 


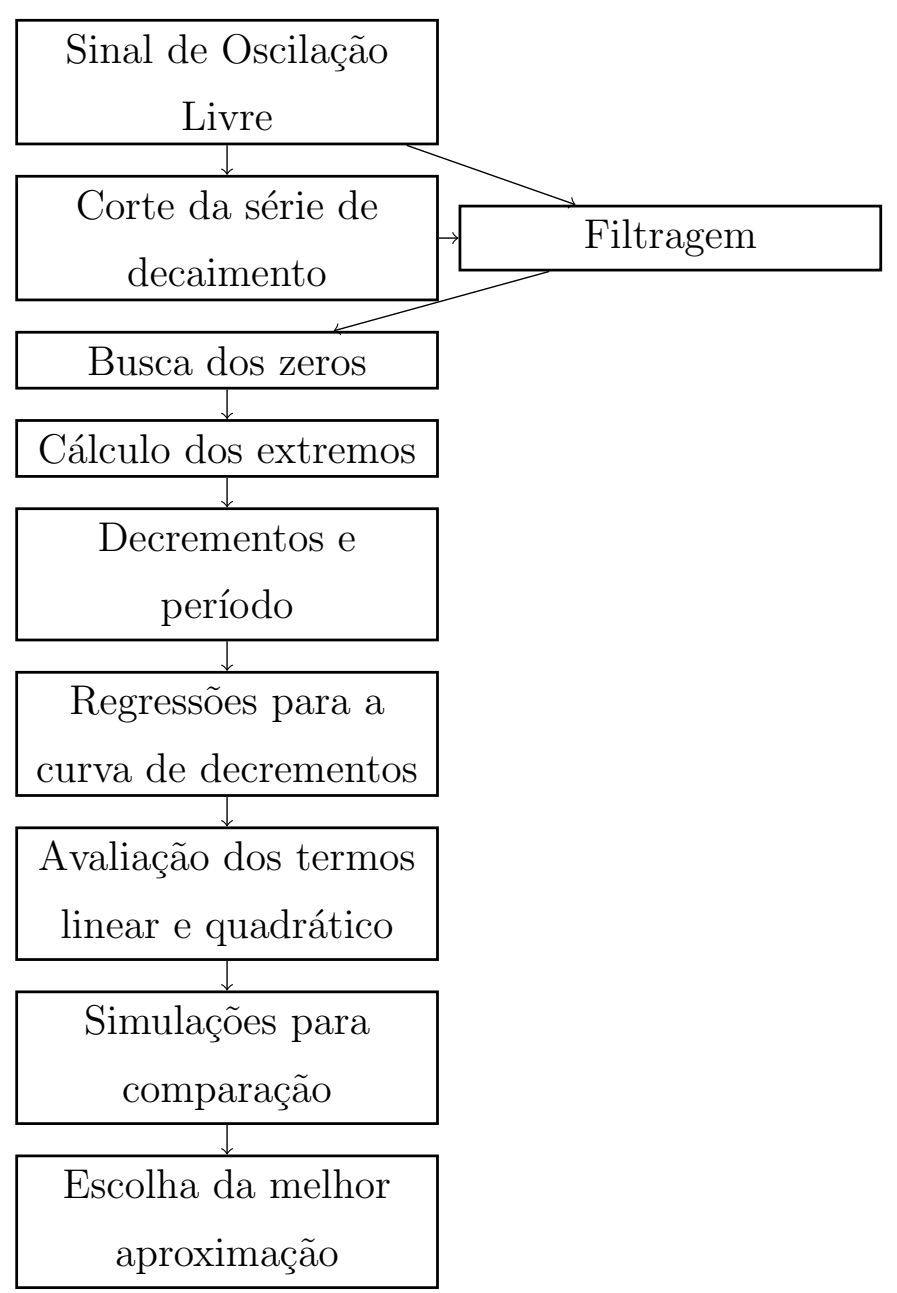

Figura 2.24: Procedimento de análise de decaimento

Períodos médios são calculados com base na identificação dos valores de ordenada nula do sinal e utilizados para a determinação dos amortecimentos, linear e quadrático. No caso do amortecimento quadrático, três tipos de regressão são realizados com base na equação 2.18. Estas são desenvolvidas para diferentes regiões da curva dos decrementos logarítmicos com função das amplitudes médias ciclo a ciclo, quais sejam: todos os pontos, apenas os pontos do início do sinal e/ou apenas os pontos do final do sinal. Desta forma, o objetivo da análise nos intervalos descritos é obter uma estimativa dos parâmetros que melhor aproximam a envoltória do sinal de decaimento, levando-se em consideração eventuais diferenças ao longo do comportamento dissipativo registrado.

Nas Figuras de 2.25 a 2.27 são apresentados os resultados da análise com a rotina decaytest, aplicada a um sinal teórico de decaimento, com período de 10 s e $\zeta=0,05$ (apenas com dissipação linear). 


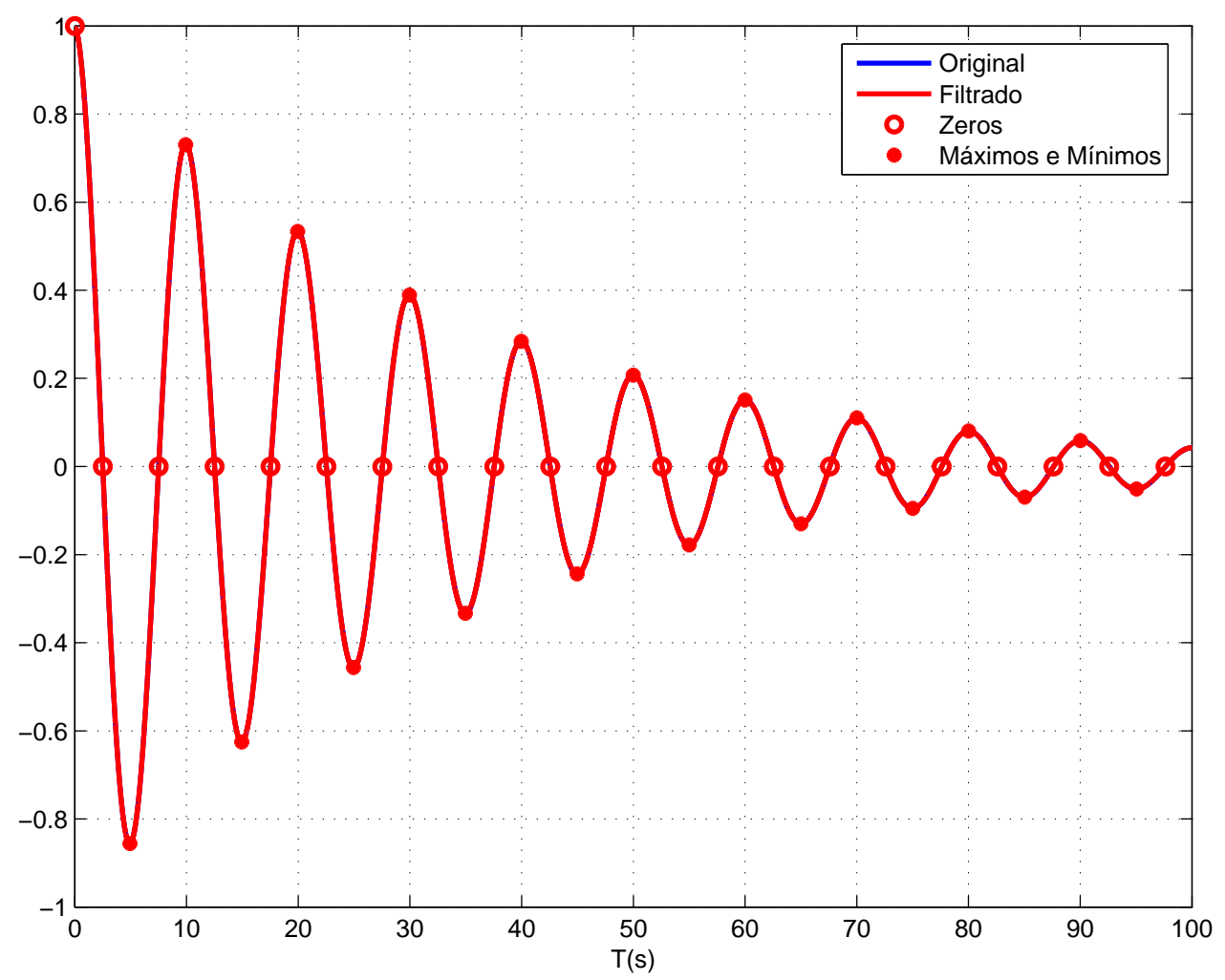

Figura 2.25: Sinal teórico com período de $10 \mathrm{~s}, \zeta=5 \%$ e $X_{0}=1$

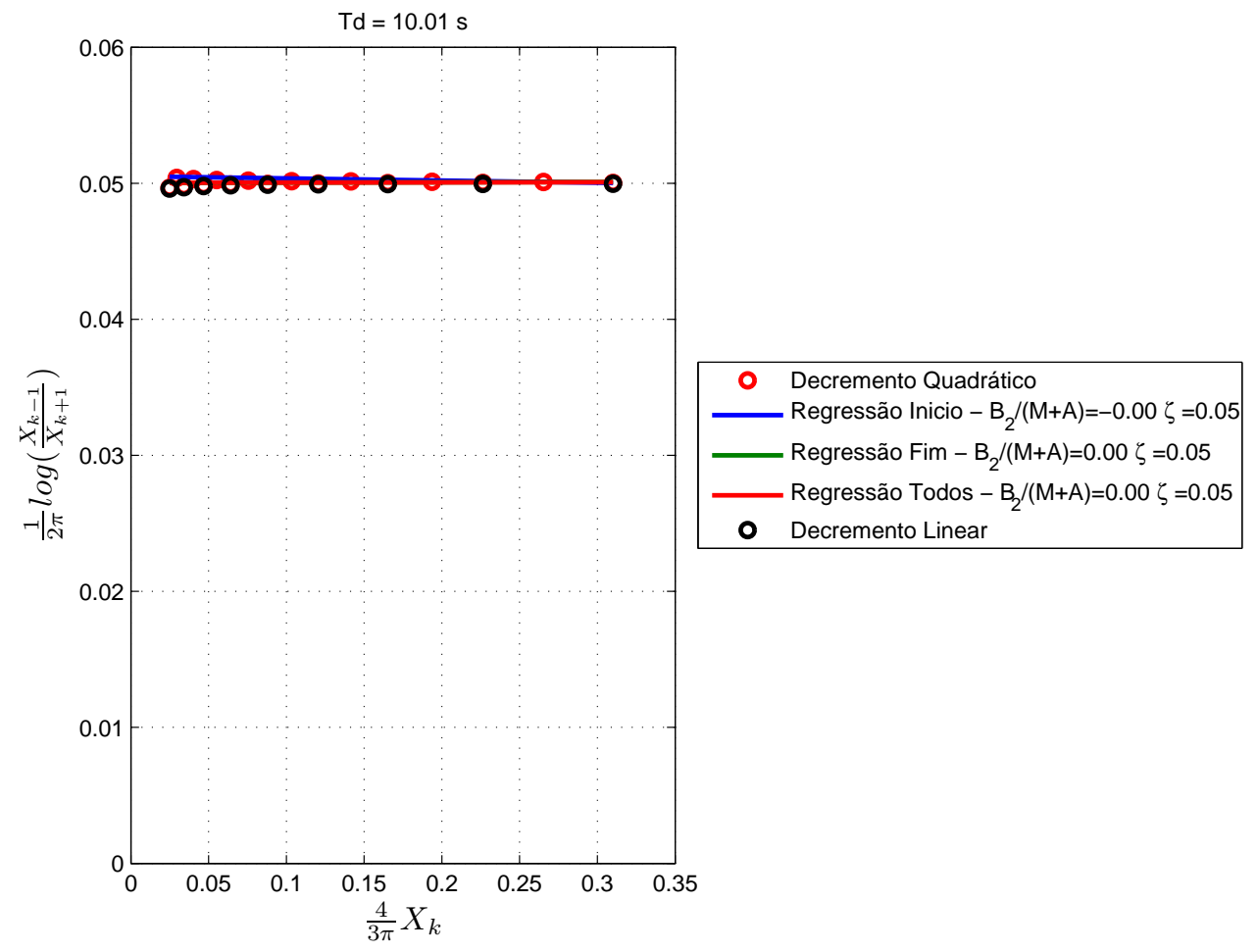

Figura 2.26: Regressões para o coeficiente de amortecimento do sinal da Figura 2.25 


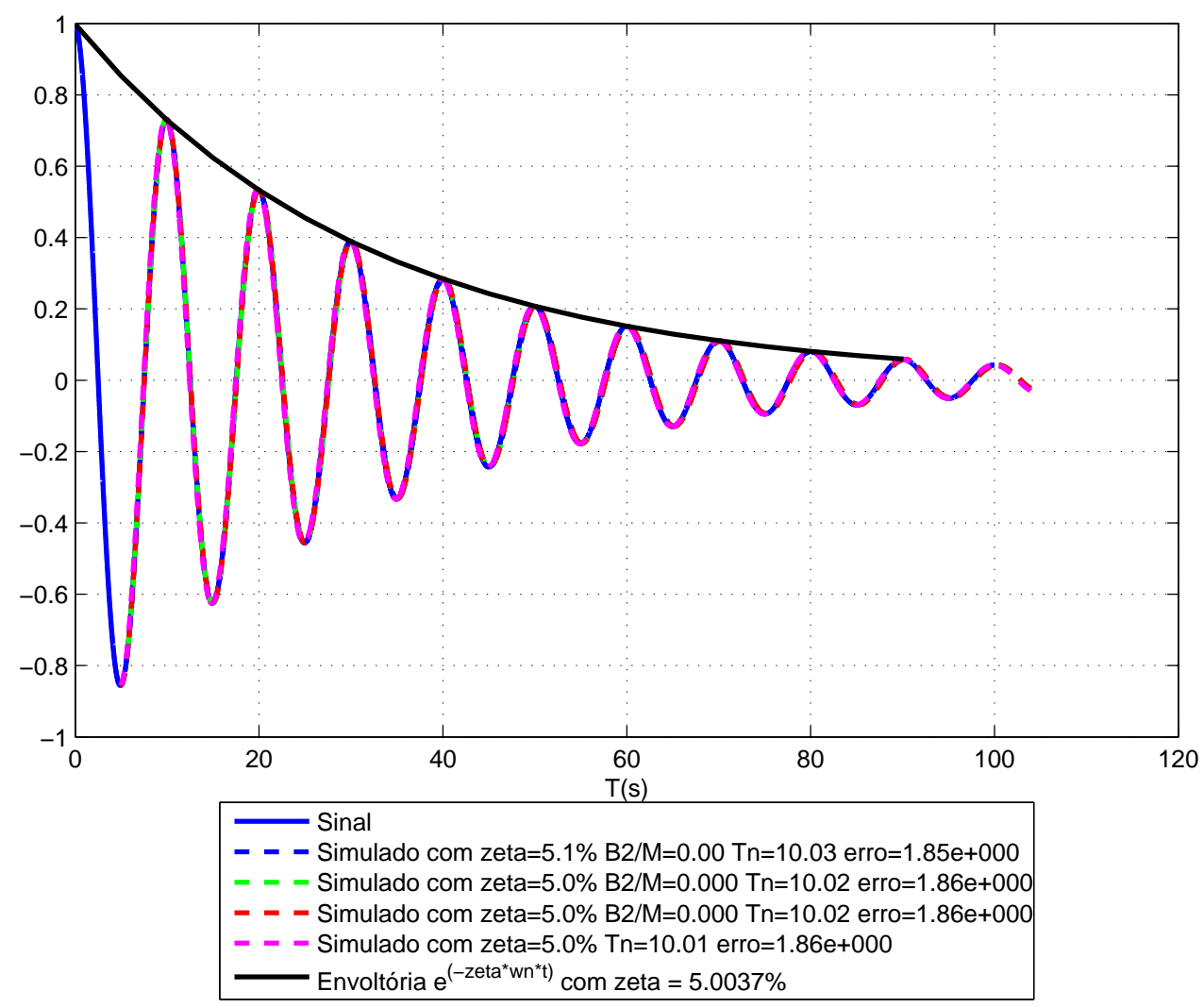

Figura 2.27: Simulações numéricas para o sinal da Figura 2.25

Pode se notar que, mesmo considerando a análise simultânea de uma dissipação quadrática que não existe no exemplo da Figura 2.25, os valores lineares obtidos com o procedimento descrito estão muito próximos dos valores definidos.

Para apresentar a análise de um sinal que contenha o termo quadrático, foi criado um decaimento considerando o termo $B_{2} /(M+A)=0.05$, para o qual são apresentados os resultados das Figuras de 2.28 a 2.30. 


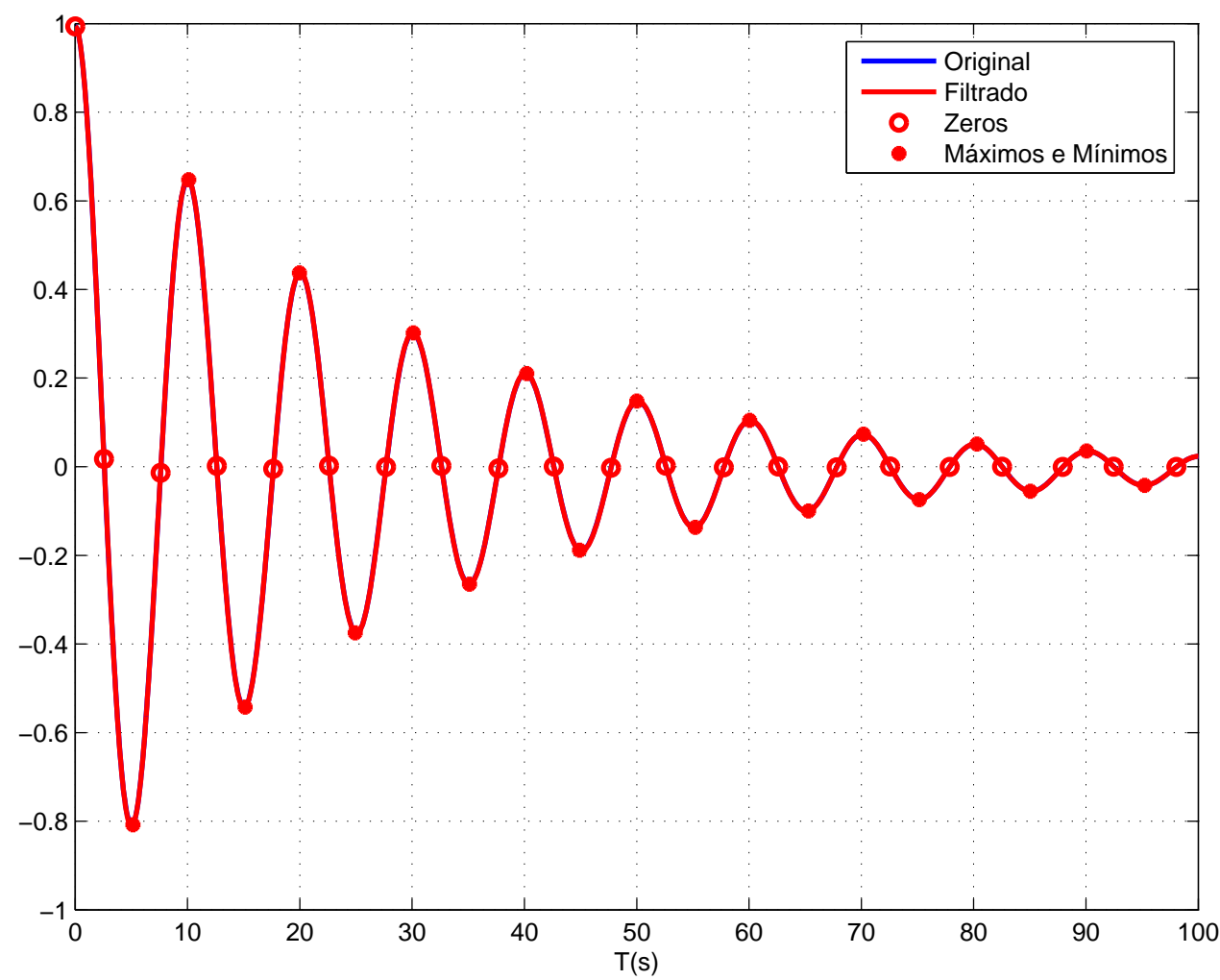

Figura 2.28: Sinal teórico com período de $10 \mathrm{~s}, \zeta=5 \%, X_{0}=1$ e $B_{2} /(M+A)=0.05$

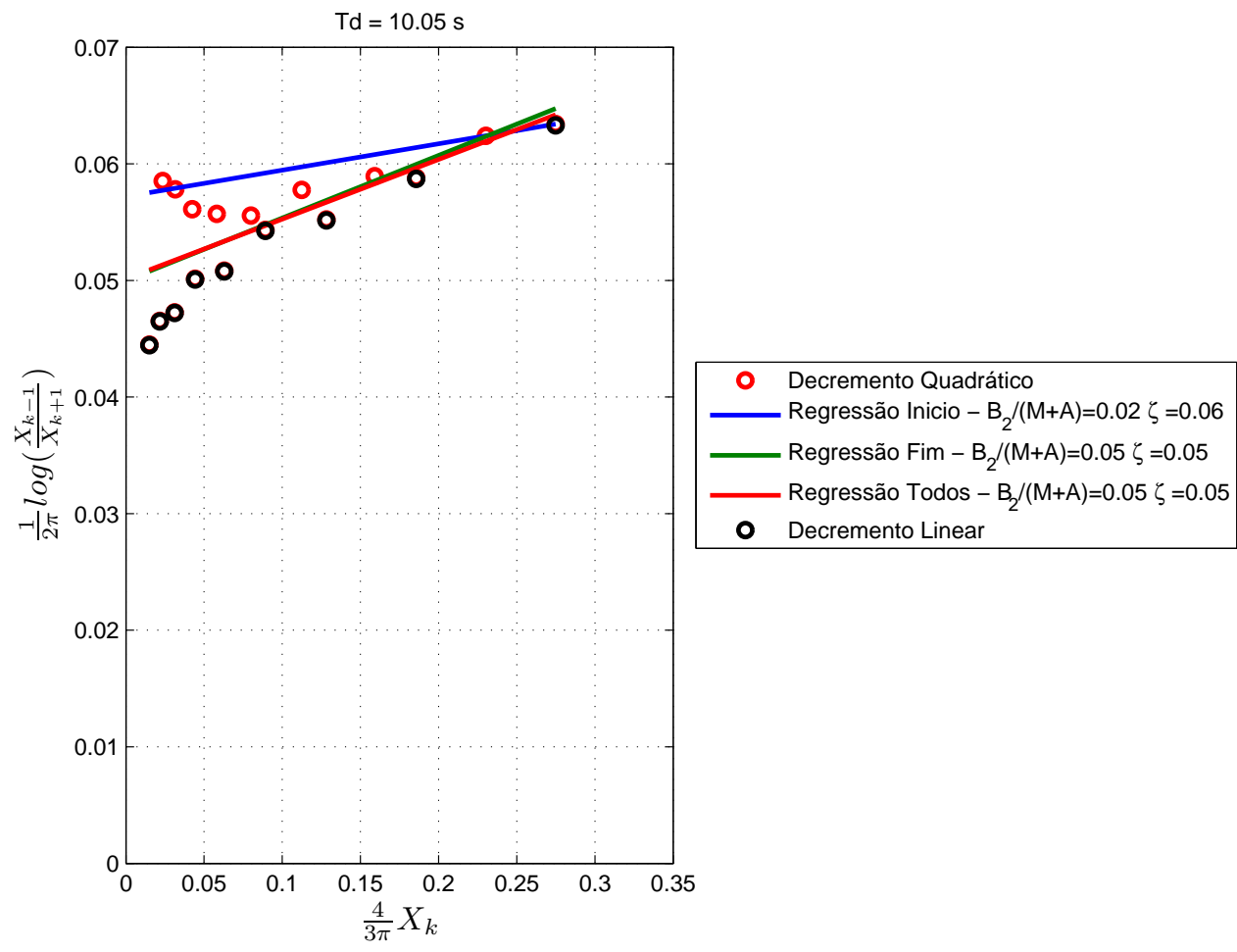

Figura 2.29: Regressões para o coeficiente de amortecimento do sinal da Figura 2.28 


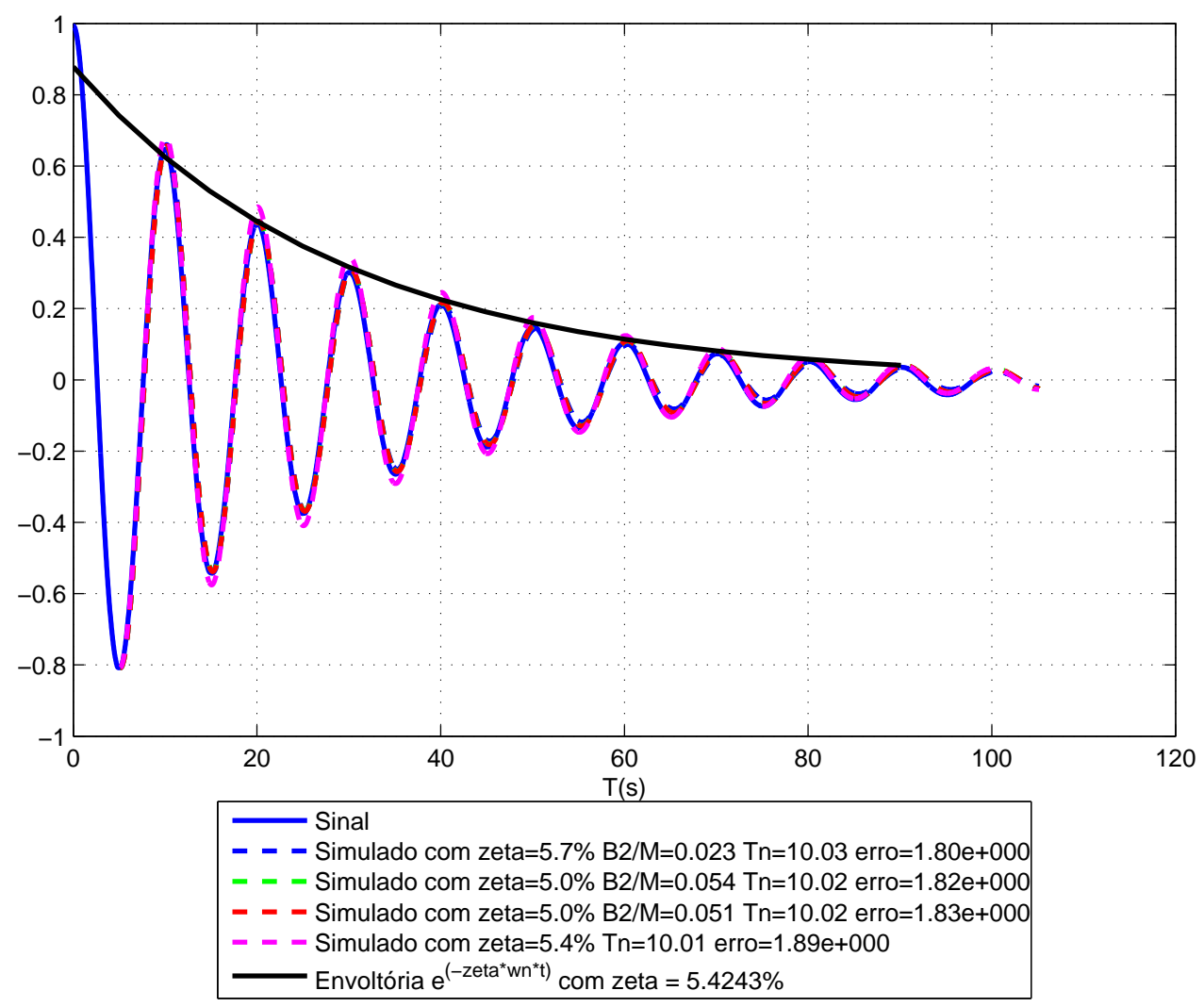

Figura 2.30: Simulações numéricas para o sinal da Figura 2.28

Mais uma vez os resultados obtidos com procedimento proposto apresentaram-se bem próximos daqueles definidos. Contudo, através da Figura 2.29, pode-se observar que a regressão considerando apenas o trecho inicial do sinal obteve um coeficiente quadrático bem abaixo do esperado. Lembrar que a possibilidade de análise segundo três situações (sinal total, apenas o trecho inicial do sinal e apenas o trecho final do sinal) foi justamente construída para lidar com comportamentos como o descrito acima.

\subsubsection{Análise de RAO}

A análise temporal no domínio do tempo é feita utilizando-se um intervalo selecionado no sinal de excitação, por exemplo a onda, e o respectivo sinal de resposta (movimentos). A seleção do intervalo é feita desconsiderando eventuais efeitos registrados que evidenciem a reflexão de ondas. A partir do intervalo selecionado são calculados os períodos médios do sinal de excitação, através da média entre os períodos de zeros ascendentes e das respectivas médias das amplitudes dos picos dos sinais de excitação e de resposta. 
O RAO é, então, calculado como:

$$
R A O\left(T_{m}\right)=\frac{\bar{A}_{\text {mov }}\left(T_{m}\right)}{\bar{A}_{\text {onda }}\left(T_{m}\right)}
$$

Essa forma simplificada de obtenção do RAO só é possível nos ensaios com ondas regulares onde a frequência de resposta é aproximadamente a mesma da excitação.

No caso de análises no domínio da frequência é necessária a obtenção dos espectros de excitação e de reposta, determinando-se o RAO a partir da equação 2.9.

$$
R A O(f)=\left[\frac{S_{y y}(f)}{S_{x x}(f)}\right]^{1 / 2}
$$

A análise de RAO pode ser realizada em sinais de ondas regulares, transientes ou irregulares.

Como apresentado no Capítulo 2.7, recomenda-se que primeiro seja realizado um ensaio em onda transiente, para que uma previsão da faixa de resposta do sistema seja obtida. A análise de ondas transientes e irregulares é realizada com base na mesma equação 2.9. Contudo, caso exista algum efeito de segunda-ordem apreciável, o mesmo deve ser filtrado ou isolado. Um bom método para isolar o efeito de segunda-ordem é apresentado no Capítulo 2.5.4. 


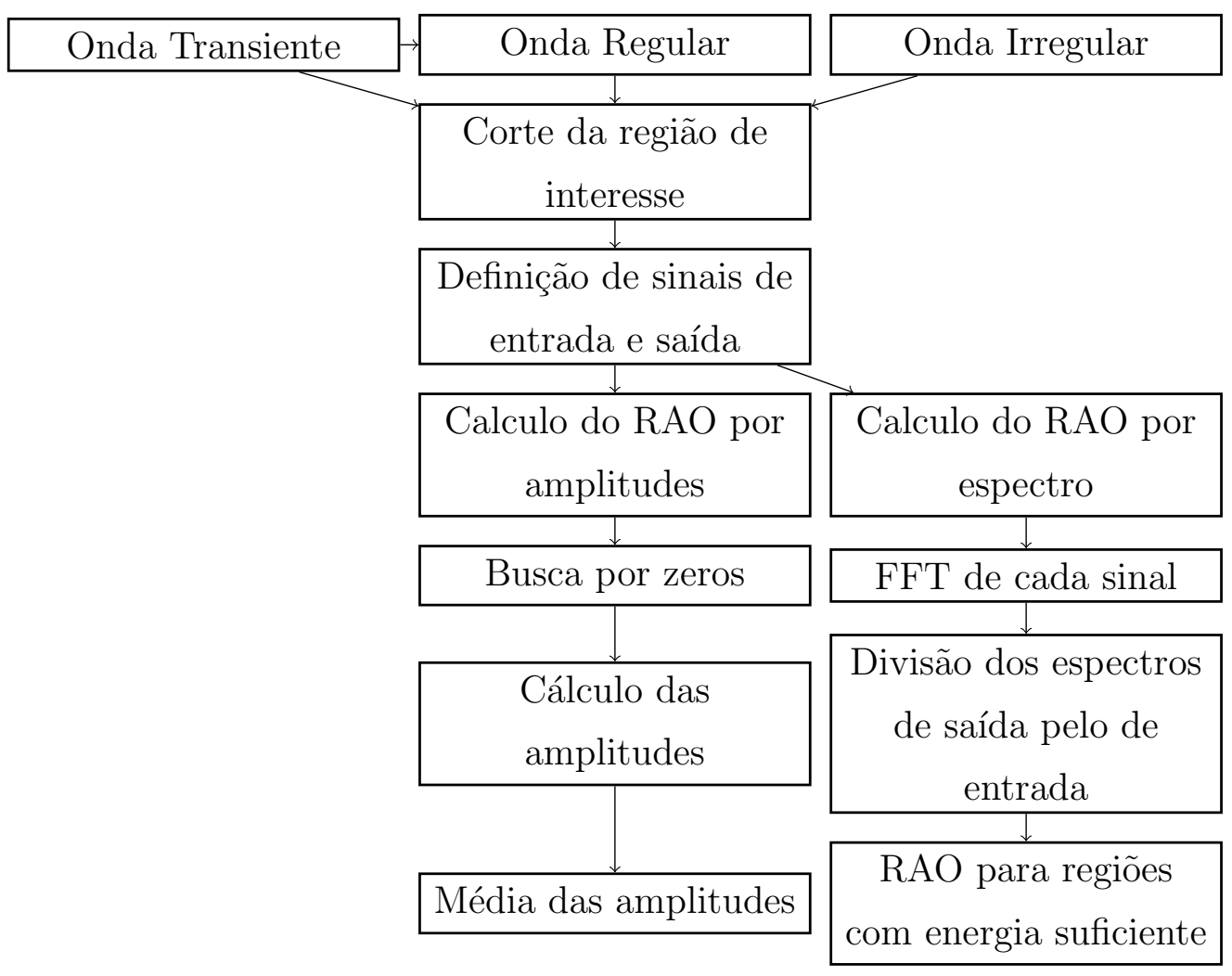

Figura 2.31: Análise de RAO

Um sinal teórico foi criado para avaliação através da rotina calculaRAo, obtido a partir de dois sinais regulares com período de 10s e defasagem de 30 graus entre si (ver Figura 2.32). Na Figura 2.33, pode-se verificar a recuperação dos valores de RAO e defasagem, além da função de coerência apresentar valor próximo do unitário. A função de coerência é uma relação entre o espectro cruzado e os auto-espectros de excitação e reposta $^{8}$, ou seja, avalia a linearidade entre os sinais. Na análise dos sinais do ensaio, valores de coerência acima de 0,6 são considerados satisfatórios [Chakrabarti, 1994]. No caso dos valores de fase, deve-se ter muito cuidado na sua consideração em comparações numéricas e/ou experimentais. Como os movimentos possuem características de primeira e segunda ordem, estes efeitos são difíceis de serem dissociados para a avaliação na fase entre excitação e resposta, sendo assim, é recomendada apenas a comparação da fase relativa entre as repostas.

\footnotetext{
${ }^{8}$ As definições dos tipos de espectro, bem como a formulação para o cálculo da função de coerência, são apresentados no Apêndice III.
} 

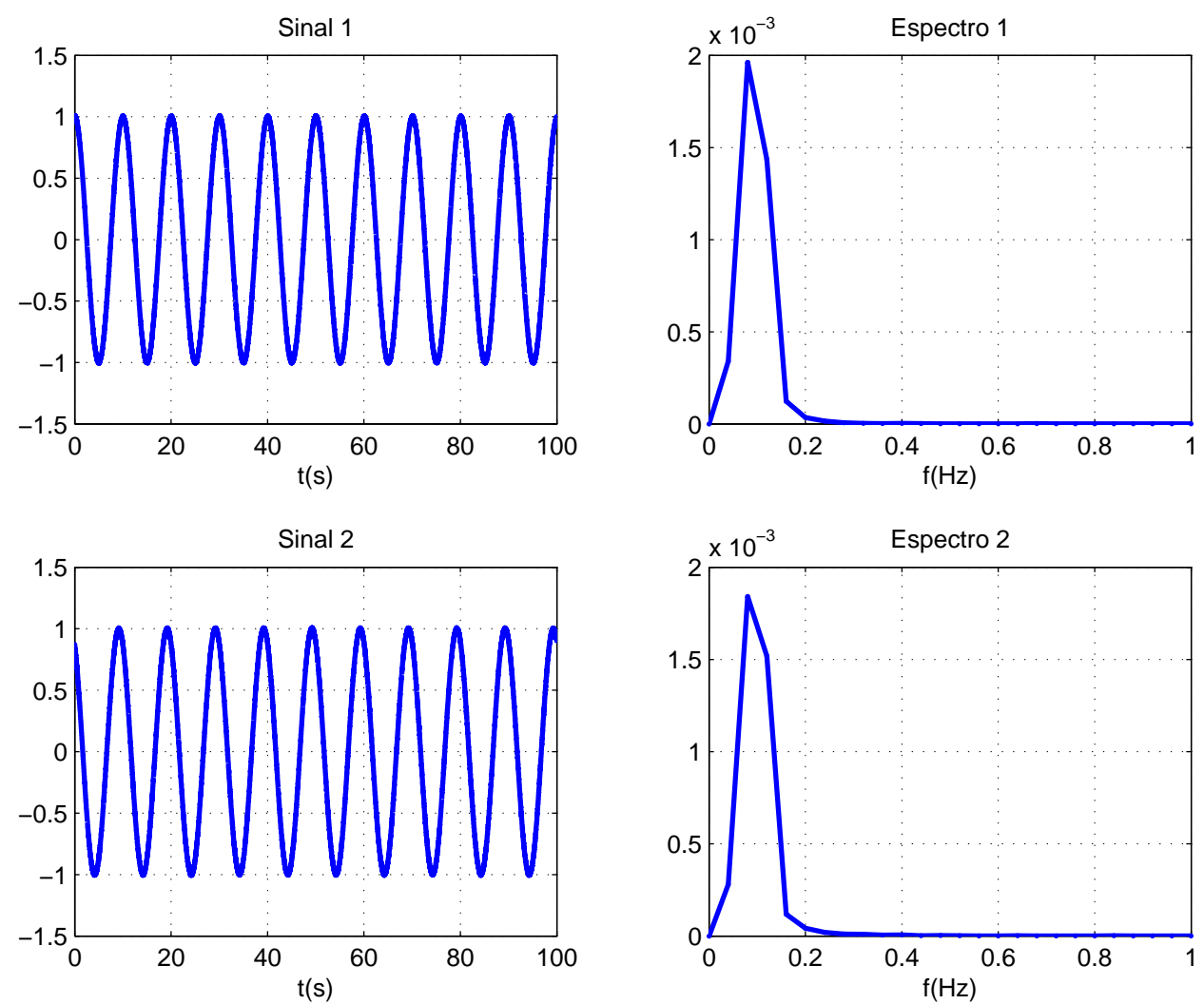

Figura 2.32: Sinais harmônicos com defasagem de 30 graus e respectivos espectros
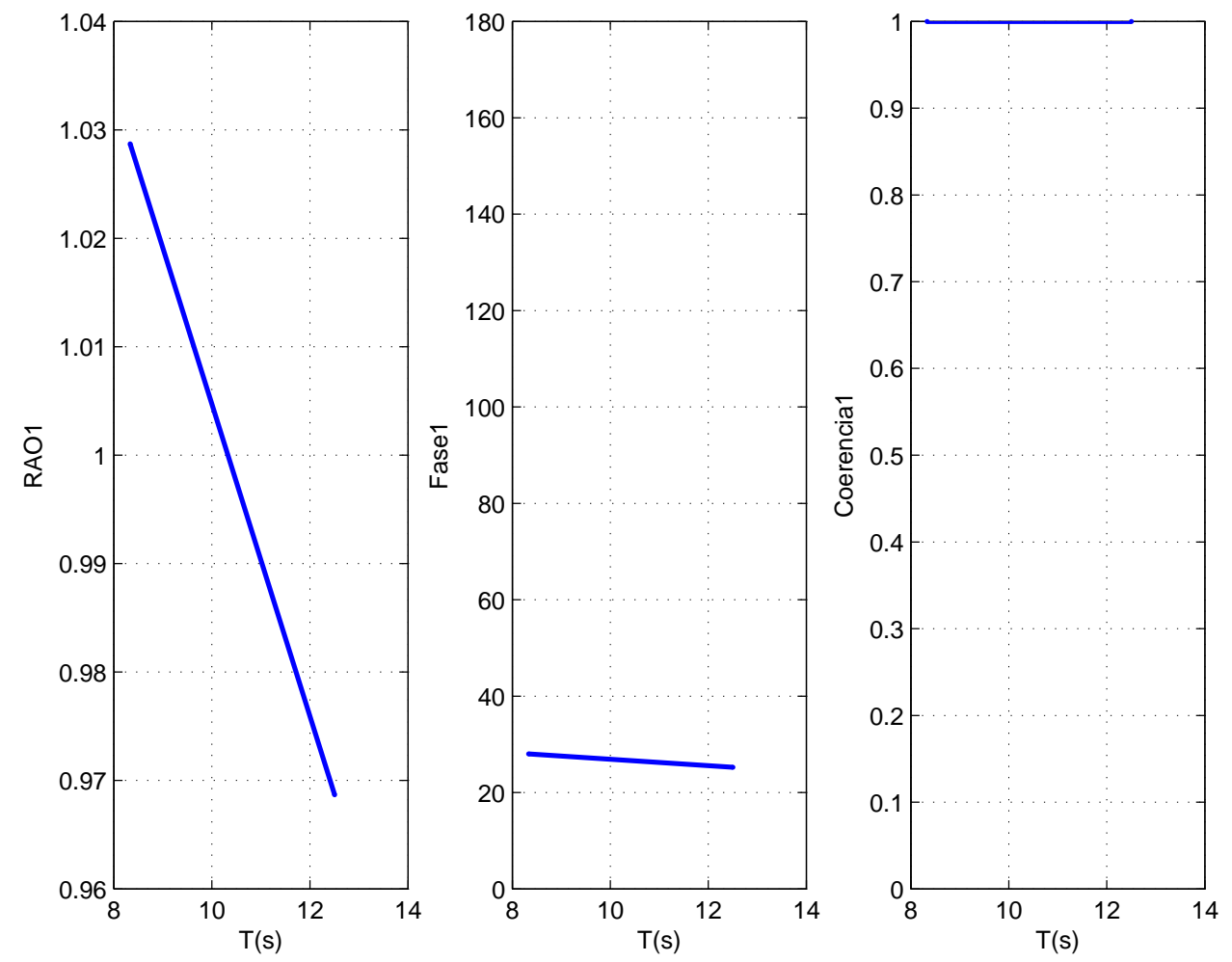

Figura 2.33: Avaliação do RAO entre dois sinais harmônicos com defasagem de 30 graus 
A avaliação do RAO também pode ser realizada através da transformada de Hilbert, construída na rotina calculaRAOHH. No entanto, essa análise é mais apropriada para sinais de ondas transientes, que possuem uma larga faixa de frequências. Quando um sinal de onda regular é analisado com base nessa transformada, o resultado apresenta variações em torno dos valores corretos de RAO, tanto para amplitudes, quanto para a fase. Estas variações podem ser vistas na Figura 2.34.
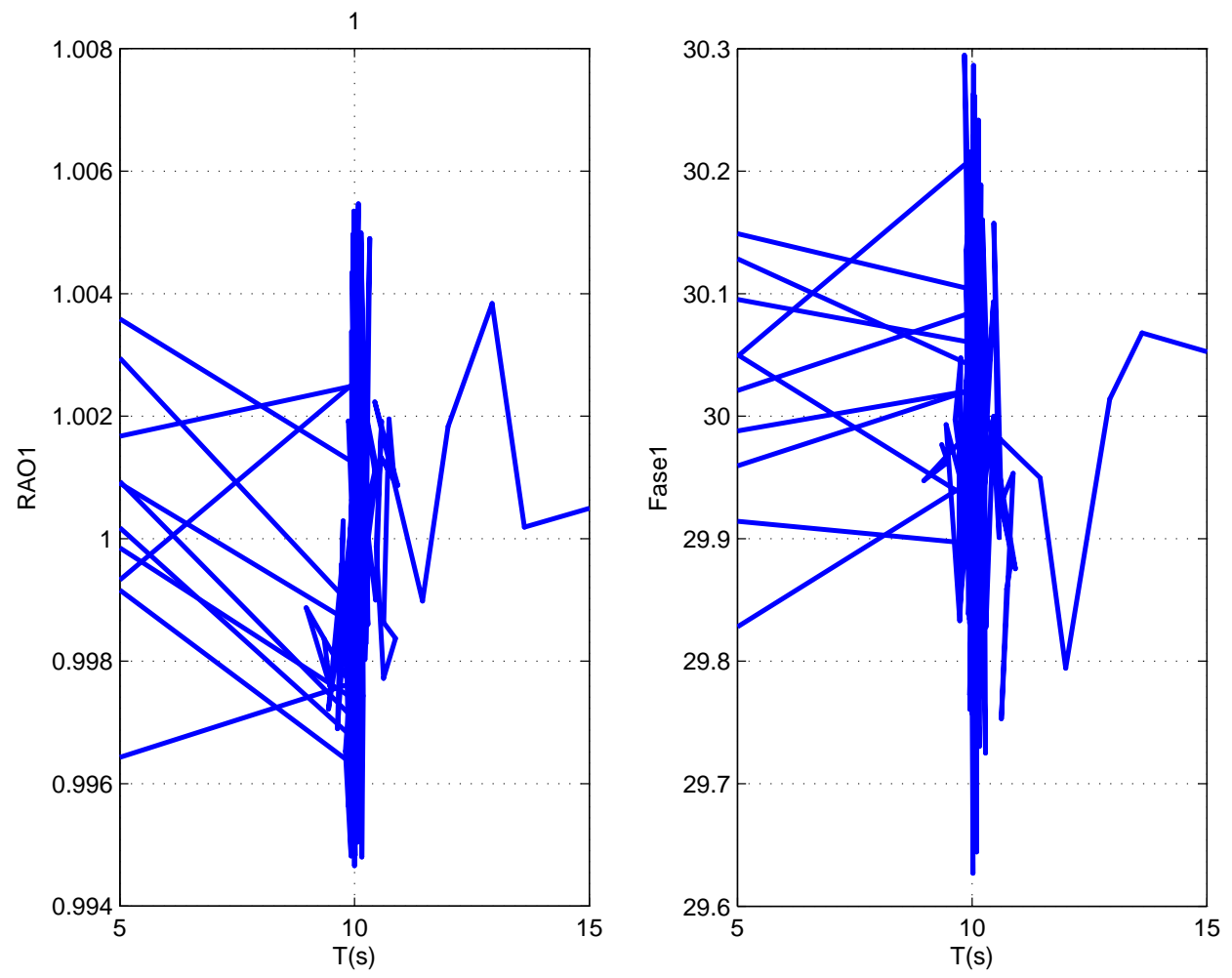

Figura 2.34: Avaliação do RAO entre dois sinais harmônicos com defasagem de 30 graus através da transformada de Hilbert

Na Figura 2.36 pode-se verificar o resultado da análise via calculaRAOHH, aplicada a um sinal de onda transiente. Esta rotina também segue o procedimento apresentado na Figura 2.31, porém com base em uma estimativa de amplitudes feita a partir da transformada de Hilbert. 

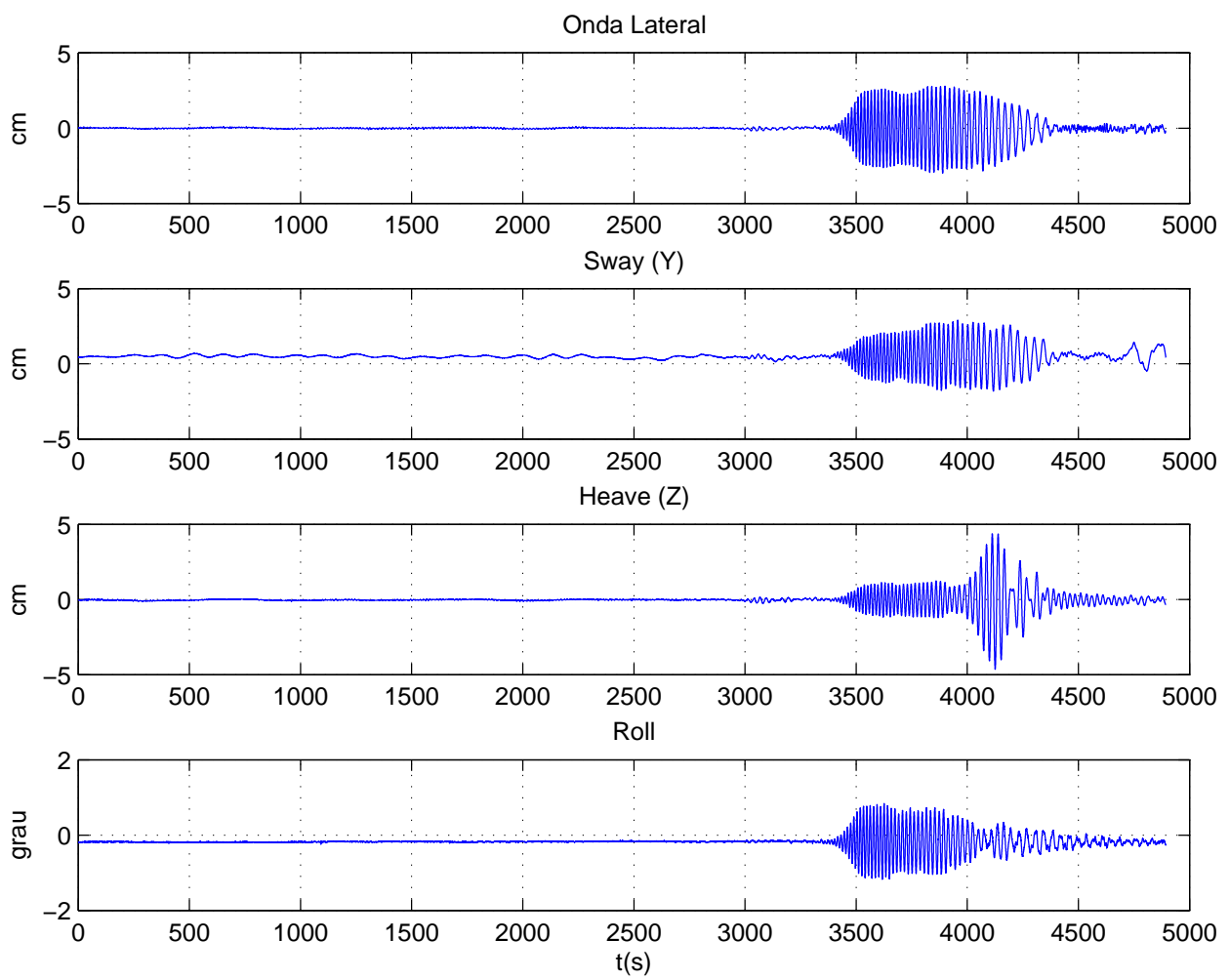

Figura 2.35: Sinal de reposta em onda transiente
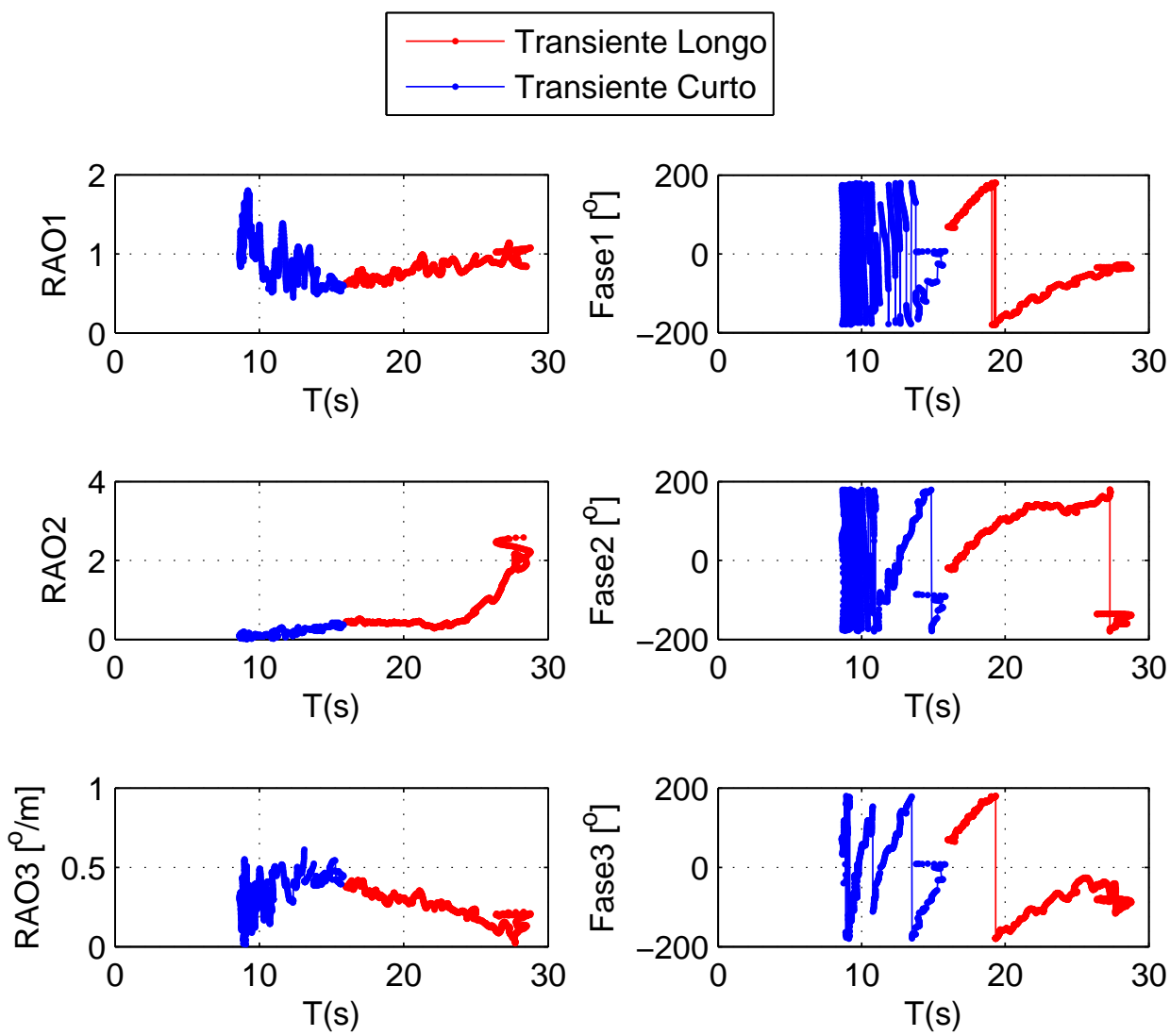

Figura 2.36: Avaliação do RAO do sinal de reposta em onda transiente da Figura 2.35 


\subsubsection{Análise de Excitações aleatórias}

A análise de Random Decrement Technique (RDT), baseada em [Yang et al., 1985], considera que a resposta do sistema flutuante é linear, quando sujeita a uma força de excitação aleatória. Assumindo que o sinal da força possui média nula, seja estacionário e apresente distribuição Gaussiana de amplitudes, os sinais de resposta apresentarão as mesmas características. A RDT calcula a média entre segmentos de mesmo comprimento no sinal. Esses segmentos são escolhidos a partir de um mesmo valor de referência (normalmente uma relação do desvio padrão), a partir do qual, são identificadas as abscissas com ordenadas mais próximas do valor de referência, alternando-se derivadas positivas e negativas que definem o início de cada segmento. A média entre ordenadas dos segmentos transladados para a origem das abcissas, instante a instante, resulta em um sinal semelhante a uma série de decaimento . A partir do sinal resultante, a rotina de análise decaytest pode ser utilizada para determinar o coeficiente de amortecimento do sinal original, aleatório. O procedimento de análise é apresentado de maneira esquemática na Figura 2.37.

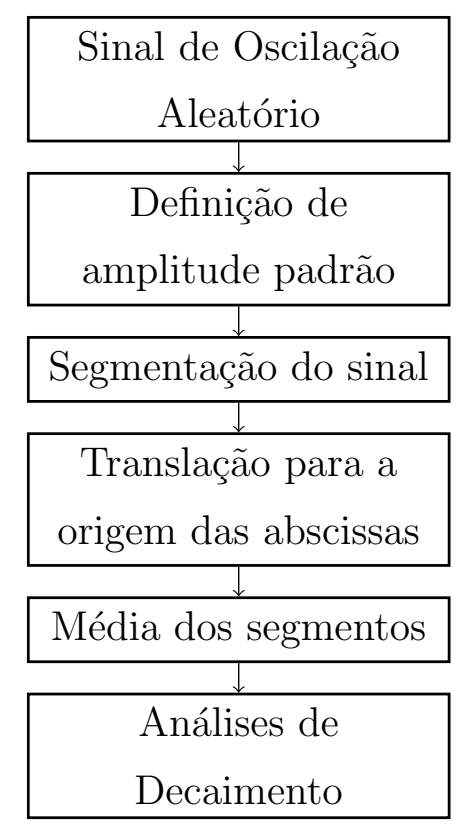

Figura 2.37: Procedimento de análise através da RDT

Utilizando-se o exemplo apresentado na Figura 2.38, referente a um sinal aleatório, os pontos em vermelho representam os inícios dos segmentos para utilização da RDT. O resultado da aplicação deste método àquele sinal pode ser visto na Figura 2.39, comparado com simulação numérica para avaliar os termos de amortecimento linear e quadrático. 


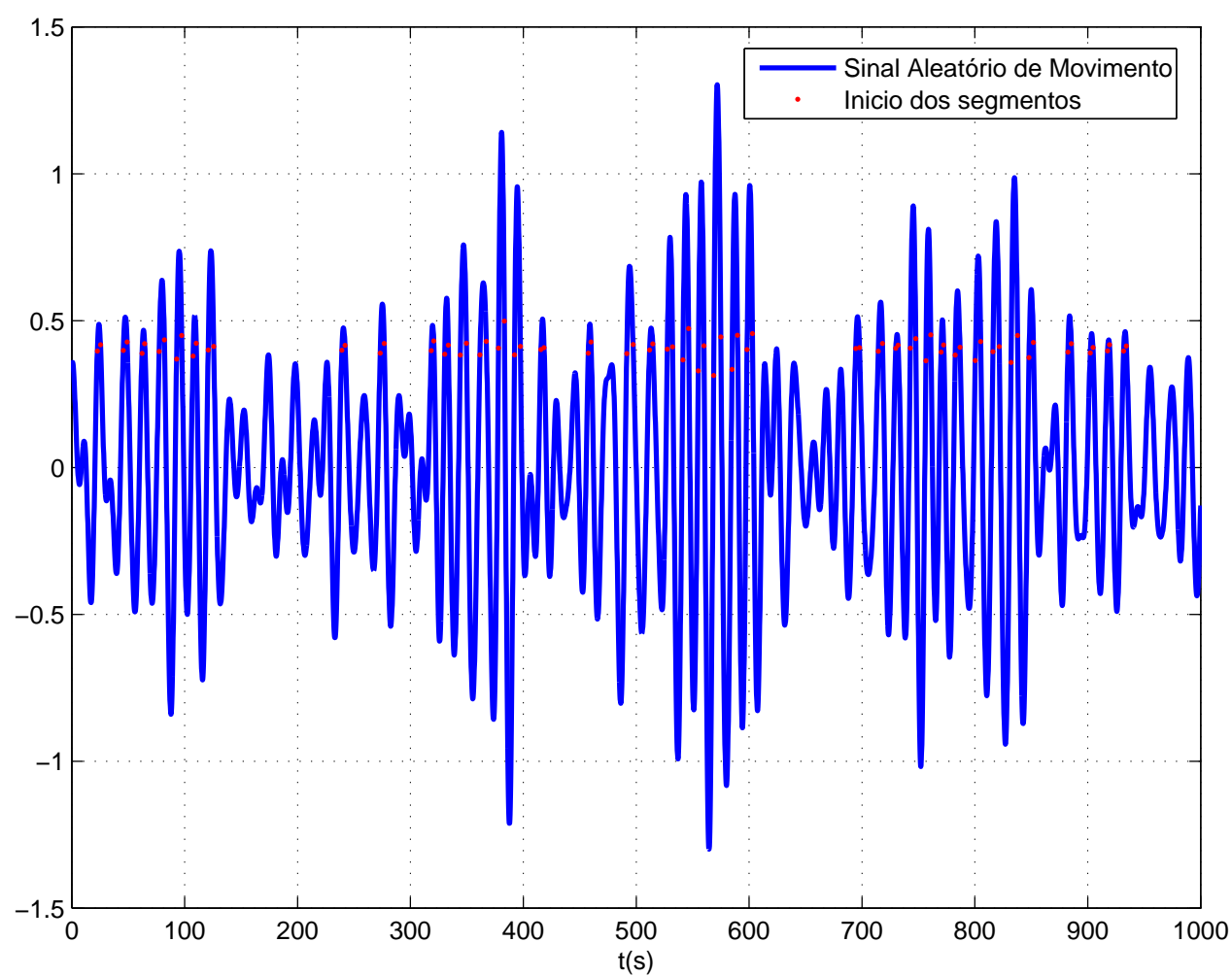

Figura 2.38: Sinal aleatório com pontos inicias dos segmentos através do método RDT

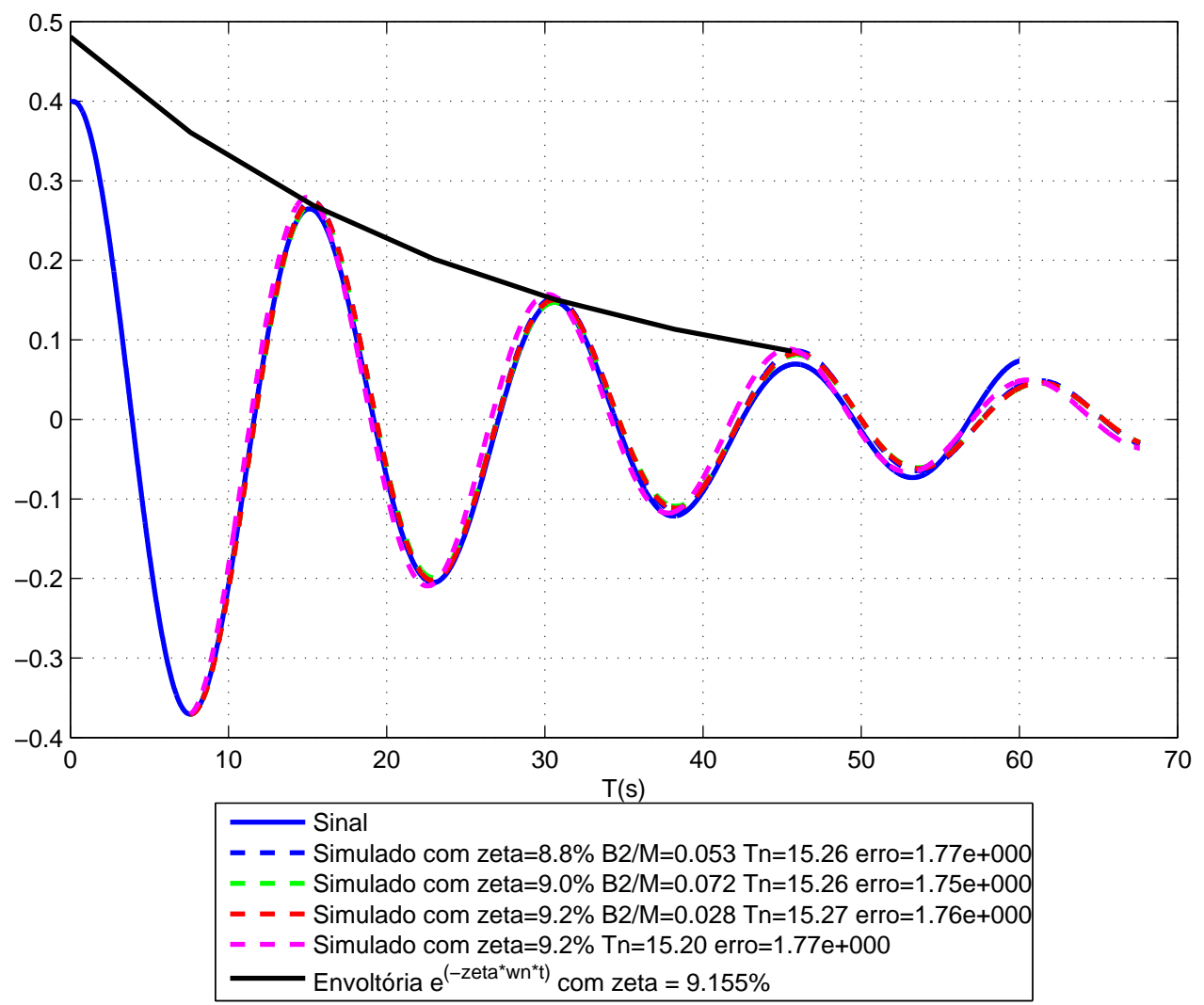

Figura 2.39: Série de decaimento obtida através da média dos segmentos do sinal da Figura 2.38 


\subsubsection{Método de Decomposição Empírica}

Outra rotina de análise foi construída para auxiliar na decomposição do sinal, com a finalidade de avaliar isoladamente comportamentos coexistentes, baseada na transformada de Hilbert e no método descrito em [Huang et al., 1998]. Aplicações deste método podem ser encontradas em [Huang \& Attoh-Okine, 2005] e um exemplo de aplicação para análise de VIV e outro de VIM, fenômenos típicos em aplicações oceânicas, são apresentados em [Pesce et al., 2006] e [Gonçalves et al., 2010]. A Empirical Mode Decomposition - EMD auxilia o cálculo de frequências instantâneas através da transformada de Hilbert. O método separa o sinal em funções chamadas de Intrinsic mode functions - IMF e aplica a transformada de Hilbert a cada uma dessas funções. O diagrama com o procedimento de análise é apresentado na Figura 2.40, referente à rotina EMD. O algoritmo utilizado para obter a transformada de Hilbert é baseado na transformada de Fourier. Basicamente o sinal é tratado através da FFT e os valores obtidos para as frequência negativas zerados. Posteriormente, o sinal é tratado com a transformada de Fourier inversa, resultando na transformada de Hilbert.

$\mathrm{Na}$ análise de sinais tipicamente obtidos em experimentos de comportamento no mar, uma das vantagens de utilizar o método EMD é que a separação em IMF's separa o sinal em componentes associadas aos efeitos distintos, por exemplo, de primeira e segunda ordens. Outra possibilidade de aplicação do método EMD diz respeito à avaliação de ensaios de decaimento, segundo a qual, pode-se verificar eventuais modulações de frequência. Ou seja, nos casos em que o sinal apresentar uma variação acentuada de frequência, os métodos de avaliação de decaimento descritos no item

Todas as rotinas acima possuem uma interface com usuário e, com os diagramas apresentados, é possível conhecer os passos necessários durante a análise. 


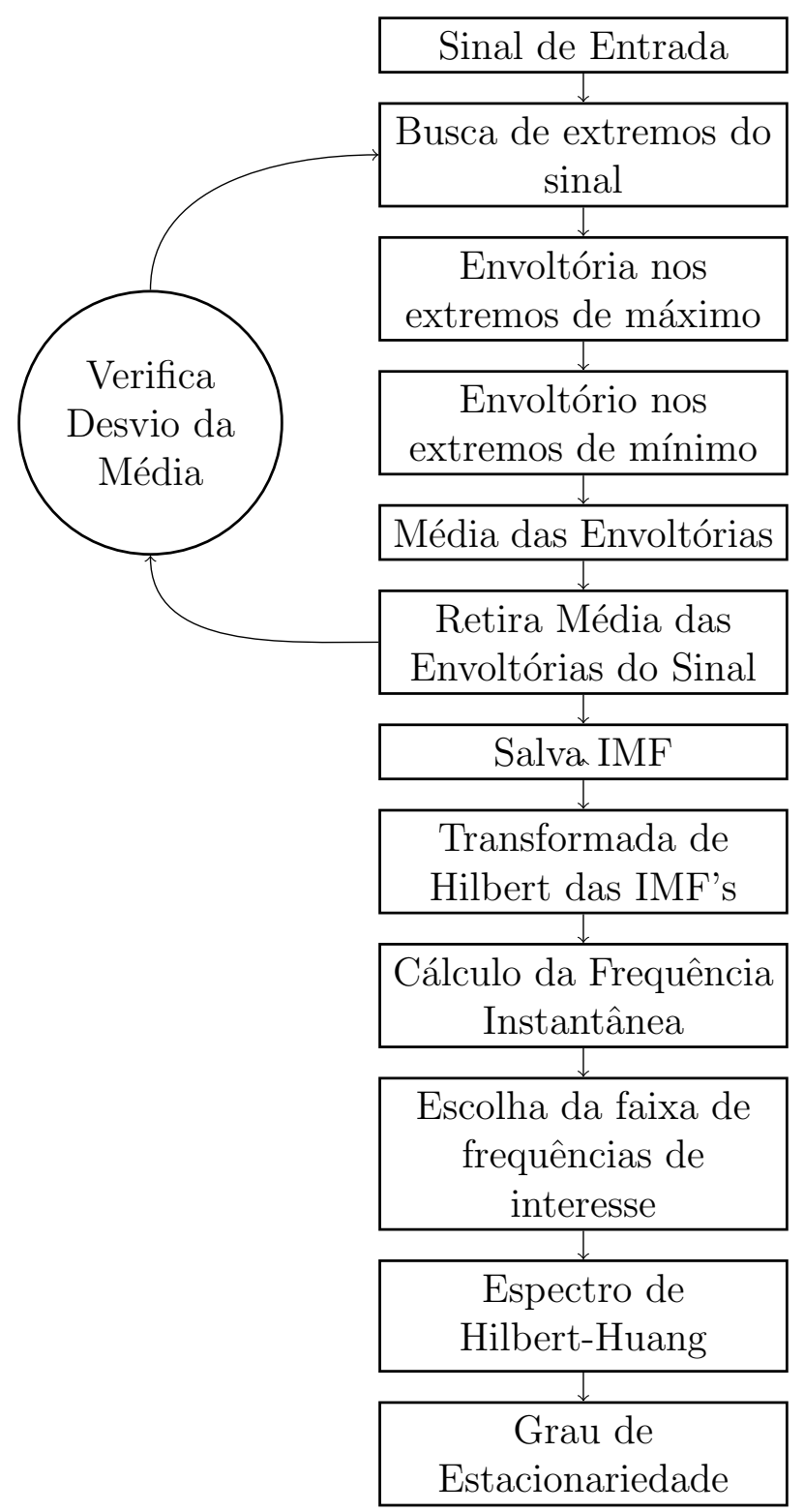

Figura 2.40: Procedimento de análise através de EMD 


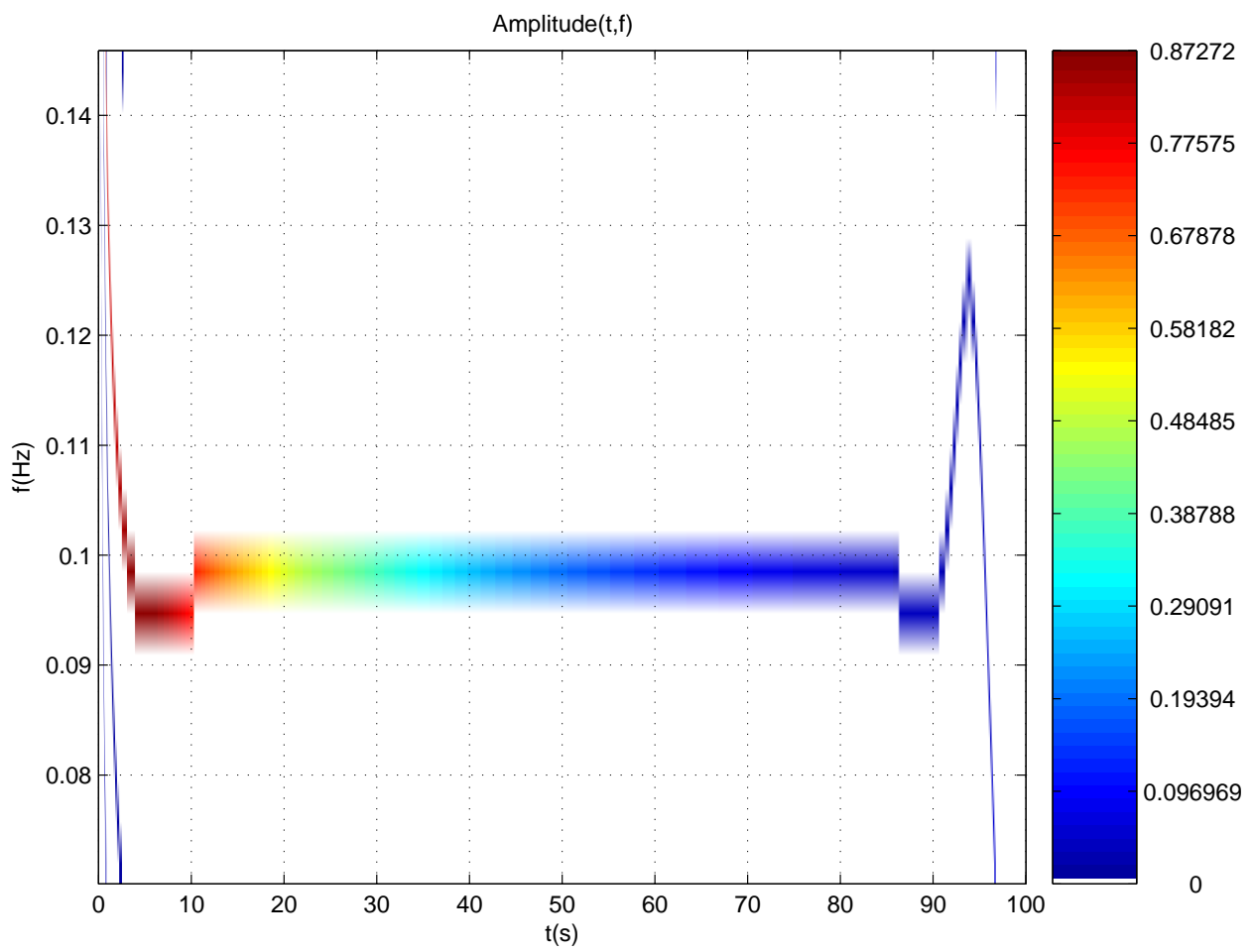

Figura 2.41: Espectro de Hibert-Huang para a série de decaimento da Figura 2.25

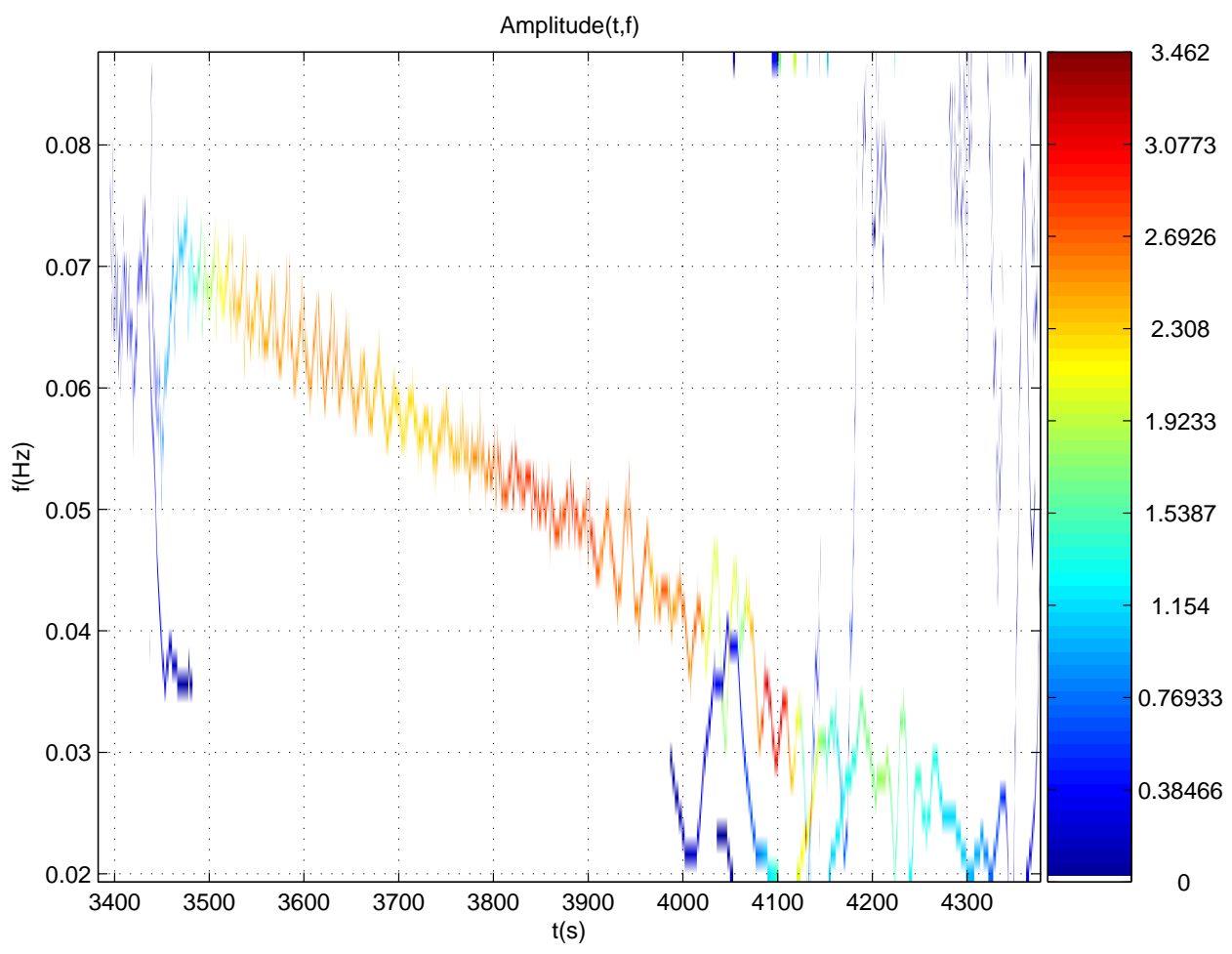

Figura 2.42: Espectro de Hibert-Huang para a onda transiente da Figura 2.35 


\subsection{Pré-Testes}

Os pré-testes foram realizados como uma continuação da calibração do modelo, para a verificação do ajuste de lastro e da restauração do sistema de amarração. Com o teste de inclinação é possível verificar os parâmetros de estabilidade intacta, enquanto com os testes de decaimento é possível verificar os períodos naturais dos graus de liberdade que serão estudados ${ }^{9}$. O teste de decaimento também é utilizado para avaliação dos coeficientes de amortecimento. O processo realizado durante o pré-teste é apresentado na Figura 2.43, cujas etapas foram executadas para o modelo com e sem as linhas de risers.

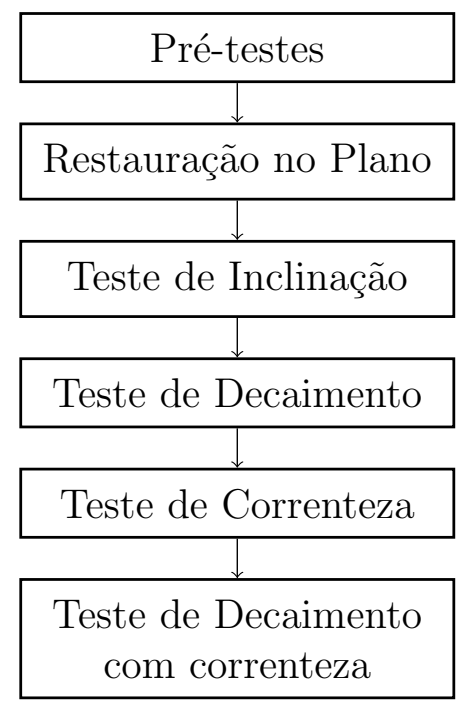

Figura 2.43: Etapas de realização dos pré-testes

Para a verificação da restauração no plano é realizado um teste estático com a variação da posição inicial do modelo, assim é possível verificar a força resultante no sistema de amarração e levantar uma curva de posição versus força. A derivada desta curva é o coeficiente de restauração no plano. Como este ensaio foi realizado com linhas de amarração e risers, a carga dos risers influenciou a restauração e a posição inicial do modelo, as quais tinham sido estimadas através do modelo numérico no TPN. Portanto, além da restauração no plano, a verificação dos parâmetros geométricos das linhas ${ }^{10}$ fizeram parte dos pré-testes. Também foram realizados testes de correnteza, onde foi ajustada a inclinação inicial do modelo para que fosse ensaiado com o mesmo volume submerso do casco nas condições sem correnteza.

Para verificar o momento causado pela correnteza, o modelo foi rebocado sem a incidência de ondas medindo, assim, o seu ângulo de inclinação. Com a informação do

\footnotetext{
${ }^{9}$ Os ensaio de decaimento foram realizados para sway, heave e roll.

${ }^{10}$ Os parâmetros são o ângulo de topo das linhas e a posição do TDP.
} 
ângulo, foi possível ajustar a inclinação com o deslocamento de massa no convés da unidade. Além disso, foi verificado o comportamento das linhas e a sua deformação devido à ação da correnteza.

Deve ser lembrado que durante os ajustes realizados nos Pré-testes, todas as variações dos lastros no modelo, foram documentadas para atualização dos modelos analíticos ou numéricos, como discutido no Capítulo 3.2.

Com a realização dos Pré-testes, desde o teste de inclinação até o de decaimento, podem ser verificados os parâmetros de altura metacêntrica (GM) e períodos naturais. Por isso, esses dois Pré-testes estão apresentados com mais detalhes abaixo.

\subsubsection{Teste de Inclinação}

O teste de inclinação tem como objetivo a verificação das características hidrostáticas do sistema flutuante. Através da aplicação de um momento emborcador, é possível, além de verificar a altura metacêntrica da plataforma, também determinar indiretamente o centro de massa do sistema (ver Apêndice II).

Contudo, deve-se ter cuidado com a realização desse tipo de teste no caso de modelos com linhas de ancoragem e risers. Como a restauração das linhas pode influenciar o braço restaurador do sistema na determinação do centro de massa, essa influência pode trazer alterações no valor do KG.

Com o intuito de se obter a altura metacêntrica do modelo, foi realizado o seguinte procedimento. Primeiro, com o modelo na água e todos os lastros posicionados, deslocase uma massa $m$ de uma distância $d$ perpendicularmente à linha de centro do modelo. Obteve-se assim, uma inclinação $\theta$ através da leitura de um inclinômetro, acelerômetro ou, como neste caso, com o próprio sistema de aquisição óptico apresentado no Capítulo 2.3. Repetindo esse procedimento para massas e/ou distâncias diferentes, obtêm-se vários ângulos de inclinação.

Em seguida, é construído um gráfico dos momentos $m \cdot d$ pela inclinação $\theta$. O valor de $G M$ é obtido através da equação II.5 igualando o momento m.d com o momento restaurador $M_{r}$ est. Um exemplo do cálculo da altura metacêntrica através do ensaio de inclinação é apresentado na Tabela 2.4 .

Como o teste de inclinação possui um procedimento simples, não foi criada uma rotina de análise. Sendo assim, basta acompanhar os passos descritos acima. Vale lembrar que para grandes ângulos de inclinação, ou mesmo para unidades que apresentam grandes 
Tabela 2.4: Determinação da altura metacêntrica

\begin{tabular}{ccccc}
\hline Massa (g) & braço (mm) & banda (graus) & Momento(g.mm) & GM (mm) \\
\hline 400 & 0 & $-0,0026$ & 0 & 0 \\
400 & -154 & 1,583 & -61600 & 66,07 \\
400 & -254 & 2,657 & -101600 & 64,9 \\
400 & -354 & 3,662 & -141600 & 65,58 \\
400 & $-507,3$ & 5,143 & -202920 & 66,83 \\
\hline
\end{tabular}

variações no valor do GM, deve ser comparada a curva de momento restaurador teórico com a curva $\theta$ versus $m \cdot d$, ao invés de apenas o valor de GM.

\subsubsection{Teste de Decaimento}

O ensaio de decaimento fornece uma das informações mais importantes para definição correta dos movimentos dos sistemas flutuantes: o nível de amortecimento do sistema. Isso se deve ao fato de algumas modelagens, principalmente as utilizadas para avaliação do comportamento em ondas baseadas na teoria potencial, não representarem os efeitos da parcela viscosa do fluído para qualquer estrutura flutuante. Nesses códigos, baseados na teoria potencial de ondas, existe a avaliação do amortecimento ligado apenas a geração de ondas. Outros códigos possuem informações empíricas, assim, só podendo ser utilizados para pequenas variações de formas pré-definidas. Ou seja, no caso de estudos de novas formas submersas, o ensaio de decaimento torna-se indispensável na avaliação das forças de origem viscosa, ou ainda, no caso deste estudo em específico, onde a presença das linhas de risers alteram os níveis de amortecimento do sistema. Caso os termos de amortecimento viscoso não fossem considerados, as amplitudes de movimento apresentariam valores muito elevados, principalmente nos graus de liberdade que possuem baixo amortecimento potencial. As informações que irão influenciar o resultado do ensaio de decaimento são massa ${ }^{11}$, restauração, amplitudes iniciais e a presença dos modelos de linhas dos risers.

\subsubsection{Metodologia do Teste de Decaimento}

Para obtenção dos valores de amortecimento foi utilizada a mesma formulação apresentada em [Chakrabarti, 1994]. Abaixo é apresentado um resumo da formulação, de acordo com a mesma nomenclatura apresentada no Apêndice I. Considerando apenas um grau de

\footnotetext{
${ }^{11}$ Massa refere-se a matriz de massa completa, ou seja, massa, inércia com os termos adicionais (ver Apêndice I).
} 
liberdade $i$, como normalmente são avaliados os termos de amortecimento, a equação diferencial do movimento de oscilação livre pode ser vista em 2.10.

$$
\left(M_{i i}+A_{i i}\right) \ddot{x}_{i}+B_{i i} \dot{x}_{i}+C_{i i} x_{i}=0
$$

onde $x_{i}$ é o movimento do grau de liberdade considerado.

A solução para a equação 2.10 é o movimento descrito pela equação 2.11 .

$$
x_{i}=X_{0} e^{-\zeta_{i} \omega_{n i} t} \sin \left(\omega_{n i} \sqrt{1-\zeta_{i}^{2}} t\right)
$$

Com $\omega_{n i}$ dado por 2.12.

$$
\omega_{n i}=\sqrt{\frac{C_{i i}}{M_{i i}+A_{i i}}}
$$

Por meio da equação 2.12, é possível verificar o motivo pelo qual o ensaio de decaimento deve ser utilizado como um pré-teste, pois para a frequência natural ter o valor esperado os termos de restauração $C_{i i}$ e de massa mais massa adicional $\left(M_{i i}+A_{i i}\right)$ devem ser coerentes. O período de oscilação do sinal pode ser obtido tanto como a média entre os tempos que o sinal cruza o eixo das abscissas, quanto através de uma análise espectral. Maiores detalhes são apresentados no Capítulo 2.5. Outra propriedade que pode ser avaliada através de um ensaio de decaimento é a massa adicional do sistema como mostrado na equação 2.13.

$$
A_{i i}=\frac{C_{i i}}{\omega_{n i}{ }^{2}}-M_{i i}
$$

Deve-se notar que a frequência de oscilação durante o ensaio de decaimento é na verdade a frequência amortecida definida em 2.14.

$$
\omega_{d i}=\omega_{n i} \sqrt{1-\zeta_{i}^{2}}
$$

Portanto, através de um sinal de oscilação livre do sistema, pode-se obter o coeficiente de amortecimento pela envoltória da série de decaimento como apresentado na Figura 2.44.

Contudo, para distinguir a parcela viscosa da parcela de geração de ondas, o coeficiente de amortecimento pode ser dividido conforme apresentado na equação 2.15. Ou seja, o 


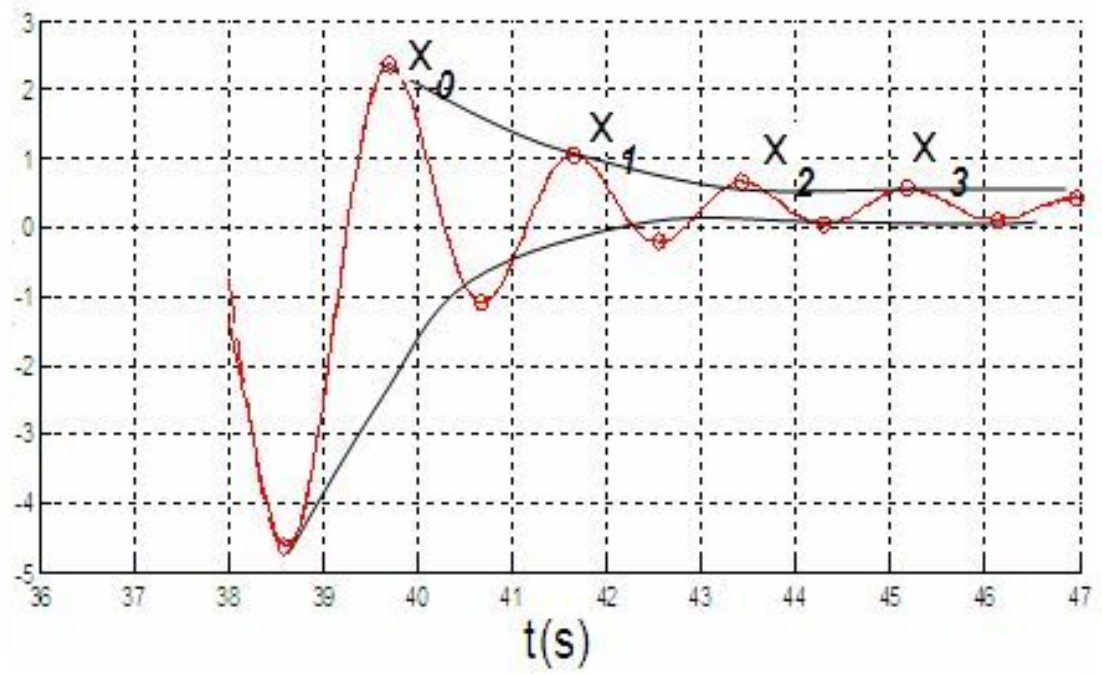

Figura 2.44: Exemplo de análise linear de decaimento

amortecimento do sistema é separado em duas parcelas: o amortecimento viscoso ${ }^{12}$ e amortecimento potencial.

$$
\zeta_{i}=\zeta_{P i}+\zeta_{E i}
$$

O amortecimento potencial é avaliado através da equação I.2 e o amortecimento externo através da equação 2.16, onde o amortecimento crítico pode ser definido por 2.17 .

$$
\begin{gathered}
B_{i i}=\left(\zeta_{P i}+\zeta_{E i}\right) B_{C i i} \\
B_{C i i}=2\left(M_{i i}+A_{i i}\right) \omega_{n i}
\end{gathered}
$$

Para a definição do coeficiente de amortecimento total, pode-se primeiramente obter o decremento logarítmico dos extremos do sinal e definir um coeficiente de amortecimento para cada amplitude média como apresentado na equação 2.18.

$$
\zeta_{i}\left(\frac{x_{k}+x_{k+1}}{2}\right)=\frac{1}{\pi} \ln \frac{x_{k+1}}{x_{k}}
$$

\footnotetext{
${ }^{12} \mathrm{O}$ amortecimento viscoso também é chamado de amortecimento externo, pois representa a parcela que não é avaliada pelos códigos numéricos baseados na teoria potencial de ondas.
} 
A equação 2.18 define um nível de amortecimento para cada amplitude média. Ou seja, no caso de movimentos que apresentem apenas amortecimento linear, como é o caso da equação do movimento 2.10, os valores de $\zeta_{i}$ são praticamente constantes.

Contudo, alguns graus de liberdade apresentam parcela de amortecimento não-linear. Nesse caso, a equação do movimento seria escrita como apresentado em 2.19.

$$
\left(M_{i i}+A_{i i}\right) \ddot{x}_{i}+B_{i i} \dot{x}_{i}+B_{2 i i}\left|\dot{x}_{i}\right| \dot{x}_{i}+C_{i i} x_{i}=0
$$

Onde o termo $B_{2 i i}$ é chamado de coeficiente de amortecimento quadrático, pois depende da velocidade quadrática $\left|\dot{x}_{i}\right| \dot{x}_{i}$. Partindo da hipótese que cada meio ciclo de oscilação pode ser representado por uma senóide, o termo quadrático é linearizado por uma expansão de Fourier apresentada em 2.20.

$$
\left|\dot{x}_{i}\right| \dot{x}_{i}=\frac{8}{3 \pi} \omega_{n i} X_{0} \dot{x}_{i}
$$

Substituindo a equação 2.20 em 2.19 obtêm-se

$$
\left(M_{i i}+A_{i i}\right) \ddot{x}_{i}+B_{i i} \dot{x}_{i}+B_{2 i i} \frac{8}{3 \pi} \omega_{n i} X_{0} \dot{x_{i}}+C_{i i} x_{i}=0
$$

Assim, a parcela quadrática do amortecimento pode ser incorporada ao termo linear como apresentado em 2.22.

$$
B_{i i} \dot{x}_{i}=\left(B_{i i}+B_{2 i i} \frac{8}{3 \pi} \omega_{n i} X_{0}\right) \dot{x}_{i}
$$

Para a análise da série temporal de um grau de liberdade que apresente um comportamento não-linear, primeiro é preciso determinar o período e as amplitudes máximas e mínimas do sinal que serão analisados, conforme apresentado na Figura 2.45.

Com os valores das amplitudes máximas e mínimas pode-se traçar uma curva de acordo com a equação 2.23, onde através de uma regressão linear os coeficientes da curva representam os termos $\zeta_{i}$ e $\frac{B_{2 i i}}{M_{i i}+A_{i i}}$, como demonstrado na Figura 2.46.

$$
\frac{1}{2 \pi} \ln \frac{X_{k-1}}{X_{k+1}}=\zeta_{i}+\frac{4}{3 \pi} \frac{B_{2 i i}}{M_{i i}+A_{i i}} X_{k}
$$

Assim, com os valores de amortecimento incorporados às matrizes $B$ e $B_{2}$, o 


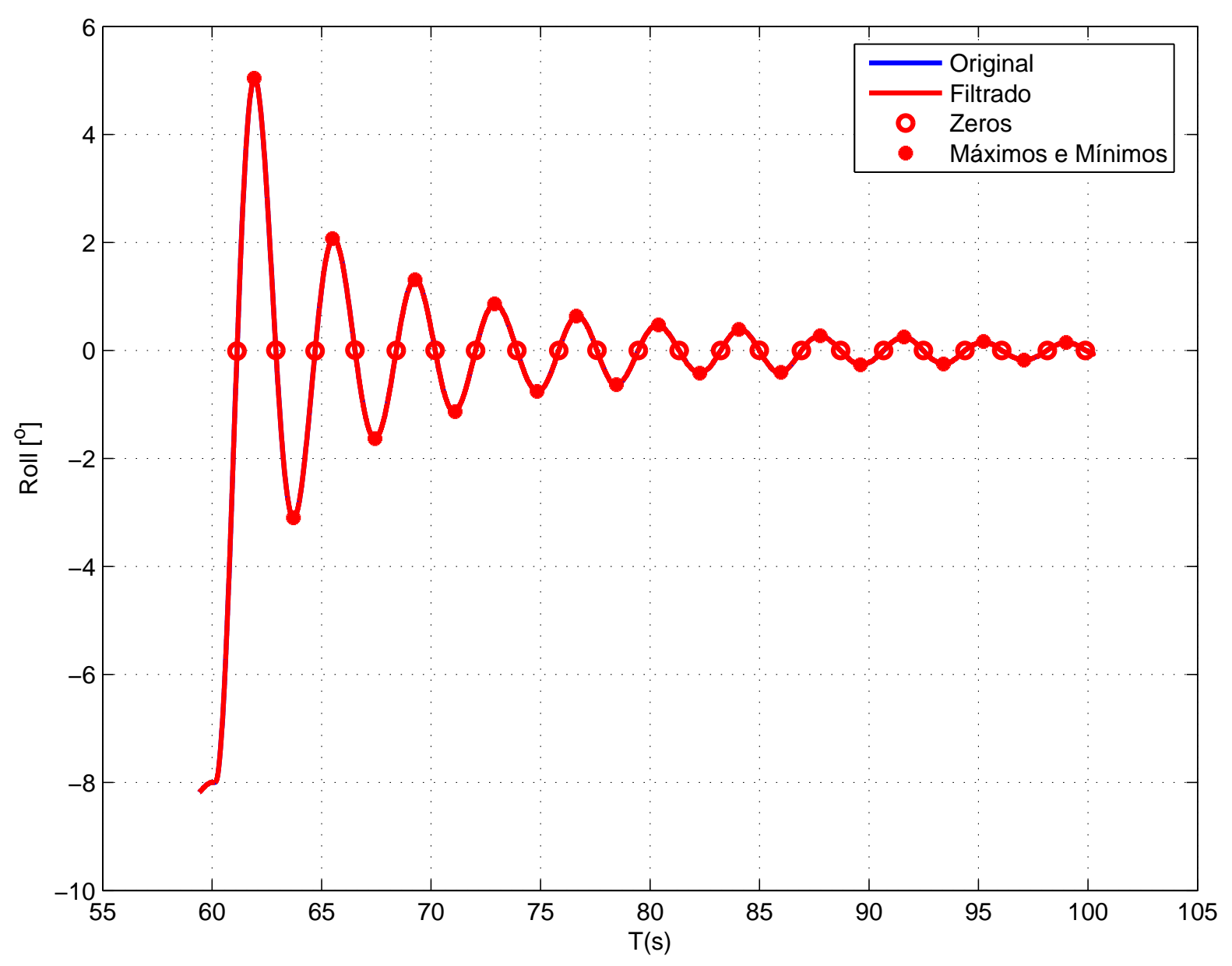

Figura 2.45: Série temporal de um teste de decaimento de roll com as linhas de risers, apresentando valores extremos e zeros ascendentes

comportamento das unidades flutuantes pode ser representado com amplitudes de movimento mais coerentes.

\subsubsection{Ordem dos Testes de Decaimento}

Os testes de decaimentos foram executados antes dos ensaios de cada configuração e auxiliaram o ajuste dos parâmetros do modelo. Para manter o período natural de roll, com os mesmos valores nas condições com e sem risers, os testes de decaimento auxiliaram neste ajuste através do período de oscilação de roll.

Os períodos de heave e depois o de roll foram verificados nesta ordem. Assim, dois parâmetros devem estar coerentes: os valores de GM, que já haviam sido verificados no teste de inclinação, e os valores de inércia, que foram ajustados por meio do teste bifilar para a inércia própria, e avaliados numericamente para a inércia adicional.

Para o heave, o valor da restauração é um parâmetro apenas geométrico, ou seja, se 


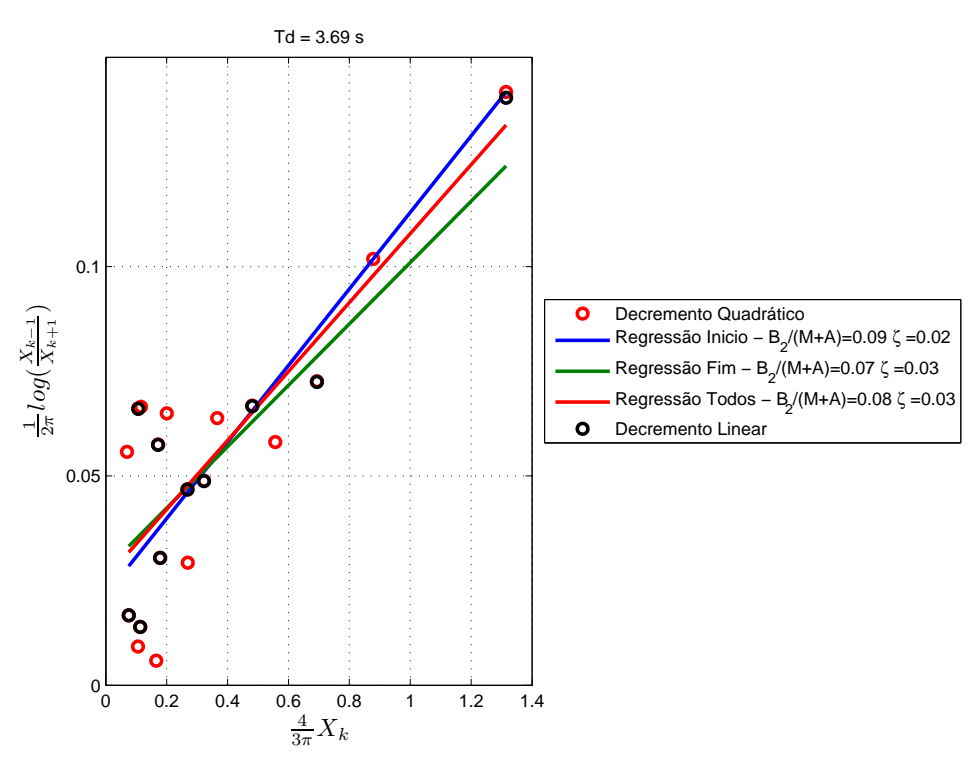

Figura 2.46: Análise de um ensaio de decaimento de roll com as linhas de risers, através da regressão 2.23

o modelo possuir as dimensões corretas em escala, e estiver calibrado para o calado desejado, o período natural de heave está praticamente definido. Algumas variações podem aparecer em sistemas muito amortecidos ou caso a restauração das linhas for considerável se comparadas com a restauração hidrostática.

No caso do roll, o período natural é mais sensível a variação dos parâmetros como o GM e inércia, além dos efeitos de linhas serem mais perceptíveis neste grau de liberdade.

Portanto, a escolha da ordem dos testes de decaimento antes da execução dos ensaios, auxilia na verificação do modelo, possibilitando uma segunda verificação do processo de calibração.

\subsubsection{Análises e Resultados do Teste de Decaimento}

Os ensaios de decaimento foram realizados para os graus de liberdade de sway, heave e roll. Todos os resultados estão apresentados em [Rateiro, 2010] e alguns detalhes da análise estão apresentados neste capítulo. Para tal, foram escolhidos os movimentos de sway e principalmente o de roll, pois, como exemplificado no item anterior, é o grau de liberdade mais sensível a mudança dos parâmetros de ensaio.

No caso do sway, na Figura 2.47, podemos ver o resultado do ensaio de decaimento, para a unidade sem as linhas de riser.

Nota-se, claramente, a linearidade no comportamento do sway, como era esperado no caso sem as linhas de risers. Por outro lado, o movimento é bem amortecido devido a 


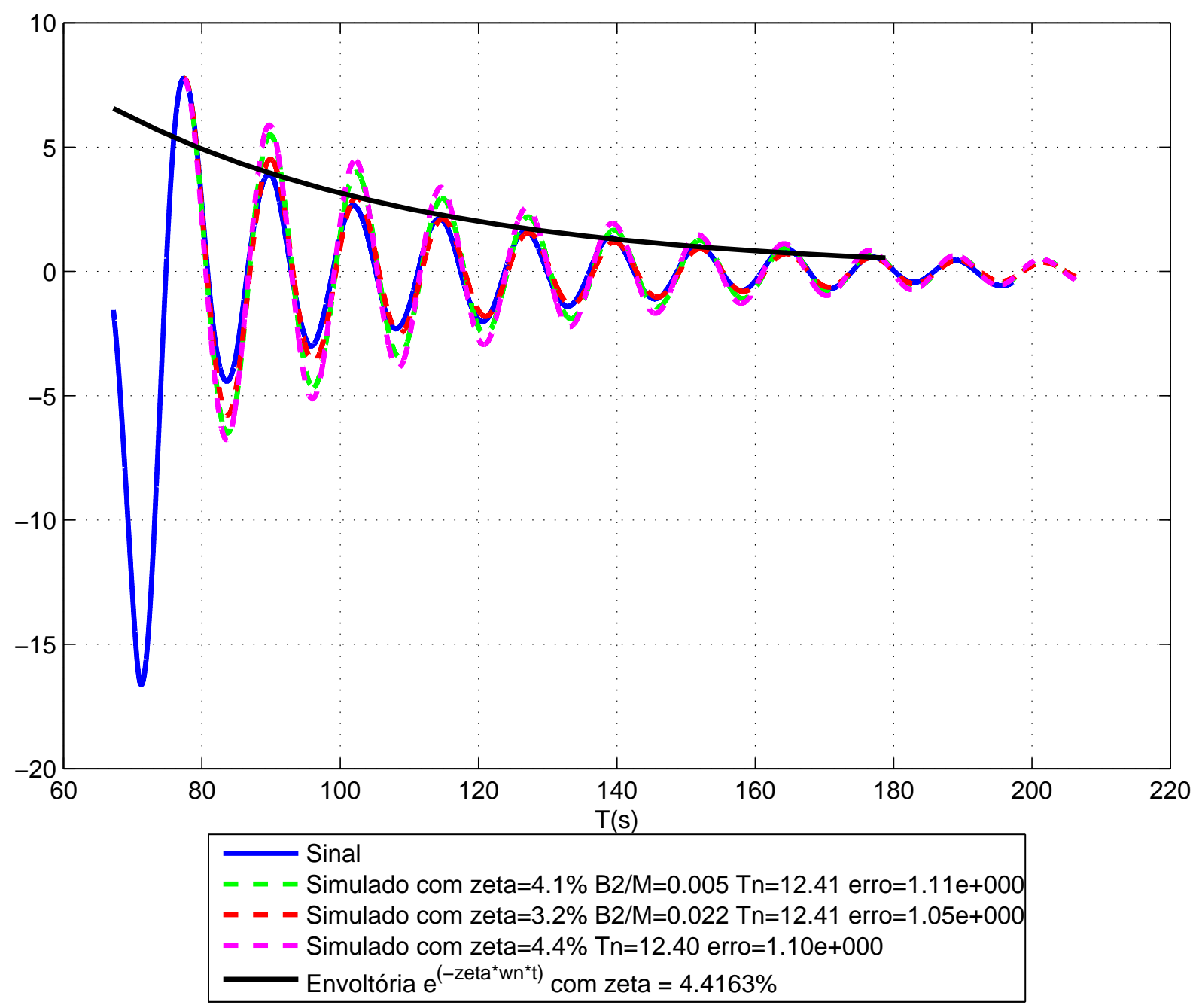

Figura 2.47: Teste de decaimento de sway para a condição sem linhas de risers

presença das linhas de risers, com o aumento do termo quadrático, conforme mostrado na Figura 2.48.

Para o movimento de roll, além dos resultados com e sem a presença dos riser, também está apresentado o efeito causado pela correnteza.

Nesse caso devido à alta não linearidade foi utilizada a rotina EMD para avaliar a frequência instantânea do sinal, pois, como mostrado no item de metodologia do teste de decaimento 2.6.3, as equações e regressões não consideram variações na frequência natural. Por esse motivo, deve se tomar muito cuidado com sinais modulados em frequência, como é o caso do decaimento com correnteza na Figura 2.50.

Todos os resultados apresentados acima foram analisados com a rotina decaytest presente no Apêndice VI.3. 


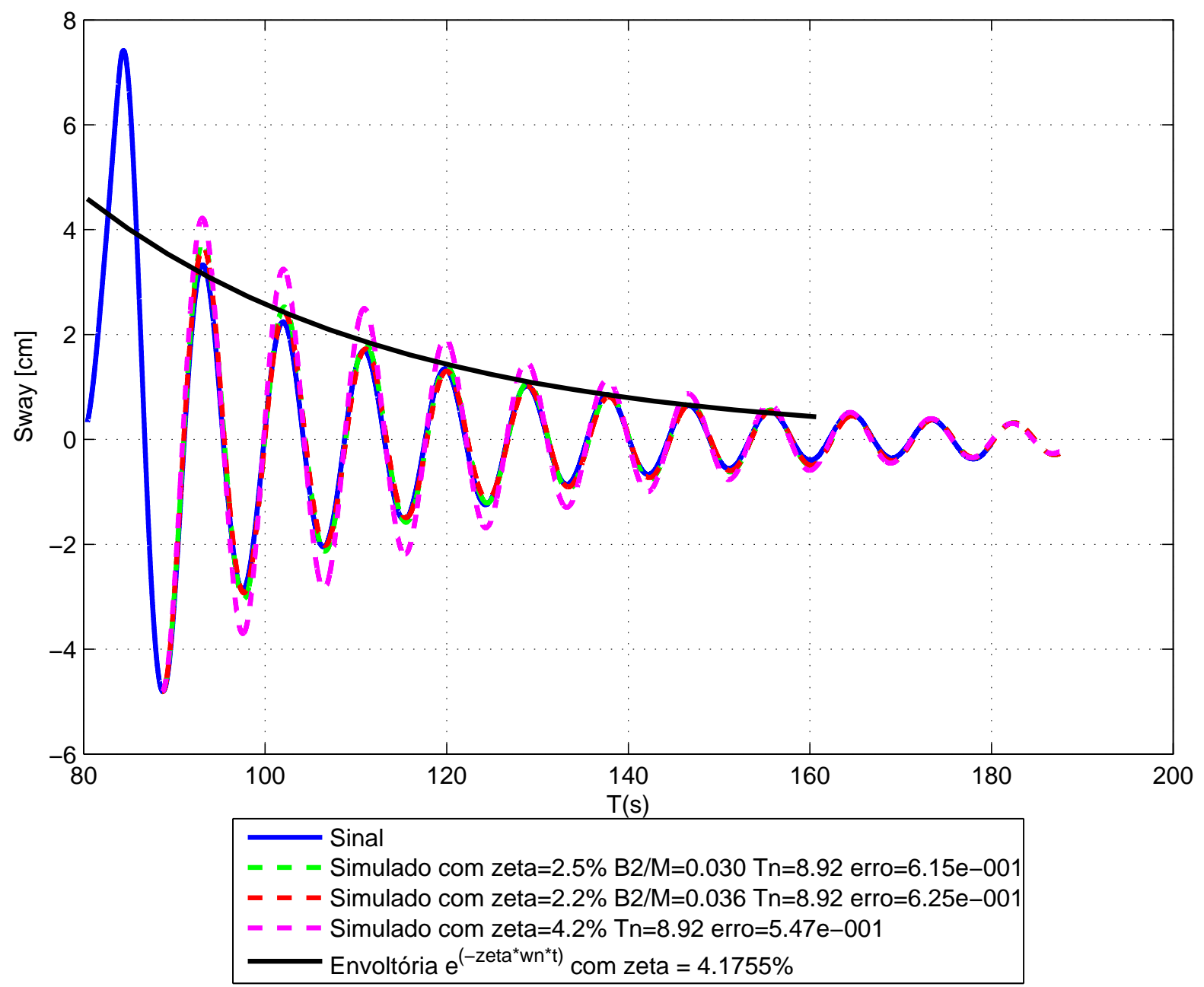

Figura 2.48: Teste de decaimento de sway para a condição com linhas de risers 


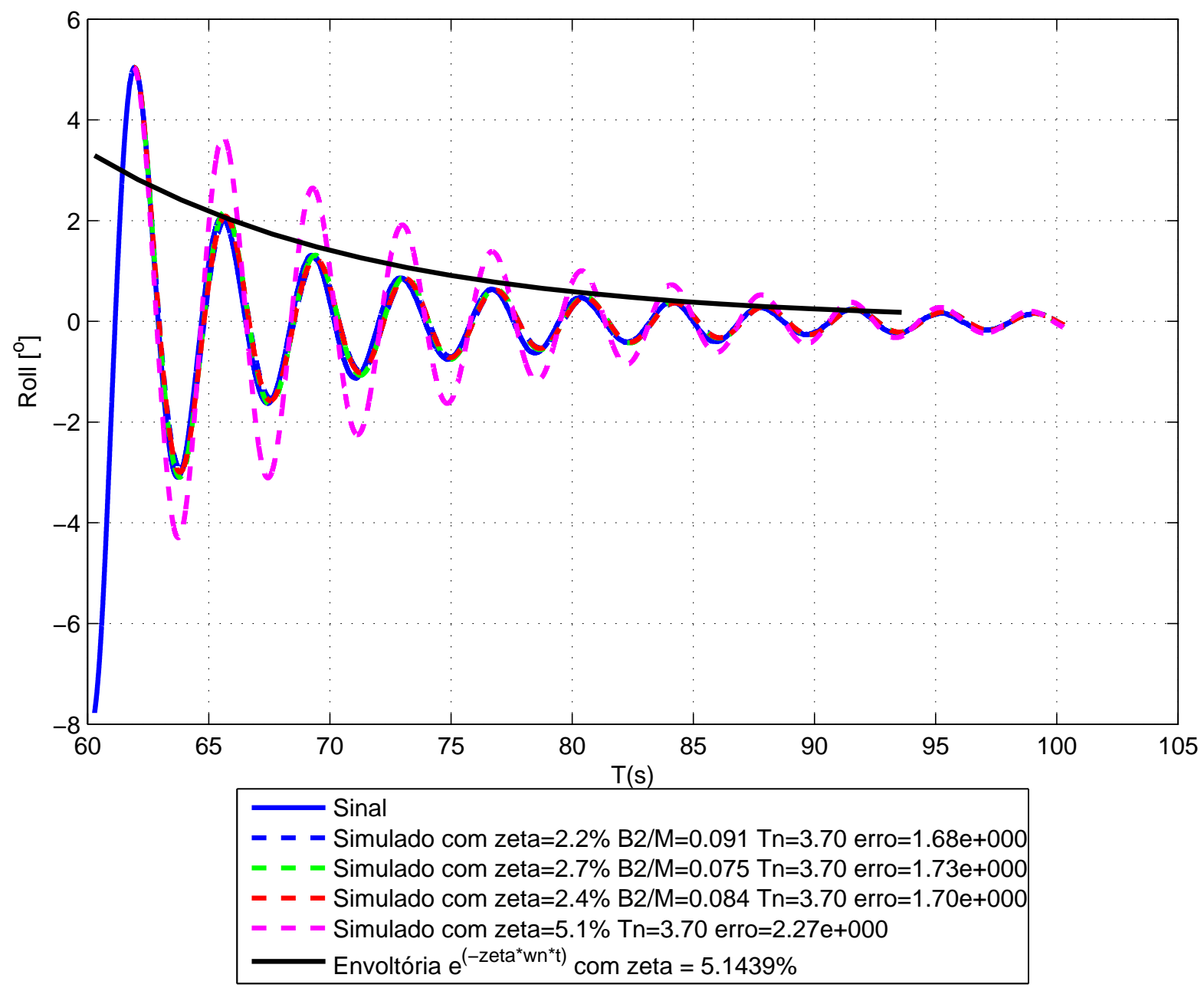

Figura 2.49: Ensaio de decaimento de roll com linhas de risers sem correnteza 


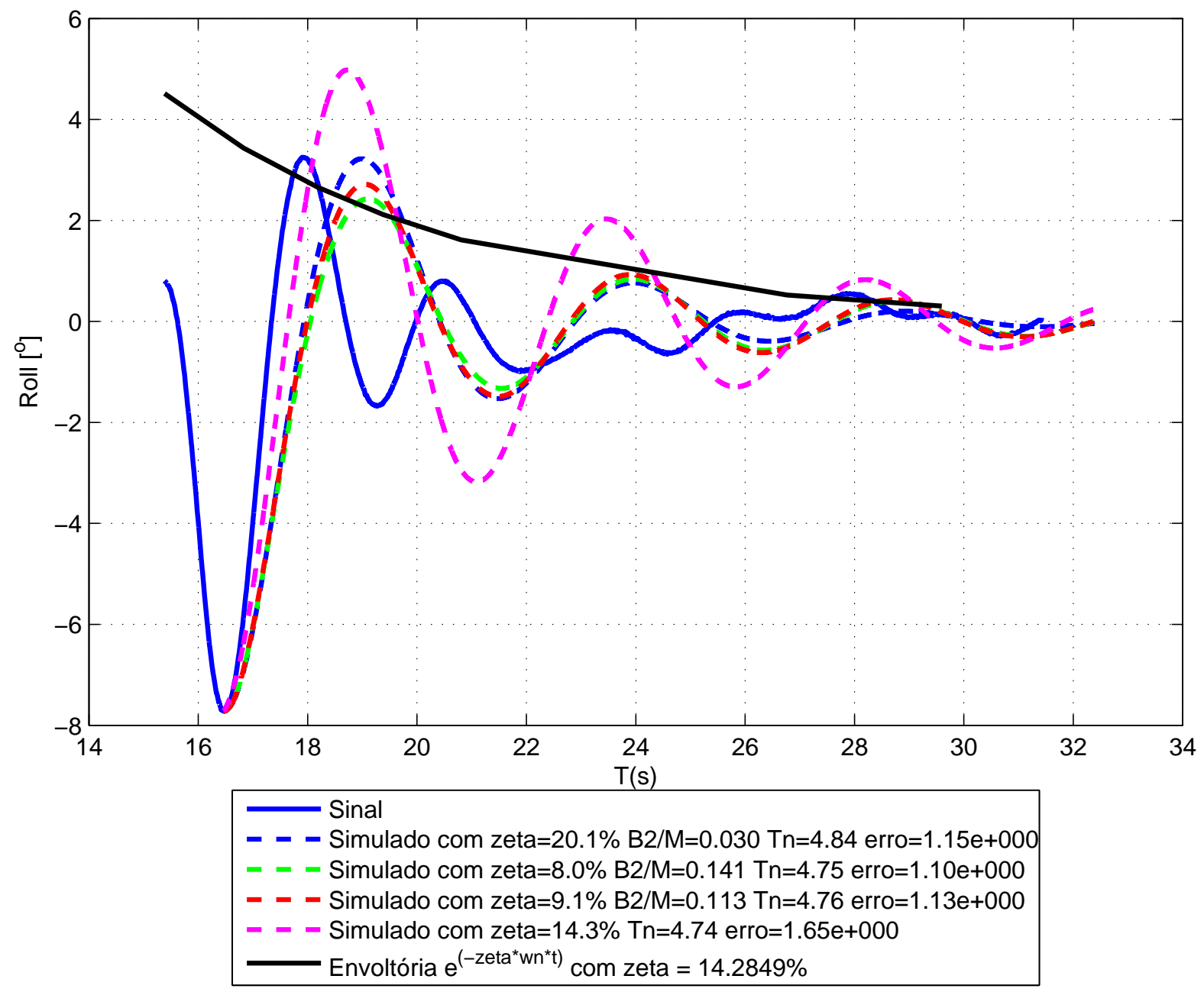

Figura 2.50: Ensaio de decaimento de roll com linhas de risers com correnteza 


\subsection{Ensaios de Comportamento em Ondas}

Nesse capítulo são apresentados os procedimentos utilizados em cada tipo de ensaio, com a descrição da metodologia, a ordem de execução dos experimentos e as análises realizadas. Para cada análise foram utilizadas as rotinas numéricas apresentadas no Apêndice VI e os procedimentos detalhados estão apresentados no Capítulo 2.5.

\subsubsection{Metodologia do Ensaio em Ondas}

Em geral, sistemas flutuantes são projetados para que seus períodos naturais não estejam sintonizados com os períodos de pico dos mares mais severos. Para avaliar se esses períodos não estão sintonizados, a metodologia consiste em obter primeiro algumas estimativas analíticas, ou numéricas, dos coeficientes hidrodinâmicos ${ }^{13}$. Posteriormente, realizam-se verificações em tanques de provas para confirmações destes coeficientes e avaliação das não-linearidades.

As propriedades potenciais ${ }^{14}$ são geralmente confiáveis, quando avaliadas através de modelos numéricos. Contudo, as parcelas viscosas ainda necessitam de ensaios em tanques de provas para obtenção de resultados mais coerentes, ainda que possam ser avaliadas através de códigos de $\mathrm{CFD}^{15}$.

Os ensaios em ondas permitem estimar as parcelas viscosas, bem como avaliar os movimentos devidos às forças de primeira e segunda ordem. Nos ensaios de comportamento em ondas, o foco é a análise dos movimentos e não das forças. Para a estimativa das forças, são realizados ensaios cativos apresentados, no Anexo C. As forças de primeira ordem são aquelas com respostas na mesma frequência da onda incidente. Dentre as forças de segunda ordem, estão as forças de deriva média e as forças de deriva lenta, descritas no Apêndice I. Para a estimativa destas forças são necessários ensaios em ondas bicromáticas ${ }^{16}$.

O ensaio em ondas é um conjunto de procedimentos utilizados para avaliar qual será o comportamento do sistema oceânico no mar. Para tal, são geradas ondas transientes,

\footnotetext{
${ }^{13}$ Os coeficientes hidrodinâmicos são as matrizes de massa adicional e amortecimento, além das forças e momentos de excitação em ondas.

${ }^{14}$ As propriedades potenciais são relacionadas às parcelas de difração e radiação de ondas do modelo, representadas pelas forças de excitação, coeficientes de massa adicional e amortecimento potencial (ver Apêndice I).

${ }^{15}$ Os códigos de CFD consideram a parcela viscosa na equação do movimento, o que não ocorre nos modelos baseados na teoria potencial de ondas.

${ }^{16}$ As ondas bicromáticas são compostas por duas frequências capazes assim de avaliar as forças devido a soma ou diferença destas frequências.
} 
regulares e irregulares. A primeira delas é importante por apresentar uma distribuição de energia ao longo de uma faixa larga de frequências, o que proporciona uma estimativa melhor do RAO para vários períodos de onda simultaneamente. Desta maneira, é possível considerar um menor número de ondas para a mesma faixa de frequência. Os dois últimos tipos são usados para avaliar a resposta da unidade flutuante frente às características do local de operação do sistema.

Portanto, nos ensaios de comportamento em ondas, cada tipo de onda traz informações importantes, embora carreguem consigo algumas restrições. Um resumo destes pontos está apresentado na Figura 2.51.

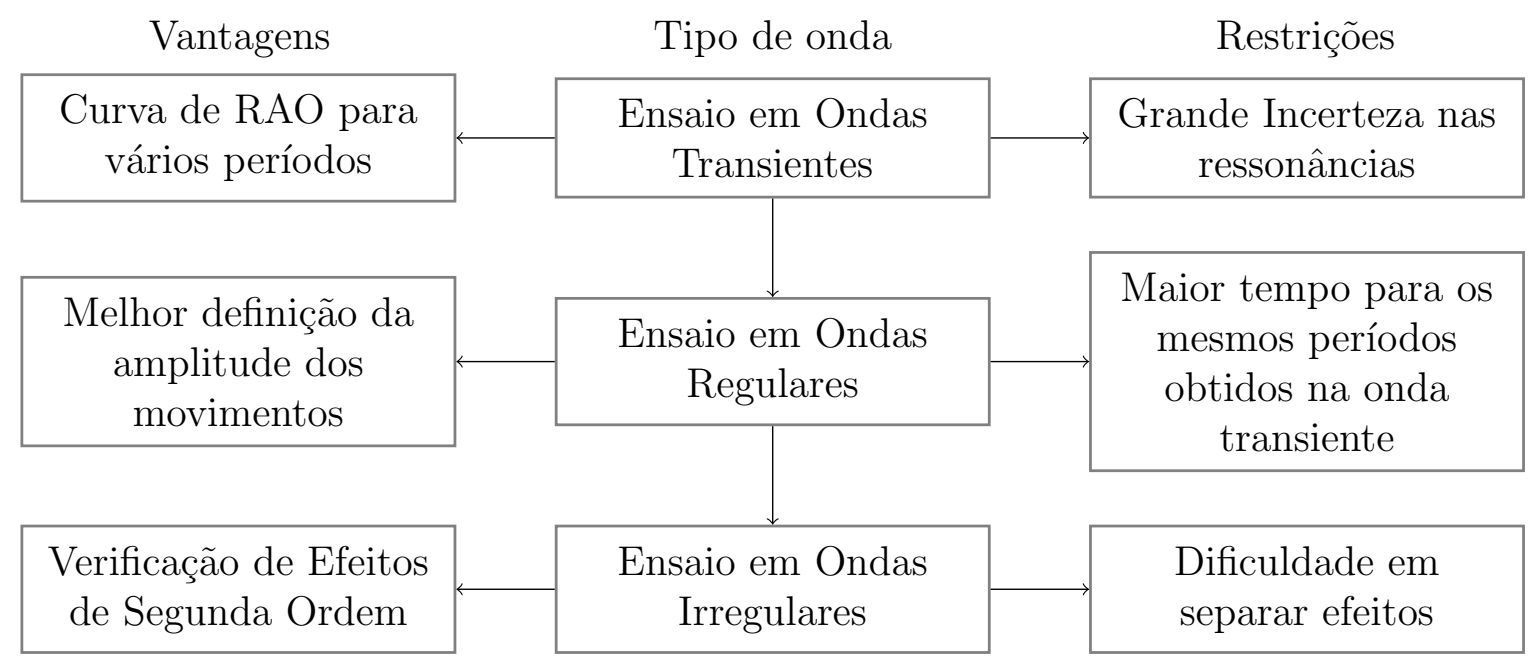

Figura 2.51: Informações relevantes obtidas em cada tipo de onda

A análise em ondas transientes consiste na obtenção do RAO dos movimentos a partir dos espectros de resposta ${ }^{17}$ e de excitação de onda, conforme será mostrado na equação 2.9. O mesmo procedimento pode ser aplicado aos outros tipos de ondas.

Para a avaliação das regiões de ressonância dos movimentos, o ideal é a utilização de ondas regulares, pois contêm somente a frequência desejada. Por esse motivo, o resultado nas frequências de ressonância da unidade flutuante, onde geralmente as não-linearidades podem ser mais pronunciadas, deve ser avaliado a partir da geração de ondas regulares, se possível com diferentes alturas. Esses ensaios são feitos para serem comparados com os de ondas transientes e um exemplo de resultado dessa confrontação é apresentado na Figura 2.52.

No caso das ondas irregulares, também são feitas avaliações com relação a não-linearidades e movimentos de segunda ordem, conforme ilustrado na Figura 2.53,

\footnotetext{
${ }^{17} \mathrm{~A}$ resposta pode ser o movimento de um grau de liberdade, ou também, a tração nas linhas de ancoragem.
} 


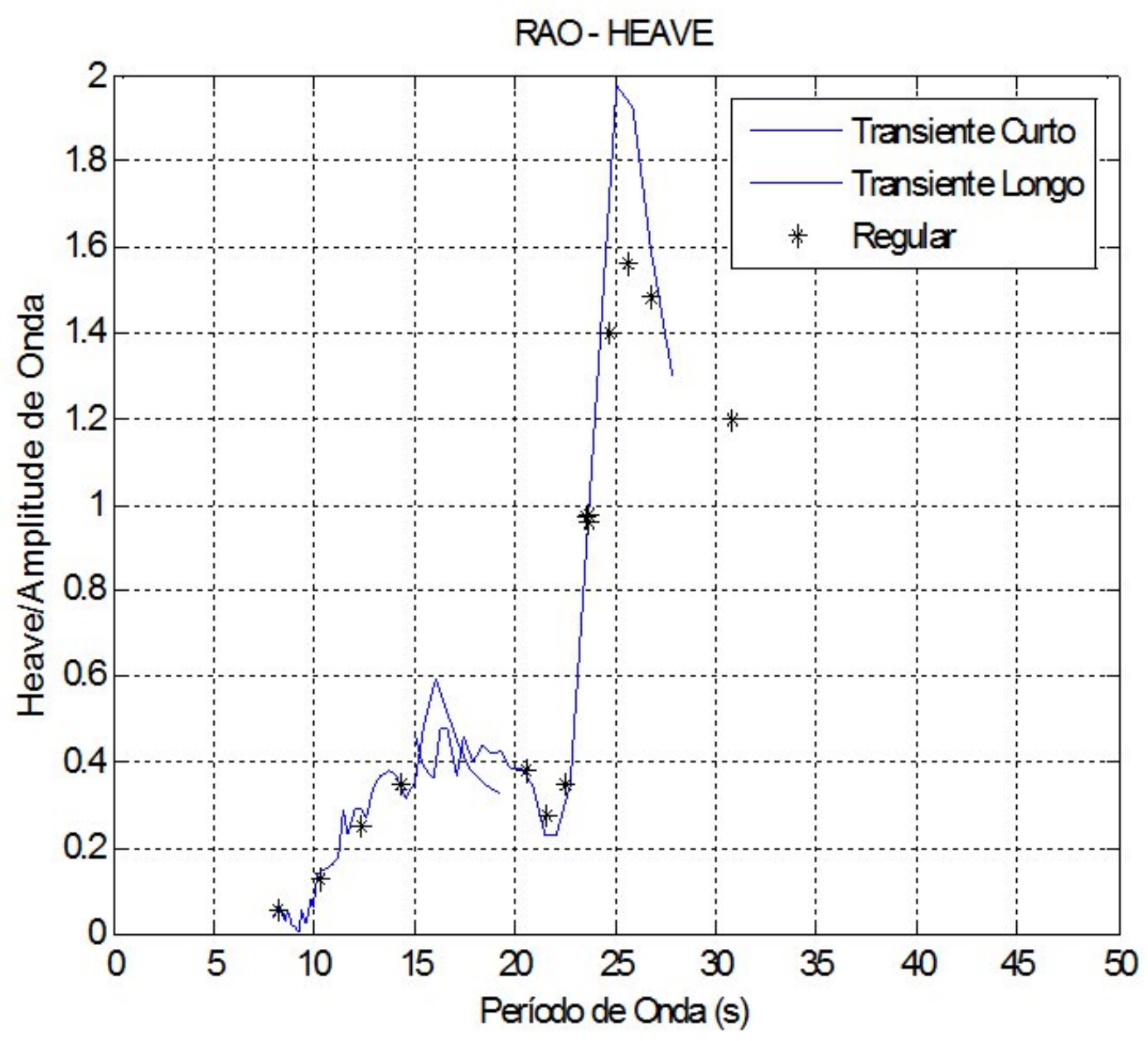

Figura 2.52: RAO obtido a partir de testes em ondas transientes e regulares

onde pode ser notado o efeito denominado deriva lenta ${ }^{18}$, através do espectro de movimento de sway. Para a estimativa dos movimentos de segunda ordem, é necessário ter a função de grupo das ondas bem ajustadas como apresentado no Capítulo 2.4.

Vale ressaltar que, para todos os tipos de ondas geradas, é recomendável uma calibração preliminar sem a presença do modelo, a fim de eliminar efeitos de difração e radiação durante as análises, conforme descrito no Capítulo 2.4.

\footnotetext{
${ }^{18}$ Deriva lenta é o nome dado ao movimento de segunda ordem nos graus de liberdade de surge e sway. Contudo, o mesmo efeito pode acontecer nos demais graus de liberdade.
} 


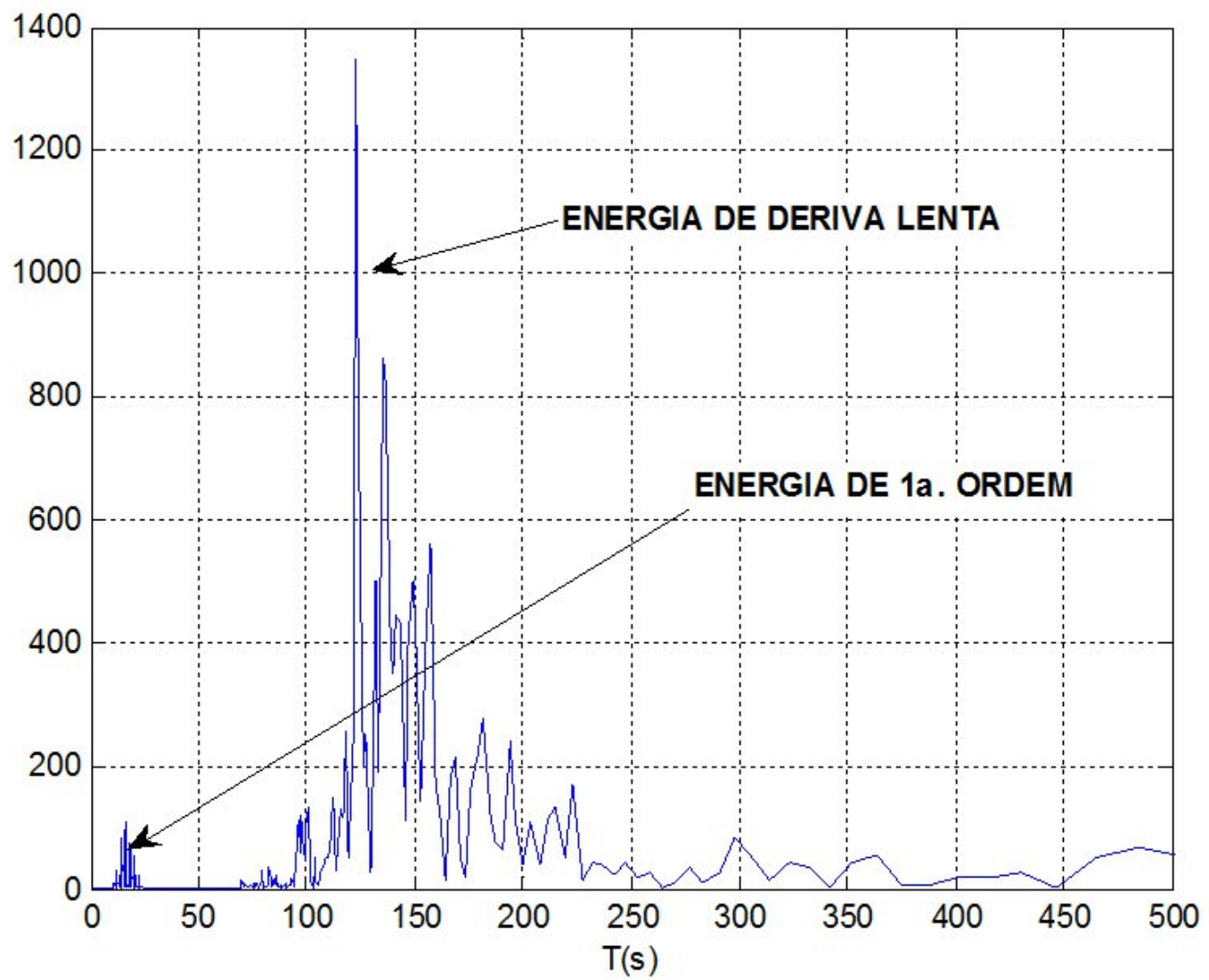

Figura 2.53: Espectro do movimento de sway em mar irregular

\subsubsection{Ordem de Execução dos Ensaios}

Conforme descrito no Capítulo 1.3, os ensaios da unidade flutuante foram planejados para serem realizados com e sem a presença dos risers, nesta ordem. Este planejamento foi adotado considerando que o resultado da unidade com os risers seria mais rico em informações, pois no outro caso, considerou-se que os modelos numéricos já representam bem os fenômenos envolvidos. A Figura 2.54 apresenta as etapas do ensaio realizado com os risers e o mesmo conjunto de experimentos foi utilizado no ensaio apenas com a unidade flutuante.

A matriz de ensaio contendo todas as características relativas aos experimentos realizados foi apresentada anteriormente na Tabela 1.1.

Primeiramente, foram geradas as ondas transientes, as ondas irregulares foram geradas por duas séries temporais cada, e finalmente, todas as ondas regulares foram geradas e os resultados comparados. 


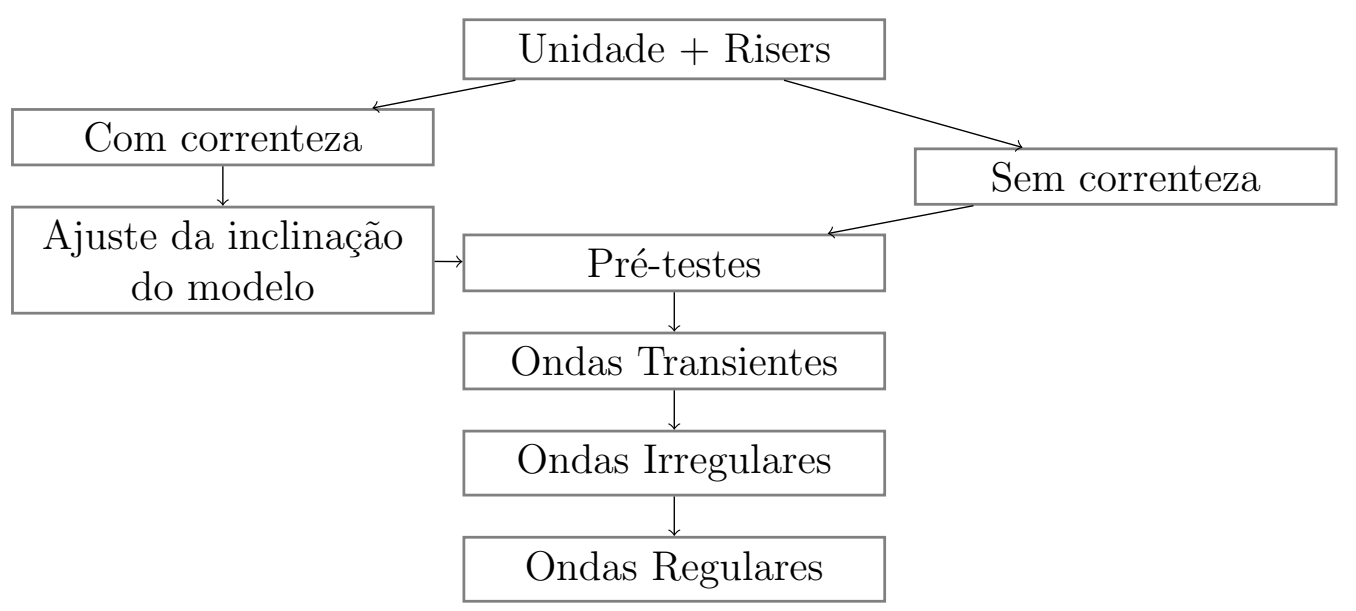

Figura 2.54: Ordem de execução dos ensaios

Durante a execução dos ensaios com correnteza foi necessário o ajuste de inclinação do modelo, para que o mesmo tivesse a média próxima de zero para o movimento de roll. Em seguida, foram realizados os pré-testes, através dos ensaios de decaimento descritos no Capítulo 2.6. Segundo o planejamento, as ondas seriam geradas na ordem apresentada na Figura 2.54. Ressalta-se que a calibração das ondas sem o modelo é realizada em diferentes posições do tanque de provas. Isso se deve ao fato de que ondas mais curtas, ou de período menor, sofrem mais com a perda de energia ao longo do tanque. As mudanças de posição do modelo provocam perturbações na água do tanque. Por esses motivos, a ordem de geração das ondas sofreu alterações. Algumas ondas regulares foram geradas entre as ondas irregulares, pois estas são as que necessitam de um tempo maior de espera para que a elevação da água no tanque de provas seja nula.

Mesmo que o planejamento de um ensaio seja feito de maneira criteriosa, eventos inesperados podem ocorrer durante a execução do mesmo. Dessa forma, recomenda-se que as análises relativas a um determinado experimento sejam realizadas simultaneamente à sua execução, a fim de permitirem eventuais modificações com relação à ordem dos ensaios.

\subsubsection{Análises e Resultados}

As análises e resultados obtidos para cada tipo de onda são descritos neste item. Algumas comparações foram feitas entre os tipos de onda para avaliar as diferenças nos resultados. Também são apresentadas quais as análises foram utilizadas em cada sinal. 


\subsubsection{Ensaio em Ondas Transientes}

As ondas transientes são caracterizadas por uma modulação de período, conforme ilustrado nas Figuras 2.55 e 2.56 .
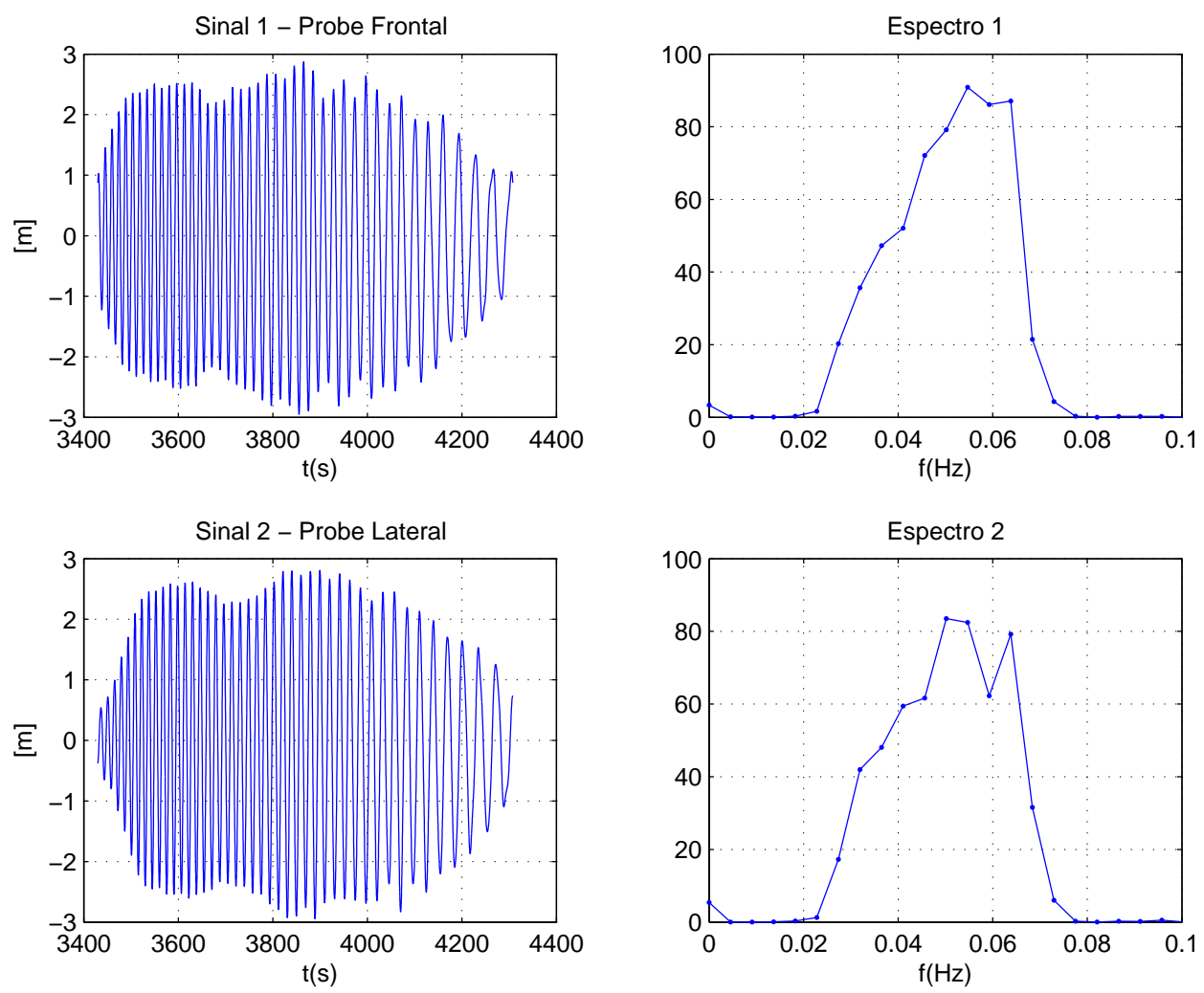

Figura 2.55: Série temporal da onda transiente longa

No experimento em questão, as ondas transientes foram geradas em duas séries: a primeira com uma faixa de energia entre as frequências de 0,03 a $0,07 \mathrm{~Hz}$, denominada de transiente longa, e a segunda com as frequências de 0,05 a $0,13 \mathrm{~Hz}$, denominada de transiente curta.

Para análise dos ensaios em ondas transientes foram utilizadas as rotinas calculaRAO e calculaRAOHH apresentadas no Apêndice VI.3. Um exemplo de curvas de RAO resultante dessa análise, é apresentada na Figura 2.57.

\subsubsection{Ensaio em Ondas Regulares}

As análises para os testes de ondas regulares, consistem na obtenção do RAO, verificação de linearidades e comparação com o ensaio em onda transiente. Estas análises foram feitas de duas maneiras: através dos pontos de máximo e através do domínio da frequência. Estes métodos estão descritos em 2.5.2. 

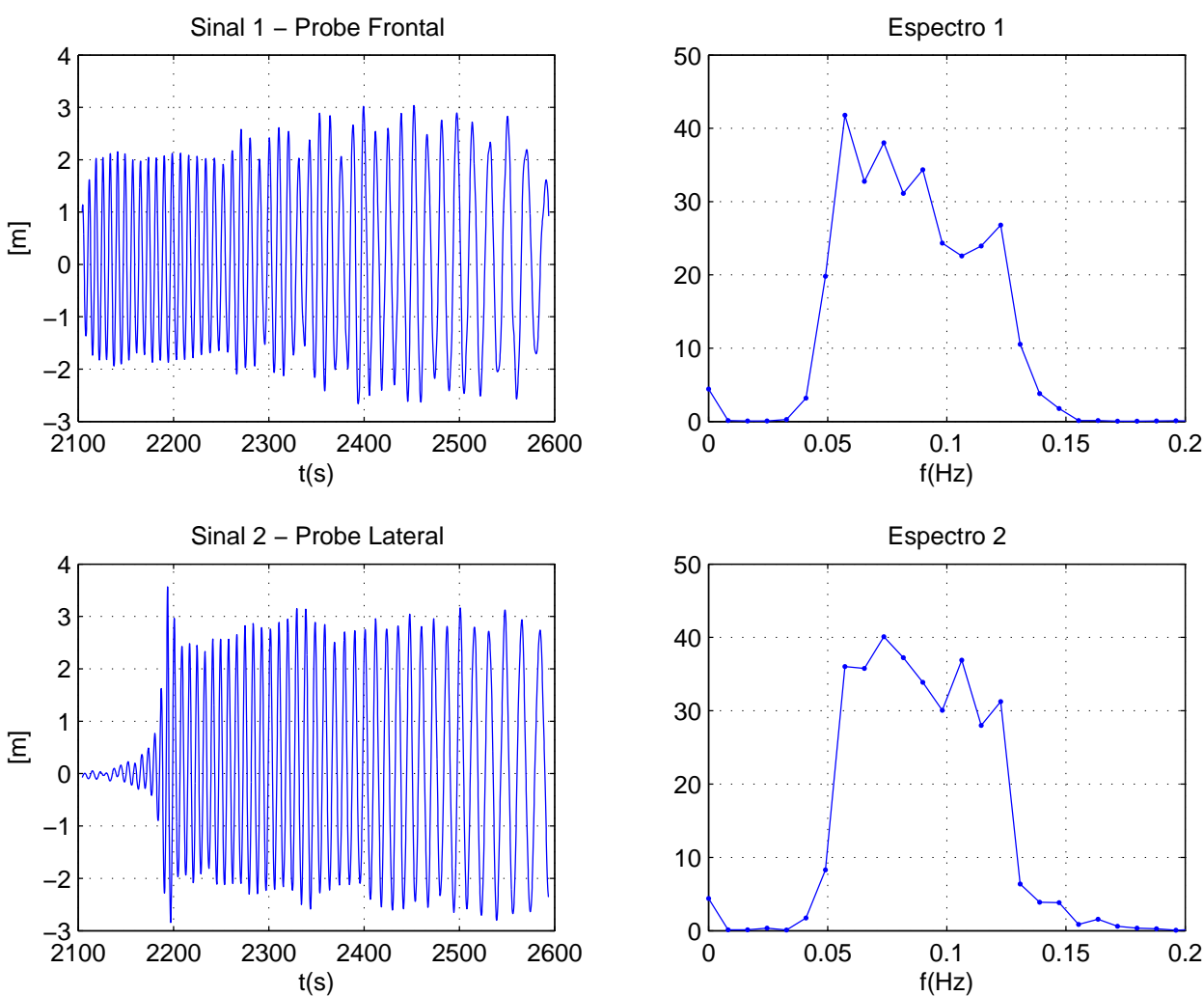

Figura 2.56: Série temporal da onda transiente curta

Exemplos de resultados obtidos para diferentes graus de liberdade em ondas regulares é ilustrado nas Figuras 2.58 a 2.60 .

Os resultados mostram a aderência das curvas obtidas através das duas análises. É possível notar que a região de ressonância da unidade em heave, que ocorre em $\mathrm{T}=$ $25 \mathrm{~s}$, foi bem determinada pelas ondas regulares. As fases apresentaram diferenças de até 180 graus. Ressalta-se que a comparação das fases é difícil de ser feita a partir dos sinais de excitação e resposta, sendo recomendada a sua comparação com base no método apresentado no Capítulo 2.5.

As rotinas utilizadas para as análises foram a calculaRAOregular e a calculaRAO. Alternativamente, poderia ser utilizada a rotina calculaRAOHH, mas neste caso, como existe apenas uma frequência de interesse, a análise através da transformada de Hilbert apresenta uma grande variação, conforme discutido no Capítulo 2.5.

\subsubsection{Ensaio em Ondas Irregulares}

Os modelos analíticos e numéricos trabalham com a sobreposição de fenômenos, ou seja, as forças de correnteza ou vento são somadas às forças de onda. Essa aproximação desconsidera que a presença de todos os agentes altera o campo de pressões no casco e 


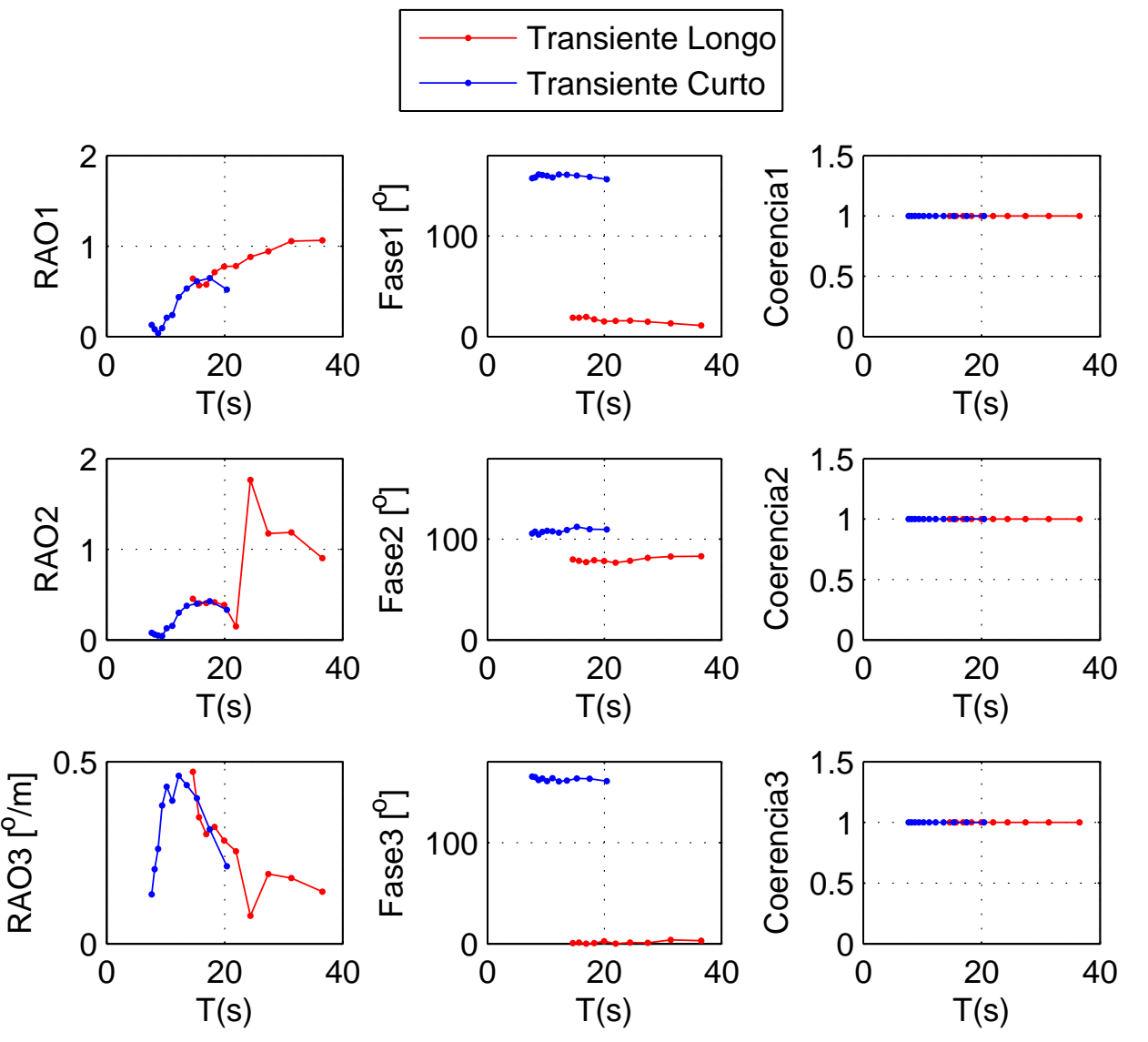

Figura 2.57: Exemplo de curva de RAO de onda transiente

no fluido, o que modifica os coeficientes hidrodinâmicos.

Os ensaios em ondas irregulares são utilizados para verificar a validade dessas aproximações e os efeitos de suas não-linearidades. Também foram verificadas as mudanças na resposta da unidade devido às cargas nas linhas de amarração e risers, com a presença das forças de segunda ordem inerentes a esse tipo de onda.

Como resultado da ação dessas forças surgem os movimentos de segunda ordem, como a deriva média e deriva lenta, os quais são avaliados através do espectro do movimento (ver Figura 2.53). Além disso, as características estatísticas para cada condição de mar são verificadas através da geração dos espectros de mar em escala (ver Capítulo 2.4).

No estudo da influência dos risers podem ser notadas diferenças significativas nos parâmetros estatísticos devido à presença da correnteza, estes resultados estão apresentados na Tabela 2.5 e Figuras 2.61 e 2.62.

É possível comparar as curvas de RAO das Figuras 2.63 e 2.57. Apesar de as ondas irregulares possuírem uma largura de banda estreita $(\epsilon<0,6)$, finalidade da confrontação é verificar se o RAO pode ser considerado uma boa aproximação dos movimentos da 

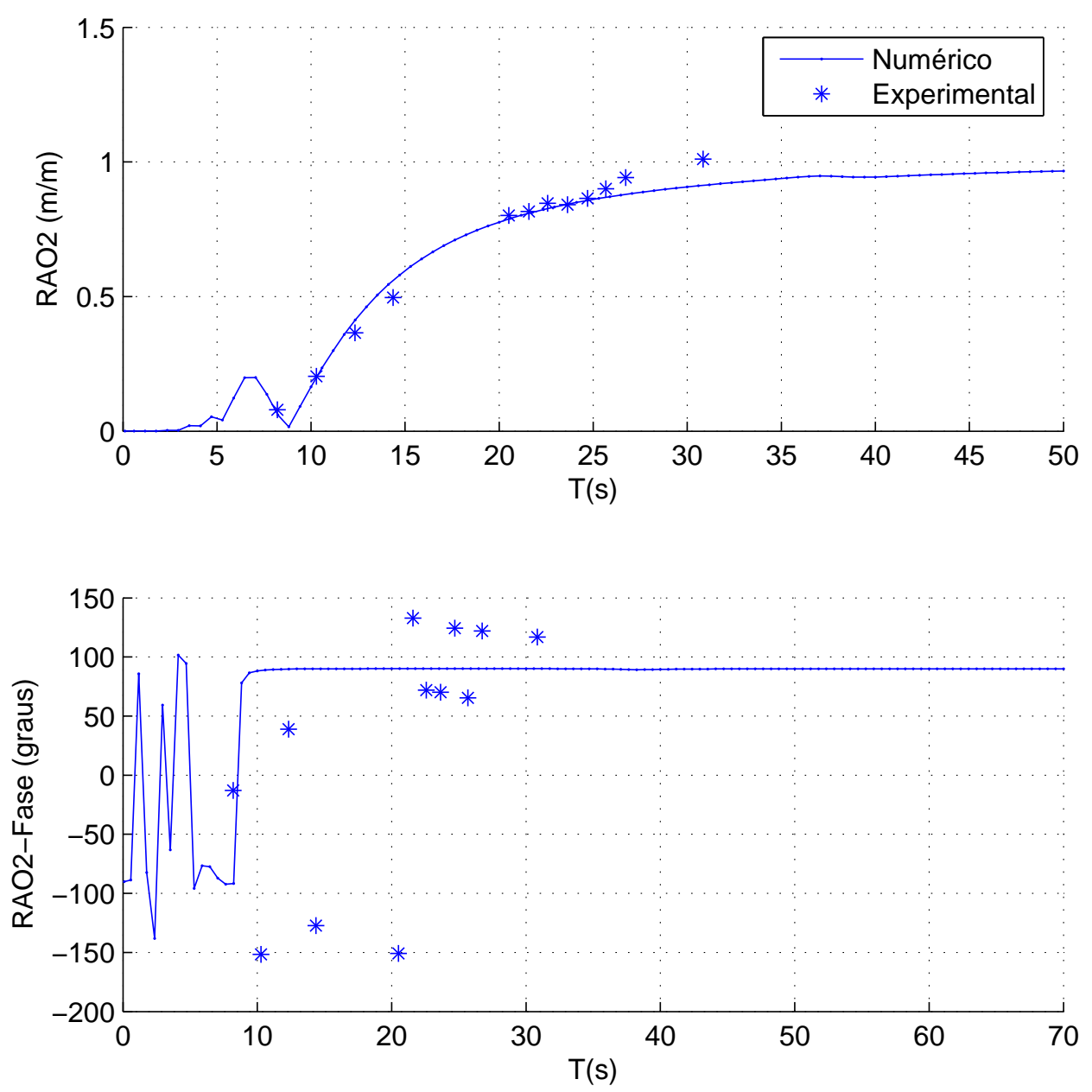

Figura 2.58: Exemplo de curva de RAO de sway em onda regular

unidade através de um cruzamento espectral. No caso do movimento de roll, é possível notar uma boa aderência entre os resultados para períodos entre 7 e 14s.

Da mesma forma que foi verificada a influência da correnteza com as linhas de riser durante o decaimento de roll (ver Capítulo 2.6), o Espectro de Hibert-Huang do movimento em ondas irregulares foi utilizado para verificar as modulaçõesde frequências e amplitudes instantâneas, além dos picos de energia para as condições com e sem correnteza. Nas Figuras 2.64 e 2.65 estão apresentados os espectros gerados para o movimento de roll.

Nas Figuras 2.66 e 2.67, a comparação do espectro de Hilbert-Huang com o espectro de Fourier permite visualizar as diferenças, devidas às aplicações destes métodos, da distribuição de energia ao longo das frequências. Contudo, os dois métodos identificaram picos de energia na região entre 35 e 45s para o movimento de roll na condição sem correnteza.

Além das análises anteriores, foi feita uma comparação dos resultados obtidos para 

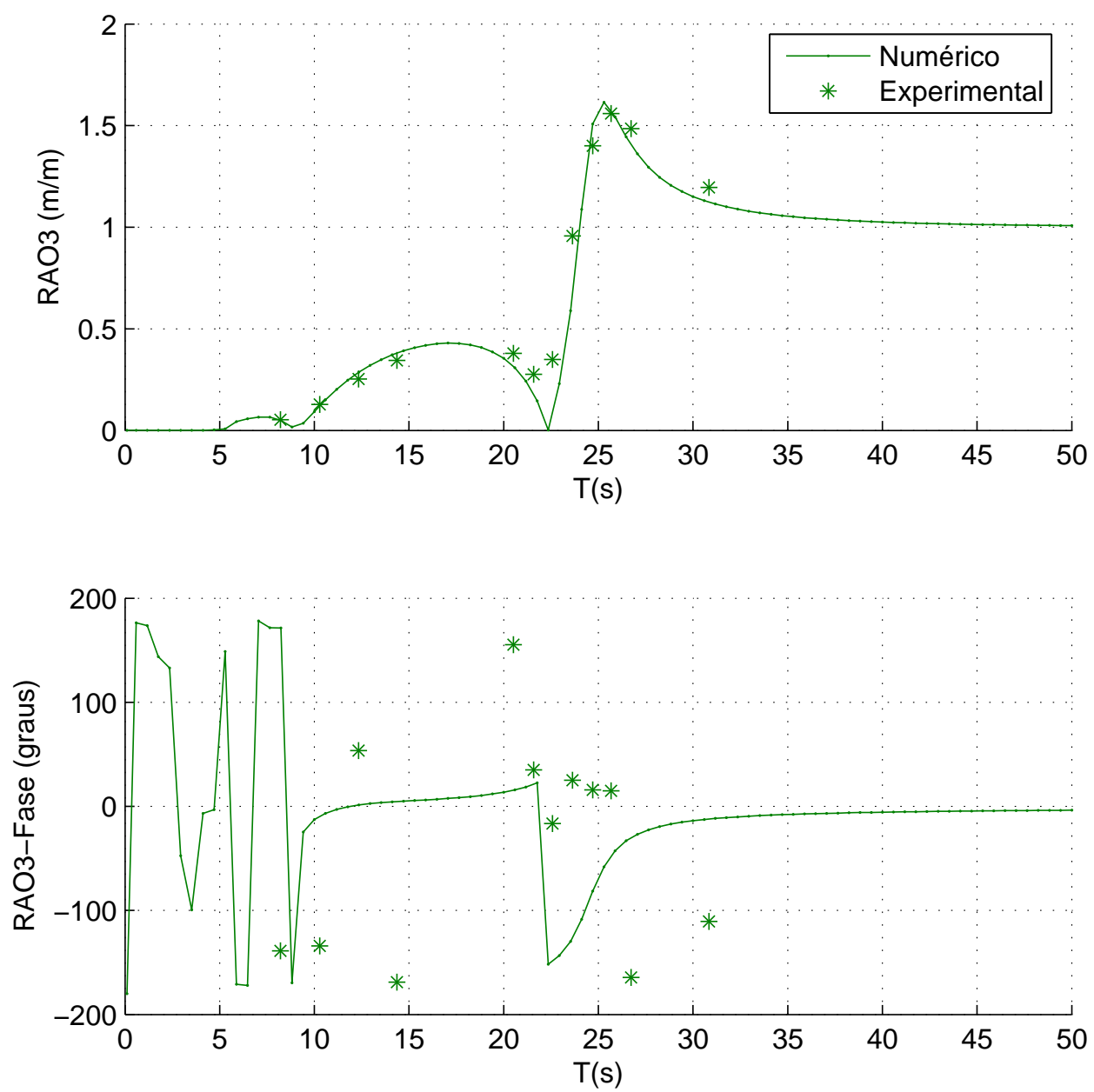

Figura 2.59: Exemplo de curva de RAO de heave em onda regular

os coeficientes de amortecimento de roll através do método RDT, para os casos sem correnteza. Nas Figuras 2.68 e 2.69 é possível notar a significativa influência da presença dos risers na unidade.

As rotinas utilizadas foram: espectro, aespectral e aestatistica. As duas primeiras serviram para determinação e análise dos espectros de Fourier dos movimentos. A última avaliou as estatísticas da série temporal. As curvas de RAO foram mais uma vez analisadas pela calculaRAO.

Para a avaliação do coeficiente de amortecimento foi utilizada a rotina randomtechinique, que obtém uma série de decaimento dos movimentos em ondas irregulares, previamente à execução do decaytest. Também foi utilizada a rotina EMD para obtenção dos espectros de Hilbert-Huang.

Além dos efeitos sobre os movimentos elencados anteriormente, foram verificados os efeitos da tração dos risers sobre a unidade flutuante e a maneira como os movimentos desta foram alterados devido a presença daqueles [Rateiro, 2010]. 

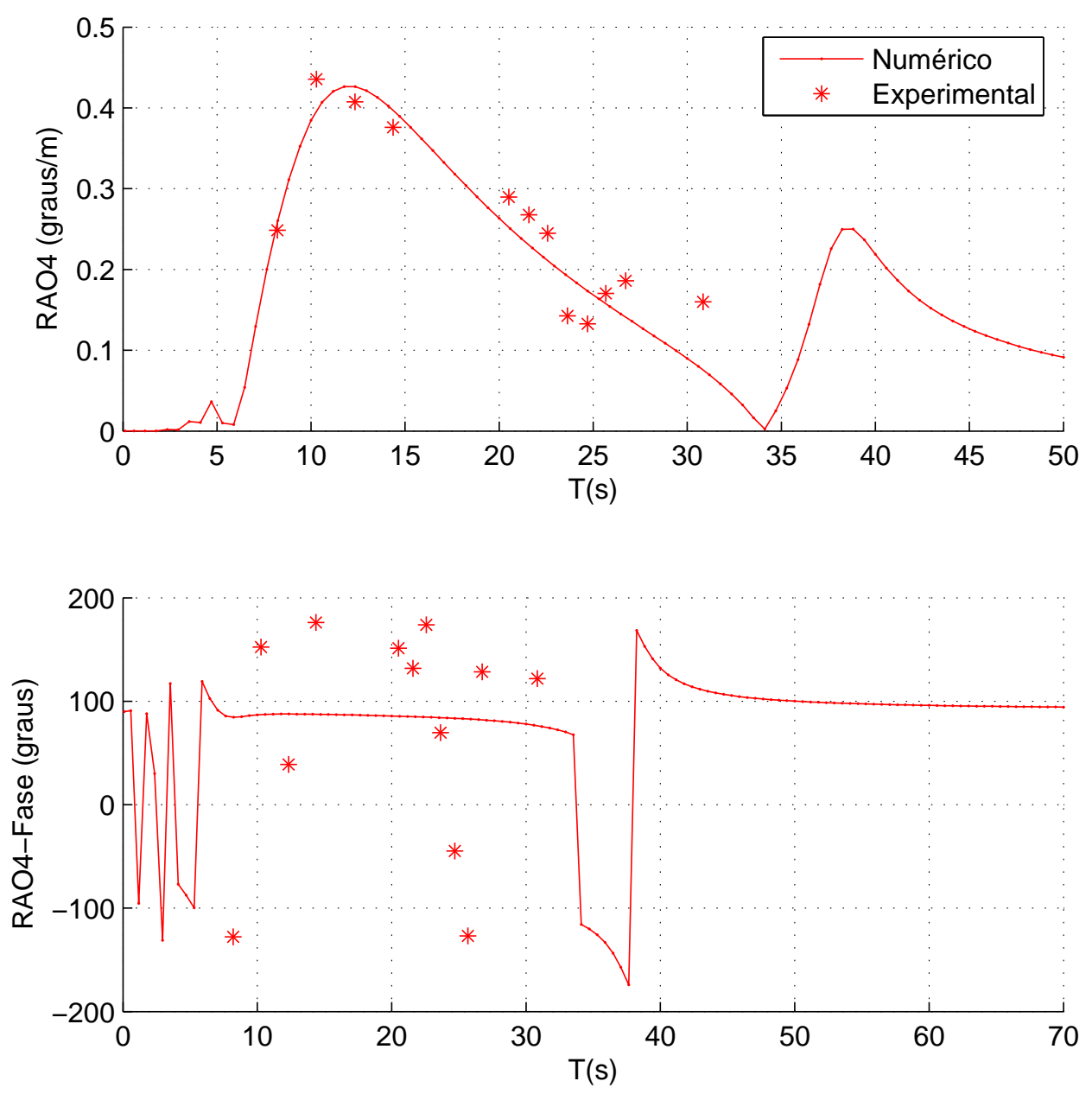

Figura 2.60: Exemplo de curva de RAO de roll em onda regular

Tabela 2.5: Comparação dos parâmetros estatísticos com e sem a presença da correnteza

\begin{tabular}{cccccc}
\hline & \multicolumn{2}{c}{ Com Risers } & \multicolumn{2}{c}{ Sem Risers } \\
\hline \multirow{5}{*}{ Média } & Com correnteza & Sem correntza & Com correnteza & Sem correntza \\
& Sway & -12.58 & -0.39 & -30.20 & -0.50 \\
& Heave & 0.74 & 0.08 & -0.29 & 0.11 \\
& Roll & -0.93 & 0.04 & -0.06 & -0.03 \\
Máximo & Sway & -9.25 & 2.98 & -26.24 & 4.64 \\
& Heave & 3.04 & 1.81 & 1.82 & 1.70 \\
& Roll & 3.33 & 3.65 & 4.33 & 4.88 \\
& Sway & -20.91 & -4.55 & -40.23 & -6.66 \\
& Heave & -0.74 & -1.18 & -2.00 & -1.71 \\
& Roll & -3.37 & -2.47 & -2.64 & -3.55 \\
Altura Máximo Padrão & Sway & 1.47 & 1.19 & 1.87 & 1.98 \\
& Heave & 0.49 & 0.38 & 0.53 & 0.43 \\
& Roll & 0.82 & 0.71 & 0.92 & 0.88 \\
& Sway & 11.66 & 7.53 & 13.99 & 11.30 \\
& Heave & 3.78 & 2.99 & 3.82 & 3.41 \\
& Roll & 6.70 & 6.12 & 6.96 & 8.43 \\
\hline
\end{tabular}



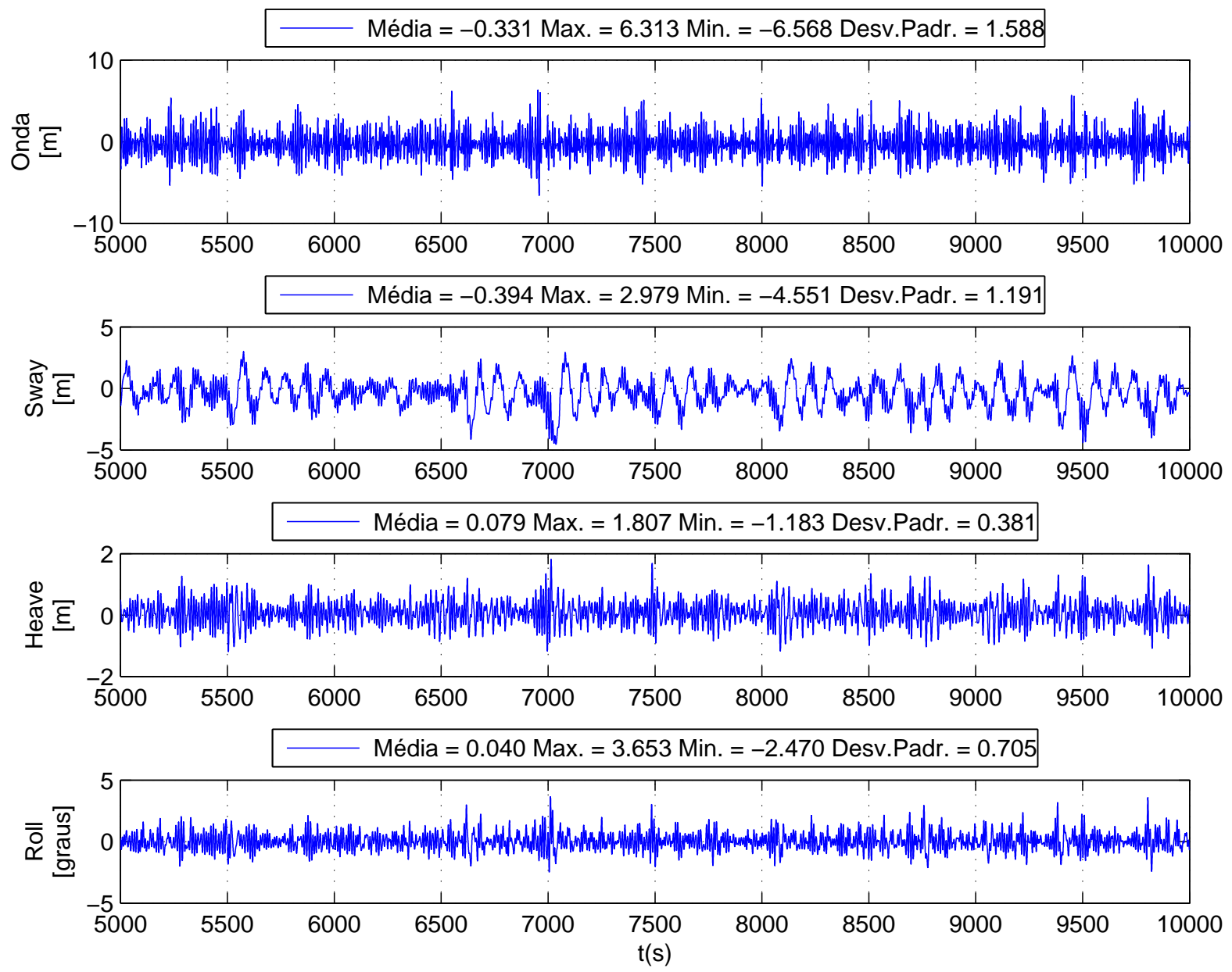

Figura 2.61: Série temporal dos movimentos no ensaio em mar irregular 

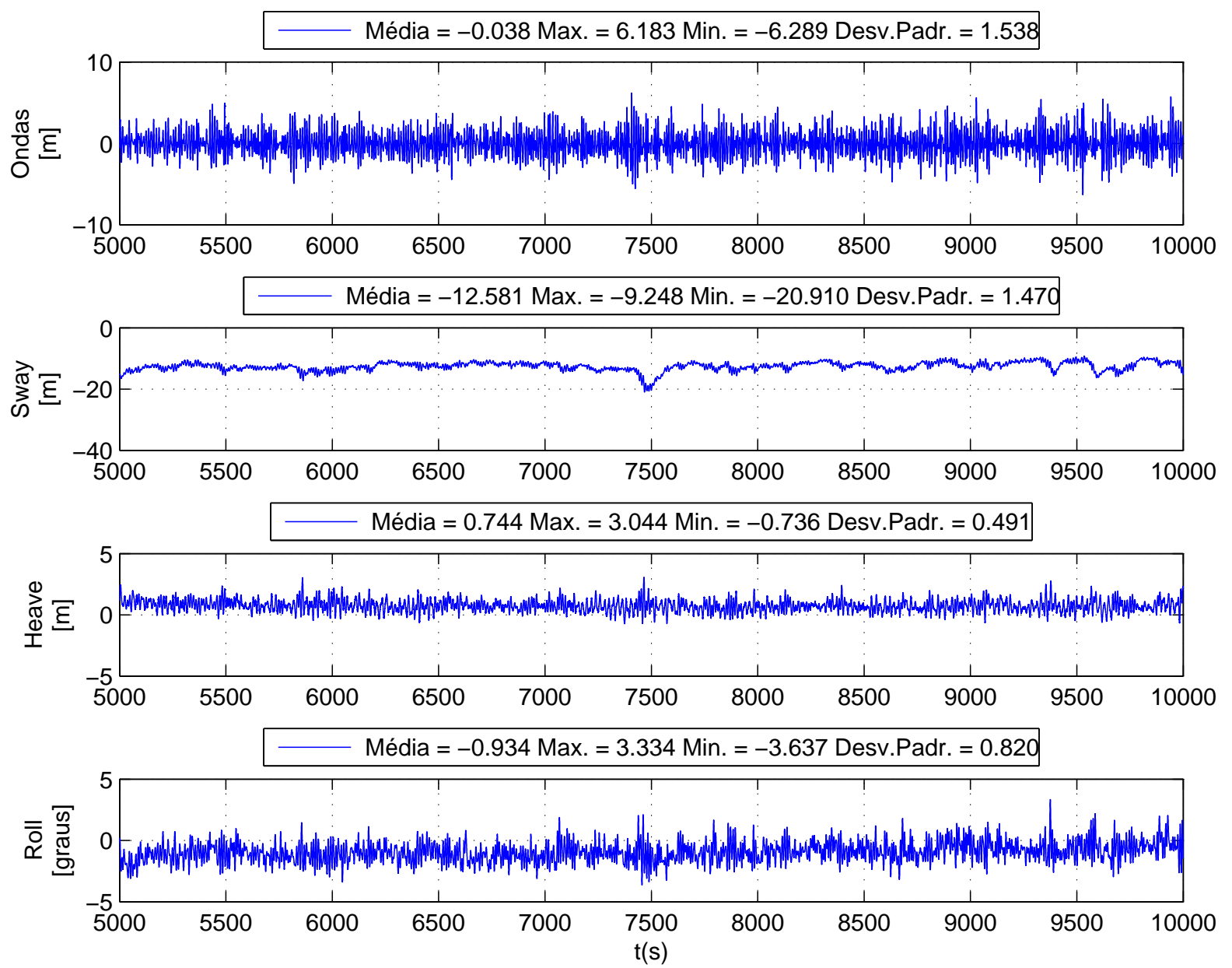

Figura 2.62: Série temporal dos movimentos no ensaio em mar irregular com correnteza 

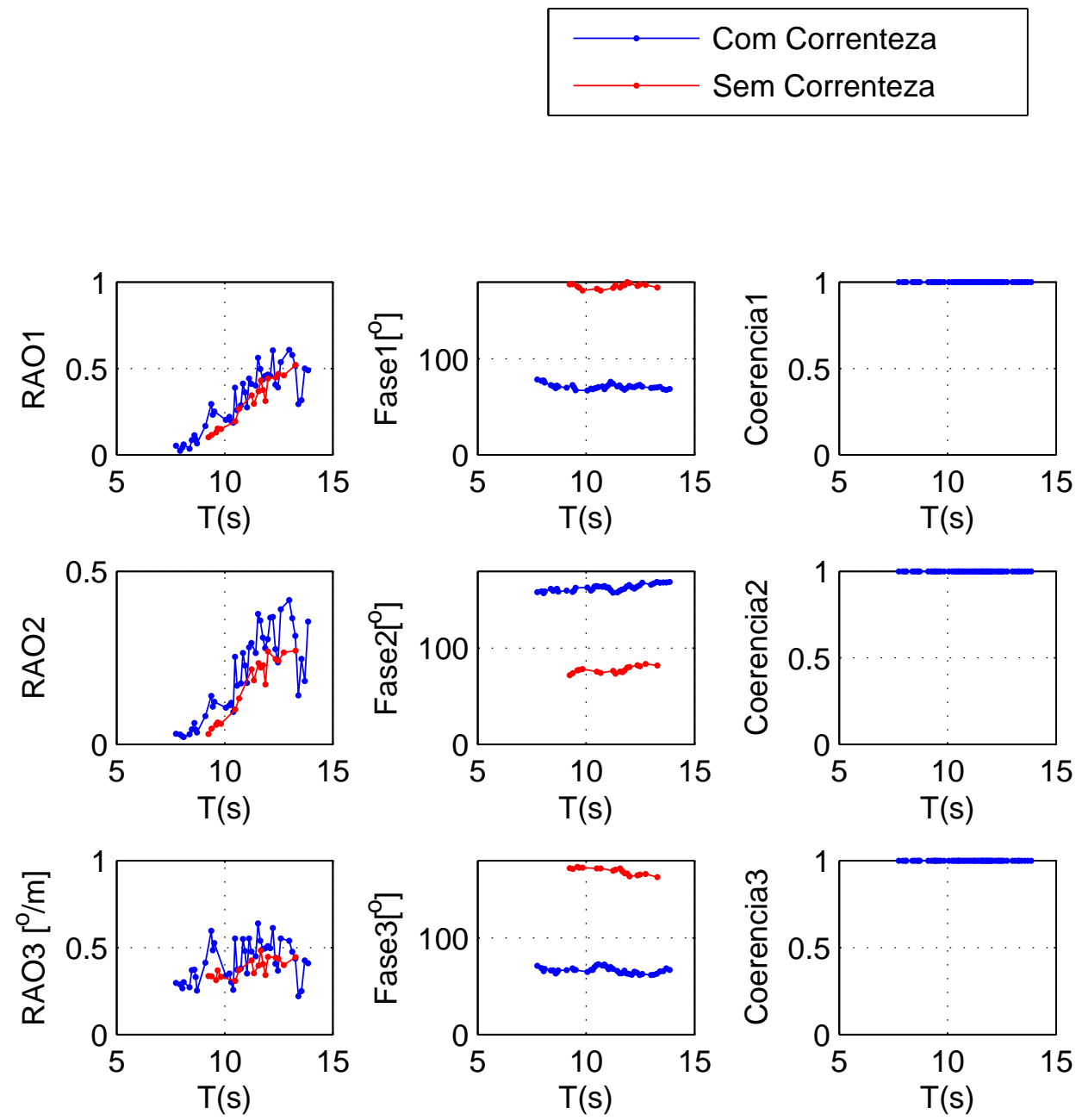

Figura 2.63: RAO dos movimentos no ensaio em mar irregular com e sem correnteza 


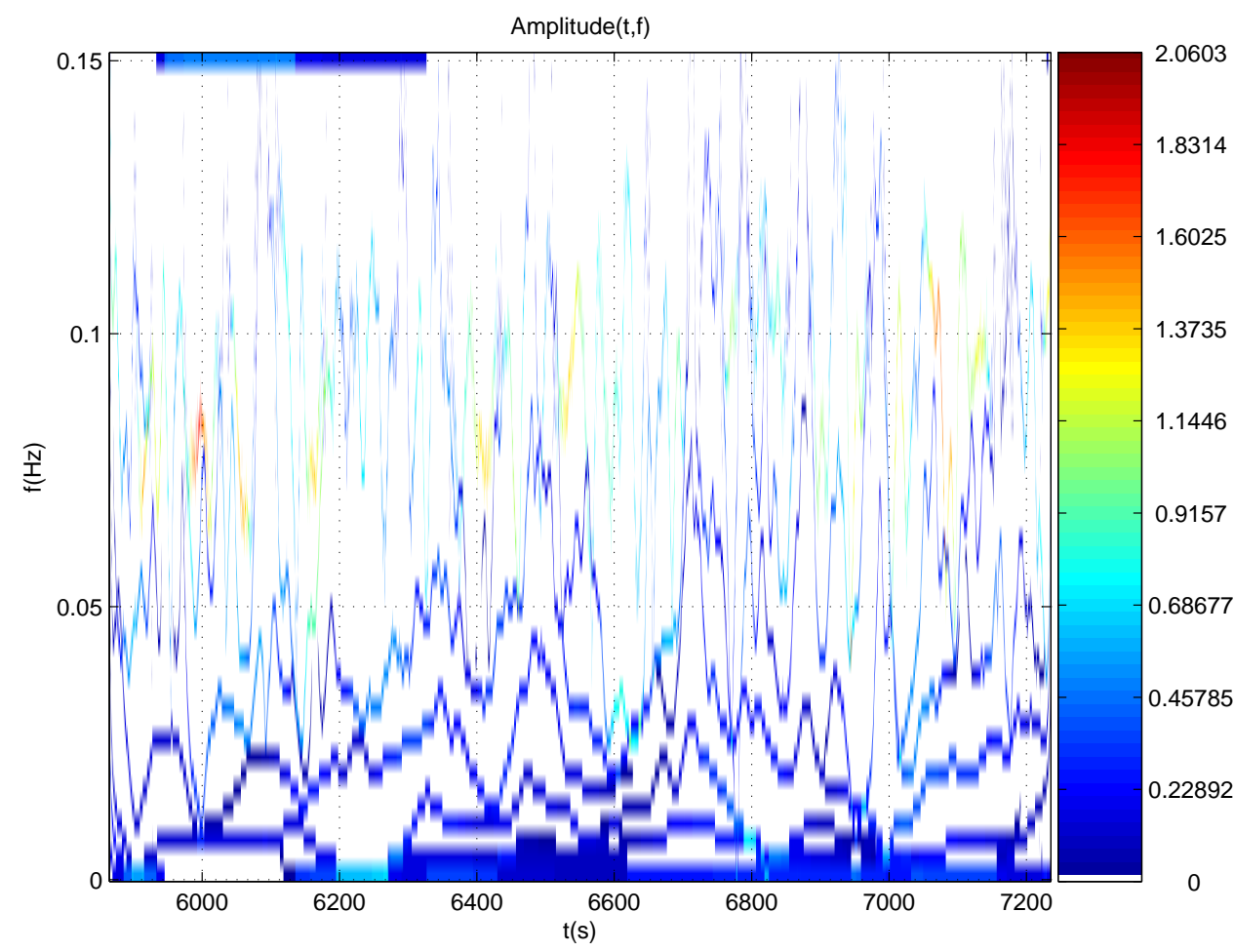

Figura 2.64: Espectro de Hilbert-Huang para o movimento de roll no ensaio em mar irregular com correnteza

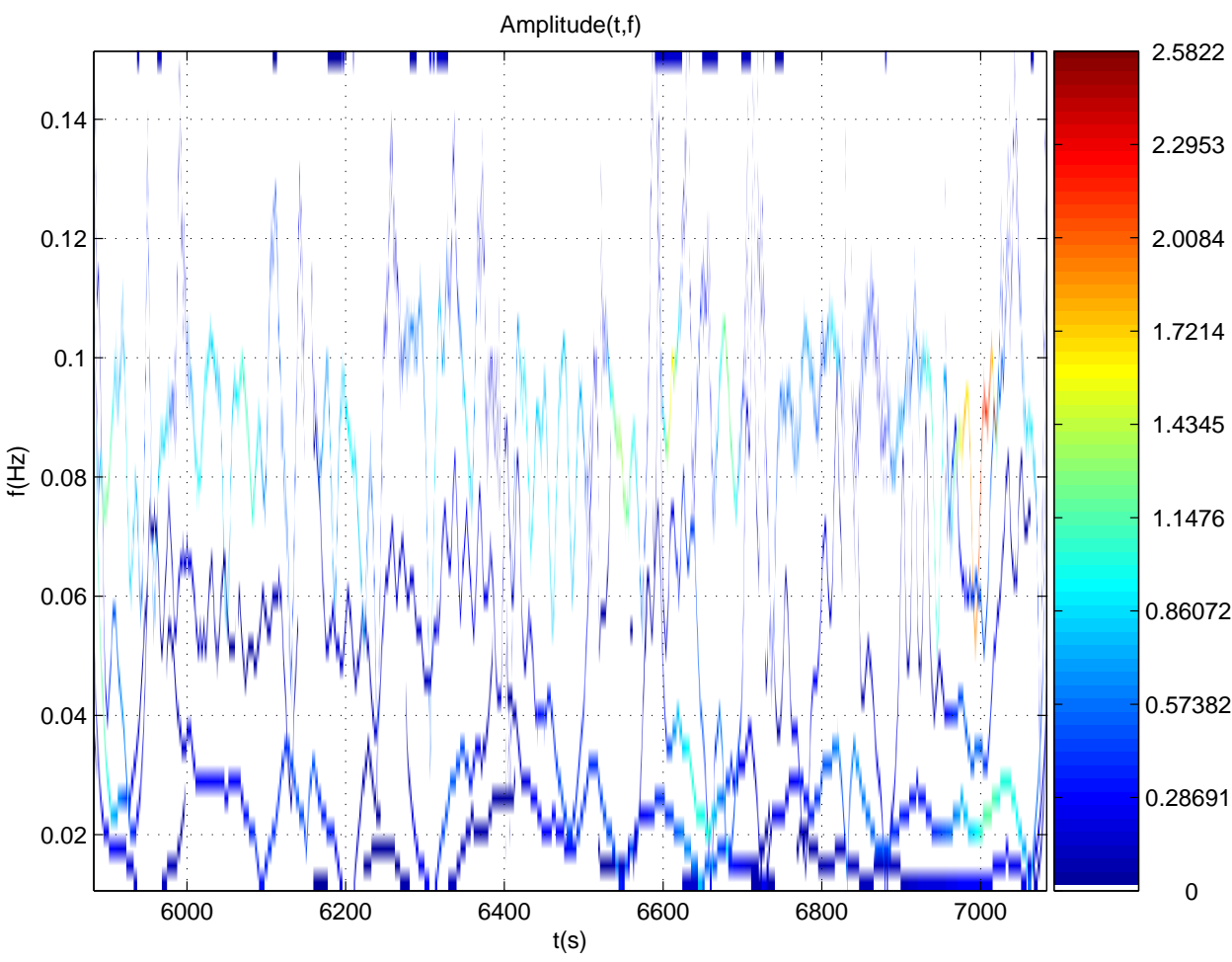

Figura 2.65: Espectro de Hilbert-Huang para o movimento de roll no ensaio em mar irregular sem correnteza 


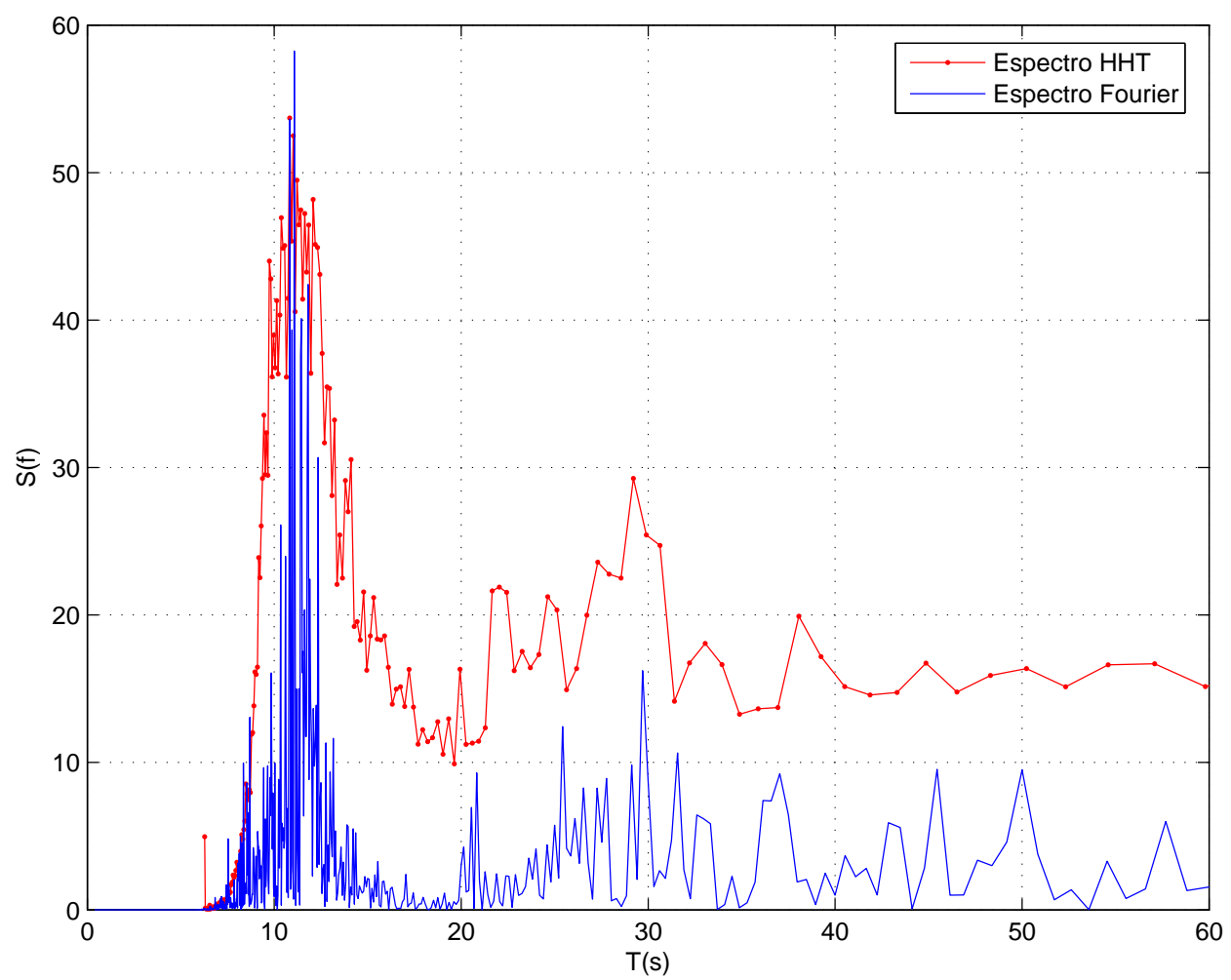

Figura 2.66: Espectro de Hilbert-Huang para o movimento de roll no ensaio em mar irregular com correnteza comparado com o espectro de Fourier

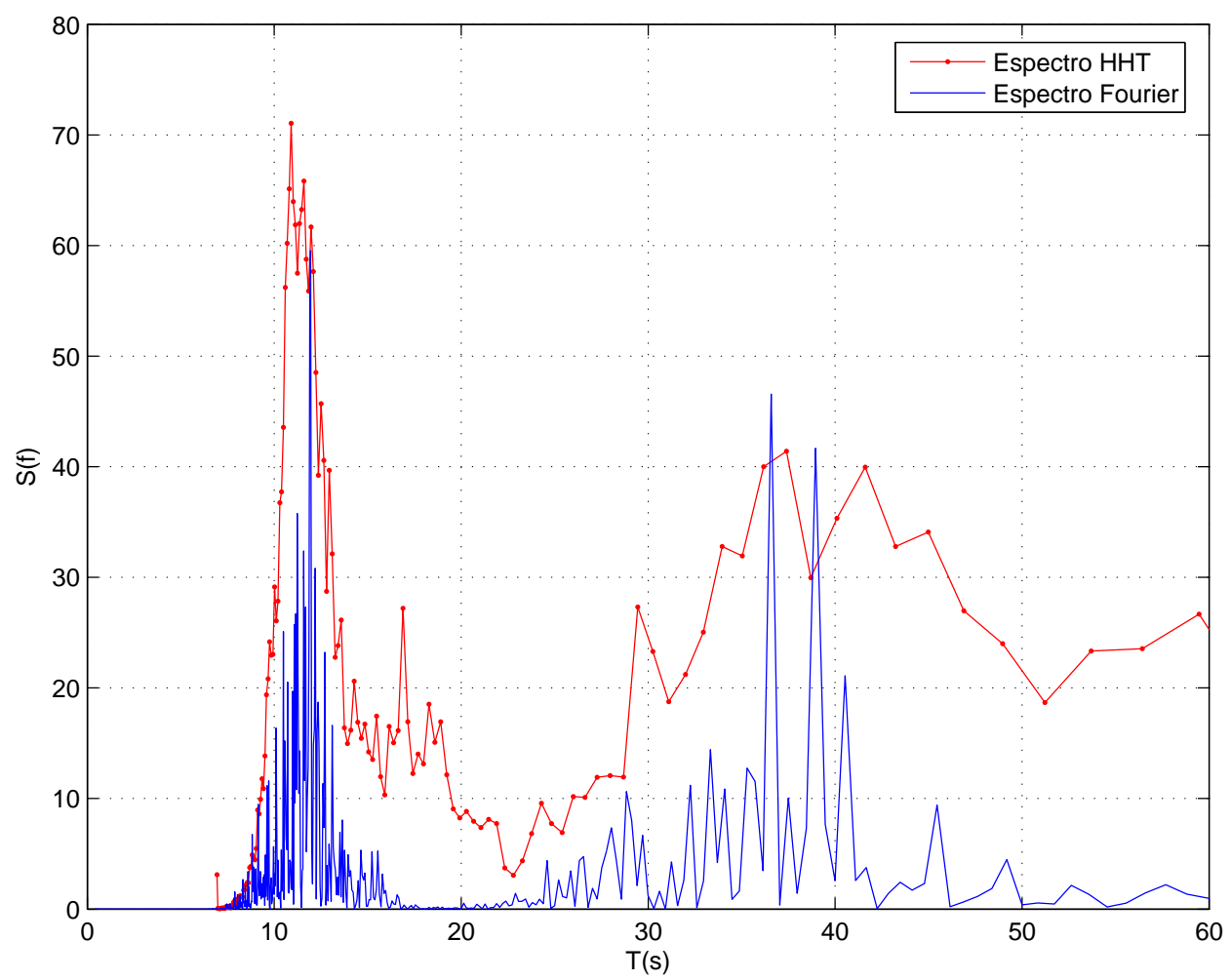

Figura 2.67: Espectro de Hilbert-Huang para o movimento de roll para o ensaio em mar irregular com correnteza 


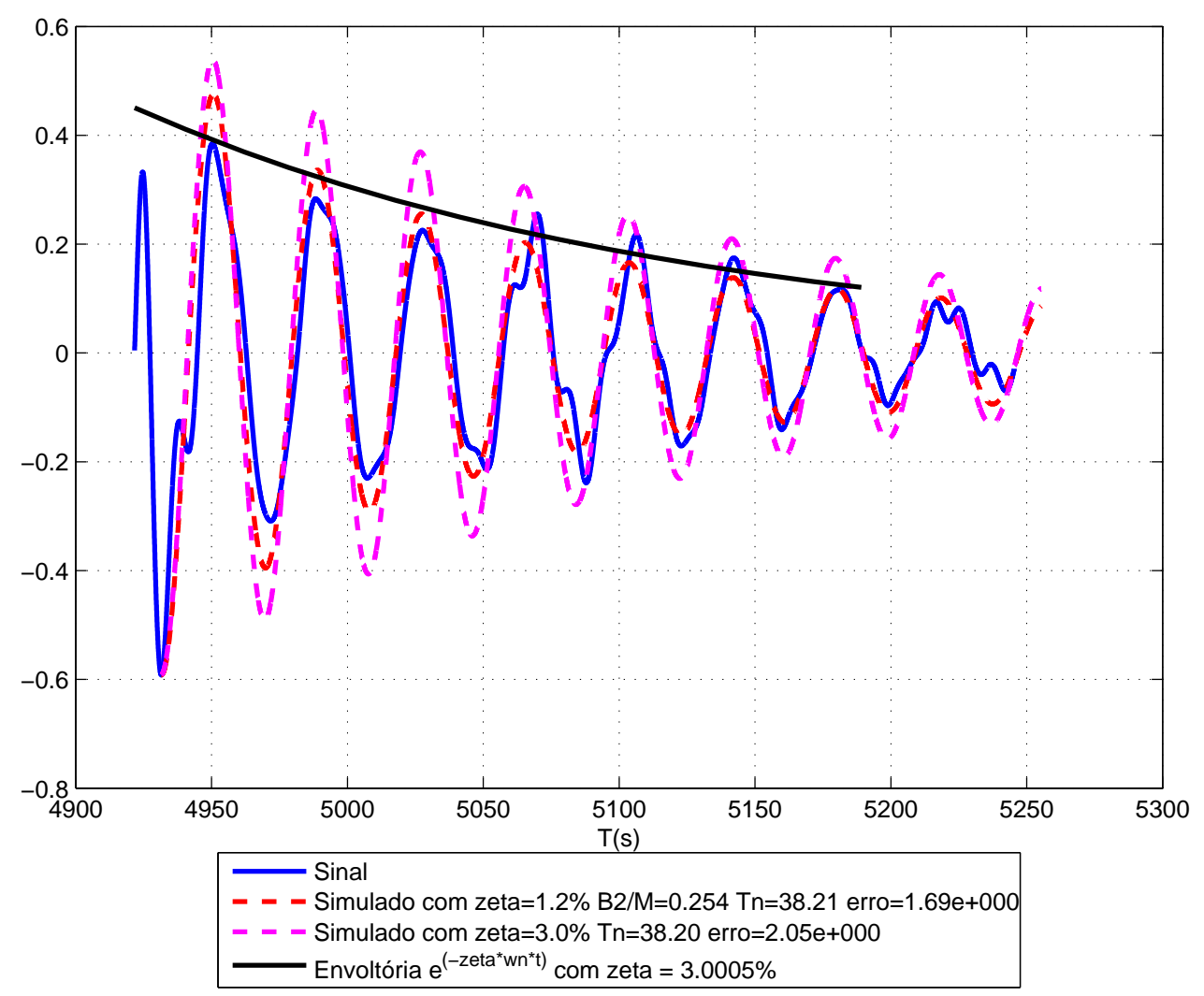

Figura 2.68: RDT para o movimento de roll no ensaio em mar irregular sem correnteza e sem risers

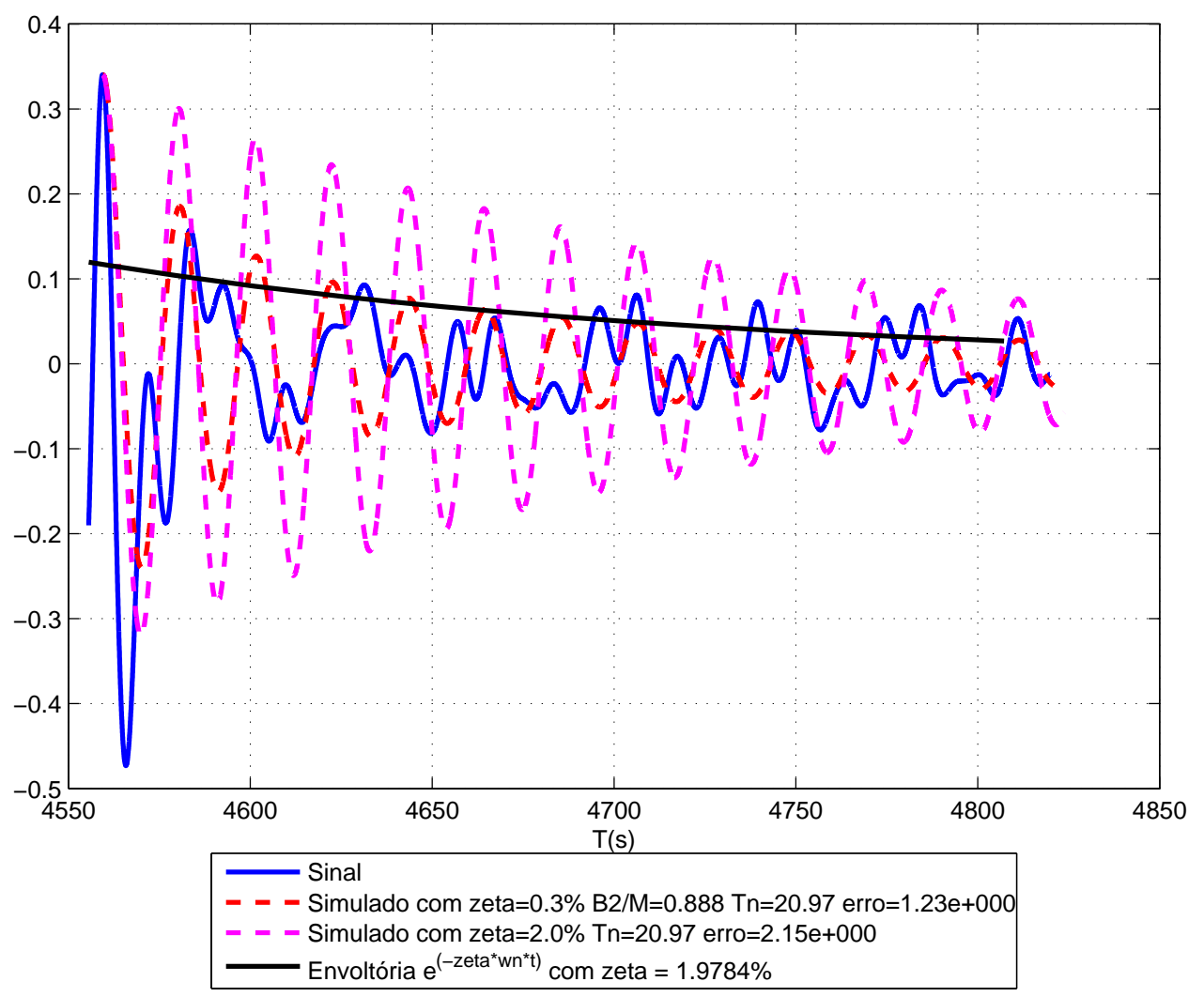

Figura 2.69: RDT para o movimento de roll no ensaio em mar irregular sem correnteza e com risers 
3 Consolidação 


\subsection{Normas dos Ensaios}

Como na maioria das atividades em engenharia, os procedimentos e cálculos realizados no ensaio em tanque de provas são regidos por recomendações ou normas. O presente trabalho se baseou, principalmente, nas recomendações do International Towing Tank Coference (ITTC).

A ITTC apresenta as recomendações sobre a maioria dos ensaios. Assim, para os ensaios de comportamento em ondas de plataformas de produção de petróleo e gás foram consultadas as normas retiradas de [ITTC, 2005a]. A ITTC sugere normas de qualidade ISO-9001, conforme apresentado em [ITTC, 2008a].

Em [ITTC, 2005b], algumas recomendações são brevemente discutidas sobre: condições de carregamento, dimensões do modelo e do tanque de provas, características das condições ambientais, sistema de amarração, número de repetições e tempo de duração dos testes. Com relação a este último, a ITTC recomenda que para a determinação de movimentos de primeira ordem, normalmente 10 ciclos são suficientes, enquanto que para a avaliação das forças de deriva, são necessários tempos de amostragem $T_{r}$ maiores em ondas irregulares, nestas são recomendados testes de 20 a 30 minutos na escala real, para que o sinal tenha características estatísticas válidas.

Nas recomendações [ITTC, 2002] são tratadas as análises em ondas regulares. Os parâmetros discutidos são os mesmos de [ITTC, 2005b], ressaltando a realização de análise harmônicas e espectrais para avaliação dos períodos e amplitudes dos movimentos.

Tabela 3.1: Tolerâncias para ondas regulares e irregulares [Chakrabarti, 1987]

\begin{tabular}{lll}
\hline Parâmetro & \multicolumn{2}{c}{ Tolerância } \\
\hline $\begin{array}{l}\text { Média das alturas de } \text { Ondas } \\
\text { regulares }\end{array}$ & $\begin{array}{l}\text { Mínimo de } 10 \text { ciclos com tolerância } \\
\text { de } \pm 5 \%\end{array}$ \\
Média dos períodos para Ondas & Tolerância de $\pm 0,2 s$ na escala real \\
regulares & & \\
Altura significativa $H_{s}$ de onda & Tolerância de $\pm 5 \%$ \\
irregular & & Tolerância de $\pm 0,5 s$ na escala real \\
Período de pico $T_{p}$ de onda irregular & Tolerância de $\pm 10 \%$ \\
Parcela significativa do formato do & \\
\hline
\end{tabular}




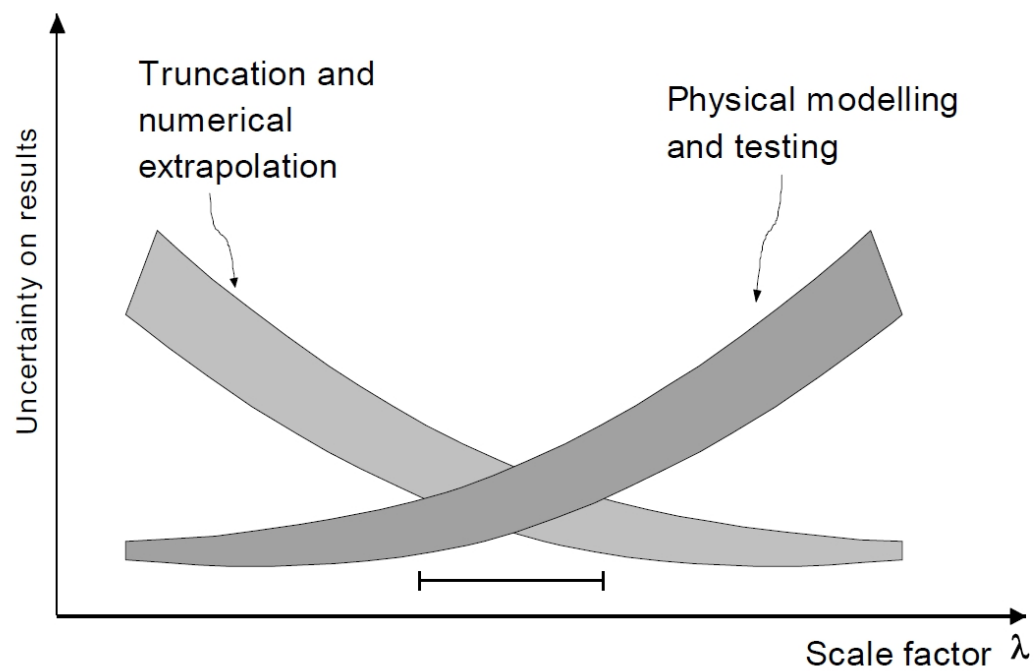

Figura 3.1: Balanço entre incertezas do modelo físico e modelo numérico truncado [ITTC, 2008b]

Outras recomendações fazem parte do material da ITTC, contudo as informações contidas nestes são referentes a outros tipos de ensaios. Apesar de [ITTC, 2008b] discutir sobre integração com modelos numéricos, o objetivo é a avaliação de ensaios truncados. Vale lembrar que o ensaio utilizados como exemplo, não representa uma condição em escala real truncada, o modelo foi construído para ser realizado na escala do modelo e avaliar os parâmetros que influenciam o movimento da unidade flutuante. A Figura 3.1, representa a dificuldade em definir a escala do modelo para simulações da condição real com um ensaio truncado, por esse motivo, foi preferível a realização de um ensaio sem correspondência física na escala real, até mesmo pelo fato da dificuldade de presentar os diâmetros dos risers reais na escala do modelo em estudo.

Em [Chakrabarti, 1987] são apresentados valores de tolerância para ondas regulares e irregulares conforme apresentado na Tabela 3.1.

A qualidade de um ensaio está diretamente ligada as incertezas envolvidas na aquisição e nos resultados, portanto, referências como [Coleman \& Steele, 1999] e [ISO/IEC, 2008] merecem atenção durante o planejamento dos experimentos e escolha dos instrumentos e métodos a serem utilizados. 


\subsection{Documentação Padrão}

A documentação dos resultados de um ensaio deve apresentar todos os pontos relevantes e descrever as informações importantes para que sejam consideradas posteriormente em simulações numéricas e avaliações futuras.

Também é recomendável que seja feita uma base de dados com as etapas e hora de cada teste, além das informações relevantes sobre ocorrências durante a execução dos ensaios. Um exemplo são as mudanças da posição de lastro do modelo durante os prétestes ou acontecimentos inesperados, como quebra de ondas, problemas com as linhas de amarração ou até mesmo água sobre o modelo. No caso da posição dos lastros, essas informações devem conter a posição final de todas as massas para correções nos valores de inércia e atualização nos modelos analíticos e/ou numéricos.

Os objetivos da documentação dos ensaios são: a repetibilidade, a facilidade de compreensão dos métodos utilizados, ressaltar os resultados mais importantes e apresentar as conclusões dos experimentos.

A documentação deve ser confeccionada desde o planejamento dos ensaios com a discussão dos métodos que serão utilizados e alguns resultados existentes. Essas informações podem ser utilizadas durante a calibração e execução dos ensaios como fonte de referência. As informações mais importantes são desenhos e tabelas com o arranjo de lastro, curvas de estabilidade e de movimento. Se essas informações já estiverem documentadas antes do início dos ensaios, o processo de montagem dos experimentos será mais eficiente. Uma possibilidade é ter esses informações em formato Wiki ${ }^{1}$, pois esses tornam-se disponíveis via internet para a consulta e sua a atualização pode ser feita durante a execução dos ensaios simultaneamente entre as pessoas envolvidas nos experimentos.

Os principais tópicos de uma documentação padrão para um ensaio em tanque de provas são:

- Sumário;

- Conclusões e recomendações,

- Introdução,

- Descrição do arranjo experimental com informações sobre o modelo, instrumentação, sistema de aquisição e condições ambientais utilizadas;

\footnotetext{
${ }^{1} \mathrm{O}$ Wiki é uma página de internet que possibilita a criação e edição de documentos por vários usuários.
} 
- Matriz de ensaio com a lista dos testes que foram realizados e em quais condições;

- Análise dos resultados com a apresentação e discussão;

- Anexos com a calibração dos instrumentos e condições ambientais, além dos demais resultados não apresentados ao longo do relatório.

Os resultados devem ser claros e breves, por outro lado, os anexos devem conter os resultados completos enquanto os resumos devem estar no texto principal. Também devem estar nos anexos as calibrações principalmente das condições ambientais, além de explicações padrões, como teorias e estatísticas utilizadas. Como alguns ensaios possuem uma quantidade significativa de informações, a organização dos arquivos relacionados aos experimentos deve estar presentes em anexos digitais. Além disso, quando existirem recomendações padrões, essas devem estar referenciadas às recomendações específicas do tipo de teste realizado. 


\subsection{Comparações Experimentais e Numéricas}

Neste capítulo, estão descritas algumas características dos modelos envolvidos para a comparação entre resultados experimentais e numéricos.

O planejamento do ensaio é feito com estimativas do modelo numérico como apresentado na Figura 1.5. Ou seja, modelos numéricos auxiliam na escolha das condições ambientais e no dimensionamento do sistema de amarração. Normalmente, esse é o mesmo processo empregado nos projetos de plataformas, pois primeiro são avaliadas diversas condições para a unidade flutuante, analítica e/ou numericamente. Posteriormente, os casos mais severos são testados em tanque de provas. Com os resultados experimentais, estes modelos podem ser refinados para o uso em trabalhos futuros. Algumas das peculiaridades destes modelos são relevantes durante a comparação dos resultados.

Os modelos numéricos utilizados em ensaios podem ser divididos em duas partes: modelagem no domínio da frequência e no domínio do tempo.

[Rateiro, 2010] apresenta um exemplo de aplicação destes modelos, nos testes com a ITTC-SR192, para todas as condições estudadas no tanque de provas e algumas destas comparações podem ser vistas nas Figuras 2.58 a 2.60 .

O modelo no domínio da frequência é utilizado para definir os coeficientes hidrodinâmicos. Estes coeficientes são: a matriz de massa adicional $A$, a matriz de amortecimento potencial $B$ e os vetores de força de excitação de primeira e segunda ordem, $F_{1}$ e $F_{2}$ respectivamente.

Os coeficientes hidrodinâmicos, baseados na teoria potencial de ondas são geométricos [Newman, 1982], ou seja, dependem apenas do formato do volume submerso e não de parâmetros de carregamento. Portanto, para a avaliação dos níveis de movimento da unidade, é necessário definir estes parâmetros externos com relação a cada condição de carregamento. Estes parâmetros são a matriz de massa $M$ e a matriz de restauração hidrostática $C$. Outros parâmetros são mais difíceis de serem determinados, entre eles: a matriz de restauração externa $C_{E}$, referente às forças das linhas de amarração e risers; e a matriz de amortecimento devido à parcela de forças viscosas $B_{E}$.

Para a avaliação no domínio da frequência, os parâmetros acima são definidos em cada frequência de oscilação e, partindo da hipótese de linearidade do sistema ${ }^{2}$, podem

\footnotetext{
${ }^{2}$ Quando os sistemas são lineares e no domínio da frequência, efeitos de primeira e segunda ordem são avaliados separadamente [Faltinsen, 1990].
} 
ser feitas estimativas estatísticas, através de cruzamento espectral, para assim definir o nível de movimento em cada condição de mar como mostrado no Apêndice III.

Outra maneira de considerar os efeitos devido à restauração externa $C_{E}$ e as forças viscosas $B_{E}$, além dos efeitos não-lineares, é a utilização de modelos no domínio do tempo. Neste caso, a restauração externa pode ser determinada através de modelos em elementos finitos tanto para as linhas de amarração quanto para as linhas de risers. No caso das forças viscosas, a parcela nas linhas pode ser estimada através de equações de Morison ([Faltinsen, 1990]). Na unidade flutuante, o amortecimento viscoso pode ser representado tanto pela parcela linear quanto pela quadrática, de acordo com a equação I.4.

Para a modelagem no domínio da frequência foi utilizado o código [WAMIT, 2006], enquanto a modelagem no domínio do tempo o TPN [Nishimoto \& Lima, 2007].

Na Figura 3.2, é apresentado um diagrama com as características dos modelos numéricos. As formulações sobre estes parâmetros estão apresentadas no Apêndice I.

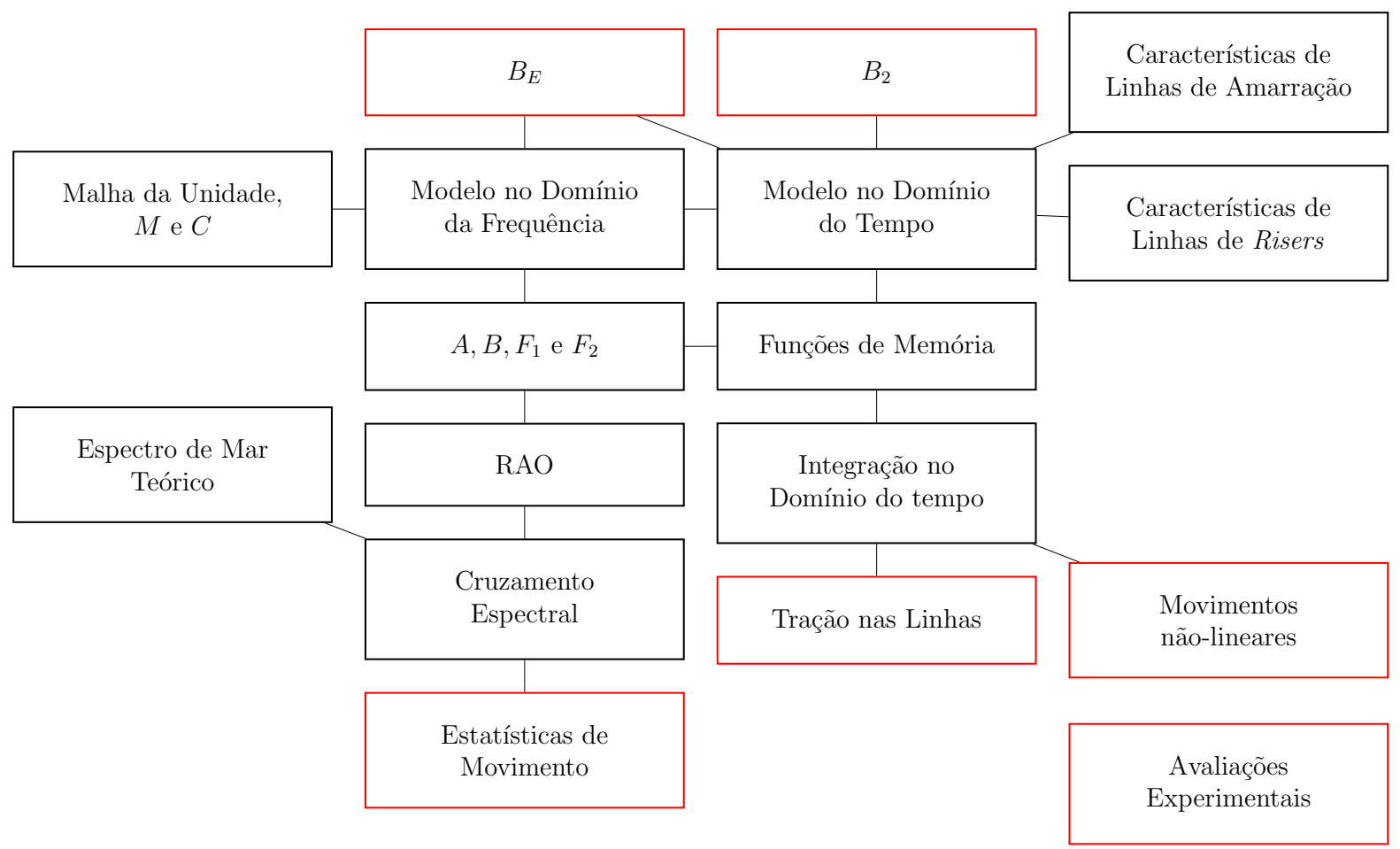

Figura 3.2: Características e propriedades avaliadas em cada modelo numérico

Durante o processo de calibração, principalmente no modelo no domínio da frequência, não é necessário avaliar todos os coeficientes hidrodinâmicos novamente. Para verificar efeitos na mudança da restauração e níveis de amortecimento, é possível apenas atualizar as matrizes $C_{E}$ e $B_{E}$. Por esse motivo foi criada a rotina dampedrao para auxiliar a calibração de modelos numéricos. Assim, através da comparação entre as curvas de RAO experimentais e numéricas, é possível encontrar os níveis de 
amortecimento e/ou restauração externa para que os resultados numéricos estejam coerentes com os experimentais, como no exemplo apresentado na Figura 3.3.

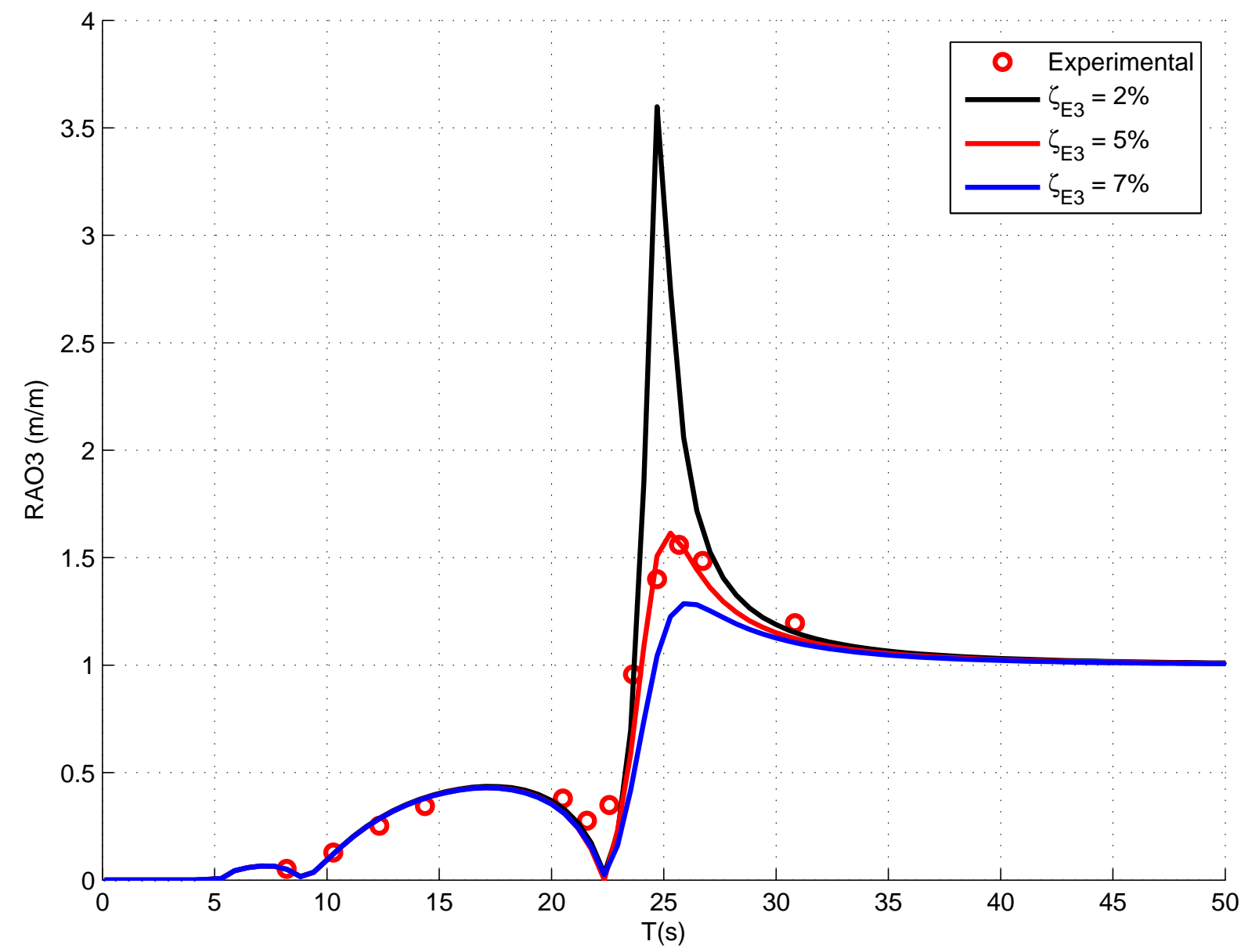

Figura 3.3: Comparação entre níveis de amortecimento para a calibração dos modelos numéricos

Posteriormente, todas as não-linearidades podem ser avaliadas no modelo no domínio do tempo. Neste caso, não é necessário definir uma matriz de restauração externa quando as linhas estiverem sendo representadas por um modelo de elementos finitos. A dificuldade é avaliar o acoplamento entre as forças destas linhas e as forças hidrodinâmicas, por isso os resultados de um ensaio como o apresentado em [Rateiro, 2010] são tão importantes. 


\subsection{Conclusões e Recomendações}

Neste capítulo, são apresentadas as principais conclusões desta dissertação, algumas sugestões para a continuação do trabalho e recomendações para pesquisas futuras.

O reboque do modelo da ITTC-SR192 em ondas no tanque do IPT, representou condições de mar com correnteza, possibilitando a avaliação do acoplamento da unidade com as linhas de riser. Efeitos da perturbação do fluxo da água devido à presença do modelo e o arrasto com várias linhas de risers, são um dos efeitos que torna esse estudo nada trivial. A soma destes efeitos de maneira independente, como é feito nos modelos numéricos, pode alterar significantemente a avaliação de carregamento nos risers, dependendo da velocidade da correnteza. Para obtenção dos resultados deste experimento foram descritas as etapas de Planejamento, Calibração, Pré-testes, Execução e Análise. Os métodos e procedimentos utilizados poderão ser referência em estudos futuros.

O planejamento do ensaio é uma etapa importante para os experimentos no tanque de provas. No caso de testes de metodologia conhecida, o planejamento é focado na escolha de escalas e definição de matriz de ensaio. Nos experimentos para investigações menos triviais, como ensaios sobre VIV e VIM, o planejamento visa desenvolver inclusive o procedimento dos testes. Nestes casos, uma análise de incerteza é recomendada. Apesar do ensaio utilizado nesta dissertação, tratar de um fenômeno complexo, a metodologia dos ensaios em comportamento em ondas é padrão, portanto, o planejamento utilizou as etapas apresentadas na Figura 1.5 e matriz de ensaio da Tabela 1.1.

Todas as informações do tanque do IPT, como as características do carro dinamométrico, frequência das ondas geradas pelo batedor e arranjo das instalações do fundo falso, foram consideradas na etapa do planejamento.

Na etapa de calibração, as propriedades ajustadas foram: massa/inércia, períodos naturais, restaurações axiais e flexionais. Foram adotados alguns procedimentos para que cada uma das propriedades fossem ajustadas ou verificadas, tanto no modelo em escala da unidade flutuante quanto nos modelos das linhas de amarração e risers.

Durante a fase de Pré-testes, o modelo foi modificado com relação ao posicionamento do lastro para que as propriedades em escala estivessem coerentes nas condições com e sem correnteza. Nesta etapa, também foi possível uma segunda verificação de algumas propriedades ajustadas durante a calibração, além da avaliação dos coeficientes de amortecimento. Uma sugestão para facilitar a verificação e 
documentação da etapa de Pré-testes, seria manter um modelo 3D atualizado com os desenhos de todas as massas, instrumentações e conexões com as linhas. Assim, as distâncias entre os elementos presentes no modelo, bem como a sua localização no tanque de provas, seriam avaliadas diretamente.

Para a etapa de execução dos ensaios, algumas surpresas são comuns. Quanto antes os dados experimentais forem analisados, menor a probabilidade de equívocos que só serão percebidos ao final do ensaio, ou pior, quando todo o aparato estiver desmontado. Por isso, manter as rotinas disponíveis para realizar as análises e comparações, no próprio tanque, é extremamente recomendável. Alguns ensaios necessitam de testes de confirmação cujo tempo requerido recomenda-se que seja considerado na etapa de planejamento de ensaios.

A documentação e utilização de procedimentos padronizados facilitam a repetibilidade dos testes, aumentando assim a credibilidade de publicações e relatórios técnicos.

Os procedimentos, em sua maioria, foram utilizados para a criação de rotinas numéricas. A descrição do processo de análise de cada rotina pode ser utilizada em ensaios de comportamento em ondas.

As rotinas de análise estão sempre em desenvolvimento, ainda mais, quando o estudo refere-se a fenômenos ainda não conhecidos. Por isso, a documentação da rotina é uma prática necessária. Ferramentas de controle de versão ou mesmo Wikis ${ }^{3}$ devem ser utilizados até mesmo para facilitar a documentação futura.

Finalmente, cumpre destacar que os objetivos do programa de mestrado foram atingidos e concretizados através do presente texto, focado na descrição detalhada dos métodos e processos envolvidos em experimentos típicos para a investigação do comportamento no mar de sistemas flutuantes, bem como através da ferramenta matemática de apoio às análises, especificamente construída e testada.

\footnotetext{
${ }^{3}$ Ambiente de internet para publicação simultânea por vários usuários.
} 


\section{Referências}

[Amarante, 2010] Amarante, Rodrigo. 2010. Estudo da Estática e Dinâmica de Linhas, sob Configuração de Catenária, através da Identificação Geométrica, Processamento e Análise de Imagens Digitais. Dissertação de Mestrado, Escola Politécnica da USP, São Paulo. 115

[Campos et al., 2004] Campos, F.C.R., Santos, B.M.R., Malta, E. B., Rampazzo, F. P., Okamoto, F., \& Nishimoto, K. 2004. Desenvolvimento de monocoluna receptora de risers. SOBENA. 112

[Chakrabarti, 1987] Chakrabarti, S.K. 1987. Hydrodynamics of Offshore Structures. WIT Press. , 32, 33, 84, 85, 106, 125

[Chakrabarti, 1994] Chakrabarti, S.K. 1994. Offshore Structure Modeling. Advanced Series on Ocean Engineering Vol. 9. , 3, 7, 10, 11, 12, 29, 45, 56, 100

[Clauss, 2007] Clauss, Gunther F. 2007. The Conquest of the Inner Space - Challenges and Innovations in Offshore Technology. Marine Systems $\&$ Ocean Technology, 3. , 2, 3

[Coleman \& Steele, 1999] Coleman, H.W., \& Steele, W.G. 1999. Experimentation and Uncertainty Analysis for Engineers. Wiley-Interscience Publication. 10, 85

[Faltinsen, 1990] Faltinsen, O.M. 1990. Sea Loads on Ships and Offshore Structures. Cambridge University Press. 7, 88, 89

[Fujarra et al., 2009] Fujarra, A.L.C., Gonçalves, R.T., Rosetti, G.F., Nishimoto, K., Cueva, M., \& Siqueira, E.F.N. 2009. Vortex-induced Motion of a monocolumn platform: New analysis and comporative study. OMAE. 6, 114

[Gonçalves et al., 2010] Gonçalves, Rodolfo T., Franzini, Guilherme R., Rosetti, Guilherme F., Fujarra, André L.C., \& Nishimoto, Kazuo. 2010. Analysis Methodology of Vortex-Induced Motions(VIM) on a Monocolumn Platform Applying the HilbertHuang Transform Method. OMAE. 51

[Gonçalves et al., 2009] Gonçalves, R.T., Fujarra, A.L.C., Rosetti, G.F., Nishimoto, K., Cueva, M., \& Siqueira, E.F.N. 2009. Vortex-induced Motion of a monocolumn platform: New analysis and comporative study. OMAE. 114

[Huang \& Attoh-Okine, 2005] Huang, Norden, \& Attoh-Okine, Nii O. 2005. The HilbertHuang Transform in Engineering. CRC Press. 51

[Huang et al., 1998] Huang, Norden E., Shen, Zheng, Long, Steven R., Wu, Manli C., Shih, Hsing H., Zheng, Quanan, Yen, Nai-Chyuan, Tung, Chi Chao, \& Liu, Henry H. 1998. The empirical mode decomposition and the Hilbert spectrum for nonlinear and non-stationay time series analysis. The Royal Society, 454, 903-995. 51 
[ISO/IEC, 2008] ISO/IEC. 2008. Guide to the expression of uncertainty in measurement. Uncertaint of measurement Part 3. 85

[ITTC, 2002] ITTC. 2002. Testing and Extrapolation Methods Loads and Responses, Ocean Engineering Analysis Procedure for Model Tests in Regular Waves. Recommended Procedures and Guidelines, 7.5.02.07.03.2. 84

[ITTC, 2005a] ITTC. 2005a. Recommended Procedures and Guidelines. 84

[ITTC, 2005b] ITTC. 2005b. Testing and Extrapolation Methods Loads and Responses, Ocean Engineering Floating Offshore Platform Experiments. Recommended Procedures and Guidelines, 7.5.02.07.03.1. 84

[ITTC, 2008a] ITTC. 2008a. Quality Manegement Manual. Recommended Procedures and Guidelines. 84

[ITTC, 2008b] ITTC. 2008b. Testing and Extrapolation Methods Loads and Responses, Ocean Engineering, Truncation of Test Models and Integration with Numerical Simulations. Recommended Procedures and Guidelines, 7.5.02.07.03.5. , 85

[Malta et al., 2009] Malta, E.B., Rampazzo, F., Cruz, R.E., Oliveira, A.C., \& Nishimoto, K. 2009. FPSO and TLWP Interacting at a Reduced Distance for Dry Tree Completion System. OMAE. , 101, 105

[Newman, 1982] Newman, J.N. 1982. Marine Hydrodynamics. 6, 88

[Nishimoto \& Lima, 2007] Nishimoto, K., \& Lima, J. 2007. Tecnologias de análise e experimentação aplicadas a sistemas oceânicos. ANP. 89

[Pesce et al., 2006] Pesce, Celso P., Fujarra, André L.C., \& Kubota, Leonardo K. 2006. The Hilbert-Huang Spectral Analysis Method Applied to VIV. OMAE. 51

[Rateiro, 2010] Rateiro, F. 2010. Análise dinâmica acoplada de risers e linhas de ancoragem em sistemas flutuantes de produção de petróleo e gás natural. Dissertação de Mestrado, Escola Politécnica da USP, São Paulo. , 6, 12, 61, 75, 88, 90

[Simos \& Fujarra, 2004] Simos, A.N., \& Fujarra, A.L.C. 2004. Dynamic Tension on Mooring Lines. Comparison of Numerical and Experimental Results. ISOP. 113

[Simos et al., 2008] Simos, A.N., Sparano, J.V., Aranha, J.A.P., \& Matos, V.L.F. 2008. 2nd Order Hydrodynamic Effects on Resonant Heave, Pitch and Roll Motions of a Large-volume Semi-submersible Platform. OMAE. 6, 114

[SNAME, 1984] SNAME. 1984. Principles of Naval Architecture. 7

[WAMIT, 2006] WAMIT. 2006. WAMIT User Manual 6.3. Massachusetts Institute of Technology. 89

[Yang et al., 1985] Yang, J.C.S, Marks, C.H., Jiang, J., Chen, D., Elahi, A., \& W.Tsai. 1985. Determination of fluid damping using random excitation. Journal of Energy Resources Technology,ASME, 105, 220-225. 49 


\section{Anexo A - Características dos Tanques de Provas}

Neste anexo estão presentes algumas características dos tanques de provas nacionais e internacionais, além de exemplos de tipos de facilidades existentes.

\section{A.1 Características Gerais dos Tanques Nacionais}

Os principais tanques de provas nacionais para o estudo do comportamento de sistemas oceânicos são o do Instituto de Pesquisas Tecnológicas do Estado de São Paulo-IPT, o LabOceano-UFRJ, o tanque do Departamento de Engenharia Naval, Oceânica-USP e o Calibrador Hidrodinâmico do Tanque de Provas Numérico (TPN).

\section{A.2 Tanque do Instituto de Pesquisas Tecnológicas do Estado de SP}

O tanque de provas do IPT é uma estrutura com $280 \mathrm{~m}$ de comprimento, 6,6 $\mathrm{m}$ de largura e $4 \mathrm{~m}$ de profundidade. Os modelos são monitorados e rebocados a fim de avaliar tanto seu desempenho hidrodinâmico, quanto a propulsão mais adequada a cada tipo de embarcação. No caso de plataformas oceânicas, as avaliações de desempenho monitoradas são feitas sob a simulação de ondas que representam as condições em alto mar.

Com o objetivo de auxiliar a construção de modelos o IPT possui um braço mecânico capaz de produzir modelos de alta precisão (ver Figura A.2).

O IPT também possui um sistema de ensaio cativos do tipo PMM (Planar Motion Mechanism) para ensaios de oscilação forçada horizontal ou de manobrabilidade (ver Figura A.3). Este dispositivo auxilia a avaliação de importantes variáveis como ângulo de incidência, velocidade de yaw, aceleração de sway e aceleração de yaw, para determinar os 
Tabela A.1: Dimensões do tanque do IPT

\begin{tabular}{lc}
\hline Comprimento total & $280 \mathrm{~m}$ \\
\hline Largura total & $6,6 \mathrm{~m}$ \\
\hline Profundidade & $4 \mathrm{~m}$ \\
\hline Velocidade de reboque máxima & $3 \mathrm{~m} / \mathrm{s}$ \\
\hline Número de geradores & 2 \\
\hline
\end{tabular}

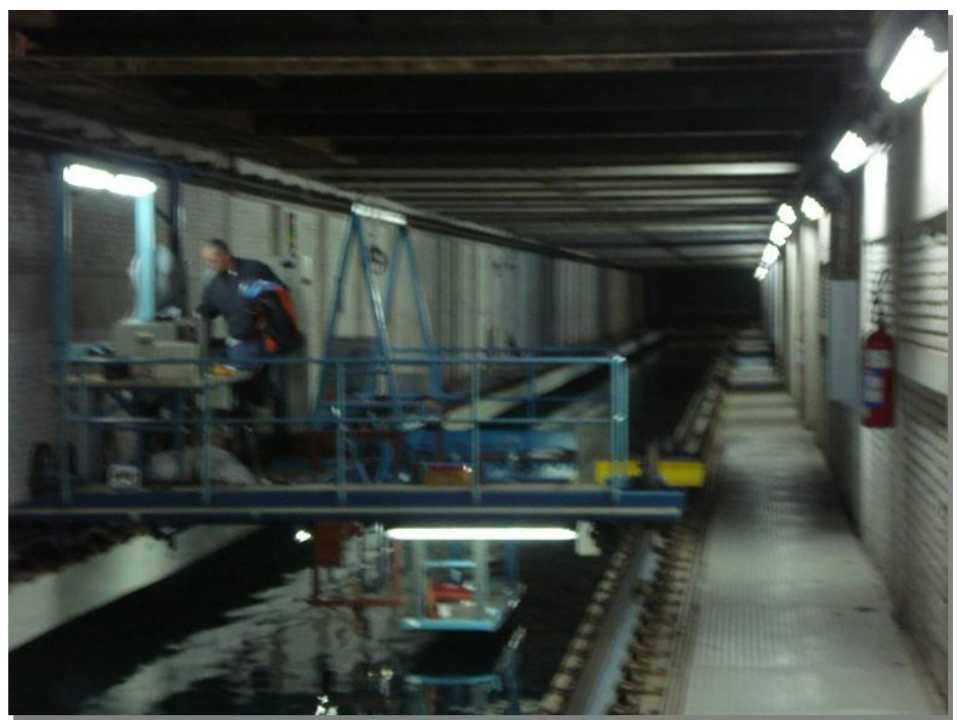

Figura A.1: Carro de reboque no tanque do IPT

coeficientes hidrodinâmicos que são utilizados nas equações de movimento dos simuladores numéricos.

\section{A.3 Laboratório de Tecnologia Oceânica - LabOceano}

O Laboratório de Tecnologia Oceânica - LabOceano, em operação desde abril de 2003, foi projetado com a finalidade de realizar ensaios de modelos de estruturas e equipamentos usados nas atividades de exploração e produção de petróleo e gás offshore, cujas operações avançam rapidamente para regiões de até $3000 \mathrm{~m}$ de profundidade.

Com uma profundidade de $15 \mathrm{~m}$ e um poço central com 10m adicionais (ver Tabela 4.2), é equipado com sistemas geradores de ondas multidirecionais, com geradores de correntes e ventos. 


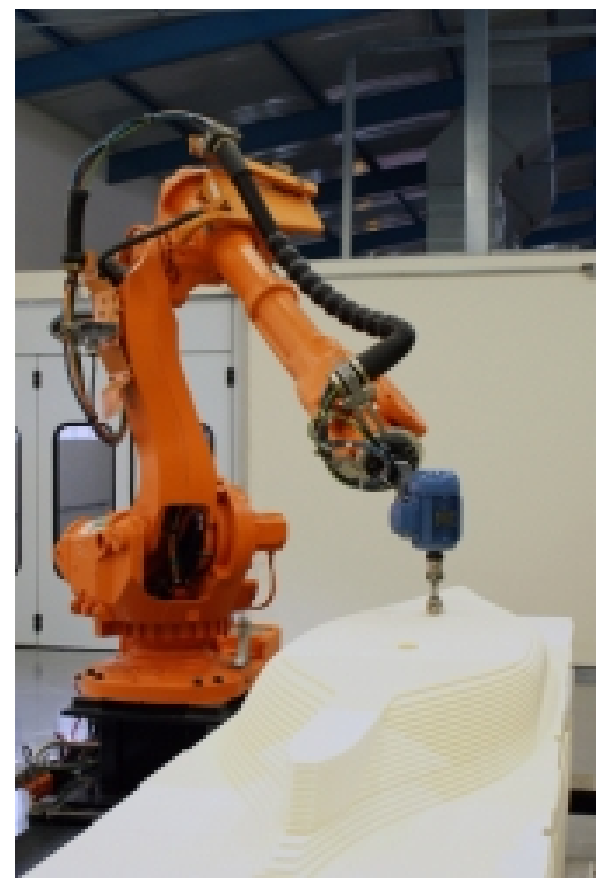

Figura A.2: Construção de modelo no tanque de provas do IPT

Tabela A.2: Dimensões do tanque do LabOceano

\begin{tabular}{ll}
\hline Comprimento total & $40 \mathrm{~m}$ \\
\hline Largura total & $30 \mathrm{~m}$ \\
\hline Profundidade & $15 \mathrm{~m}$ \\
\hline Poço central & $10 \mathrm{~m}$ \\
\hline
\end{tabular}




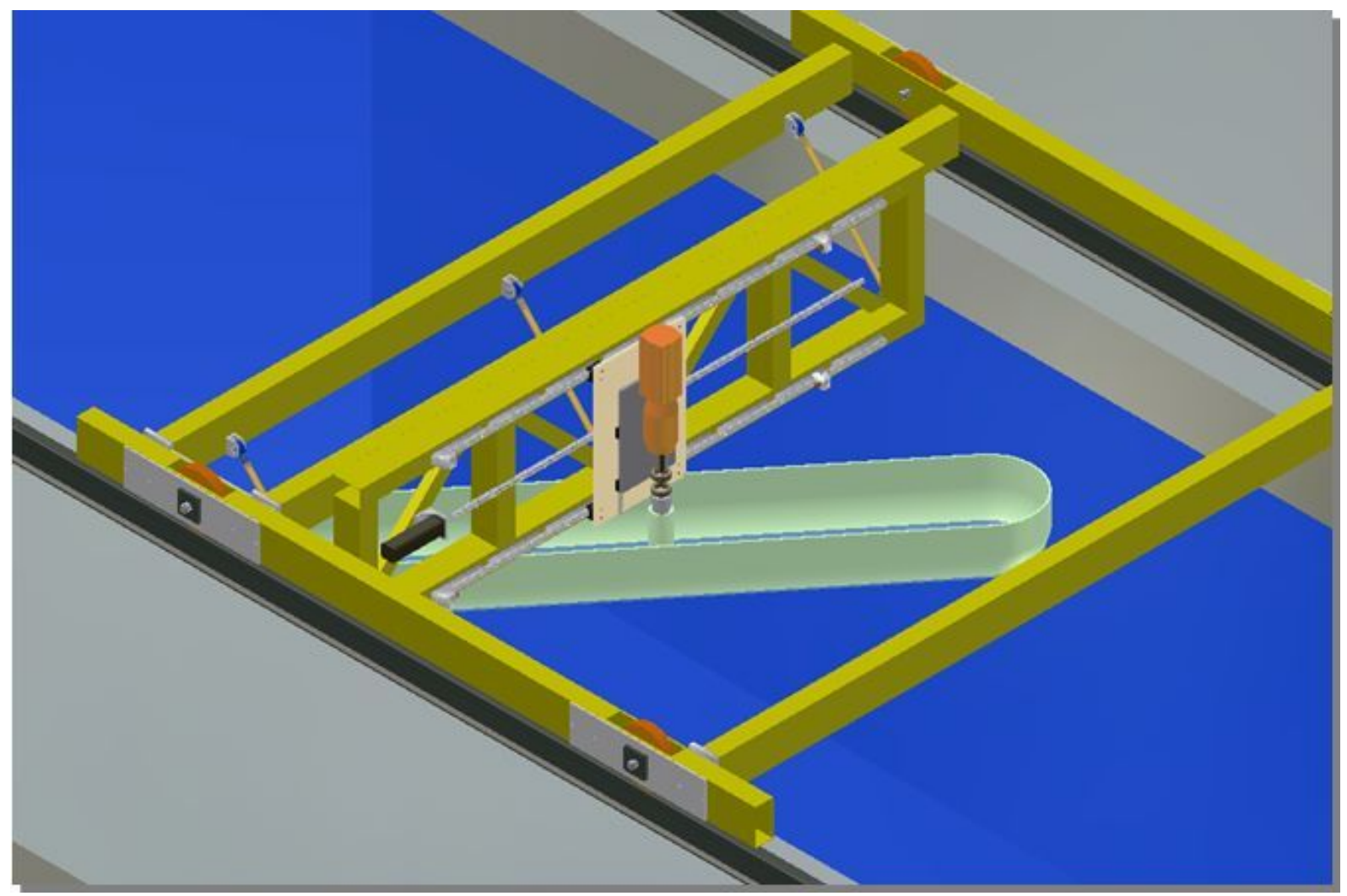

Figura A.3: Carro do sistema PMM

\section{A.4 Tanque do Departamento de Engenharia Naval e Oceânica da USP}

O tanque de provas do Departamento de Engenharia Naval e Oceânica da Universidade de São Paulo (DENO-USP) é um tanque de pequenas dimensões mais que possibilita investigações preliminares dos sistemas oceânicos. Suas principais dimensões são: comprimento de 21,61 m, largura de 4,85 m e profundidade máxima de 1,78 m (ver Figura A.5). Seu gerador de ondas é composto por um único flap com a mesma largura do tanque, sendo localizado a 1,32 metros da parede do tanque. Dada à inércia do gerador e o comprimento do tanque, as ondas geradas estão no intervalo de 0,5 a 2,0 Hz;

Para atenuar o efeito de reflexão de onda a parede oposta ao gerador, conta com uma praia de dois níveis de inclinação 8 e 11 graus conforme ilustrado na Figura A.6.

\section{A.5 Calibrador Hidrodinâmico - TPN}

O Calibrador Hidrodinâmico é o resultado da necessidade de ensaios mais rápidos para o ajuste das simulações no TPN. Com as características de um tanque oceânico, mas 


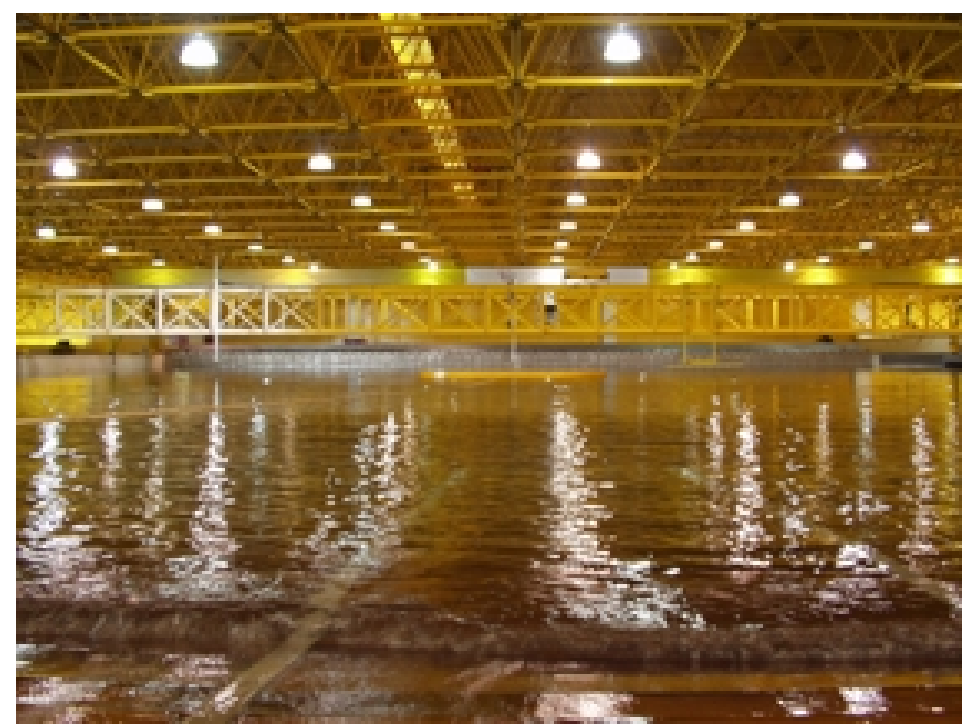

Figura A.4: Laboratório de Tecnologia Oceânica - LabOceano

Tabela A.3: Dimensões do Calibrador Hidrodinâmico

\begin{tabular}{lc}
\hline Comprimento total & $20 \mathrm{~m}$ \\
\hline Largura total & $20 \mathrm{~m}$ \\
\hline Profundidade & $4 \mathrm{~m}$ \\
\hline Comprimento útil (entre flaps) & $14 \mathrm{~m}$ \\
\hline Número de geradores/absorvedores & 148 \\
\hline
\end{tabular}

uma profundidade de $4 \mathrm{~m}$, e sem a geração de vento ou correnteza, o principal diferencial desse tanque é a presença de geradores de ondas ao redor de toda a seção de testes, o que possibilita além da geração de ondas multidirecionais, também a absorção das mesmas, bem como as ondas refletidas do próprio modelo. As características do calibrador hidrodinâmico estão apresentadas na Tabela A.3.

Na Figura A.7 é possível verificar os limitantes dos geradores de onda, bem como uma comparação com os espectros de algumas ondas centenárias usuais em projetos para um modelo em escala $1 / 100$.

Outro dispositivo que é utilizado no CH-TPN, para a avaliação de massas adicionais e amortecimentos, é o sistema de oscilação forçada apresentado na Figura A.8.

Nas mesmas instalações também é possível visualizar os resultados de simulações numéricas e experimentais de uma forma bem particular. Um observador pode ver o estado de mar em uma projeção, mostrado na Figura A.9, e simultaneamente sentir os movimentos quando sentado sobre uma base móvel que representa os seis graus de liberdade do sistema flutuante observado. 


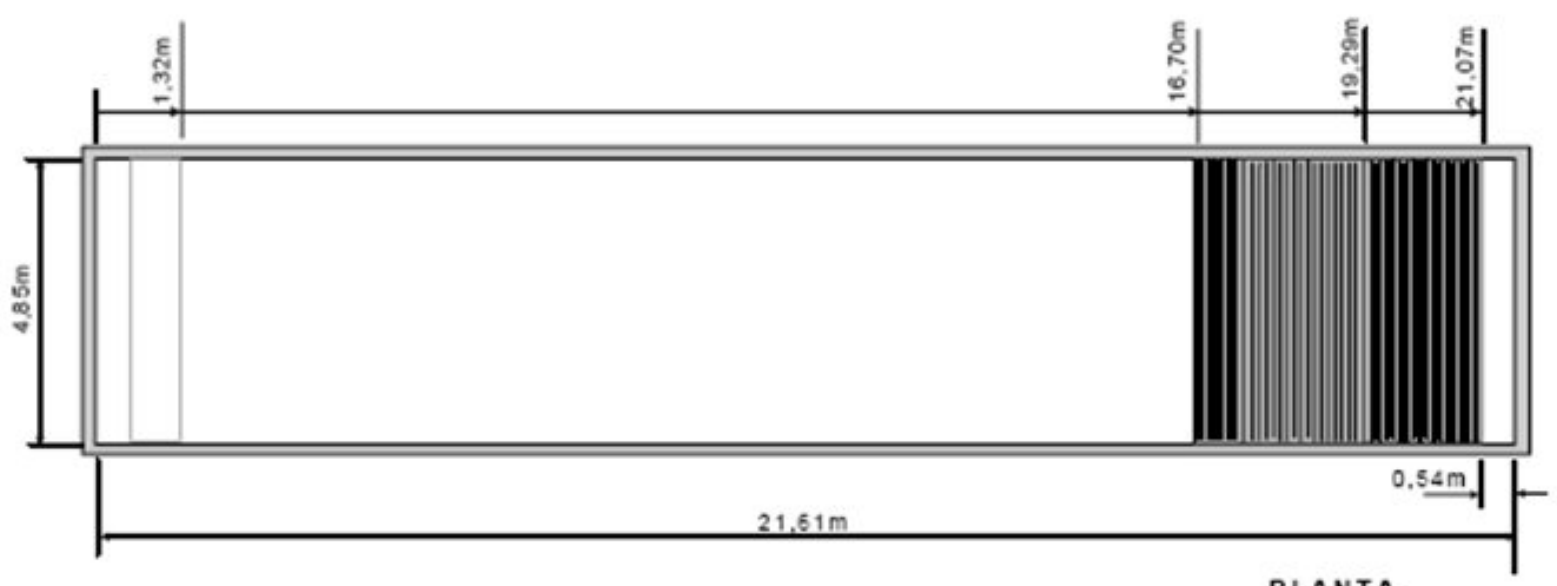

PLANTA

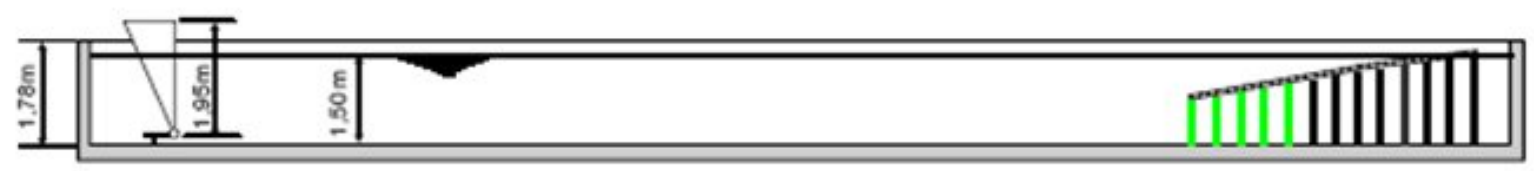

PERFIL

Figura A.5: Dimensões principais do tanque de provas DENO-USP

\section{A.6 Características de Tanques no Mundo}

Conforme apresentado em [Chakrabarti, 1994], as características dos principais tanques do mundo, principalmente os que realizam ensaios de sistemas oceânicos para águas ultra profundas, são apresentados na Tabela A.4. Também pode ser vista uma imagem na Figura A.10 das instalações do David Taylor, maior tanque do mundo e uma imagem da sua oficina de modelos na Figura A.11.

O Deep Sea Basin do NMRI Japão na Figura A.12, com características semelhantes

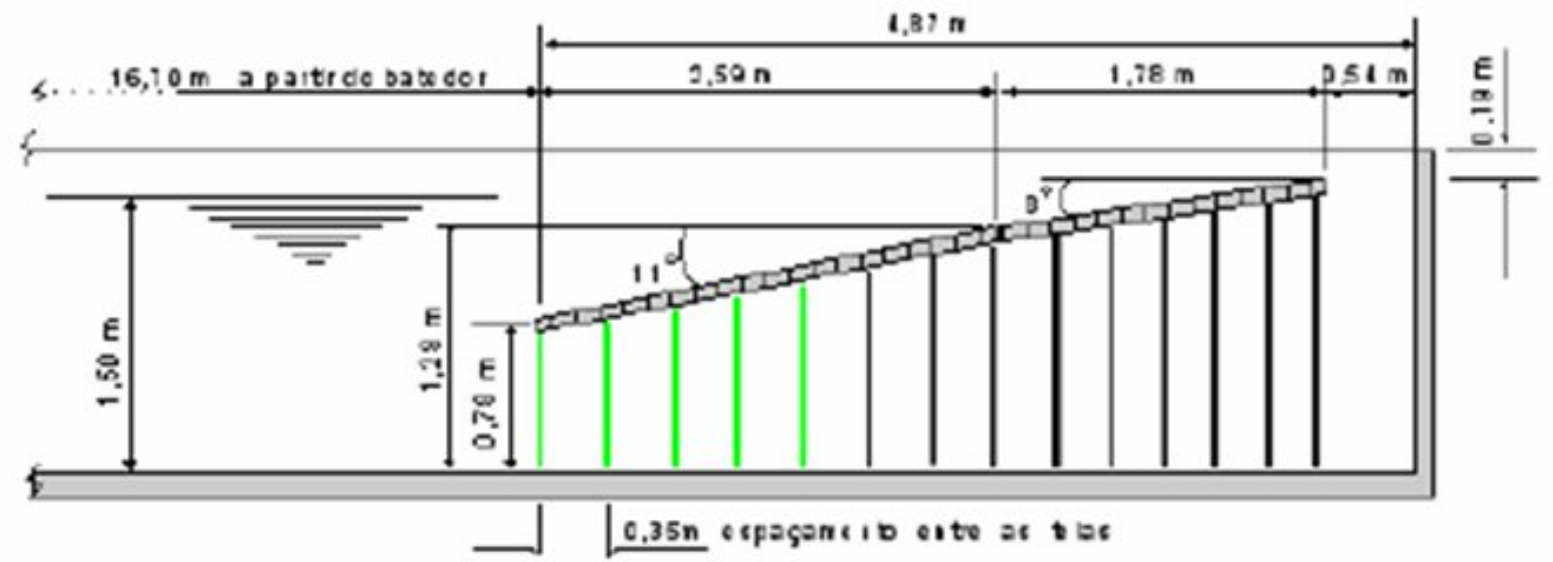

Figura A.6: Dimensões principais do atenuador de ondas DENO-USP 


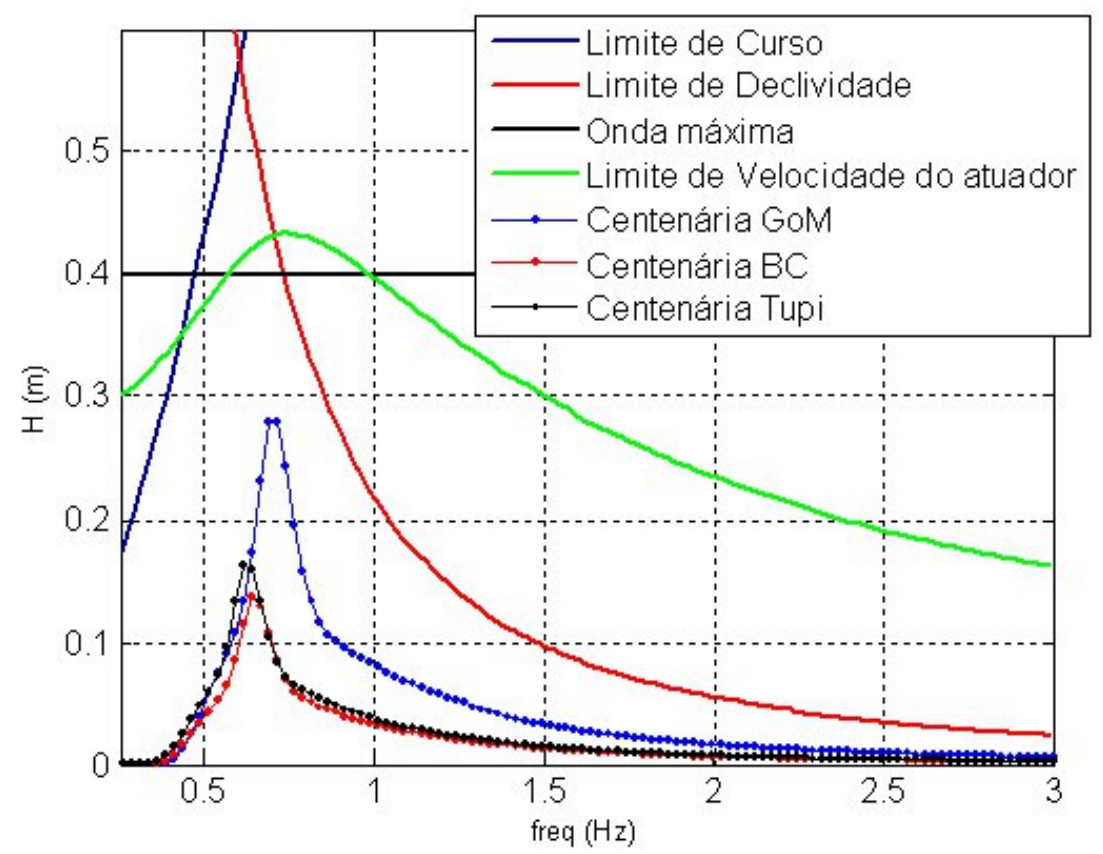

Figura A.7: Capacidade de geração de ondas do CH-TPN

ao CH-TPN, também possuí a capacidade de geração e absorção de ondas. Este tanque possui um poço de $30 \mathrm{~m}$ de profundidade, onde podem ser ensaiados modelos de TLP.

Neste caso, o comprimento dos modelos de tendões deve ser ajustado com muita precisão, pois como são feitos de material rígido, qualquer diferença milimétrica pode causar uma variação na pré-tração dos modelos, ainda mais que a pré-tração só pode ser ajustada pela diferença do peso e empuxo do casco da TLP (ver Figura A.13). Os resultados deste ensaio estão apresentados em [Malta et al., 2009].

Uma das facilidades presentes em alguns tanques são as balanças de inércia. Este arranjo pertence ao dispositivo do Offshore Model Basin, localizado na cidade de Escondido, EUA. A balança de inércia possui um suporte para que o modelo seja posicionado e apoiado sobre facas ajustadas para a altura do VCG do modelo, possibilitando assim, a avaliação da inércia do modelo.

Na Tabela A.4 estão presentes algumas características de tanques de provas em todo o mundo. 
Tabela A.4: Principais característica dos tanques no mundo

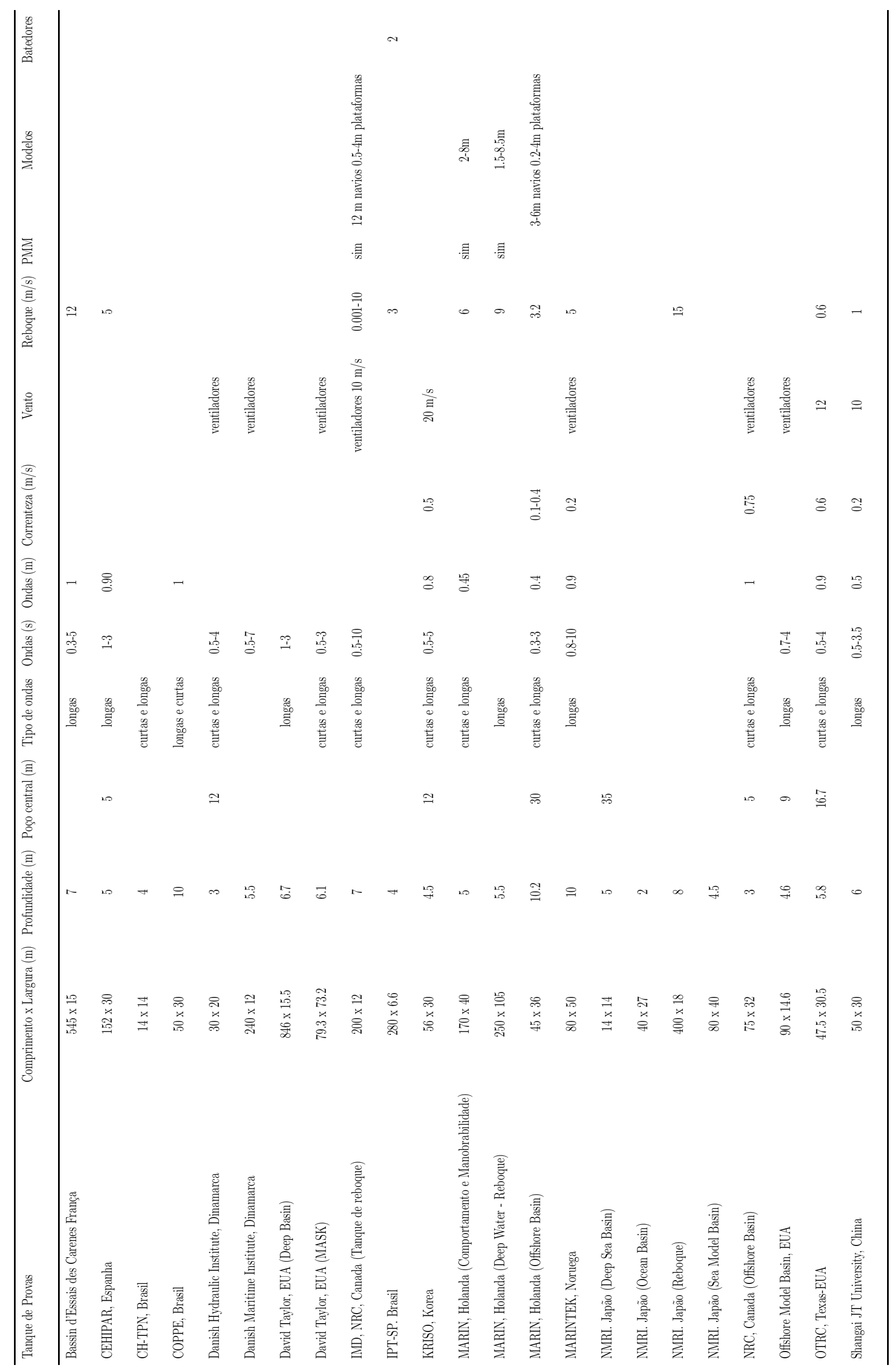




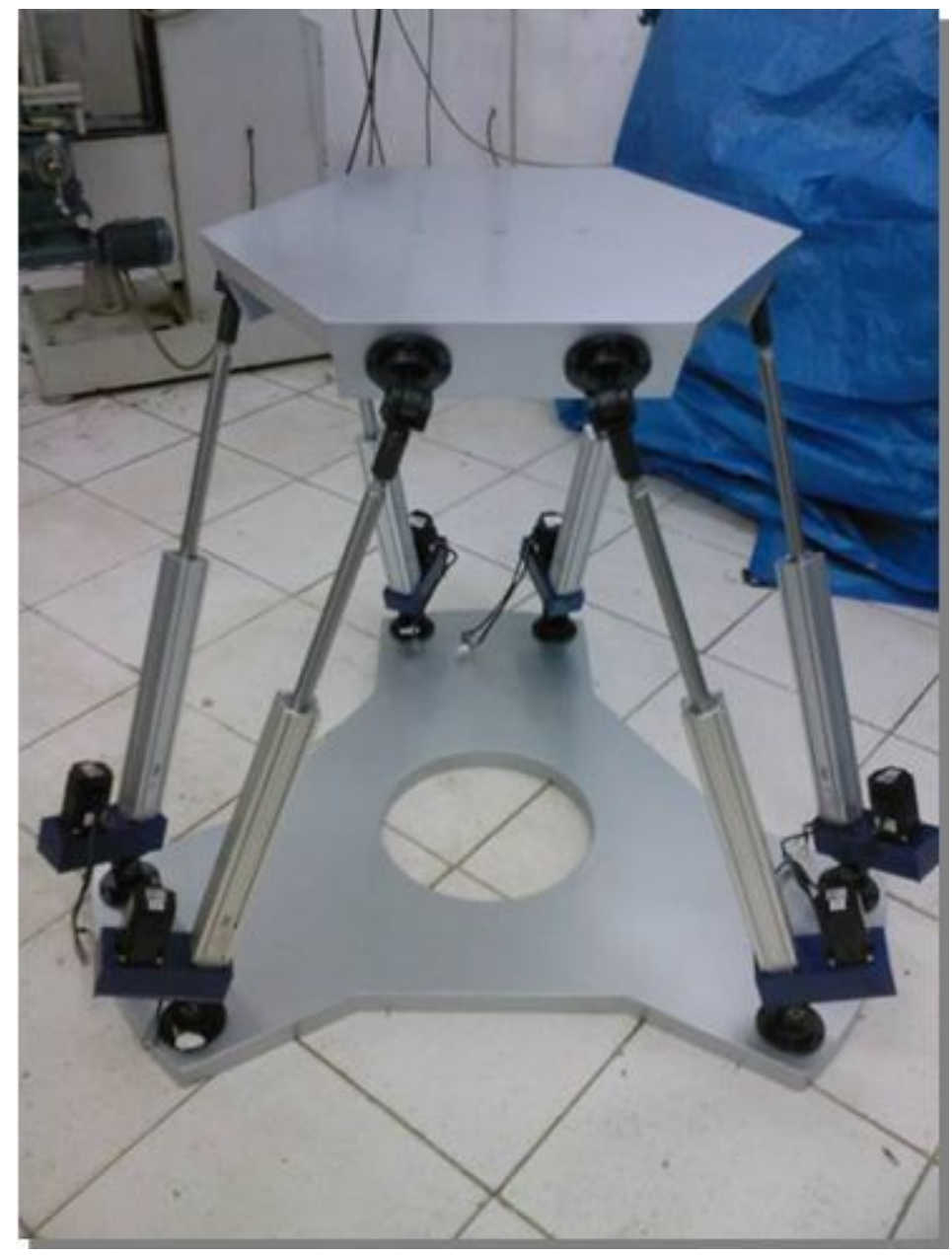

Figura A.8: Sistema de Oscilação Forçada

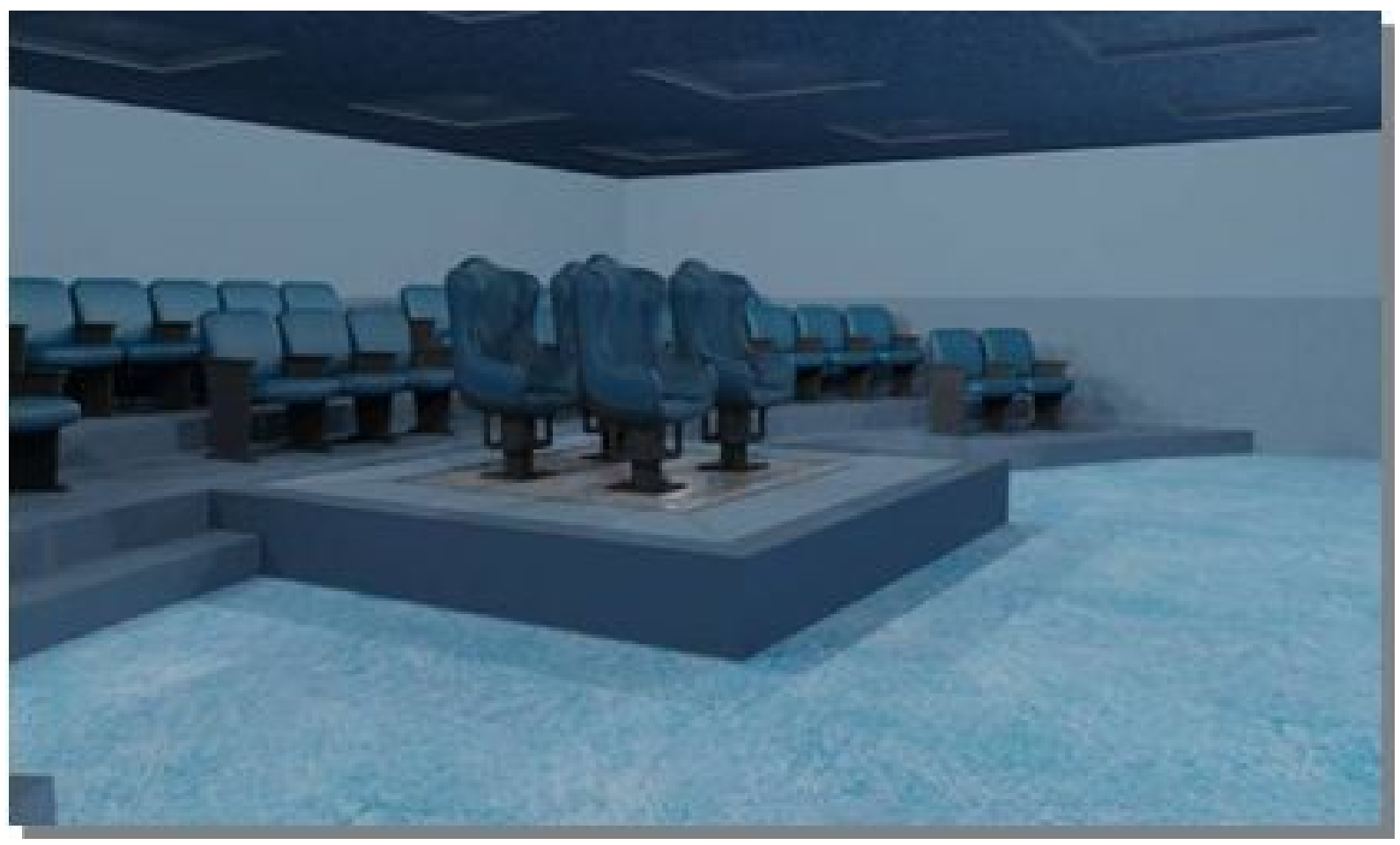

Figura A.9: Sala de Visualização 


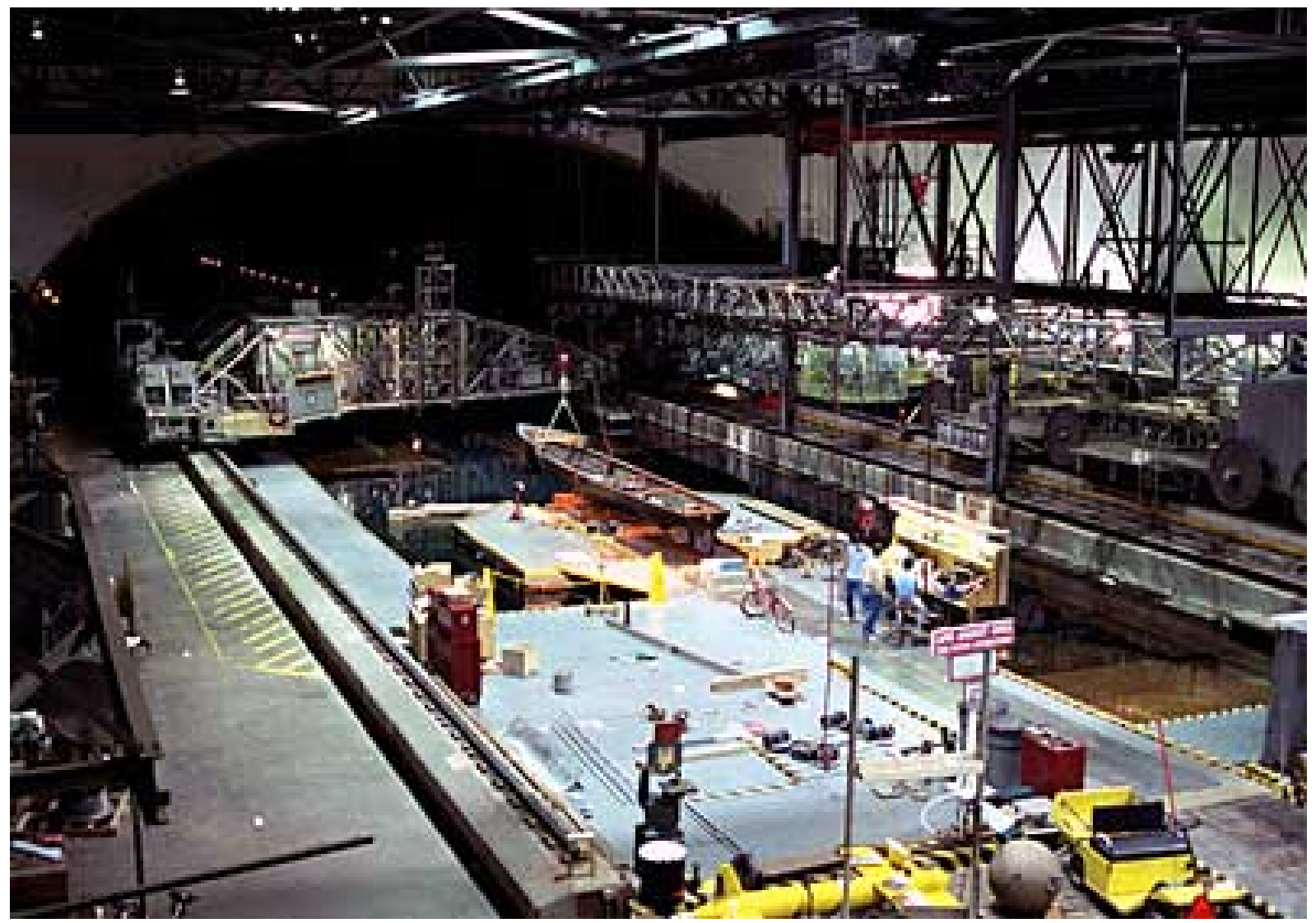

Figura A.10: David Taylor - Deep Sea Basin

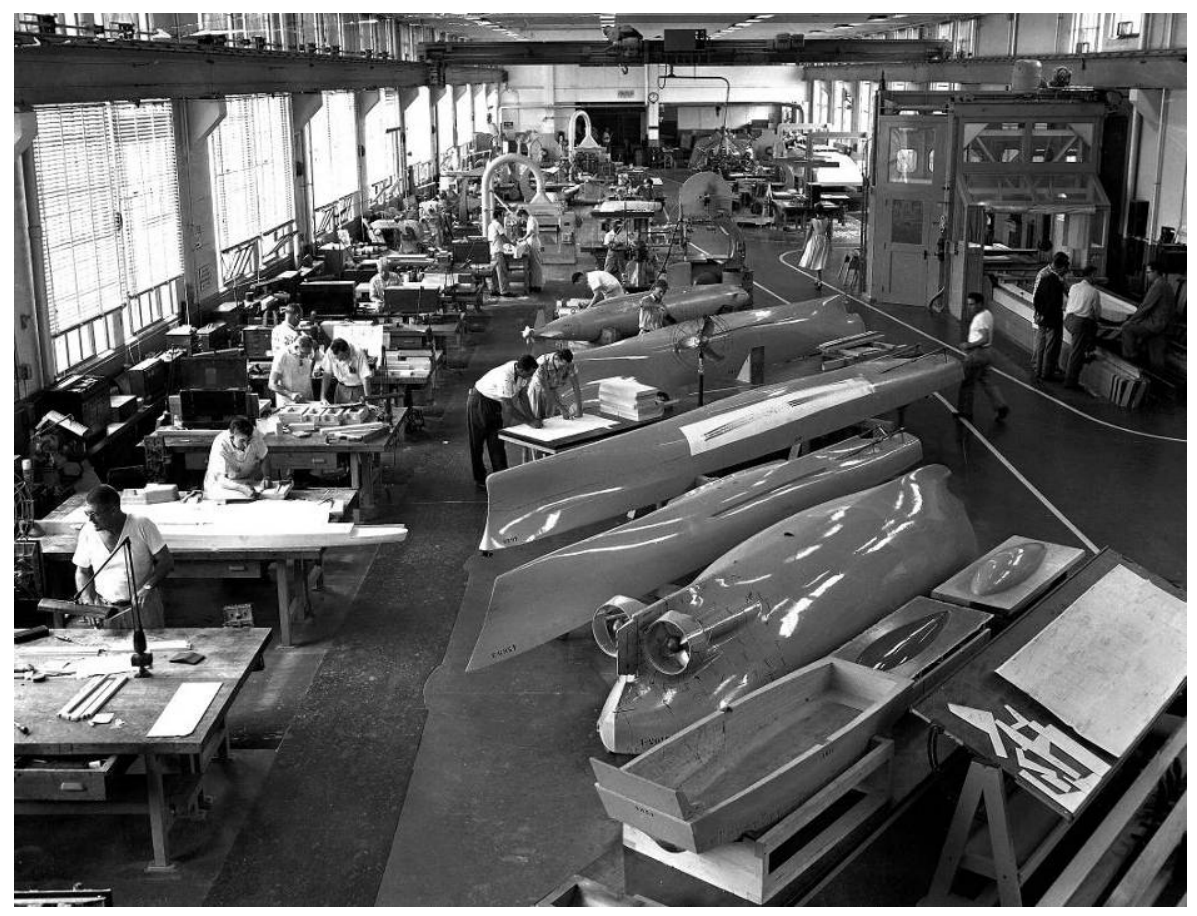

Figura A.11: Exemplo da oficina de modelo do Tanque David Taylor 

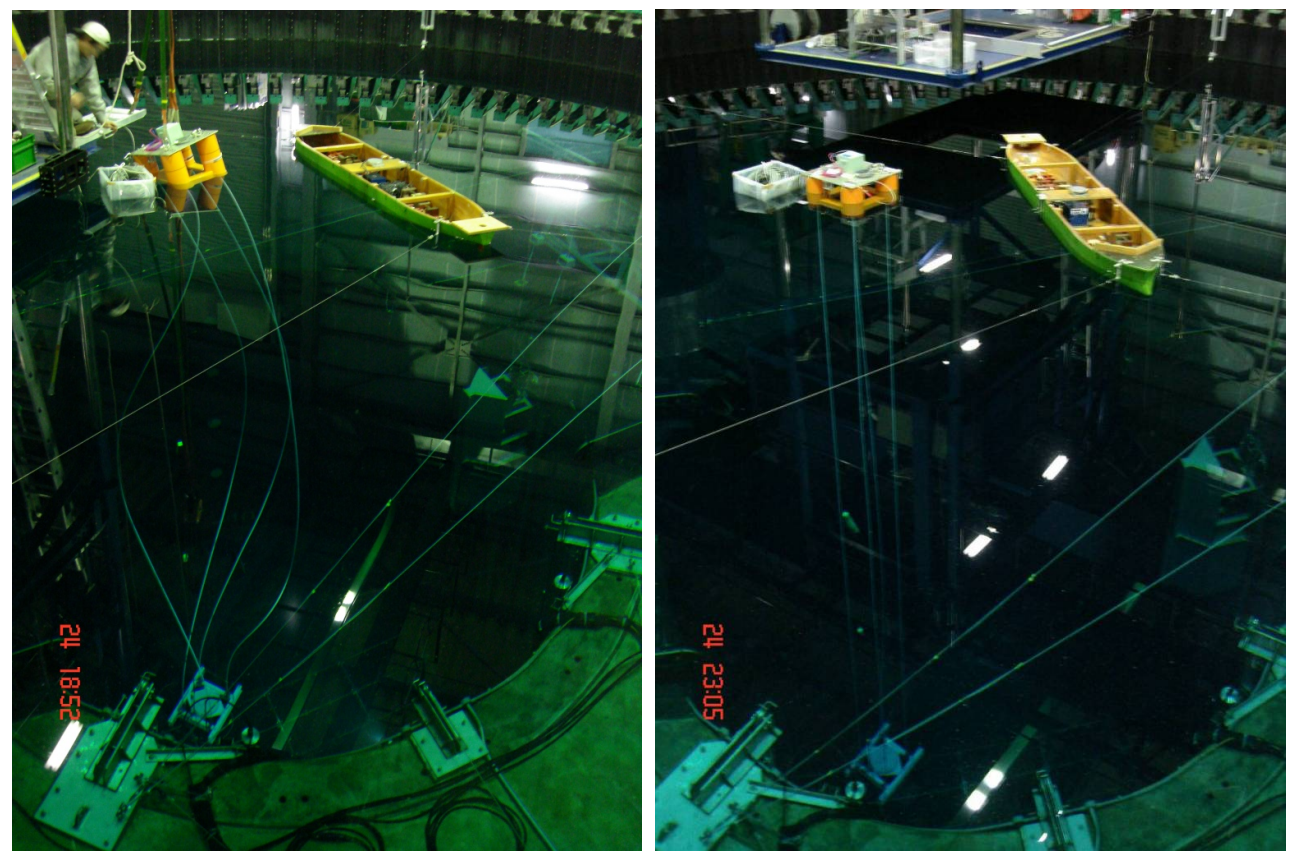

Figura A.12: NMRI Japão - Deep Sea Basin - [Malta et al., 2009]

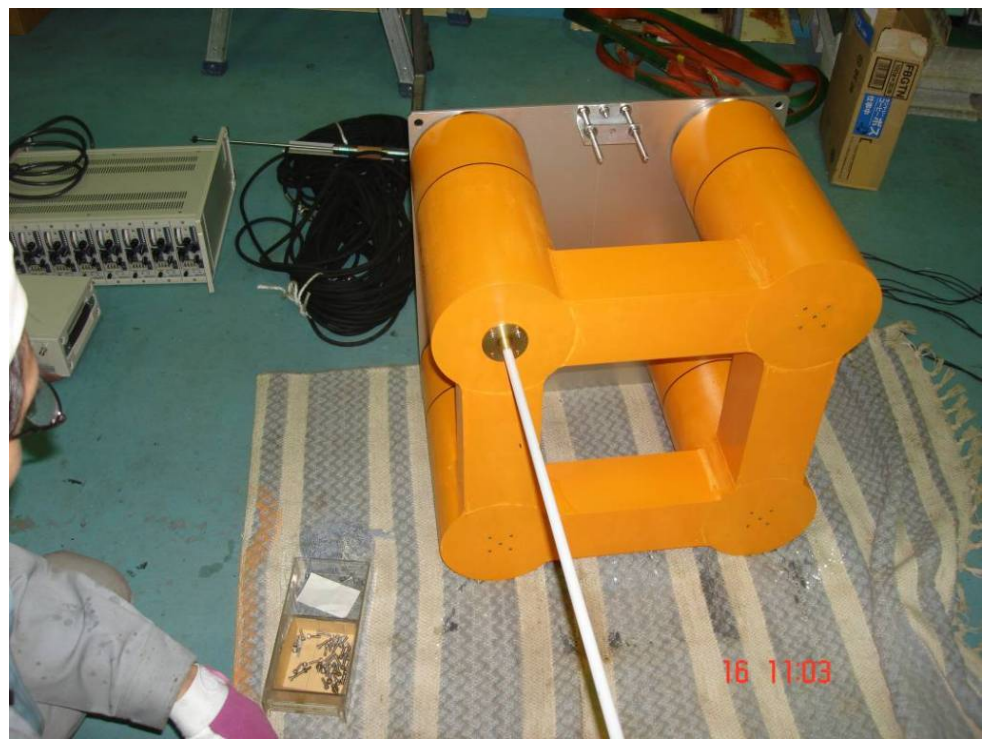

Figura A.13: Visão geral de montagem de ensaio com tendões 

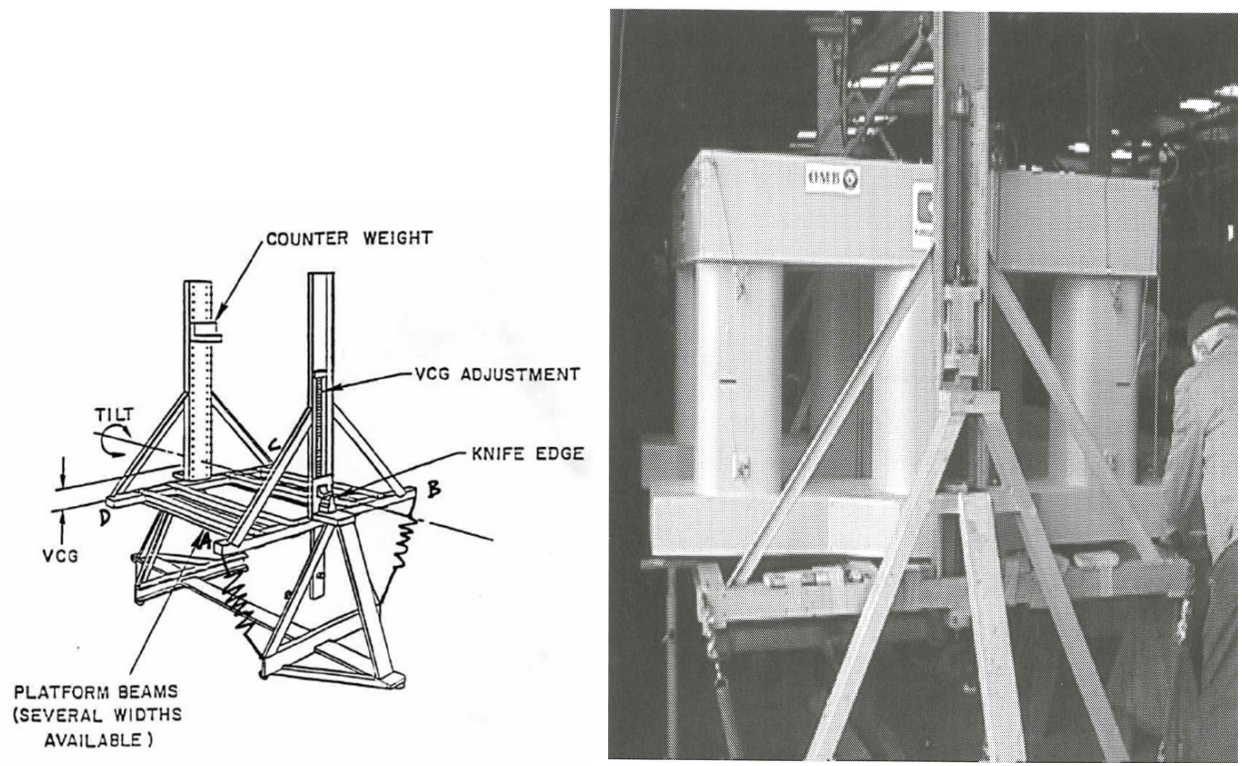

Figura A.14: Balança de inércia do Offshore Model Basin [Chakrabarti, 1987] 


\section{Anexo B - Sistemas Oceânicos}

A idéia básica dos sistemas flutuantes é possuir baixos níveis de movimentos para as condições de mar onde estes serão instaladas. Na Figura B.1 está comparado o período natural de heave de algumas plataformas com três espectros de mares.

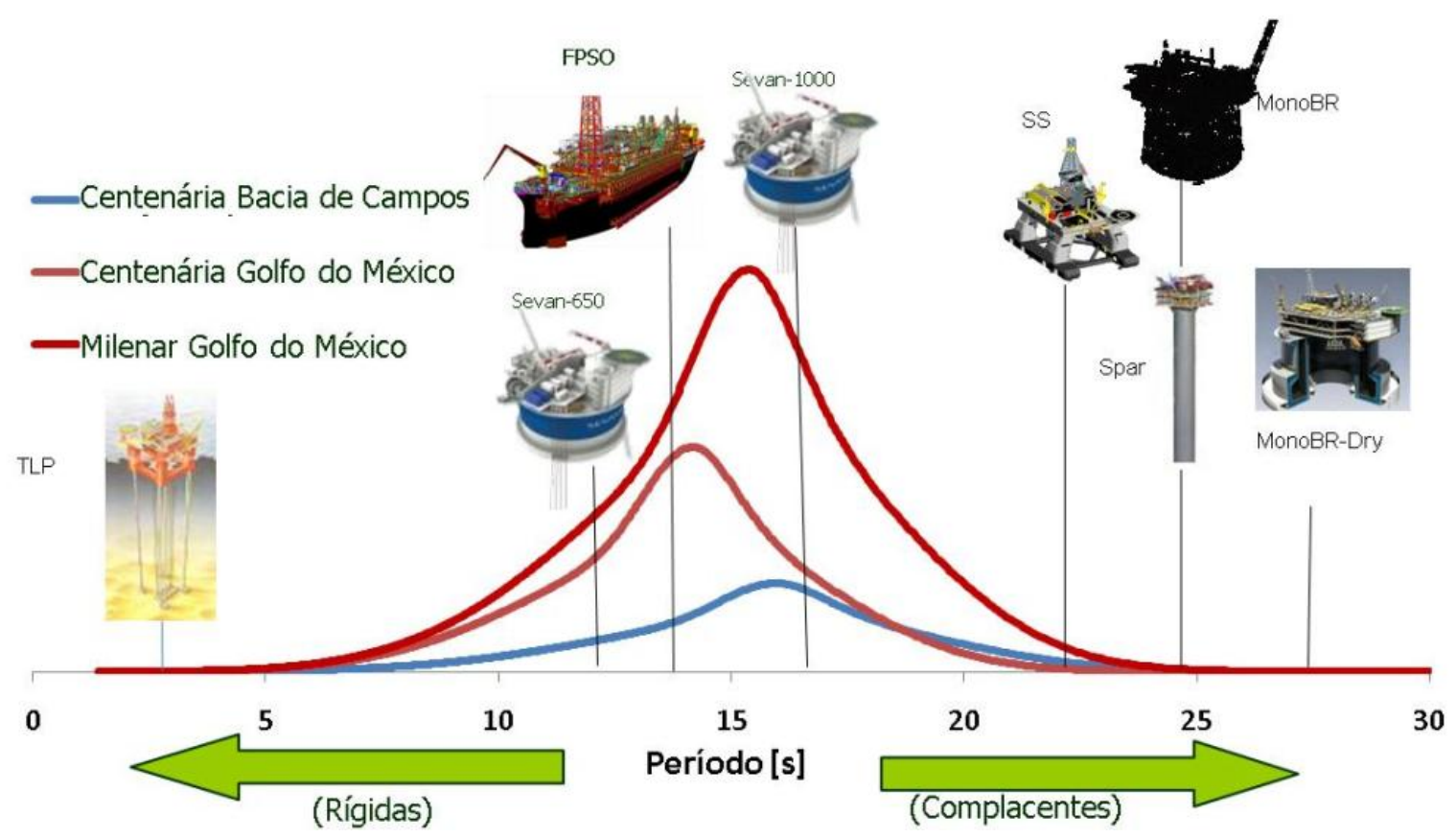

Figura B.1: Comparação entre ressonância dos sistemas e espectros de mar

\section{B.1 Floating, Production, Storage and Offloading - FPSO}

Floating Production Storage and Offloading (FPSO) é uma embarcação pela indústria petrolífera para a exploração, armazenamento de petróleo e/ou gás natural e escoamento da produção para navios aliviadores. São utilizados em locais de produção distantes da 
costa e com inviabilidade de ligação por oleodutos ou gasodutos. No convés da embarcação, como apresentado na Figura B.2, é instalada um planta de processo para separar e tratar os fluidos produzidos pelos poços. Depois de separado da água e do gás, o petróleo é armazenado nos tanques do próprio navio, sendo transferido para um navio aliviador de tempos em tempos. O navio aliviador é um petroleiro que atraca no FPSO para receber petróleo que foi armazenado em seus tanques e transportá-lo para terra. O gás comprimido é enviado para terra através de gasodutos e/ou re-injetado no reservatório. Os maiores FPSOs têm sua capacidade de processo em torno de 200 mil barris de petróleo por dia, com produção associada de gás de aproximadamente 2 milhões de metros cúbicos por dia.

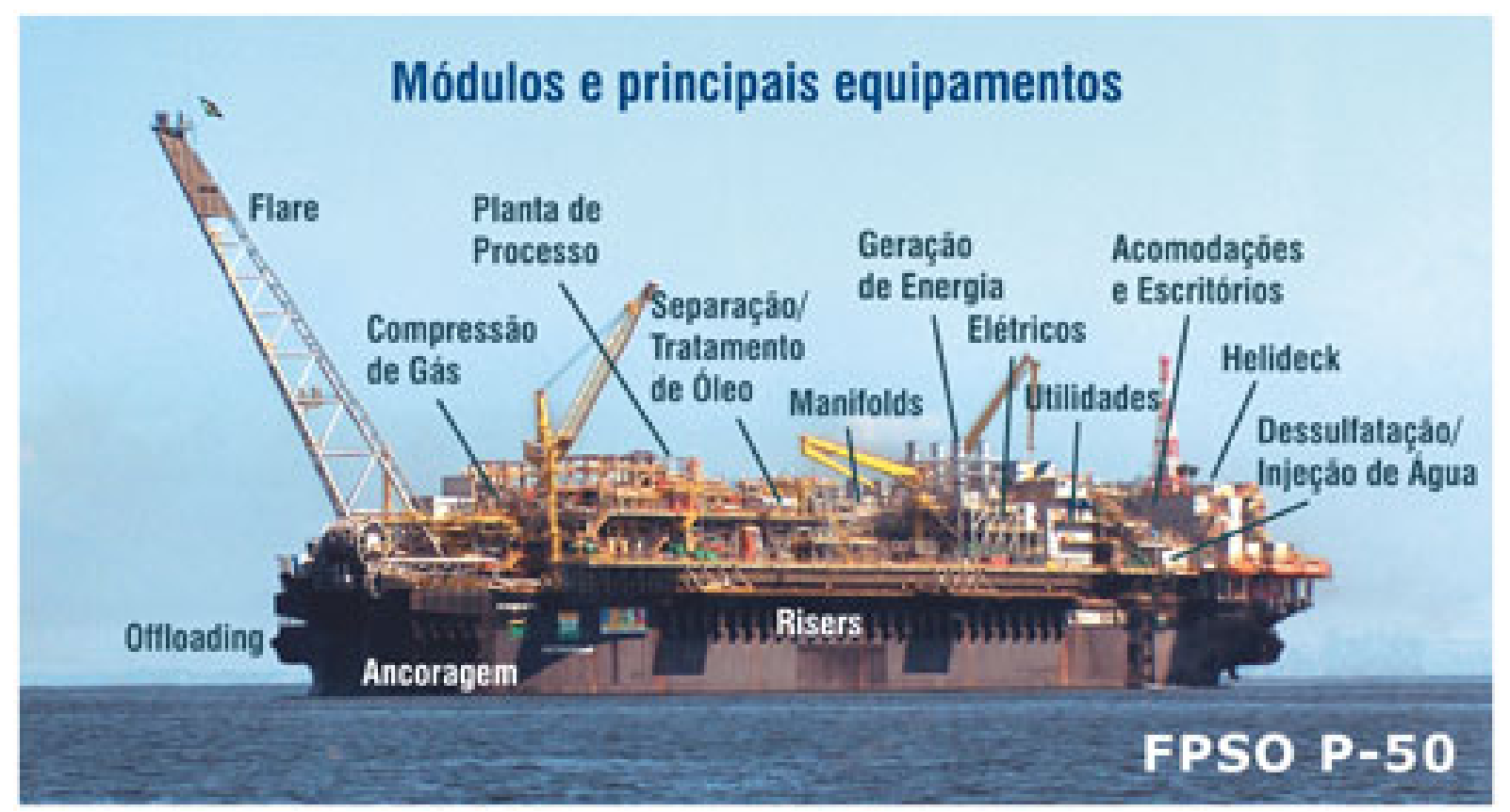

Figura B.2: P-50 - Sistema do tipo FPSO

\section{B.2 Semi-submersíveis}

As plataformas semi-submersíveis são compostas de uma estrutura de um ou mais conveses, apoiados em colunas e flutuadores submersos, podendo ou não ter propulsão própria (ver Figura B.3). De qualquer forma, apresentam grande mobilidade, sendo as preferidas para a perfuração de poços exploratórios.

Esses tipos de plataformas não são adequadas para o armazenamento de óleo e gás, contudo devido à sua área de linha dágua reduzida, possuem um comportamento em ondas melhor do que os FPSO. 

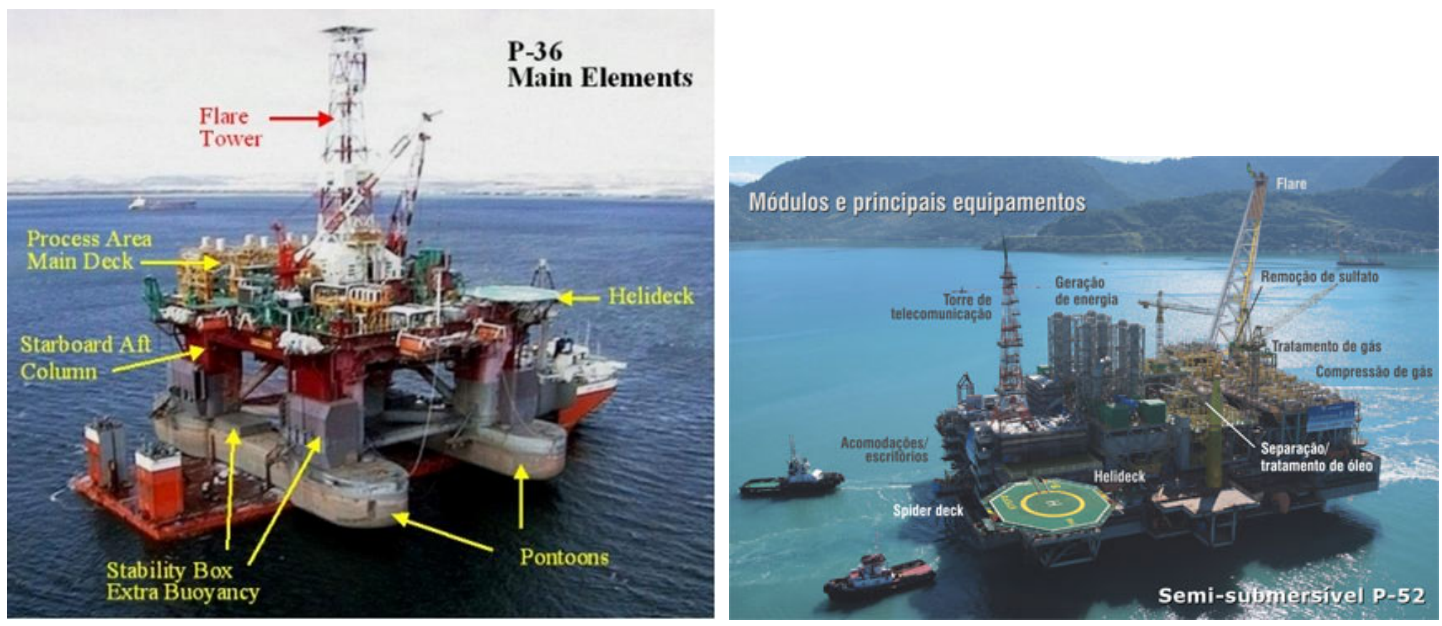

Figura B.3: P-36 e P52 exemplos de sistemas do tipo semisubmersível

\section{B.3 Tension Leg Platform - TLP}

Plataforma de Pernas Atirantadas (Tension-Leg Plataform - TLP) são unidades flutuantes utilizadas para a produção de petróleo. Sua estrutura é bastante semelhante à da plataforma semi-submersível. Porém, sua ancoragem ao fundo mar é diferente: as TLPs são ancoradas por estruturas tubulares chamadas tendões, como mostrado na Figura B.4. Esses tendões são fixos ao fundo do mar por estacas e mantidos tracionados pelo excesso de flutuação da plataforma, o que reduz severamente os movimentos da mesma. Desta forma, as operações de perfuração e de completação são iguais às das plataformas fixas.

A grande vantagem do sistema TLP é a utilização de completação seca . Neste caso, o conjunto de válvulas que controla a produção do poço é simples e de fácil manutenção, assim como o acesso ao poço. Este sistema é dependente de unidades flutuantes de produção com movimentos extremamente reduzidos, de forma a não comprometer a integridade dos risers rígidos que conectam a árvore de natal na superfície à cabeça do poço no fundo do mar.

\section{B.4 Spar}

As plataformas do tipo spar são utilizadas para perfuração e produção para águas ultra profundas. Sua estrutura é composta de um casco de seção transversal circular que se posiciona verticalmente na água, sustentado pelos tanques de flutuação localizados na parte superior do conjunto. Em caso de necessidade, sua estabilidade pode ser aumentada 


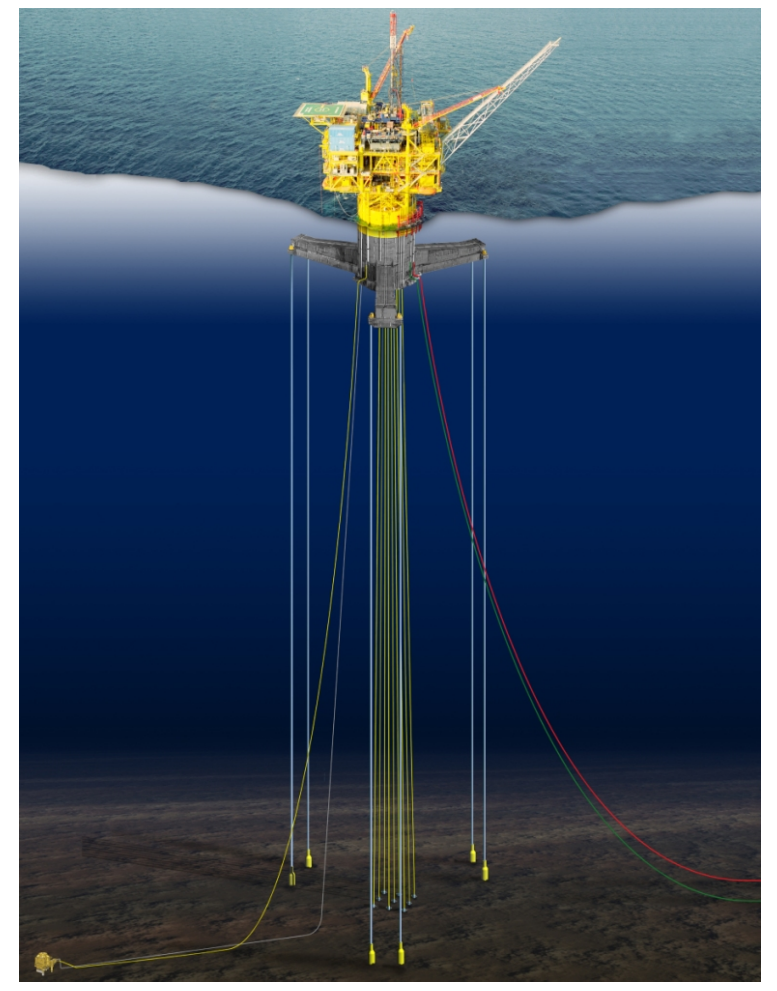

Figura B.4: Seastar - Sistema do tipo TLP

através da adição de lastro sólido nos compartimentos localizados em sua base. Este tipo de unidade possui amplitudes de movimento bastante reduzidas, o que também permite sua utilização em poços de completação seca.

Alguns modelos de spar, como apresentado na Figura B.5, permitem o armazenamento do óleo produzido em tanques internos. Entretanto, em sistemas sem capacidade de armazenamento, o escoamento da produção também deverá ser feito por meio de dutos, ou através de uma unidade de armazenamento de produção auxiliar, ou mesmo navios aliviadores.

\section{B.5 Monocolunas}

As plataformas do tipo mono-coluna têm como característica marcante a utilização de um casco com formato cilíndrico ou cônico, acoplado a sistemas adicionais de redução de movimento. De maneira geral, o conceito assemelha-se às plataformas do tipo spar, porém com calado menor, facilitando os processos de construção, instalação e manutenção.

O movimento reduzido das plataformas do tipo monocoluna é possível através de algumas características peculiares a esse tipo de sistema como o moonpoool, a saia e a 


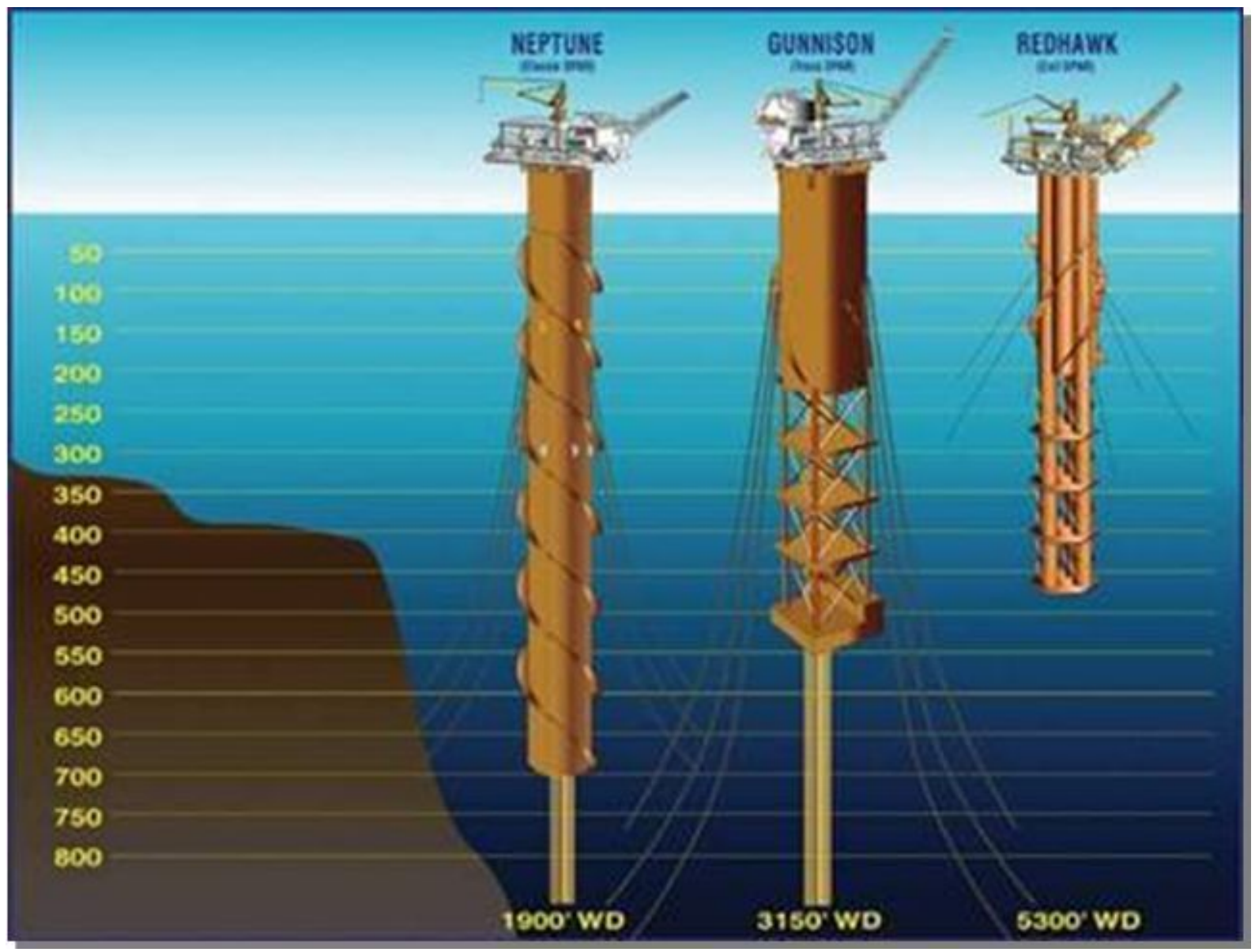

Figura B.5: Exemplos de sistemas do tipo spar

praia (ver Figura B.6).
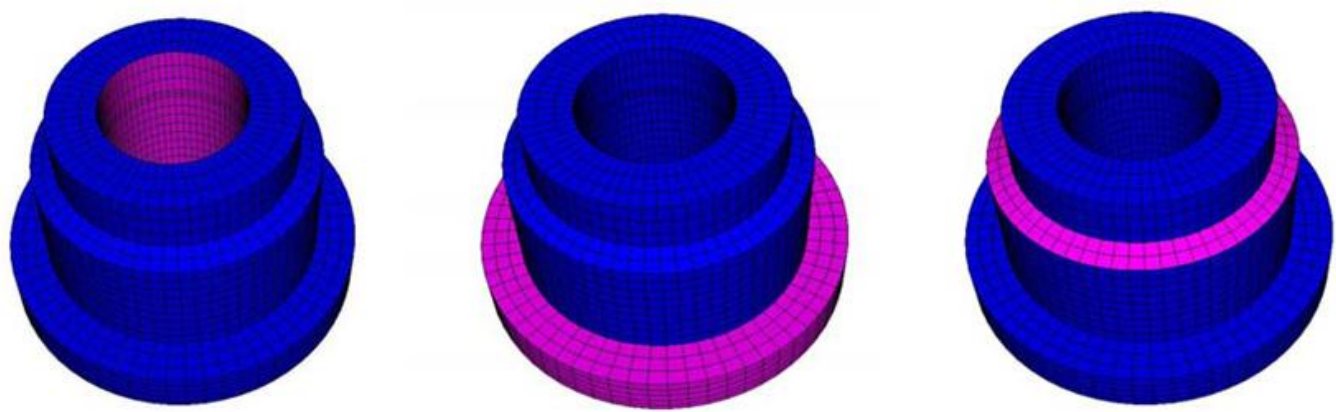

Figura B.6: Moonpool, saia e praia de uma monocoluna

O moonpool consiste em um tanque, normalmente no centro da embarcação, ligado ao oceano através de uma restrição no fundo. Sua aplicação usual visa reduzir o movimento da água interna ao tanque, para que não haja avaria nos equipamentos que serão movimentados através do mesmo. No caso das monocolunas, o moonpoole sua 
restrição foram ajustados para também diminuir os movimentos da plataforma, em particular o vertical.

O uso de bolinas para a redução do movimento de roll em navios é bem conhecido. Embora seu efeito seja proporcional ao aumento de suas dimensões, nos navios existe uma limitação devido ao aumento da resistência ao avanço, o que não é um problema nas plataformas para exploração. Isso pelo fato desses sistemas flutuantes serem estacionários, assim possibilitando o aumento das dimensões da bolina, para transformá-la em uma saia estruturada. Por esse motivo, a saia é utilizada obtendo dois bons efeitos para a monocoluna: o aumento do amortecimento e da massa adicional [Campos et al., 2004].

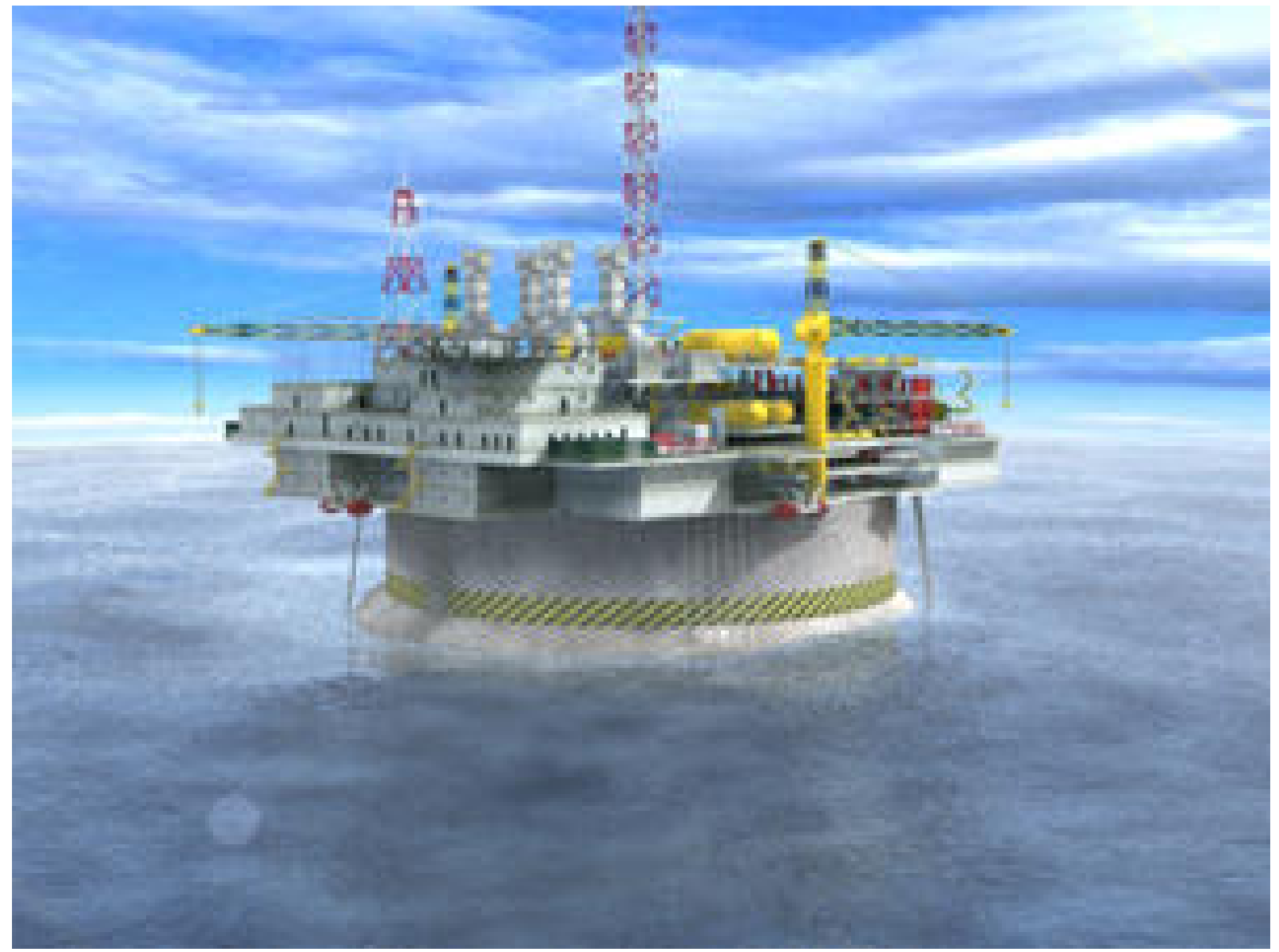

Figura B.7: Exemplo de um sistema do tipo monocoluna 


\section{Anexo C - Tipos de Ensaios}

Neste capítulo estão descritos alguns tipos de ensaios que auxiliam na avaliação de unidades flutuantes e não foram discutidos ao longo do texto. Os ensaios podem ser divididos em três grupos: ensaios cativos, ensaios de oscilação forcada e ensaios de comportamento.

Os ensaios cativos são utilizados para a avaliação de forças de onda, vento ou correnteza nos modelos de sistemas flutuantes. Com o modelo travado a uma estrutura rígida e uma célula de carga para a fixação do modelo, os ensaio cativos em ondas são utilizados para obter as forças de excitação para diversas frequências e incidências.

Outro ensaio cativo, são os de arrasto para representar o efeito de correnteza são utilizados para determinar coeficientes de arrasto e/ou sustentação dos sistemas flutuantes

Os ensaios para determinar as forças envolvidas devido à incidência do vento são utilizados para avaliar os coeficientes de arrasto da superestrutura. Embora esse tipo de ensaio possa ser realizado em um túnel de vento, outra possibilidade é que o modelo seja fixado em um carro dinamométrico de um tanque de reboque para representação da velocidade do vento e posteriormente a diferença entre as densidades da água e do ar são corrigidas para obtenção da força no ar.

Os ensaios de oscilação forçada são utilizados para avaliar os coeficientes devido a radiação de ondas dos sistemas flutuantes. Estes coeficientes que são os termos de massa adicional e amortecimento podem ser comparados com os resultados obtidos numericamente para a calibração dos simuladores. A avaliação dos modelos de linhas e a comparação entre resultados experimentais e numéricos também ser feita através de oscilação forçada e pode ser vistas em [Simos \& Fujarra, 2004].

A avaliação das forças de segunda ordem são essenciais para a estimativa de derivas médias e lentas no plano horizontal, mas também devem ser verificadas as forças de heave, roll e pitch. Apesar das primeiras resultarem em movimentos de grandes amplitudes e ser 
mais comumente consideradas nas simulações numéricas, a avaliação de forças de segunda ordem de heave, roll e pitch, como mostrado em [Simos et al., 2008], pode ter grande influência no movimentos dos sistemas flutuantes.

Os ensaio de comportamento em ondas com correnteza foram apresentados no Capítulo 2.7. Contudo, ensaios em tanque de provas para a avaliação de movimentos induzidos por vórtice (Vortex-Induced Motions - VIM) têm sido realizados principalmente nos sistemas flutuantes do tipo spar e monocolunas. Alguns resultados e detalhamento do procedimento de ensaio escolhido estão presentes em [Gonçalves et al., 2009] e [Fujarra et al., 2009]. 


\section{Anexo D - Tipos de Instrumentação}

Neste anexo estão apresentados outros equipamentos de medição, além dos utilizados no ensaio de influência das linhas na dinâmica de unidades flutuantes que estão descritos no Capítulo 2.3.

Com o desenvolvimento de novas tecnologias de instrumentação, a aplicação nos ensaios em tanque provas visam tanto facilitar a inspeção dos modelos, quanto aumentar a precisão dos resultados obtidos nos testes. Os sistemas por imagem e até mesmo de GPS tem sido utilizados com este propósito.

A aquisição por imagem, é cada vez mais utilizada nos estudos no tanque de provas, devido à sua facilidade de instalação e sua menor influência nas características dos modelos, pois os alvos posicionados no modelo possuem uma massa muito pequena e podem ser desprezados durante a calibração de massa e inércia do modelo. Esse método pode ser utilizado tanto para obter os movimentos da unidade flutuante, quanto o campo de velocidades do fluído.

Um exemplo de aquisição por imagem para um modelo de riser pode ser visto em [Amarante, 2010] e na Figura D.1.

O sistema de Particle Image Velocimetry (PIV) é um método óptico para a visualização da velocidade do fluído. A velocidade instantânea é determinada através da trajetória de partículas dispersas no fluído com as suas posições capturadas por câmeras que emitem feixes de laser (ver Figura D.2).

Os outros equipamentos são mais comuns, como os acelerômetros que medem a aceleração através de strain gages ou extensômetros, calibrados com o auxílio de um condicionador. Na Figura D.3, pode-se ver outro dispositivo construído com extensômetros para a medição de pressão.

O rate gyro, mostrado na Figura D.4, funciona com um arranjo de cristais piezoelétricos que quando solicitados a oscilações angulares fornecem uma voltagem especifica. 


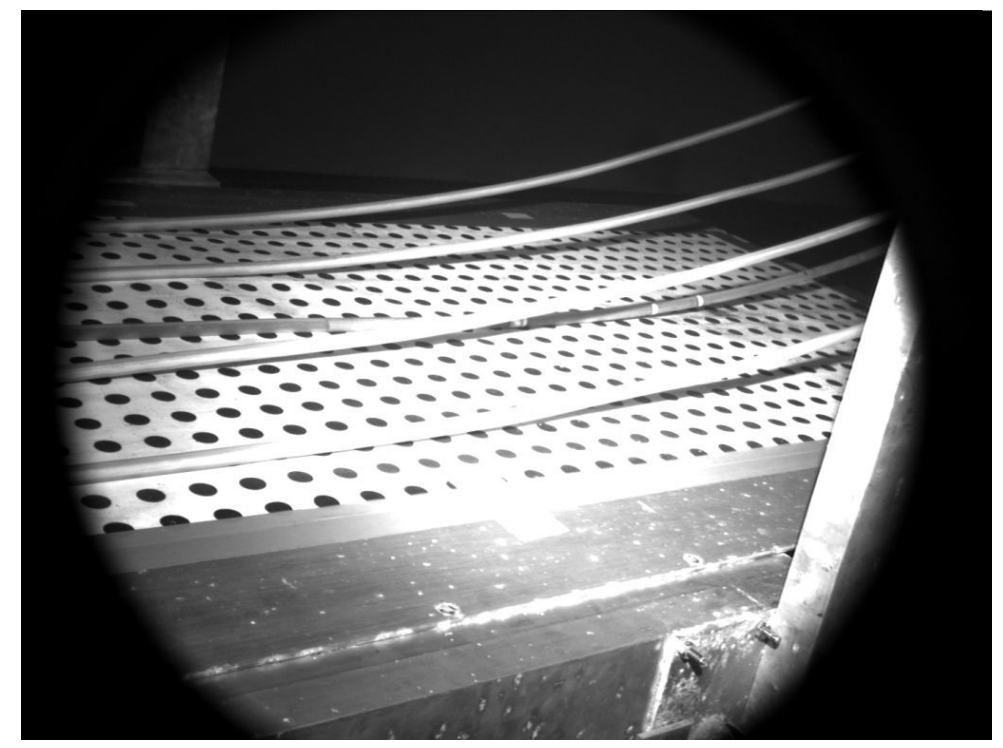

Figura D.1: Imagem utilizada na aquisição do TDP de um modelo de riser

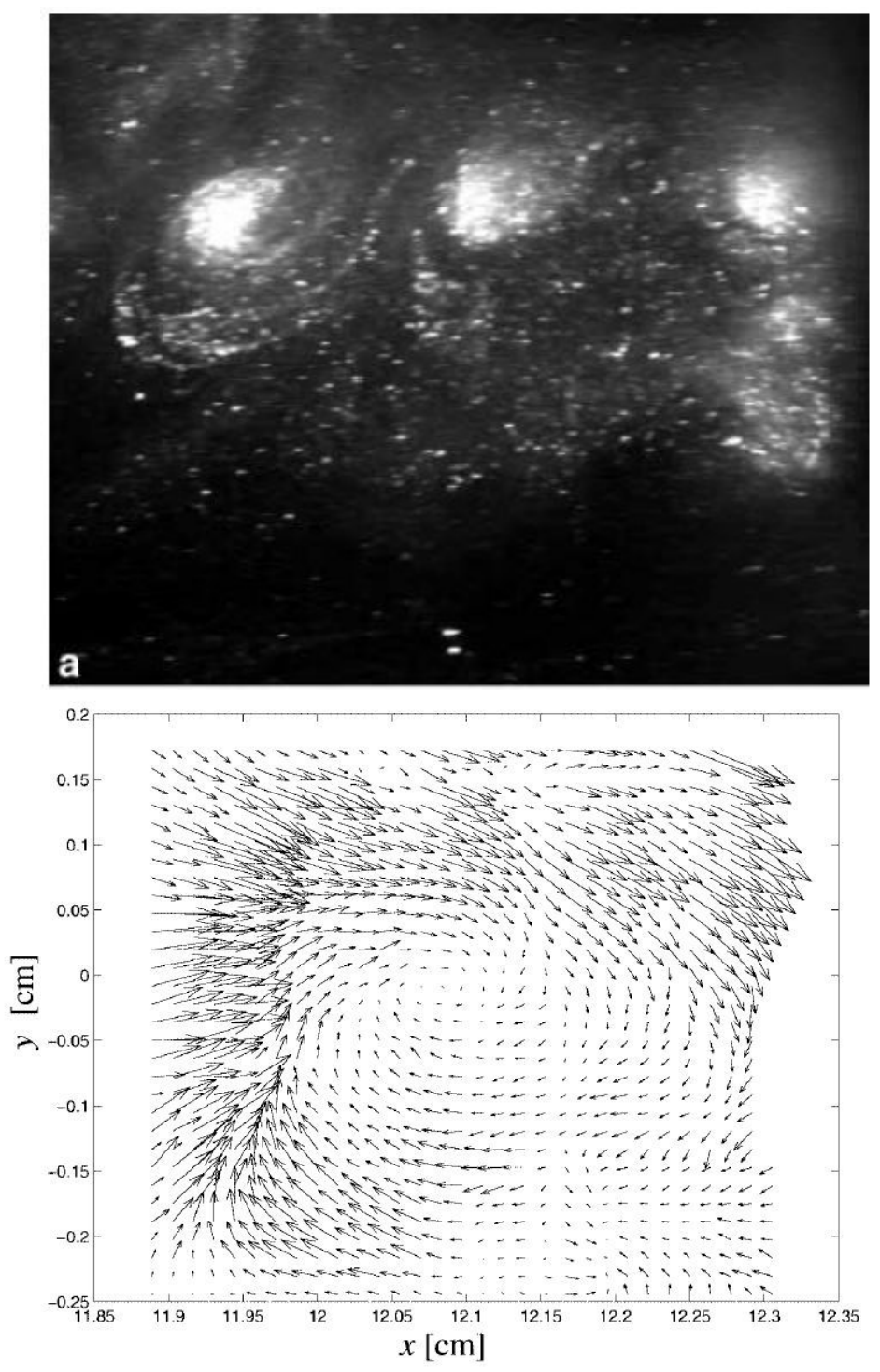

Figura D.2: Exemplo de campo de velocidades através de um análise de PIV 


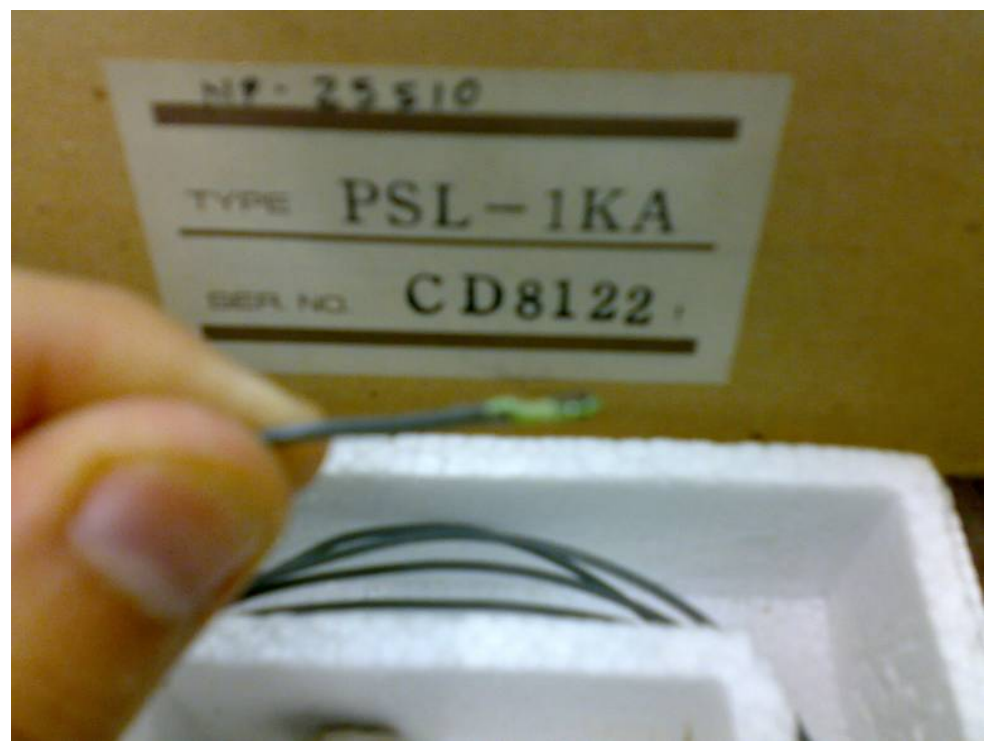

Figura D.3: Medidor de pressão

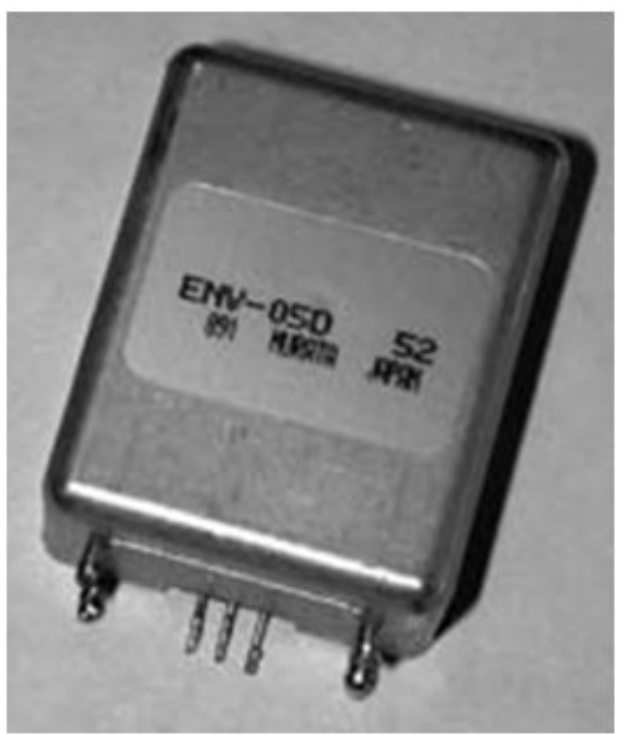

Figura D.4: Exemplo de rate gyro para medida de velocidade angular 


\section{Apêndice I - Modelagem Analítica e Numérica}

Conforme apresentado no capítulo 1.1, no estudo dos sistemas flutuantes, além dos modelos experimentais, são utilizados modelos analíticos e numéricos. Nesse apêndice está descrito de maneira geral quais são os parâmetros mais comuns envolvidos na dinâmica dos sistemas flutuantes nestes tipos de representações.

Os graus de liberdade estudados na dinâmica de sistemas, mostrados na Figura I.1, são os movimentos de surge, sway, heave,roll,pitch e yaw ${ }^{1}$.

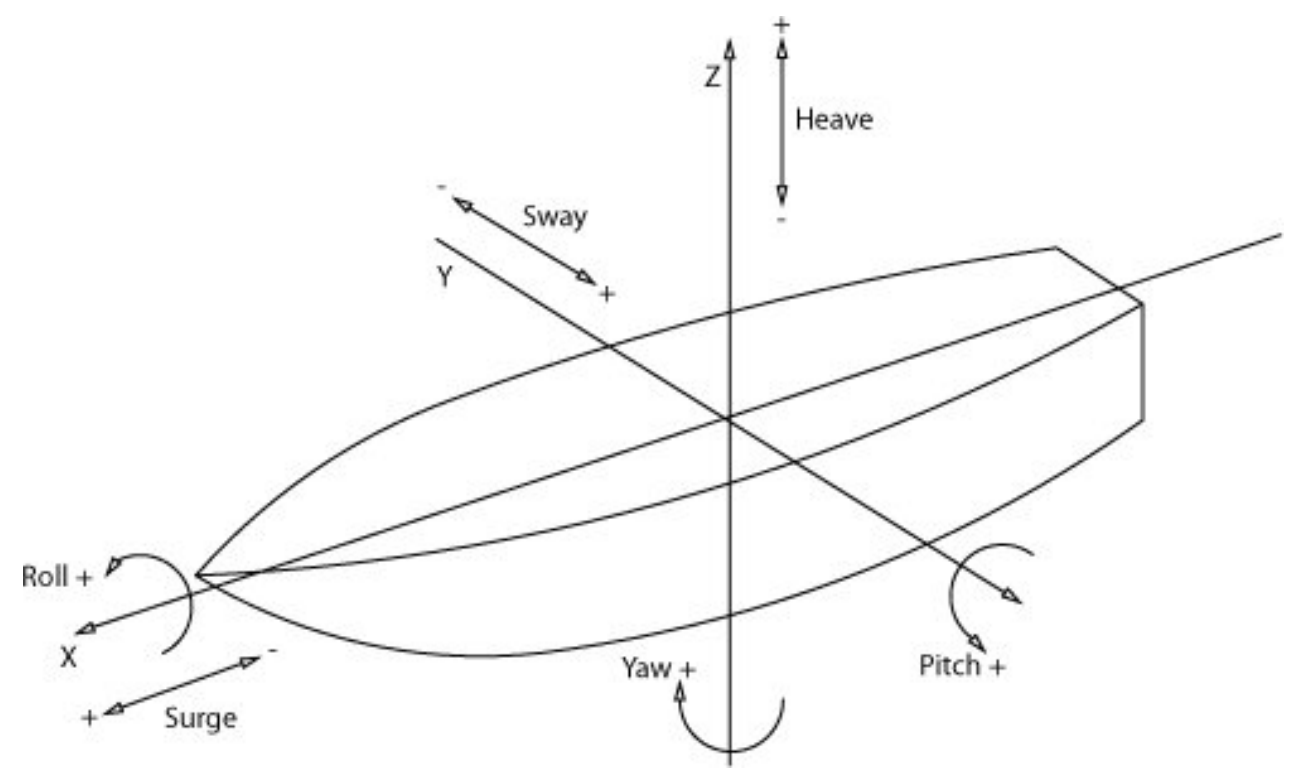

Figura I.1: Graus de liberdade dos sistemas flututantes

Em geral, a dinâmica dos sistemas flutuantes são baseadas na teoria potencial de ondas. As formulações usadas para resolução do problema potencial são as seguintes. Considerando as seguintes hipóteses:

\footnotetext{
${ }^{1}$ Os termos em português são menos utilizados mesmo em publicações nacionais. São eles: Avanço (Surge), Deriva (Sway), Afundamento (Heave), Jogo (Roll), Caturro ou Arfagem (Pitch) e Guinada (Yaw).
} 


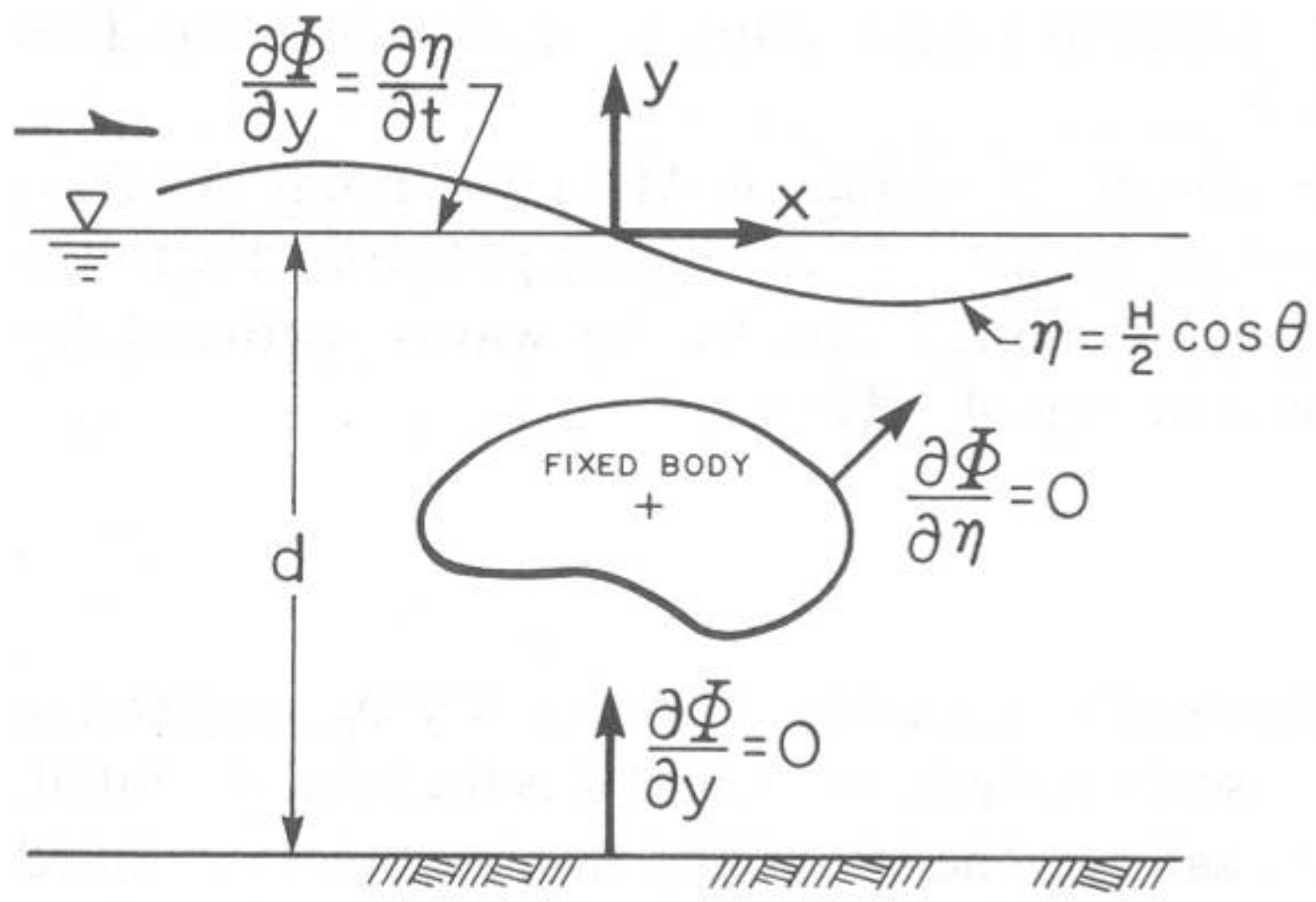

Figura I.2: Condições de contorno do modelo potencial

- Fluído incompressível;

- Fluído irrotacional;

- Movimentos Oscilatórios;

- Sem consideração de efeitos de descolamento da camada limite e "lifting".

Pode-se representar o fluído através de um potencial que deverá atender a condição de Laplace e as condições de contorno mostradas na Figura I.2.

$$
\nabla^{2} \Phi=0
$$

Através da resolução da análise potencial, através de funções de Green, os parâmetros hidrodinâmicos podem ser a obtidos da seguinte forma.

$$
A_{i j}-\frac{i}{\omega} B_{i j}=\rho \iint_{S_{b}} \sum n_{i} \phi_{j} d S
$$

Para a representação dos movimentos no domínio da frequência, a equação do 
movimento pode ser escrita como em I.3, na qual são obtidos os movimentos para os graus de liberdade analisados.

$$
\sum_{i=1}^{6}\left[-\omega^{2}\left(M_{i j}+M_{i j}^{E}+A_{i j}\right)+i \omega\left(B_{i j}+B_{i j}^{E}\right)+\left(C_{i j}+C_{i j}^{E}\right)\right] \xi_{j}=F_{1 i}
$$

onde:

$$
M=\left(\begin{array}{cccccc}
m & 0 & 0 & 0 & m z_{g} & -m y_{g} \\
0 & m & 0 & -m z_{g} & 0 & m x_{g} \\
0 & 0 & m & m y_{g} & -m x_{g} & 0 \\
0 & -m z_{g} & m y_{g} & I_{x x} & I_{x y} & I_{x z} \\
m z_{g} & 0 & -m x_{g} & I_{x y} & I_{y y} & I_{y z} \\
-m y_{g} & m x_{g} & 0 & I_{x z} & I_{z y} & I_{z z}
\end{array}\right)
$$

As forças externas podem ser causadas pelos agentes: onda, vento ou correnteza. Dentro das forças de ondas elas podem ser separadas em forças de primeira e segunda ordem. As forças de primeira ordem são as com resposta na mesma frequência da onda incidente. As forças de segunda-ordem apresentam resposta constante, na soma ou na diferença de frequências. As forças de resposta constante, principalmente nos graus de liberdade surge e sway, são chamadas de deriva média. Contudo, essa forças também ocorre nos demais graus de liberdade. As forças devido a diferença de frequências são normalmente chamadas de derivas lentas. Em I.4, pode ser vista a equação utilizada para representar os movimentos não lineares nas simulações no domínio do tempo.

$$
\left(M_{i i}+A_{i i}\right) \ddot{x}_{i}+B_{i i} \dot{x}_{i}+B_{2 i i}\left|\dot{x}_{i}\right| \dot{x}_{i}+C_{i i} x_{i}=F_{1}+F_{2}+F_{v}+F_{c}+F_{L}
$$

onde $F_{1}$ são as forças de onda de primeira ordem, $F_{2}$ as forças de onda de segunda ordem, $F_{v}$ as forças de vento, $F_{c}$ as forças de correnteza e $F_{L}$ as forças das linhas de amarração e risers.

As forças de onda de segunda ordem $F_{2}$ podem ser separadas em forças de devido a soma de frequências e forças devido a diferença de frequências. Para os sistemas flutuantes projetados para que seus períodos naturais sejam maiores do que os períodos de pico dos espectros do mar, as forças de segunda ordem devido a diferença de frequências são relevantes. Estas forças são ainda divididas em força de deriva média e força de deriva 
lenta. A força de deriva média, refere-se a frequência diferença nula, ou seja, é um valor de força constante. 


\section{Apêndice II - Estabilidade Básica}

A estabilidade de um sistema é a capacidade de restaurar a sua posição devido à uma força ou momento externo. Na definição da matriz de restauração hidrostática $C$ presentes nas equações I.3 e I.4, os termos de restauração hidrostática estão descritos abaixo.

$$
\begin{gathered}
C_{33}=\rho \cdot g \cdot A_{w l} \\
C_{44}=\rho \cdot g \cdot \nabla \cdot G M_{T} \\
C_{55}=\rho \cdot g \cdot \nabla \cdot G M_{L} \\
G M_{T}=K B+I_{W L} / \nabla-K G
\end{gathered}
$$

Para pequenas variações na restauração de linha d'água, o momento restaurador pode ser considerado como em II.5.

$$
M_{\text {rest }}=\Delta G M \operatorname{sen}(\theta)
$$




\section{Apêndice III - Estatística Básica}

Alguns parâmetros estatísticos tornam-se indispensáveis para a descrição de condições de mar, bem como, para definir o movimento dos sistemas oceânicos sujeitos a carregamentos aleatórios com distribuições estatísticas conhecidas. Abaixo estão descritos alguns dos termos estatísticos considerados ao longo desta dissertação retirados de [Chakrabarti, 1987].

Para os valores de uma séria temporal, as características básicas são: máximo, mínimo, média e desvio padrão. A partir destas características e considerando que ondas lineares respeitam uma distribuição Gaussiana de média zero para a elevação $\eta$ e distribuição de Rayleigh para as alturas $H$.

$$
\begin{gathered}
p_{\text {Gauss }}(\eta)=\frac{1}{\sqrt{2 \pi} \sigma_{\eta}} e\left[-\frac{\eta^{2}}{2 \sigma_{\eta}^{2}}\right] \\
p_{\text {Rayleigh }}(H)=\frac{2 H}{H_{R M S}^{2}} e\left[-\frac{H^{2}}{2 H_{R M S}^{2}}\right] \\
H_{1 / 3}=H_{s}=4 \sigma \\
H_{\text {max }}=H_{1 / N}=H_{R M S}\left[\sqrt{\ln N}+\frac{0.2886}{\sqrt{\operatorname{lnN}}}\right]
\end{gathered}
$$

Para o espectro $S(f)$ do mar, ou mesmo dos movimentos da unidade, as seguintes propriedades estatísticas podem ser obtidas.

$$
\begin{gathered}
\eta(x, t)=\sum_{n} \frac{H(n)}{2} \cos [k(n) x-2 \pi f(n) t+\delta(n)] \\
H(f)=2 \sqrt{2 S(f) \Delta f}
\end{gathered}
$$




$$
\begin{gathered}
m_{n}=\int \omega^{n} S(f) d f \\
\sigma=\frac{H_{s}}{4}=\sqrt{m_{0}} \\
T_{m}=\frac{m_{1}}{m_{0}} \\
T_{z}=\sqrt{\frac{m_{2}}{m_{0}}} \\
T_{c}=\sqrt{\frac{m_{4}}{m_{2}}} \\
\epsilon=1-\left(\frac{T_{c}}{T_{z}}\right)^{2} \\
\Gamma^{2}(f)=\frac{S_{x y}(f)}{\left[S_{x x}(f) S_{y y}(f)\right]^{\frac{1}{2}}}
\end{gathered}
$$




\section{Apêndice IV - Análise de Incertezas}

Neste apêndice estão apresentadas algumas técnicas para análise de incerteza de novos ensaios de sistemas flutuantes. Os sinais aquisitados podem conter três tipos de erros de medidas: os erros de calibração, erros constantes e erros aleatórios. Os erros de calibração são devido à variação entre a medida dos instrumentos e a sua curva de calibração. Esse tipo de erro resulta em um desvio sobre os valores aquisitados quando expressos em unidades de engenharia. Os erros constantes aparecem durante o tratamento de sinais, como por exemplo, durante a filtragem de ruídos ou o enjanelamento para a avaliação dos espectros de potência dos sinais. Os erros aleatórios aparecem em operações que são realizadas durante o cálculo de estatísticas de um número finito de amostras dos ensaios.

A estimativa da incerteza de uma medida pode ser realizada pela equação IV.2.

$$
\begin{gathered}
y=f\left(x_{1}, x_{2}, \cdots, x_{n}\right) \\
u_{c}^{2}(y)=\sum\left[\frac{\partial f}{\partial x_{i}}\right]^{2} u^{2}\left(x_{i}\right)
\end{gathered}
$$




\section{Apêndice V - Filtragem de Sinais}

Um dos tratamentos de sinais mais importantes refere se a capacidade de extrair de um sinal, que talvez possua alguns ruídos indesejáveis, apenas a informação sobre os efeitos em estudo. Para tal, o procedimento mais comum é a análise do sinal no domínio da frequência, podendo assim distinguir quais as frequências que se sabe não estarem na faixa de reposta do sistema analisado. Particularmente no caso de provas para plataformas de petróleo, essas dificilmente possuem respostas menores do que 0,001 Hz e maiores de $1 \mathrm{~Hz}$. Portanto, se for considerado uma escala de 1:100, o modelo apenas apresentaria resposta em frequência na faixa de 0,01 a $10 \mathrm{~Hz}$, conforme apresentado na Tabela V.1. Sendo assim, em caso de frequências fora dessa faixa, podem-se ter efeitos de interferência no sinal criando ruídos, onde o exemplo mais comum são os da rede elétrica ou mesmo entre dispositivos eletrônicos utilizados durante a realização do ensaio.

Tabela V.1: Faixa de frequência na escala do modelo

\begin{tabular}{ccc}
\hline & \multicolumn{2}{|c}{ Frequência na Escala do Modelo(Hz) } \\
\hline Escala 1: & Mínima & Máxima \\
50 & 0,007 & 7,071 \\
100 & 0,010 & 10,000 \\
150 & 0,012 & 12,247 \\
200 & 0,014 & 14,142 \\
\hline
\end{tabular}

Para que seja realizada a filtragem desse sinal um método é a utilização de rotinas de Fast Fourier Transform (FFT). Com essas rotinas é possível retirar amplitudes indesejadas do sinal e posteriormente realizar a operação inversa chamada de Inverse Fast Fourier Transform (IFFT), caso queria-se obter a nova série temporal no domínio do tempo. Basicamente, o espectro de potência é obtido diretamente da série temporal. Para uma série temporal com $\mathrm{N}$ pontos e discretização $\Delta t$ e tempo total $T_{r}=N \Delta t$, o espectro associado ao sinal é dado por . 


$$
S(f)=\frac{2}{N \Delta t}\left(\sum_{m=1}^{N} x_{m} e^{\frac{i \pi m f}{N}} \Delta t\right)
$$

O espectro de potência também pode ser calculado utilizando-se do método de Welch com janela do tipo Hamming e com ou sem sobreposição dos sinais. 


\section{Apêndice VI - Rotinas dos Ensaios}

Nesse capítulo estão presentes as rotinas para auxílio no planejamento, tratamento, análise e documentação dos dados envolvidos nos ensaios em tanque de provas de sistemas flutuantes. As rotinas de tratamento são utilizadas anteriormente as análises para que ajustes no sinais possam ser realizados. Posteriormente com as análises em si, são possíveis obter as informações e resultados dos ensaios. Finalmente, a documentação também foi auxiliada por algumas rotinas, as quais ajudaram a salvar os sinais tratados e analisados dos experimentos para verificações e consultas futuras.

\section{VI.1 Rotinas de Planejamento dos Ensaios}

As rotinas de planejamento auxiliam na definição dos parâmetros do ensaio a ser executado, como o tipo de instrumentação a ser utilizada e detalhes da matriz de ensaio.

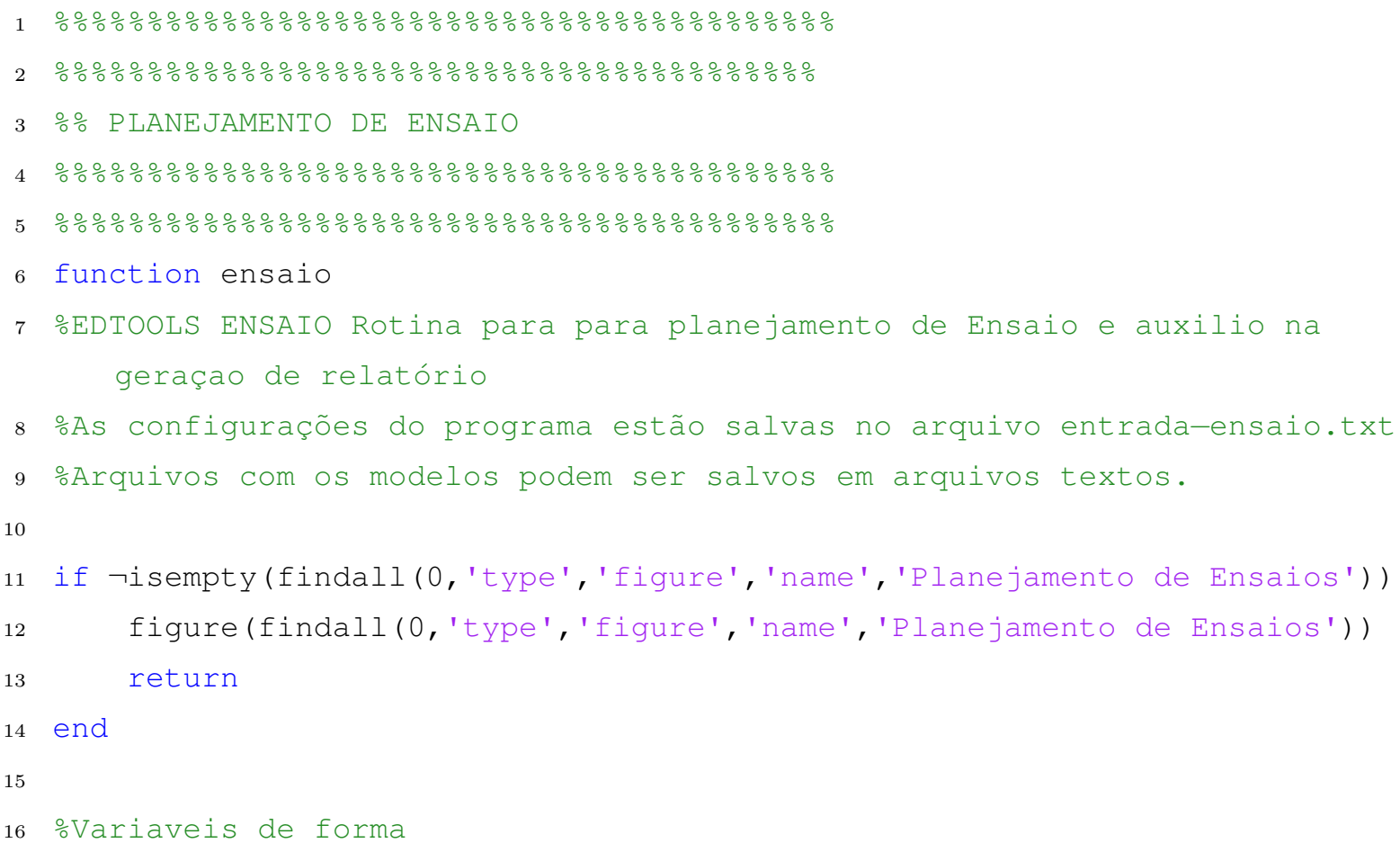




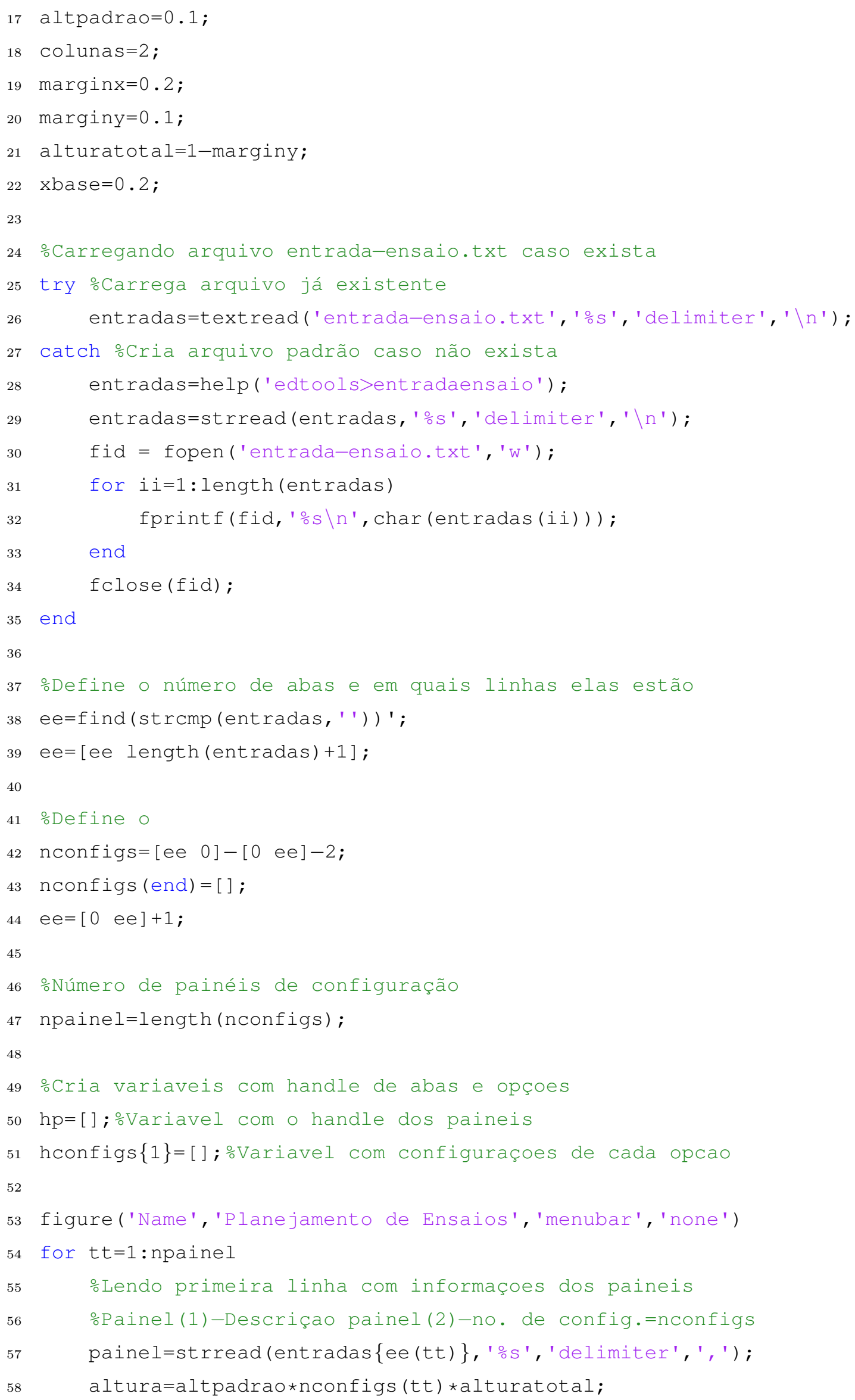




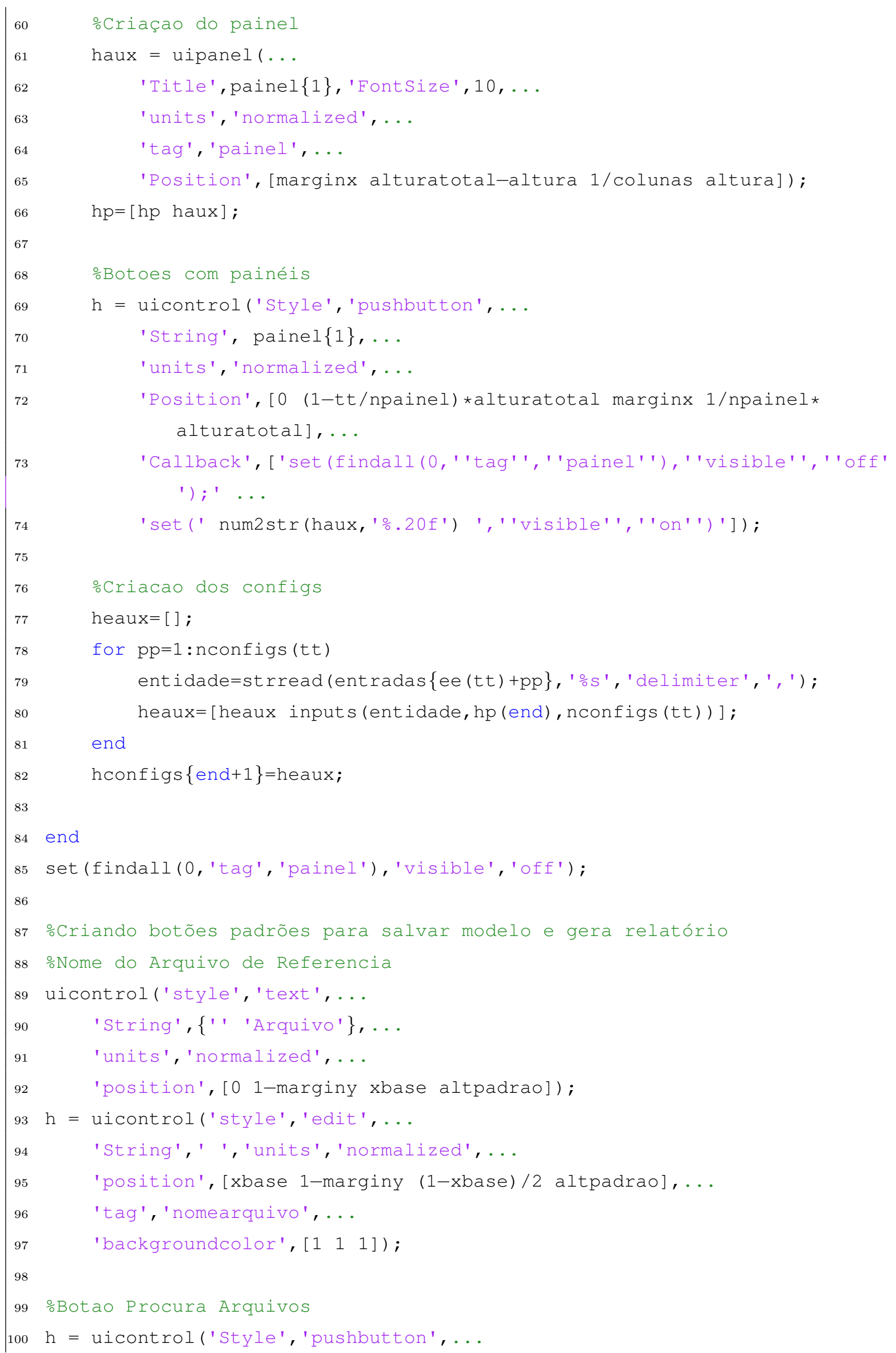




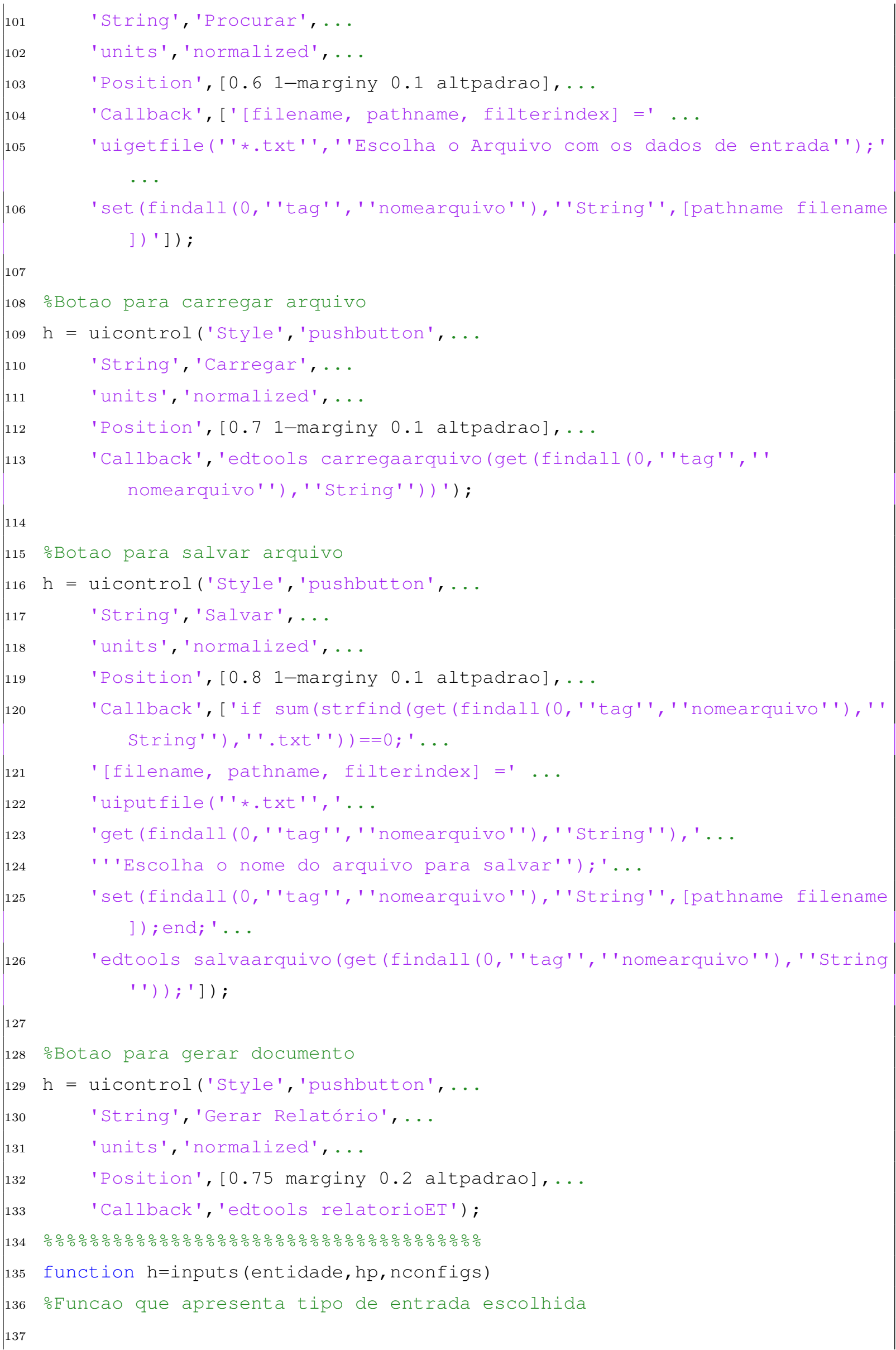




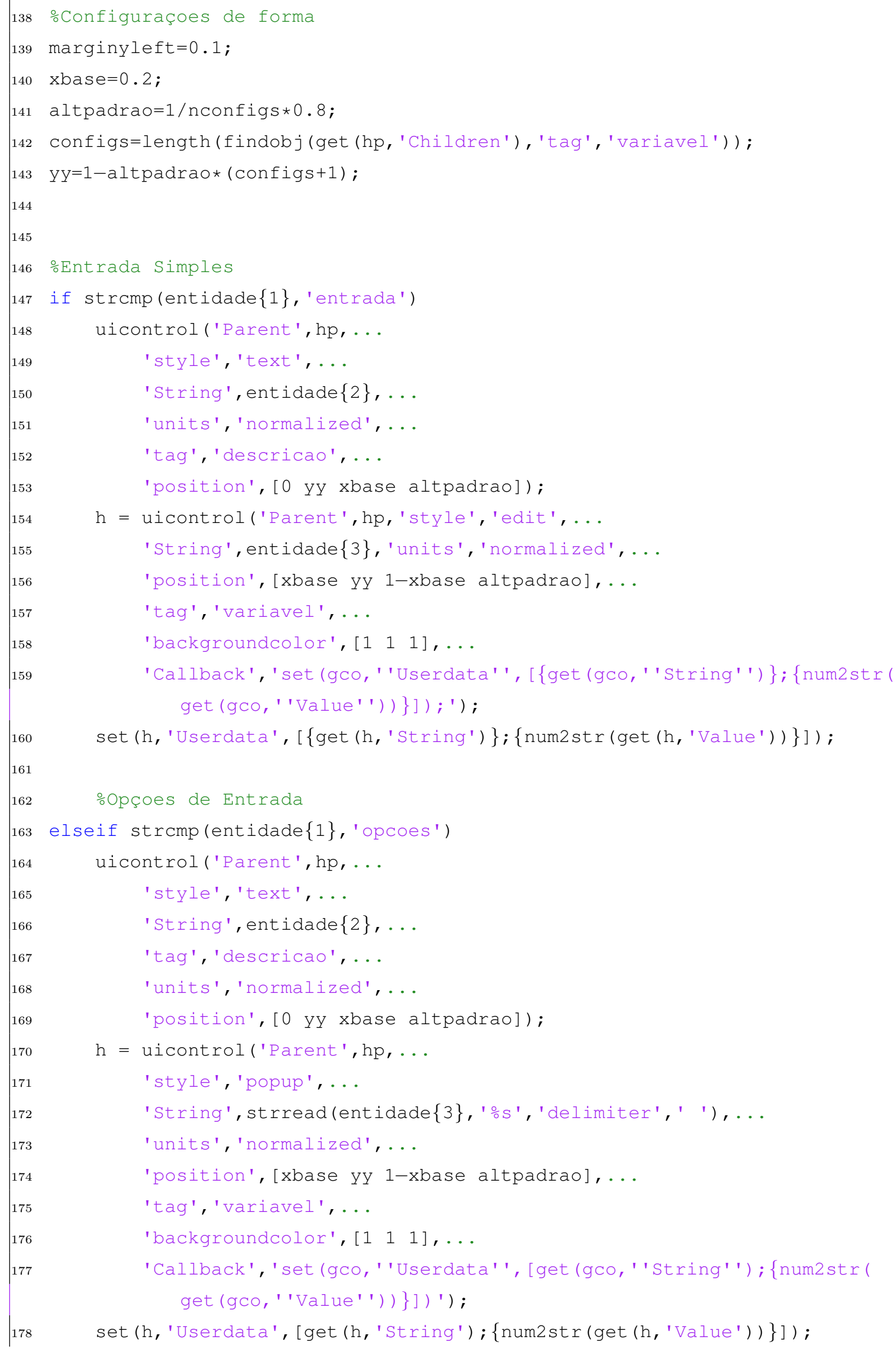




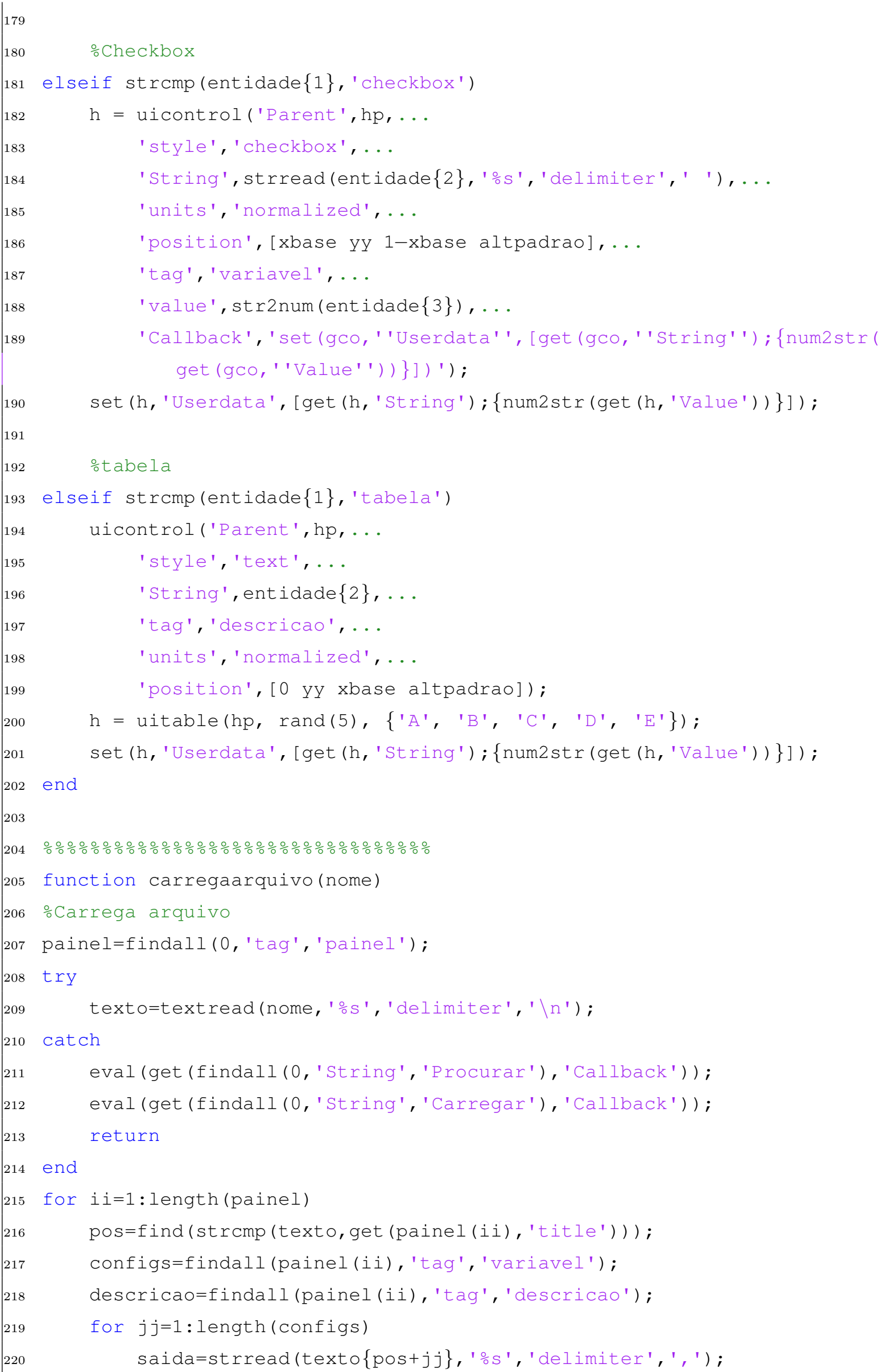




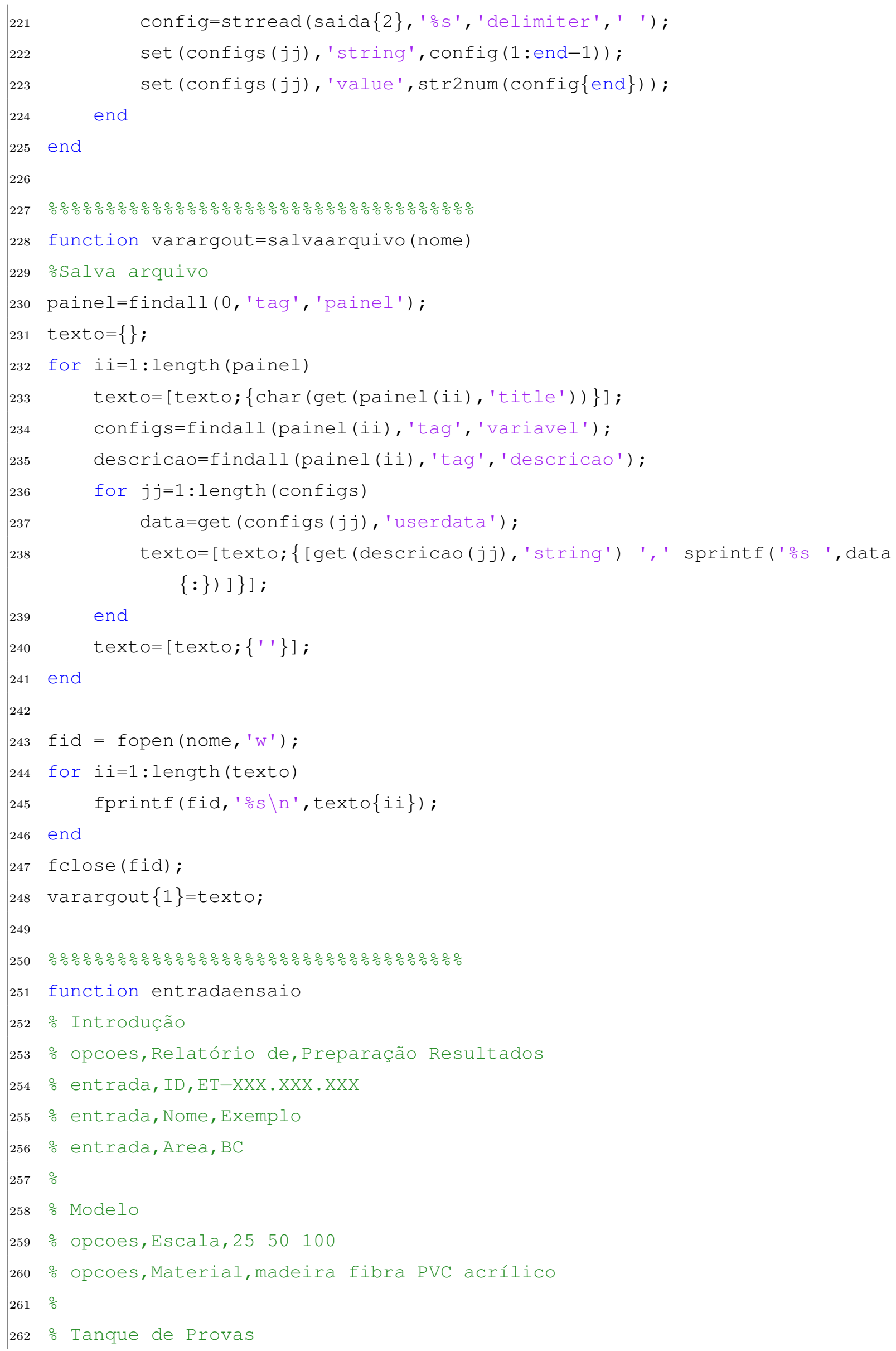




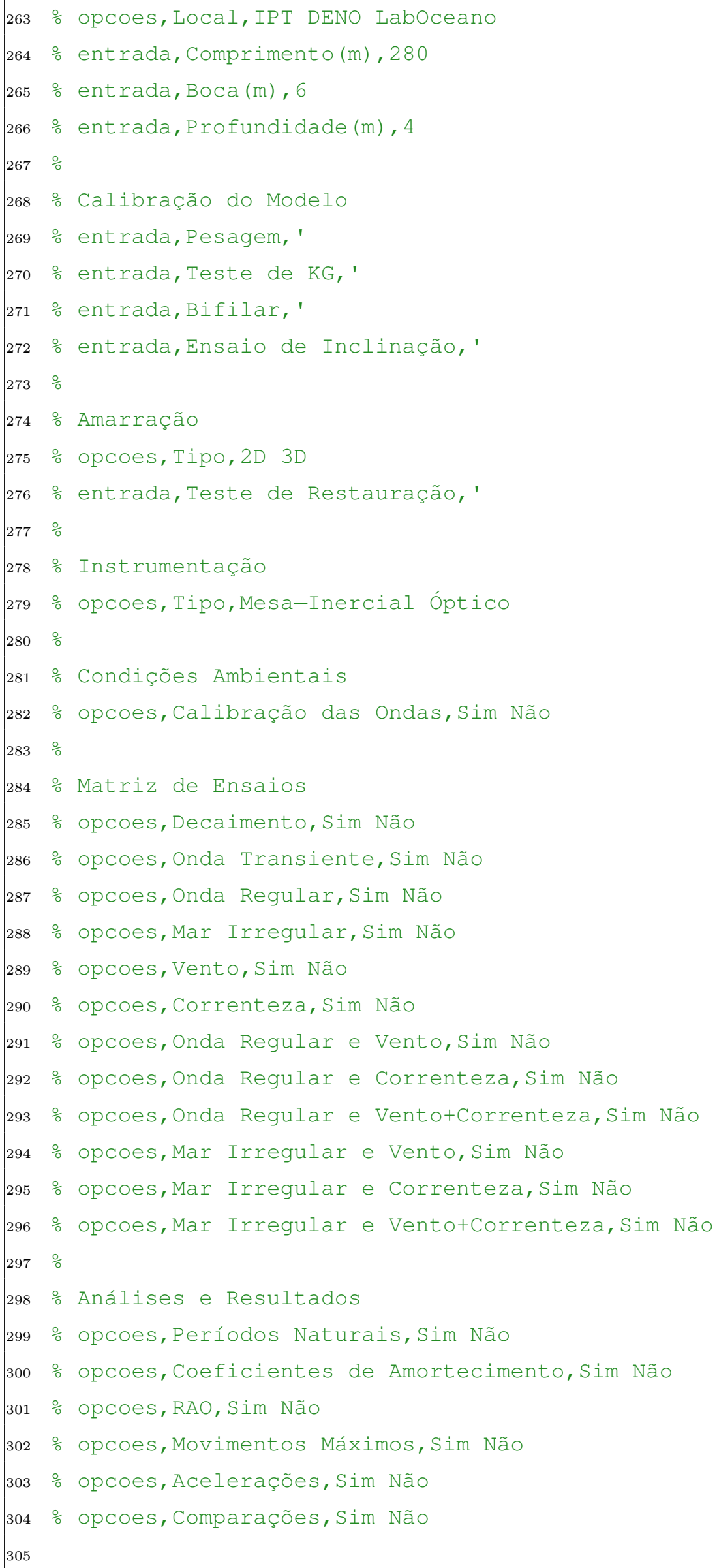




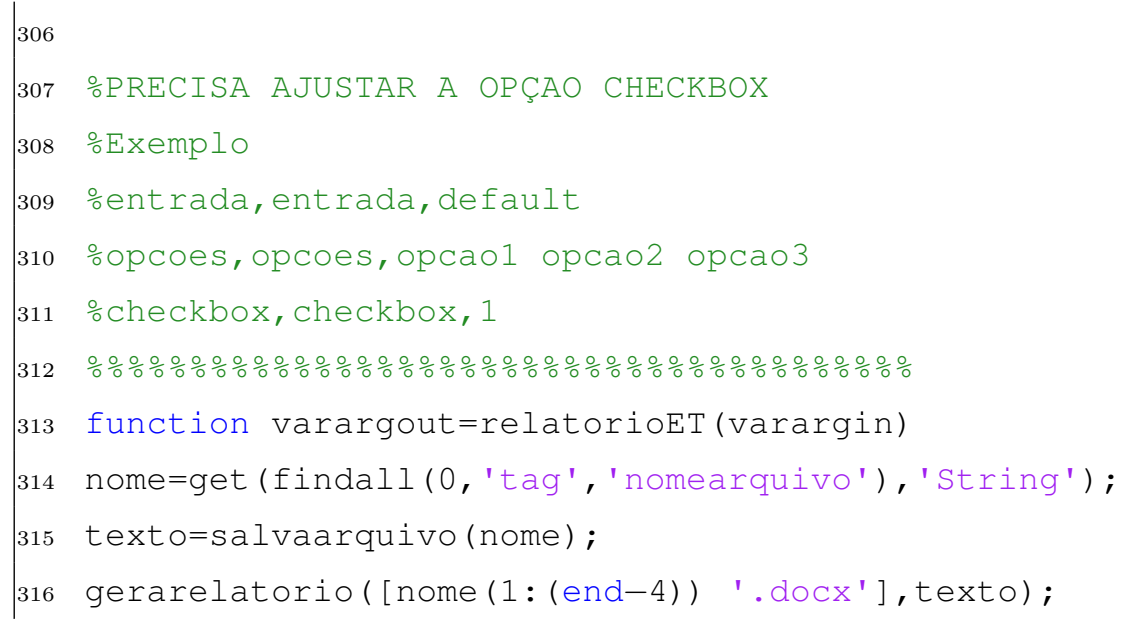

\section{VI.2 Rotinas de Tratamento de Dados}

As rotinas de tratamento de dados auxiliam no corte, filtragem, reamostragem, interpolação e demais operações necessárias anteriormente as análises.

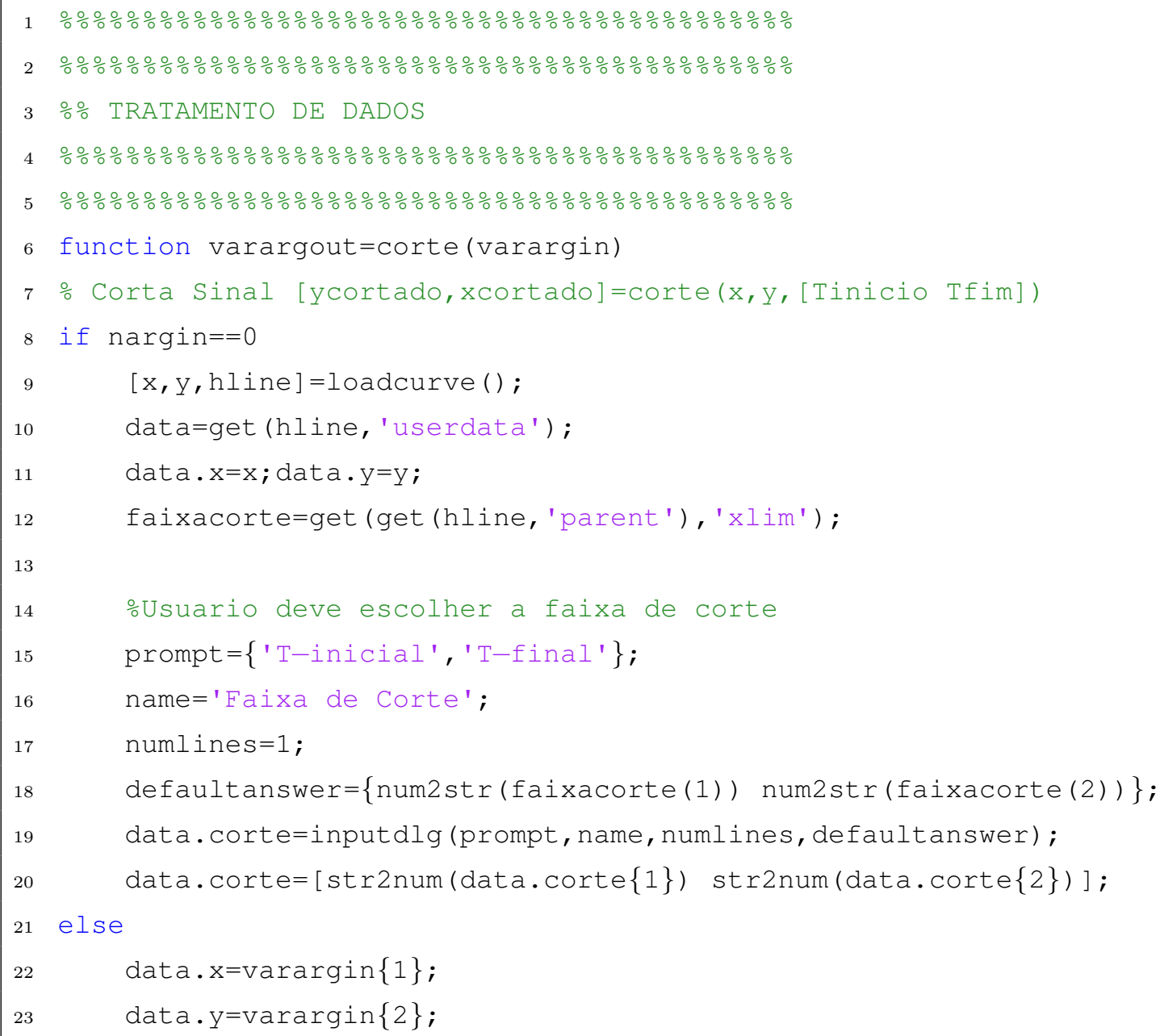




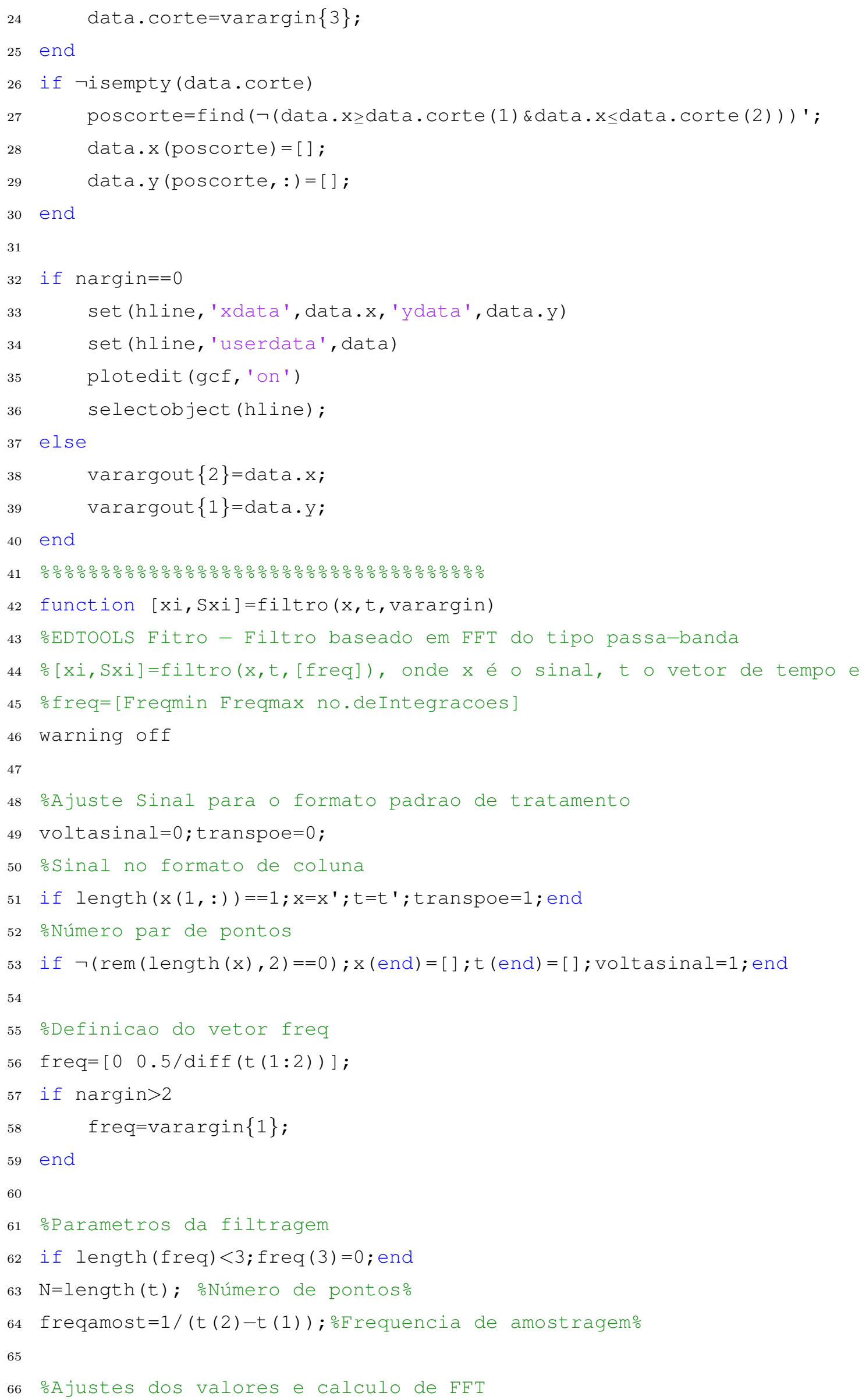




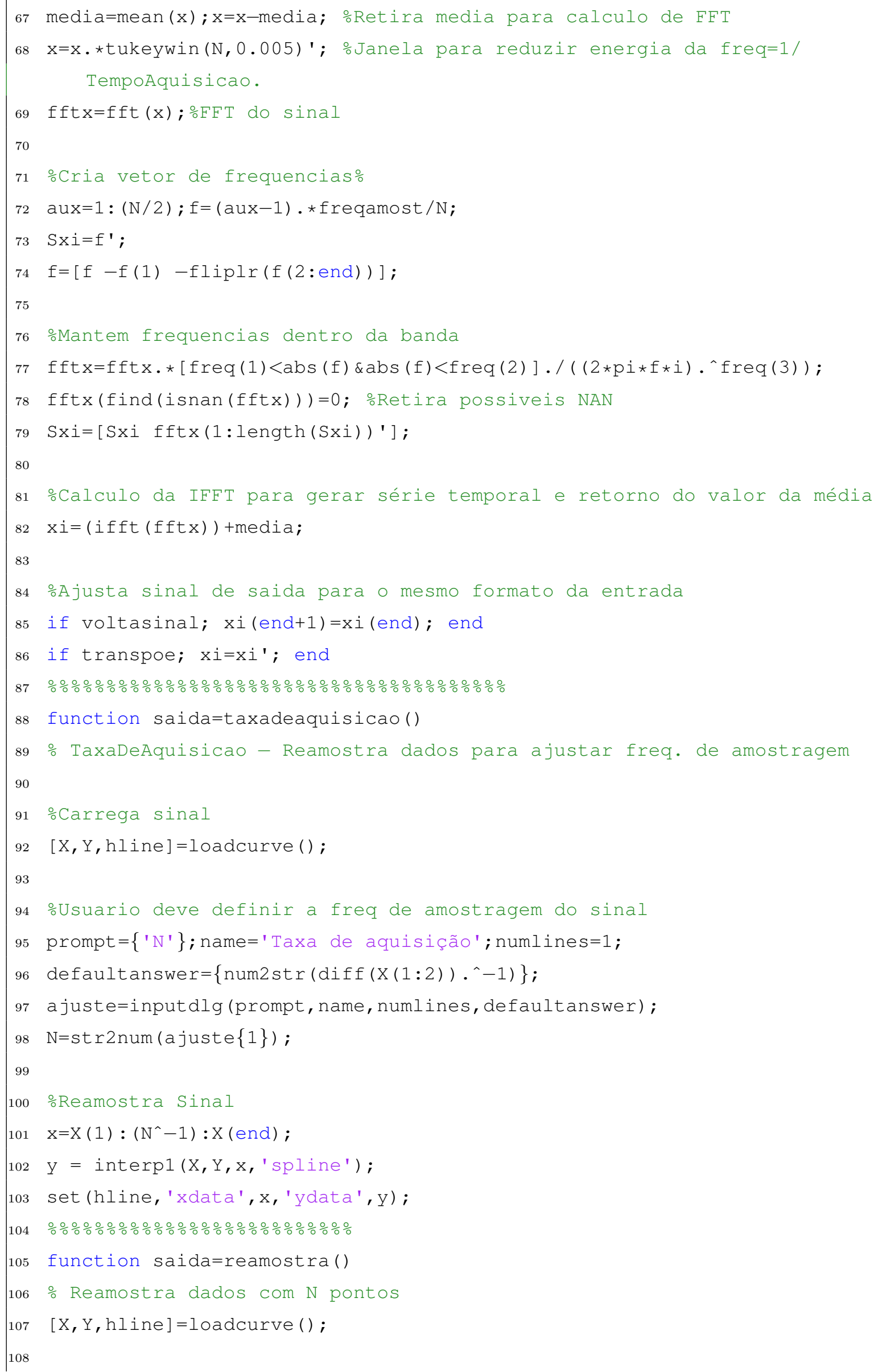




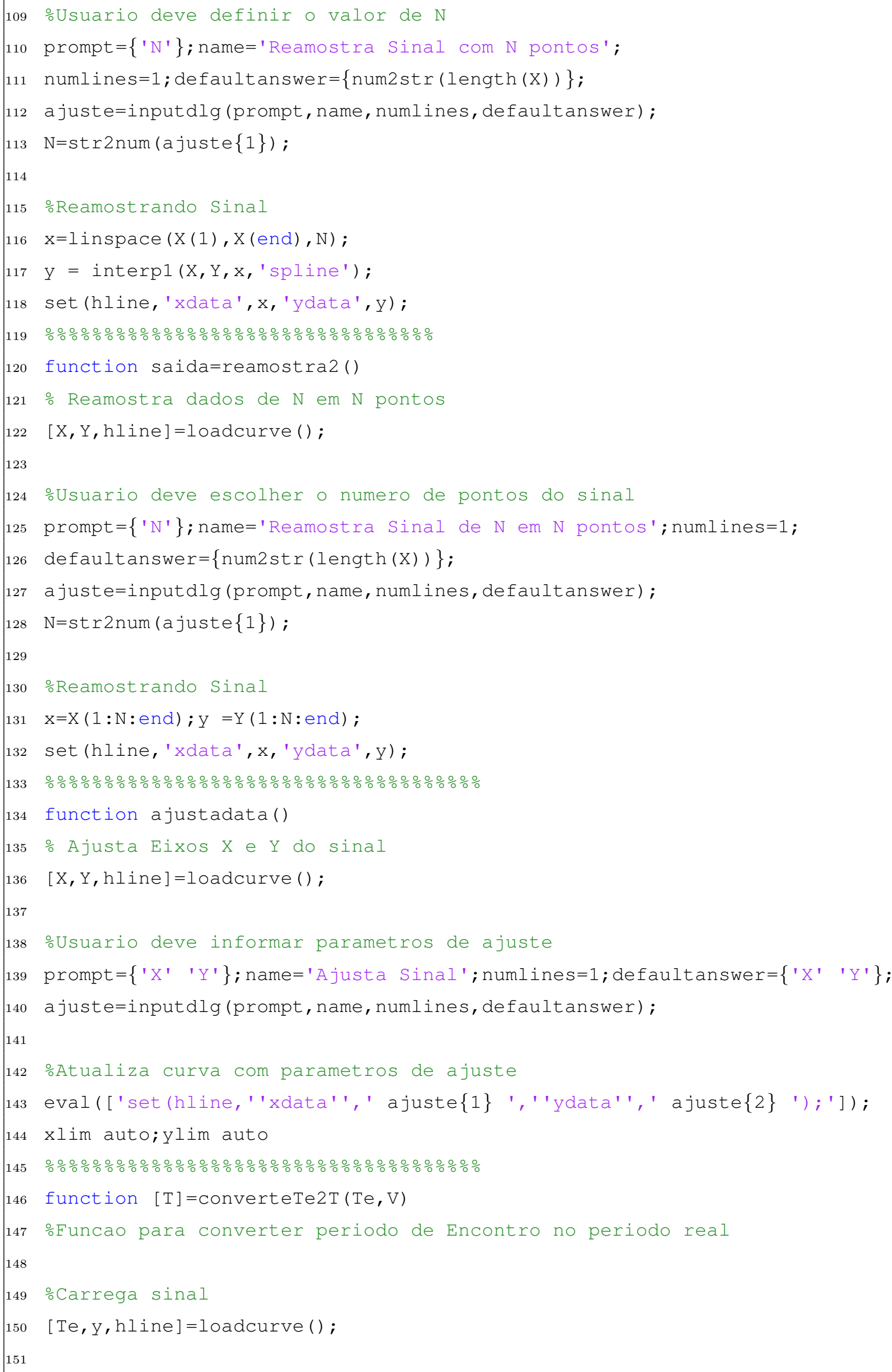




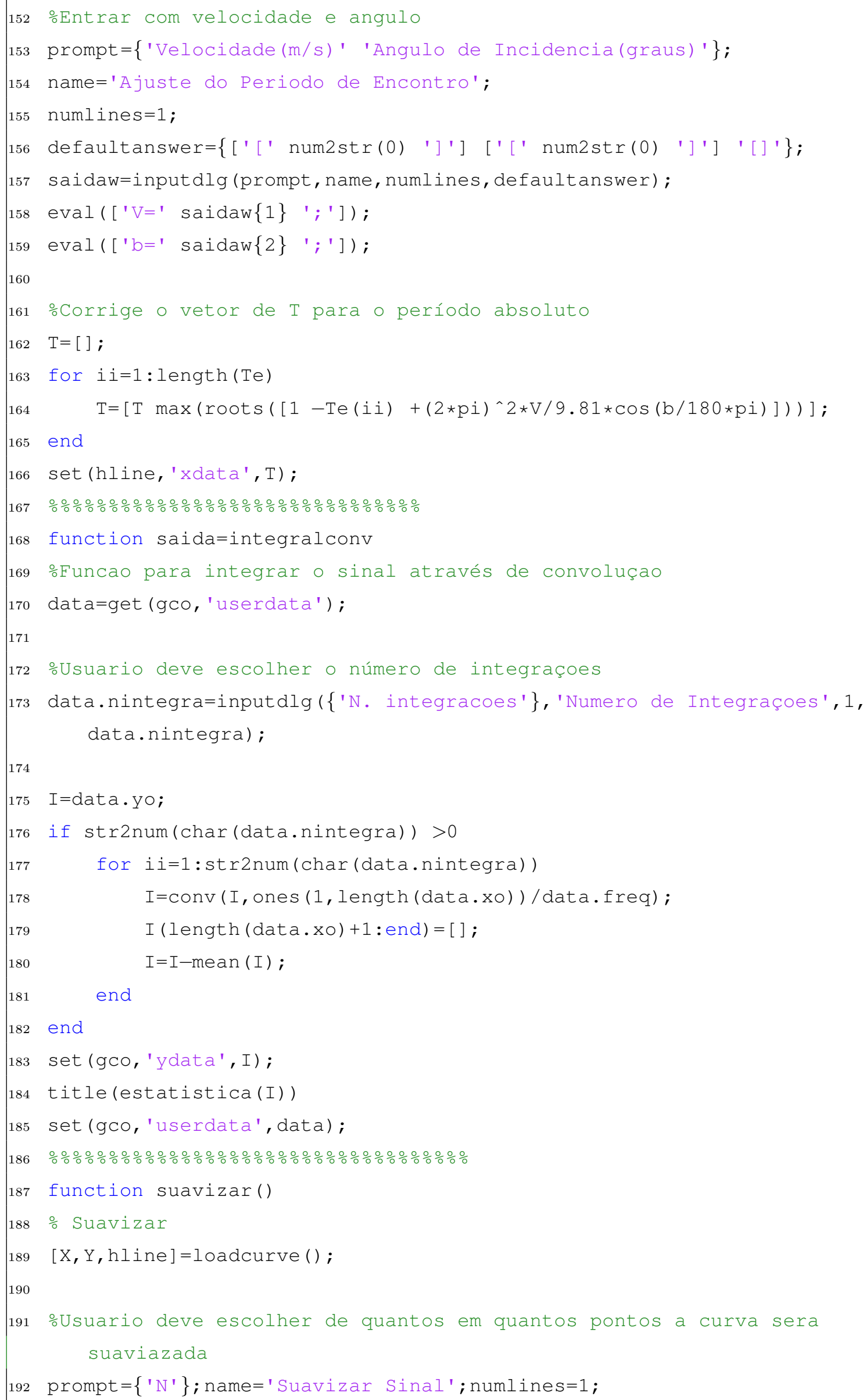




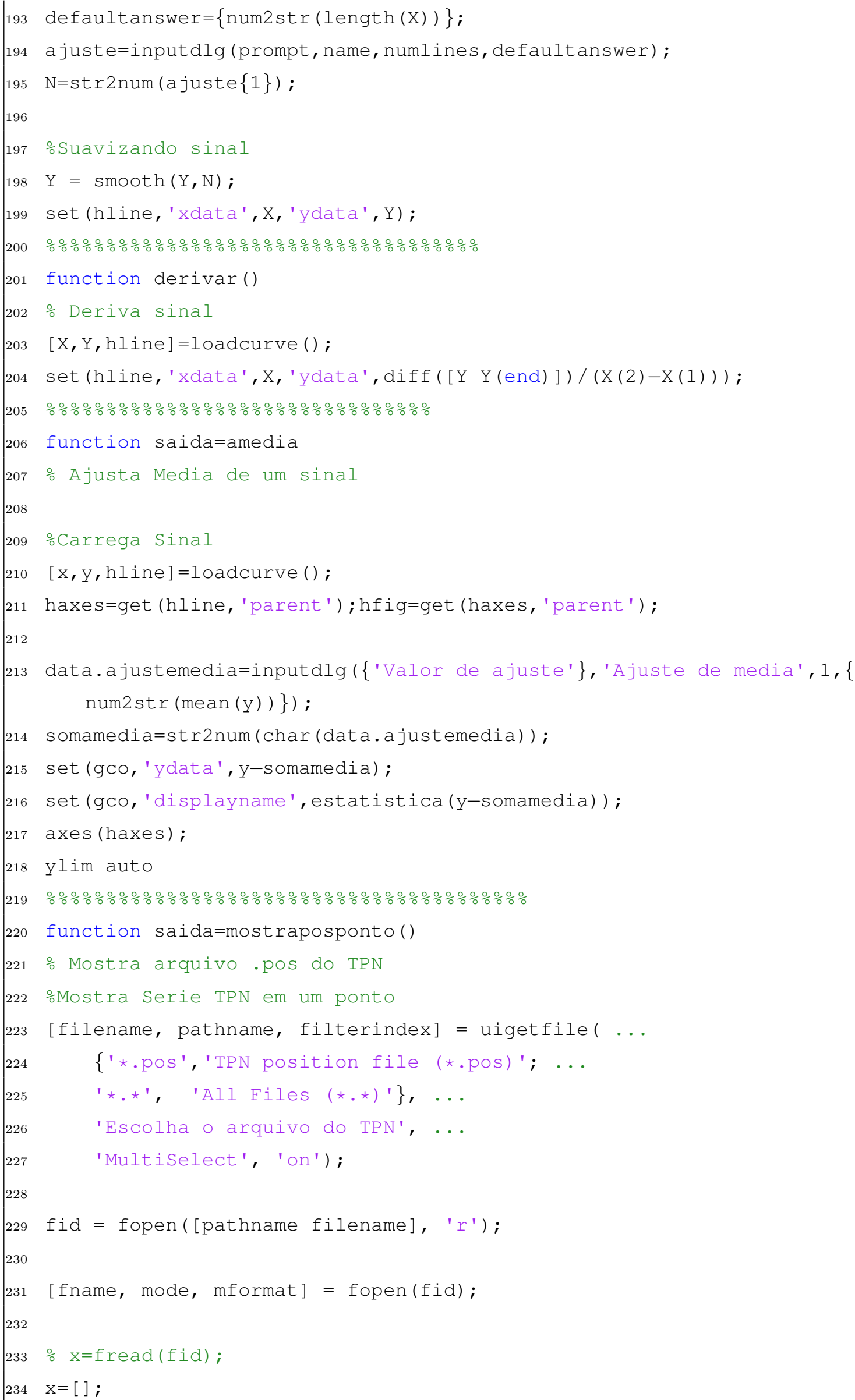




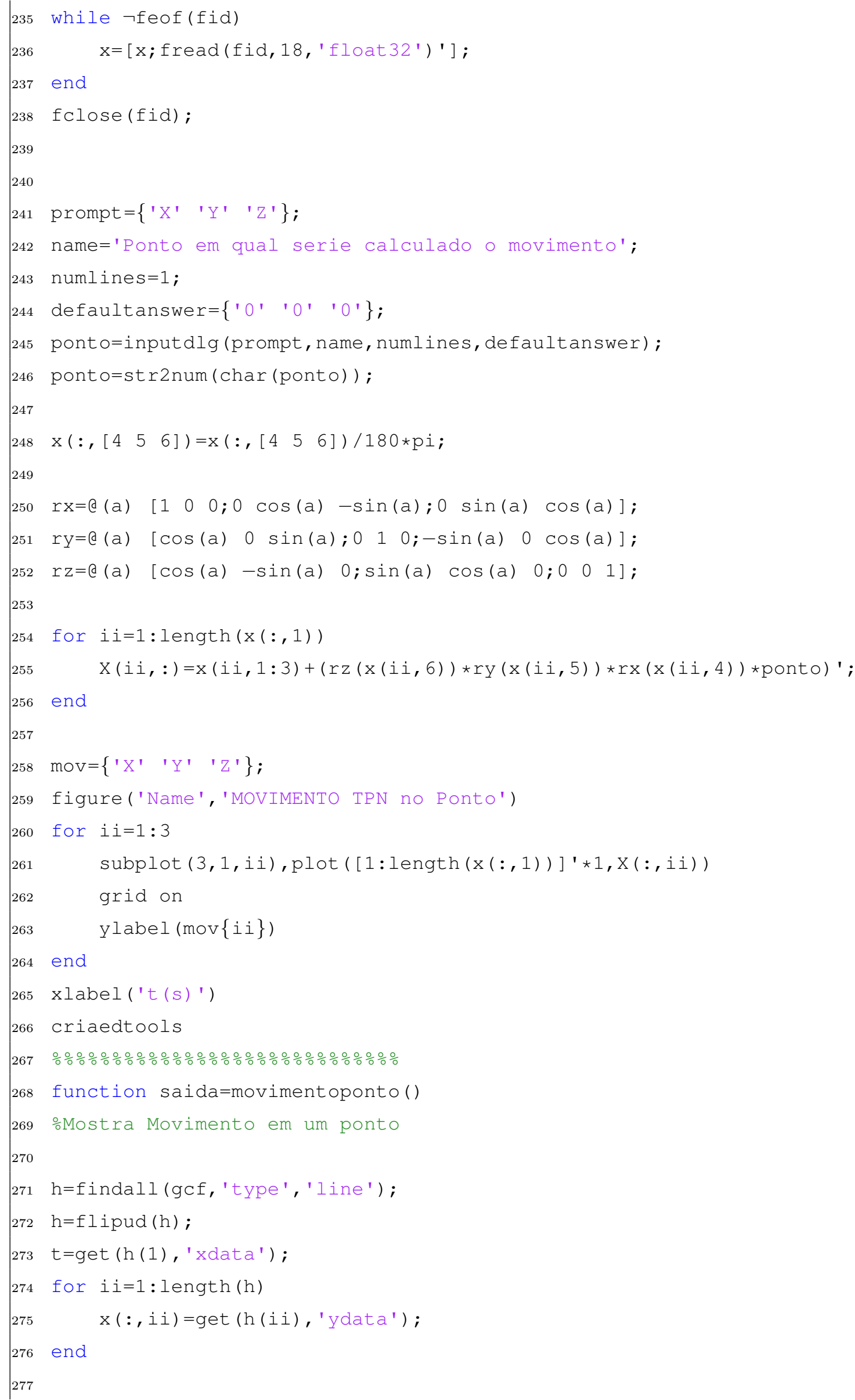




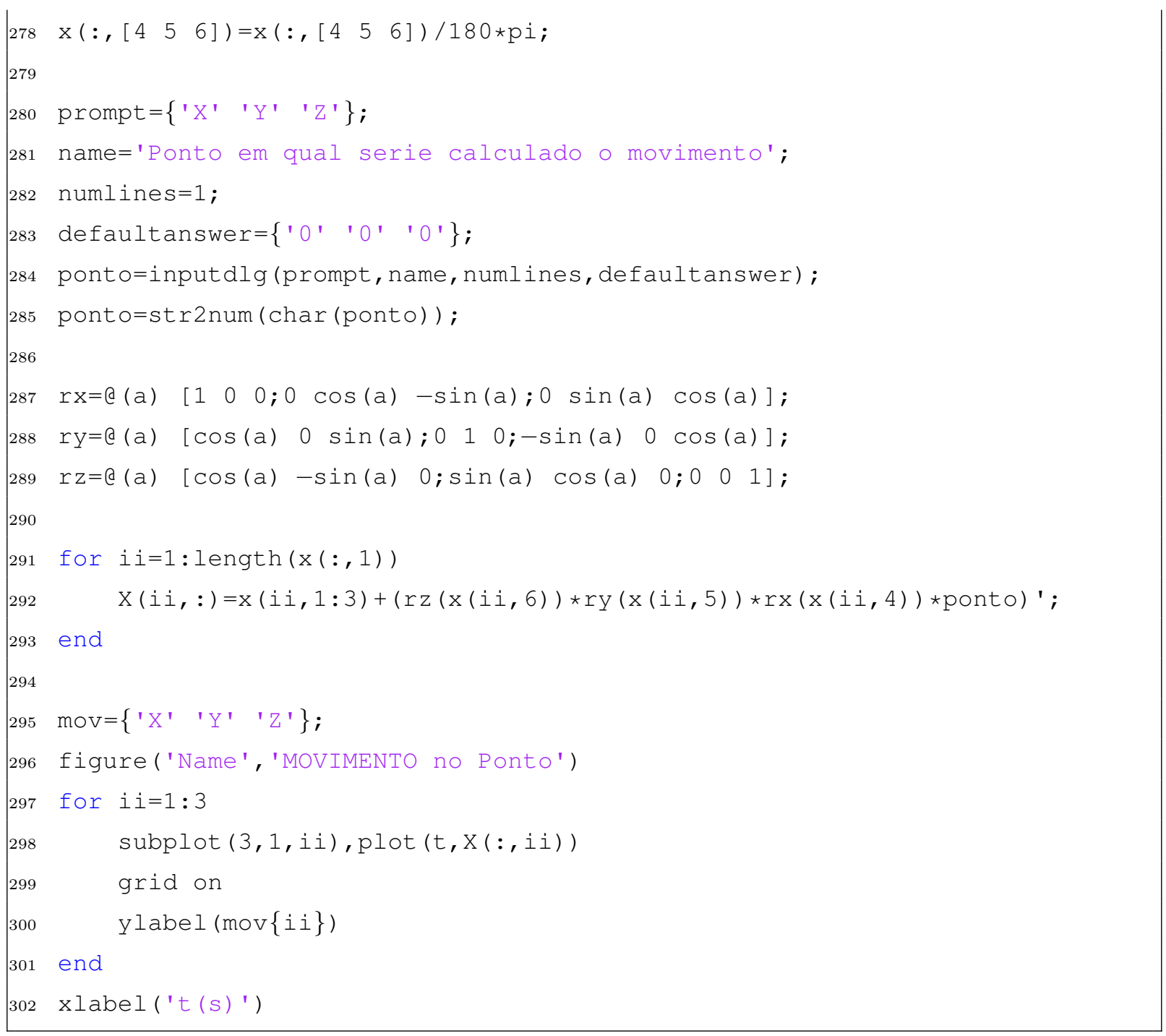

\section{VI.3 Rotinas de Análise}

As rotinas de análise auxilam a obtenção de informações relevantes dos ensaios, como os períodos e coeficientes de amortecimento dos ensaios de decaimento, curvas de RAO dos ensaios de Ondas regulares e transientes, além de propriedades espectrais e estatísticas dos mares irregulares.

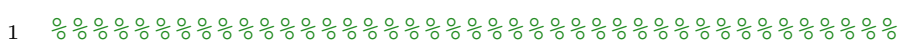

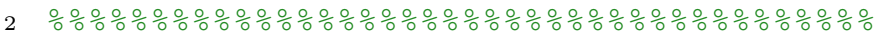

3 응 ANÁLISE

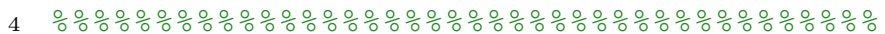

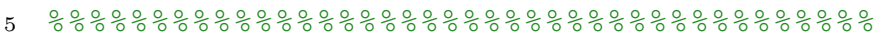

6 function [estachar, numout]=estatistica (sinal)

7 \% Estatistica Basica da série temporal
} 


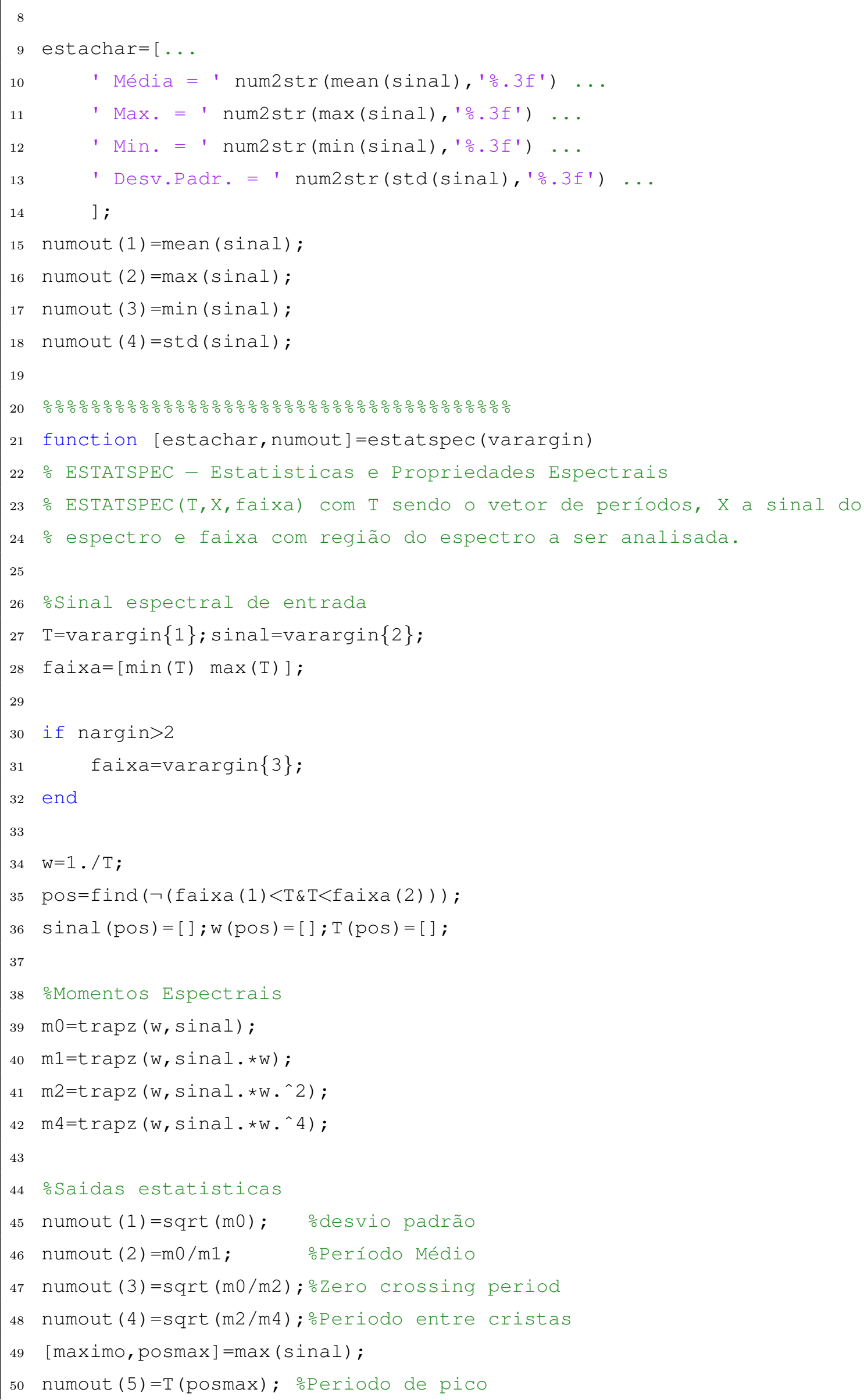




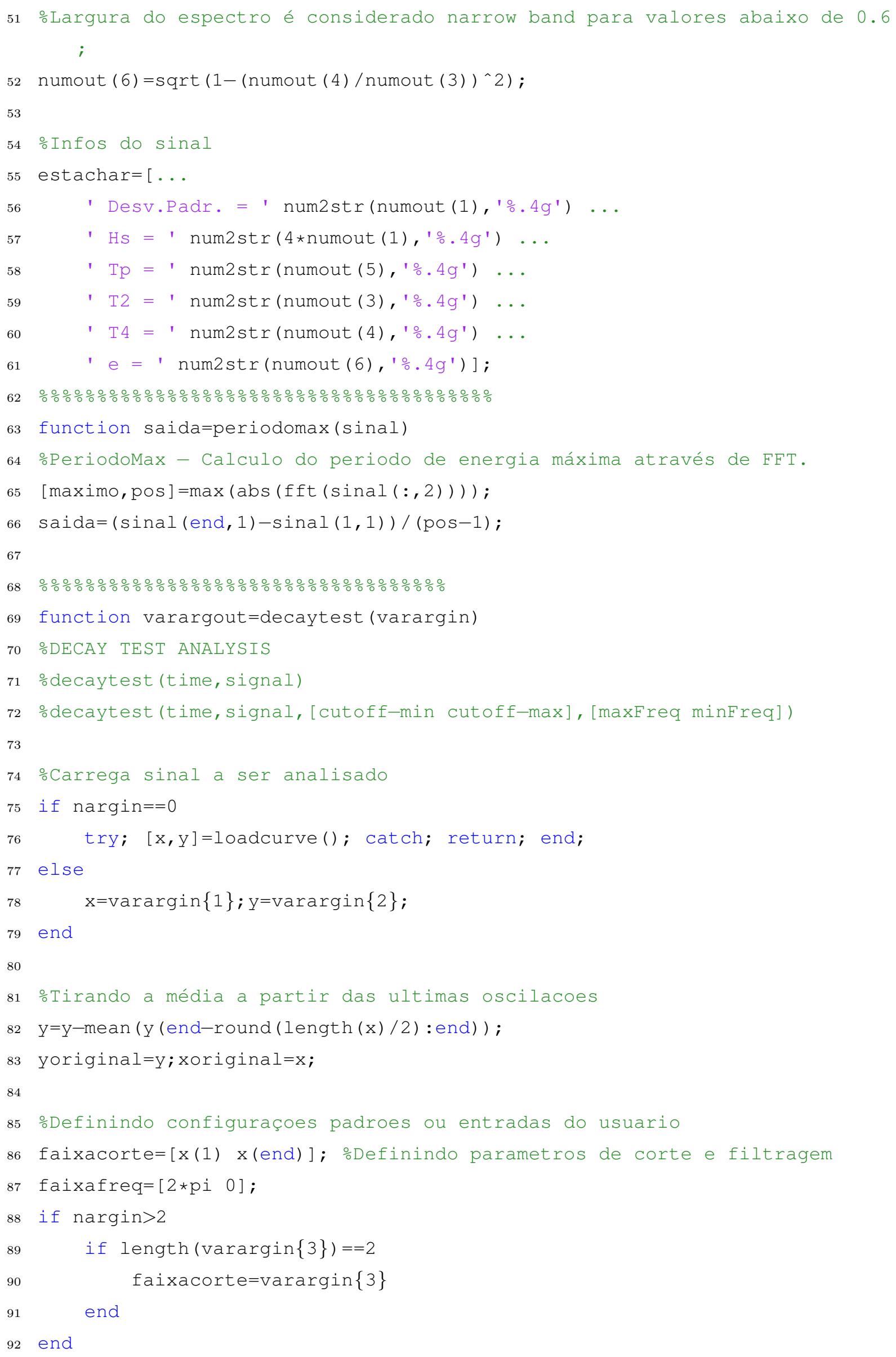




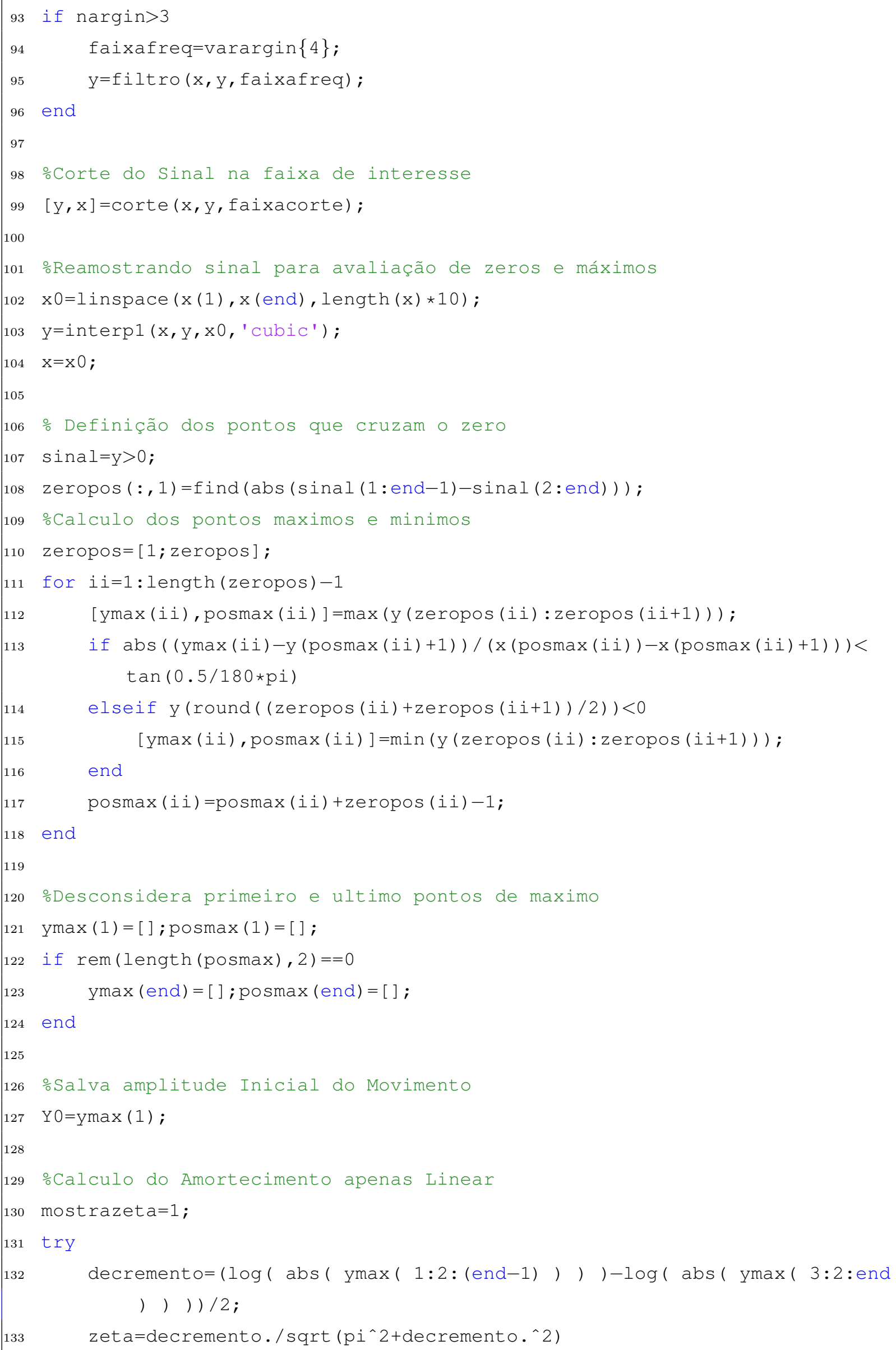




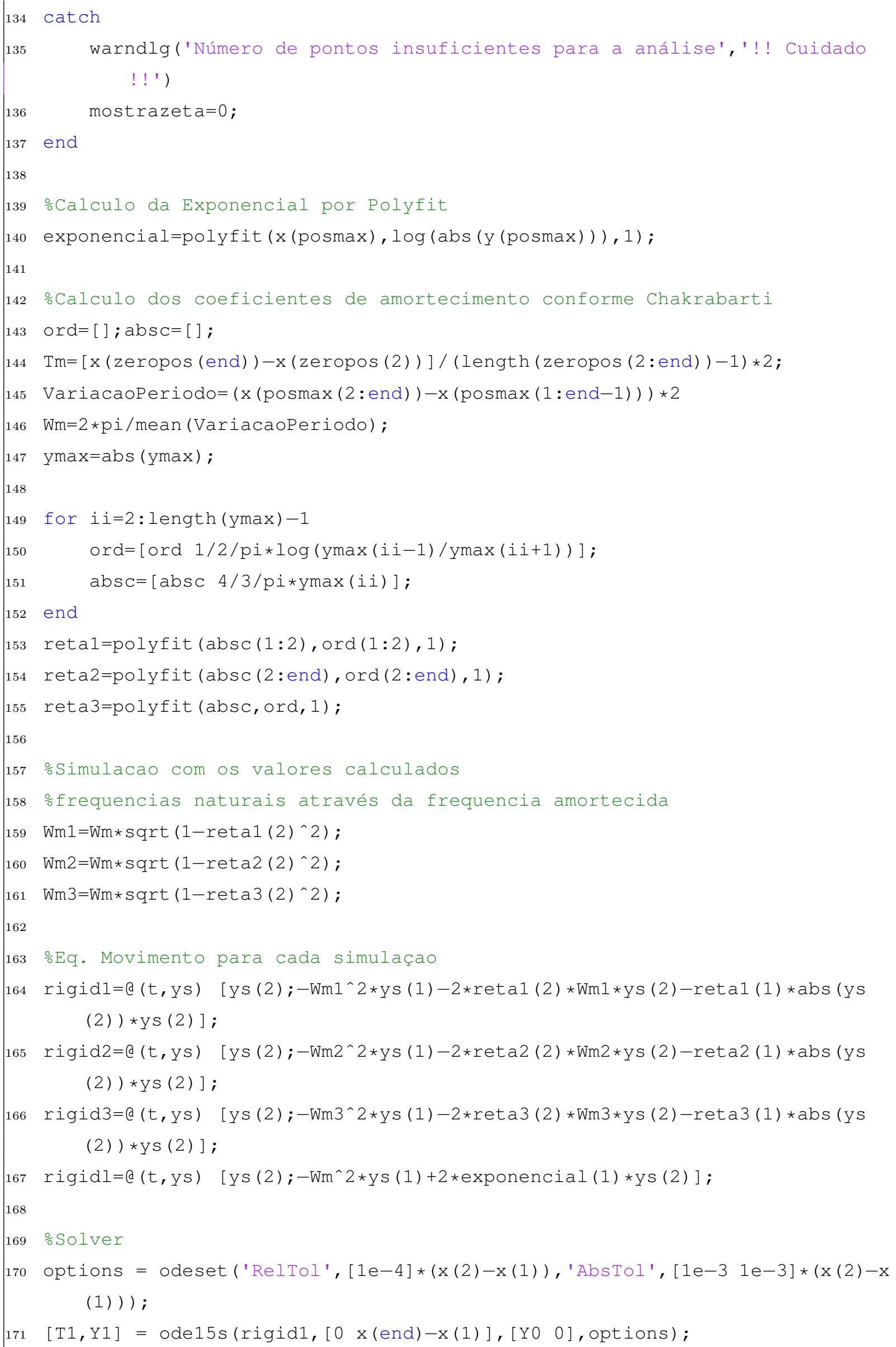




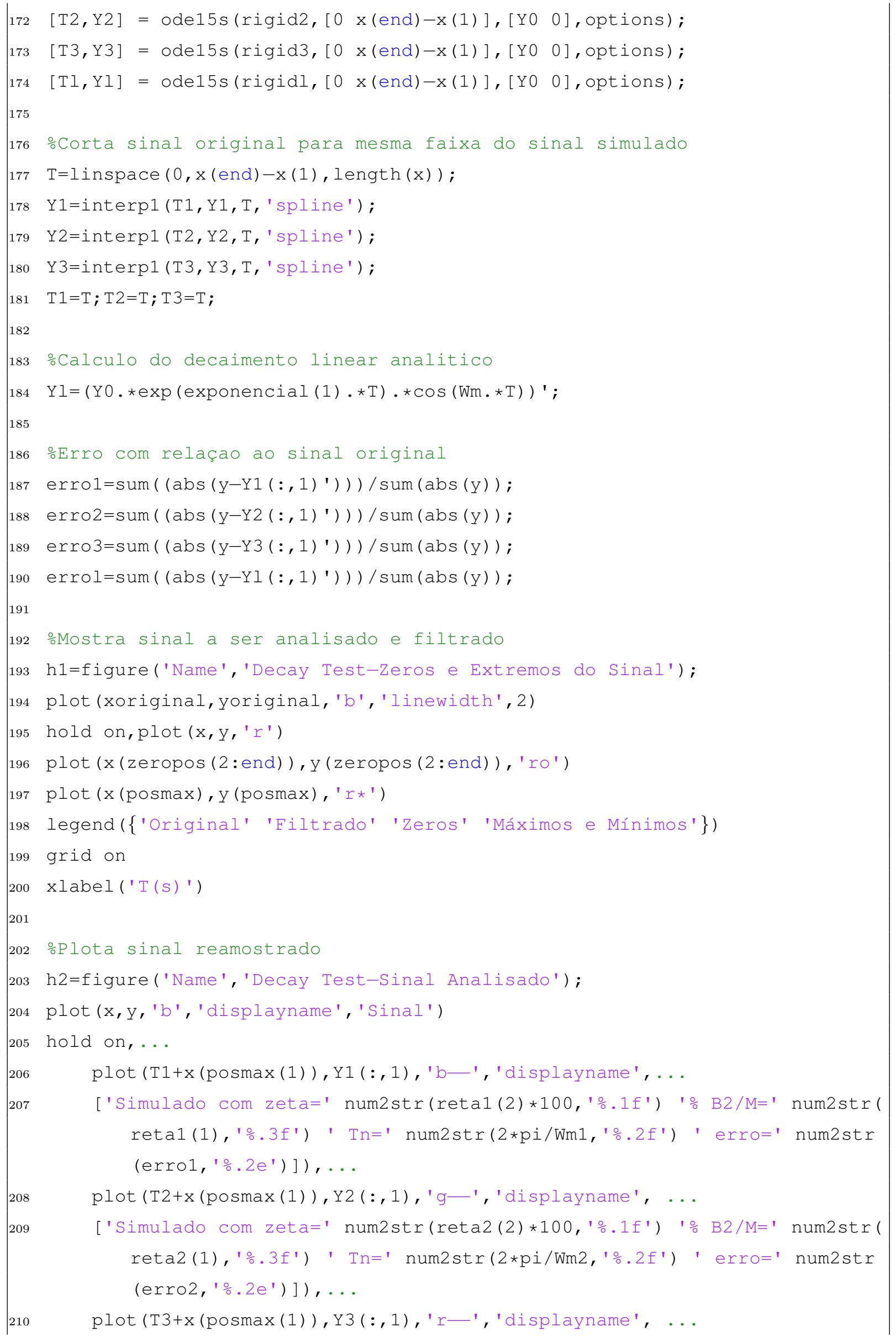




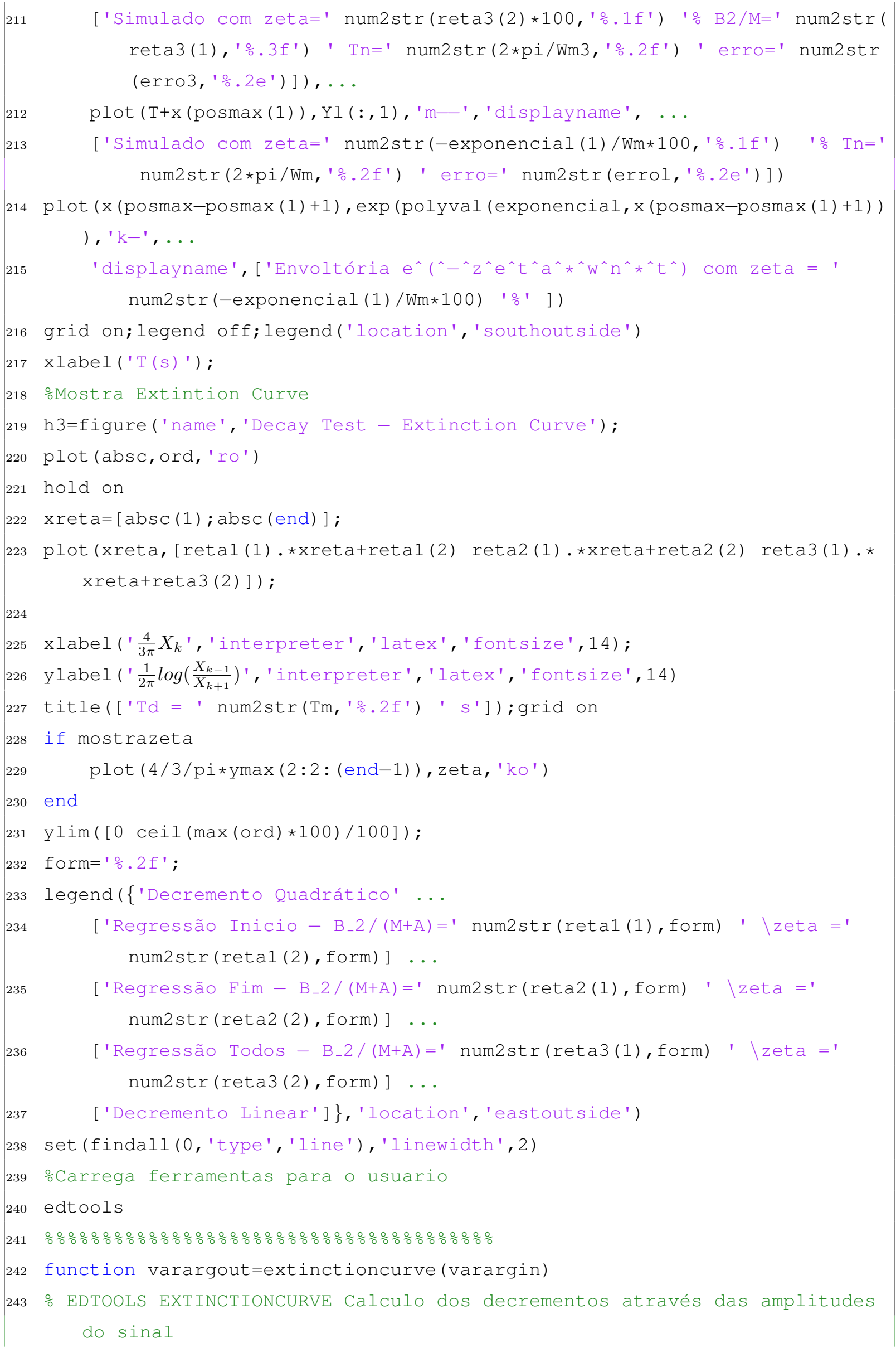




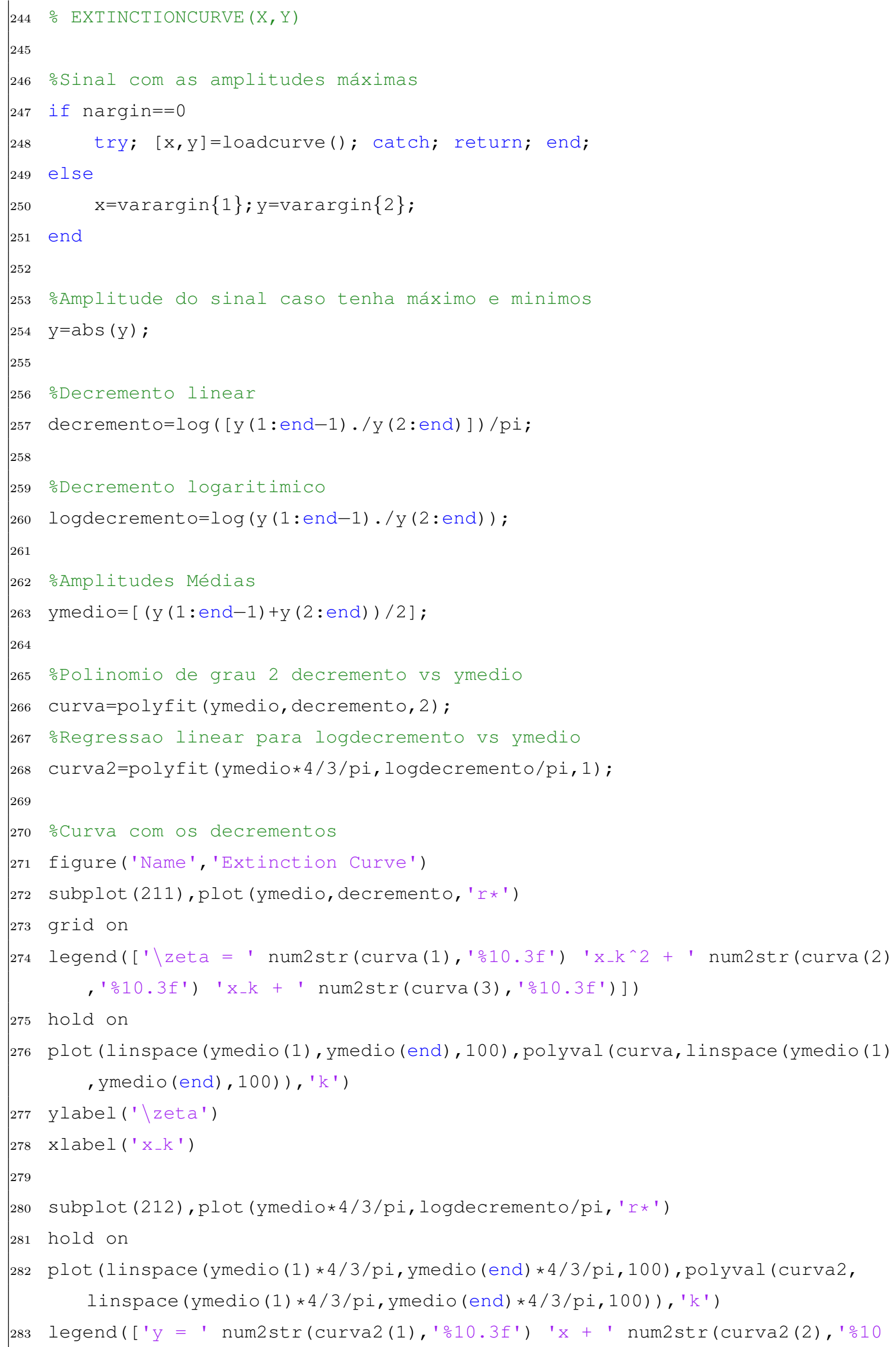




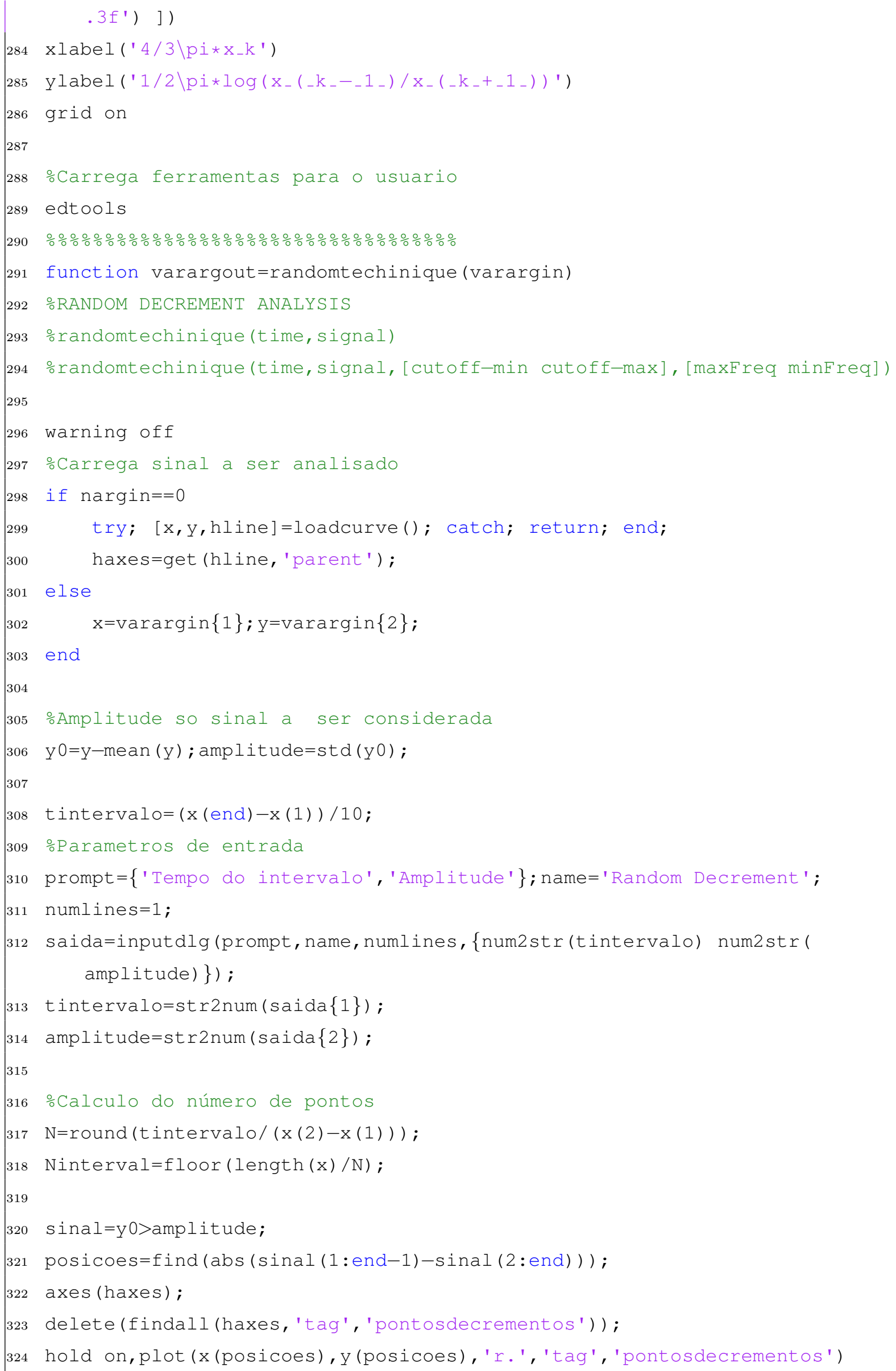




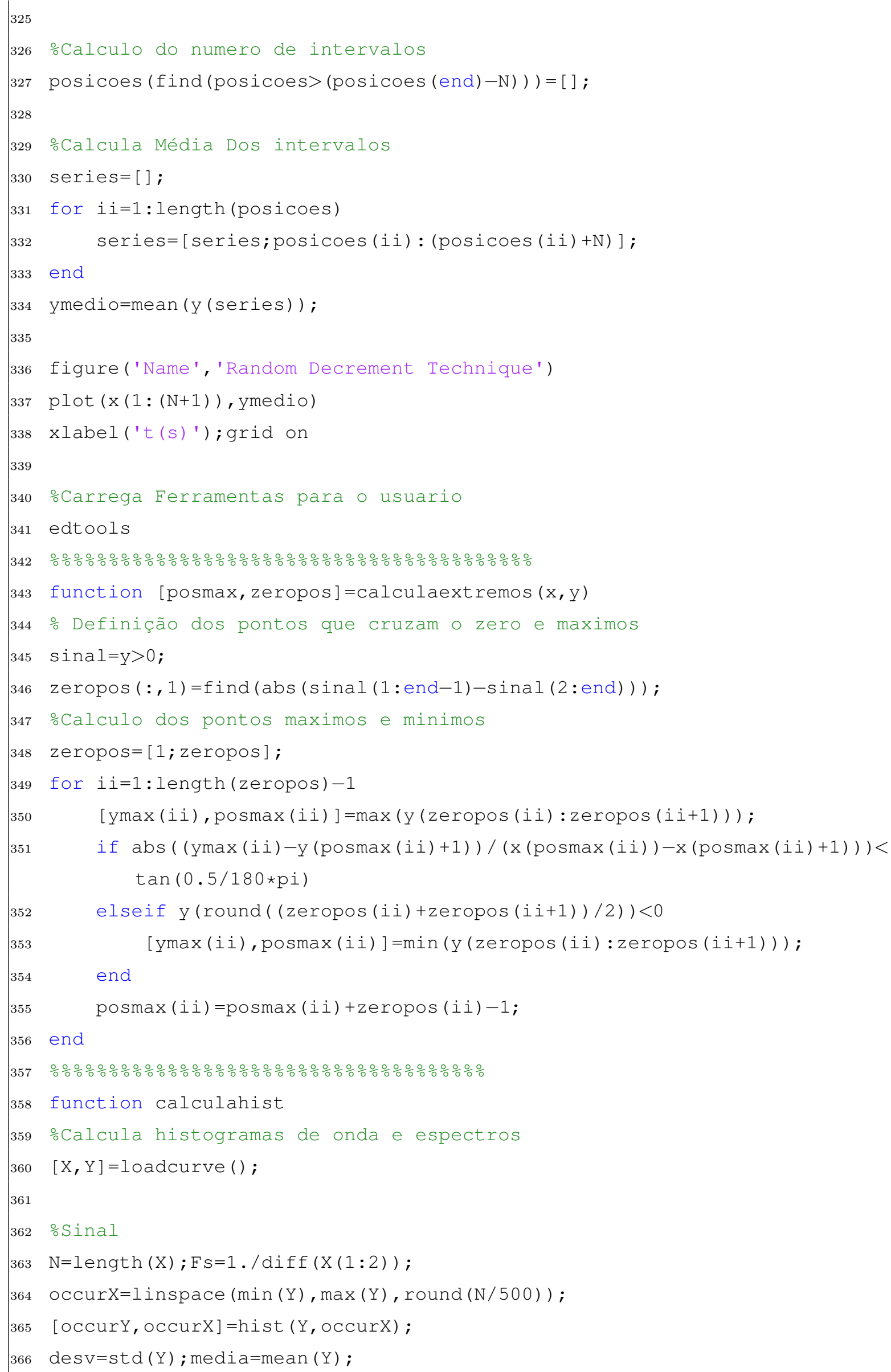




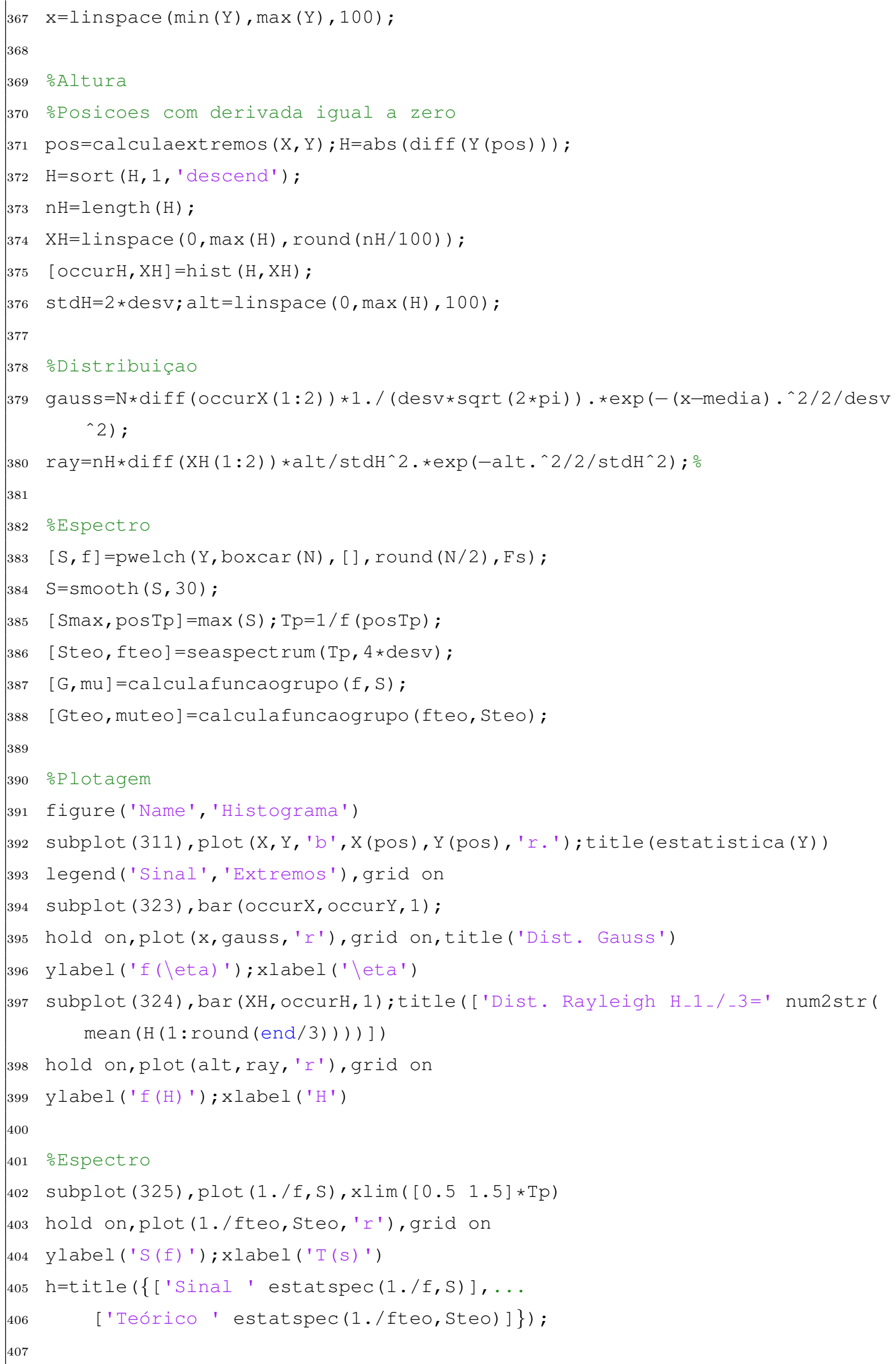




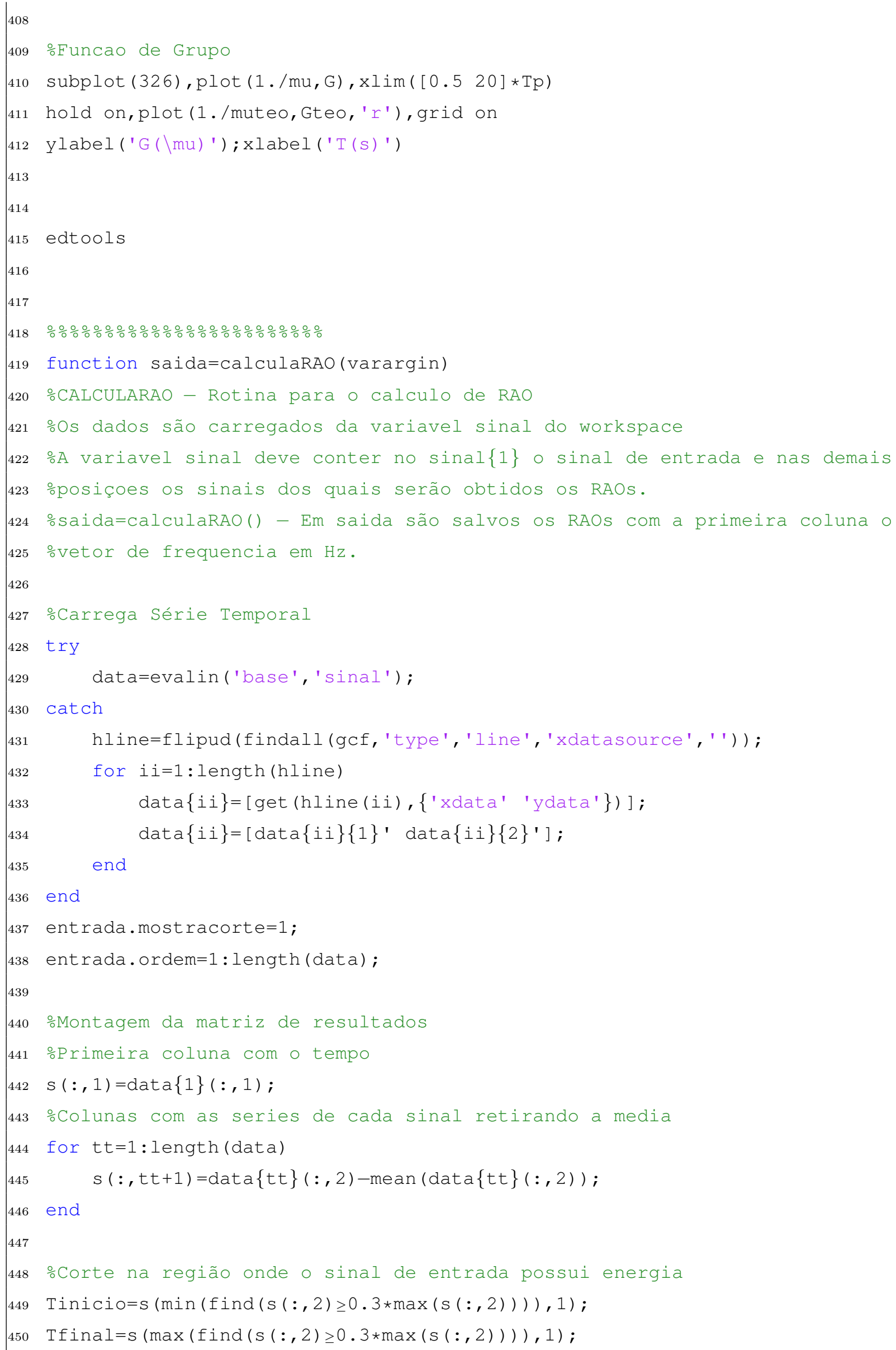




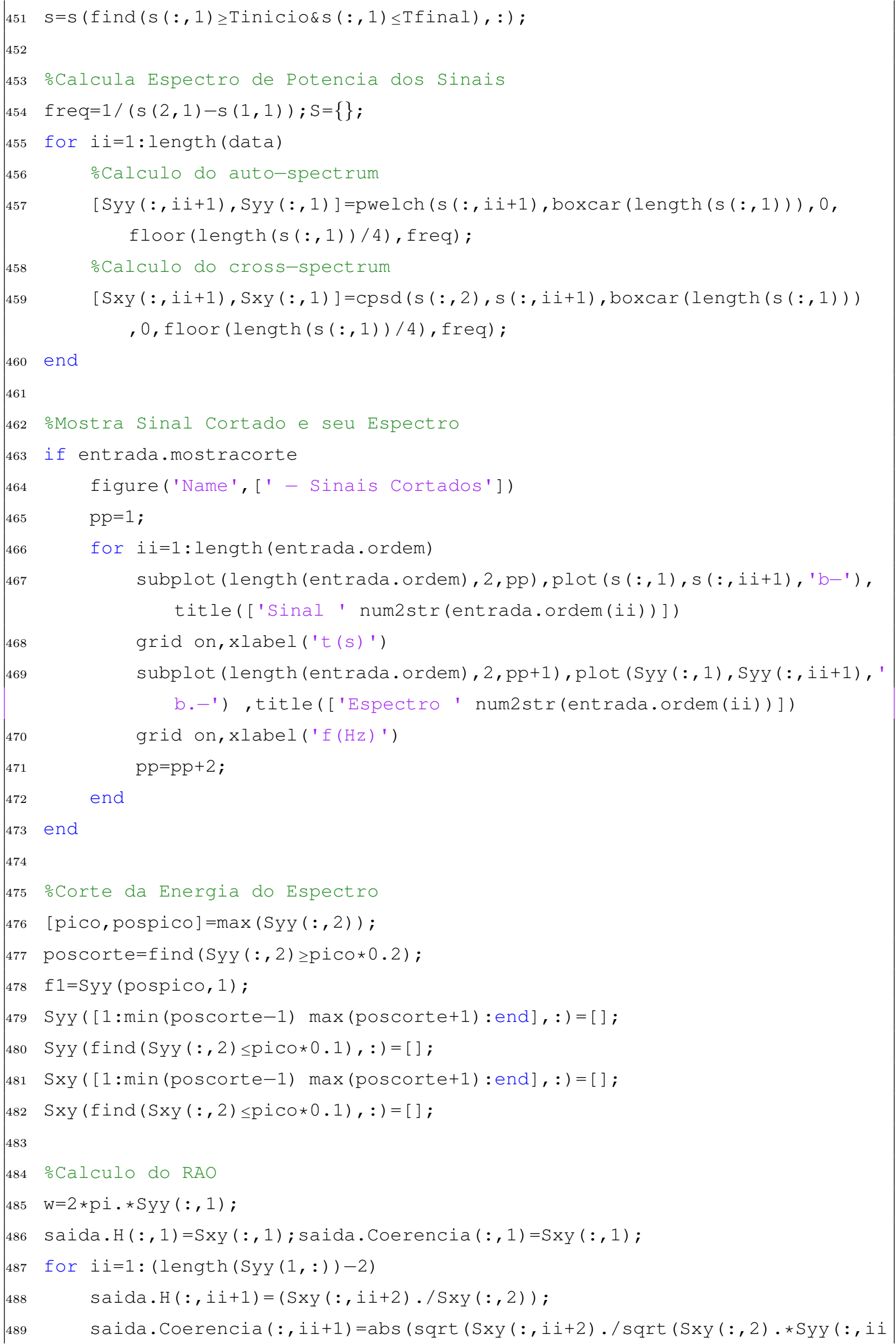


+2))) ) ;

490

491

492 OMostra Resultados do Calculo do RAO

493 figure('Name', [get (gcf, 'Name') ' RAO'])

$494 \mathrm{pp}=1$;

495 for $i i=1$ : length (entrada.ordem) -1

496 subplot (length (entrada.ordem)-1,3,pp), plot (saida.H (: , 1).^^1, abs ( saida.H ( : , i i+1)), 'b.-' )

497 grid on,ylabel(['RAO' num2str(ii)]), xlabel(['T(s)'])

498 subplot (length (entrada.ordem) -1,3,pp+1), plot (saida.H ( : , 1) .^-1, abs ( unwrap (angle (saida.H (:, ii+1))/pi*180)), 'b.-' )

505 OSalva resultado no Workspace 


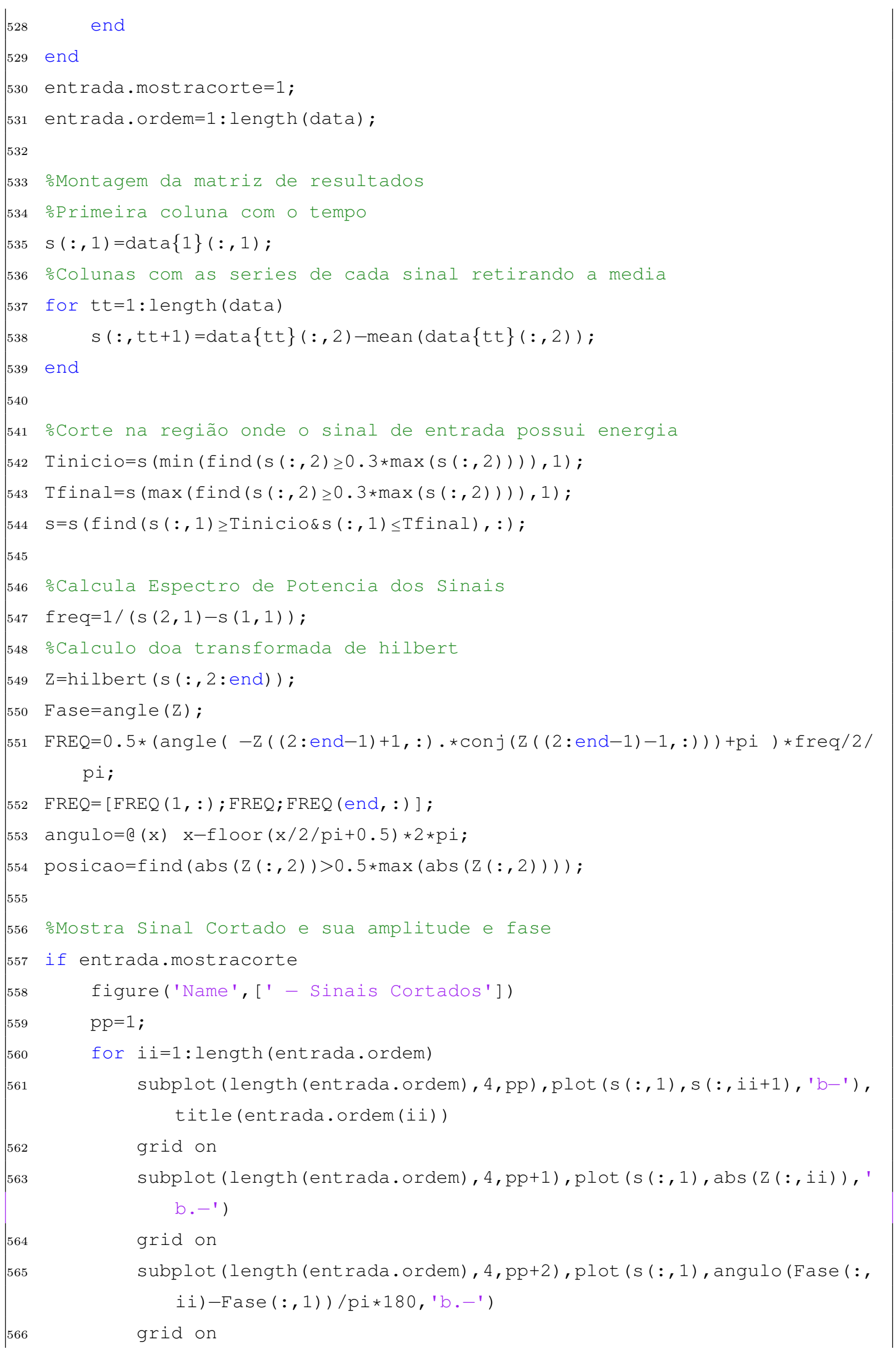




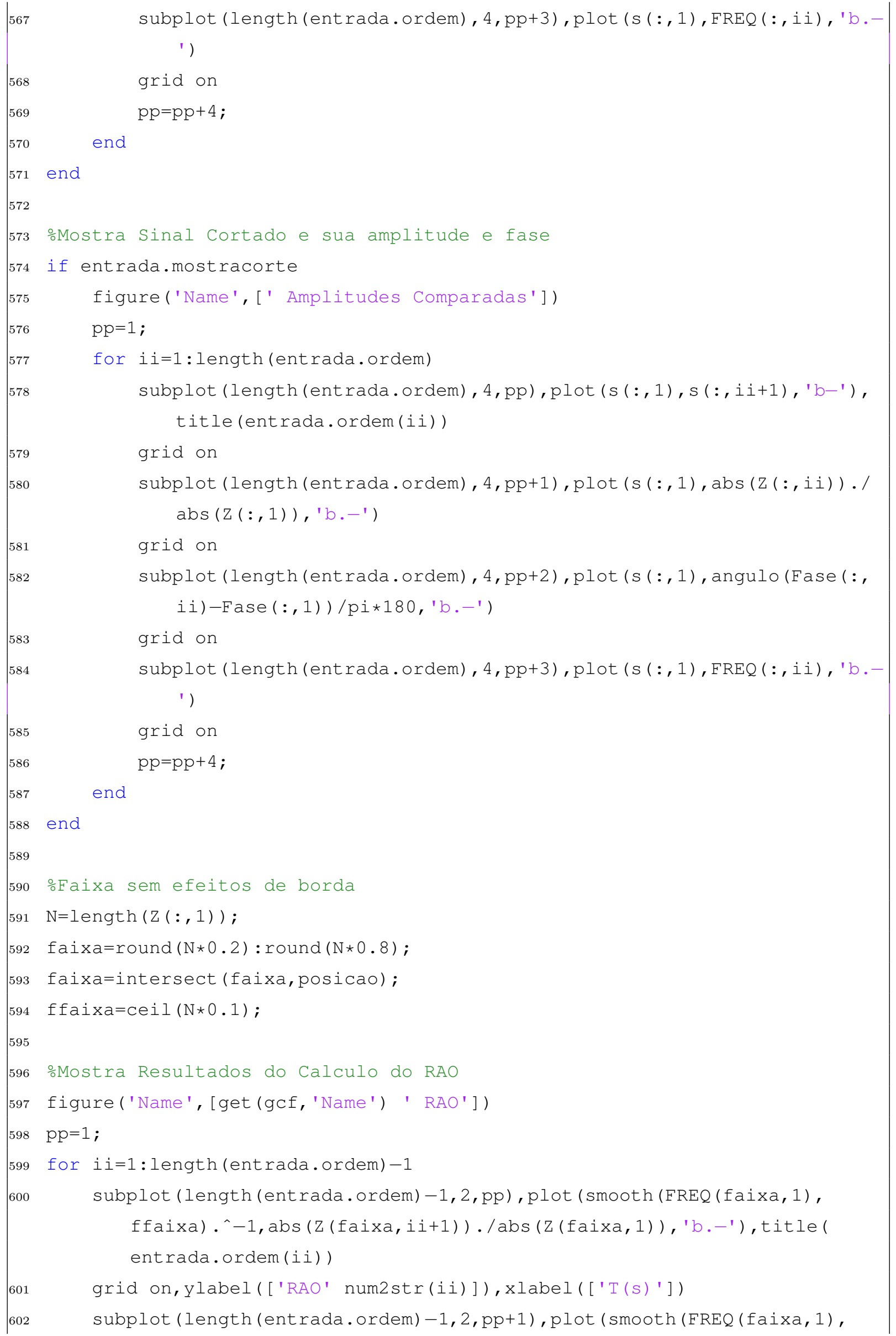




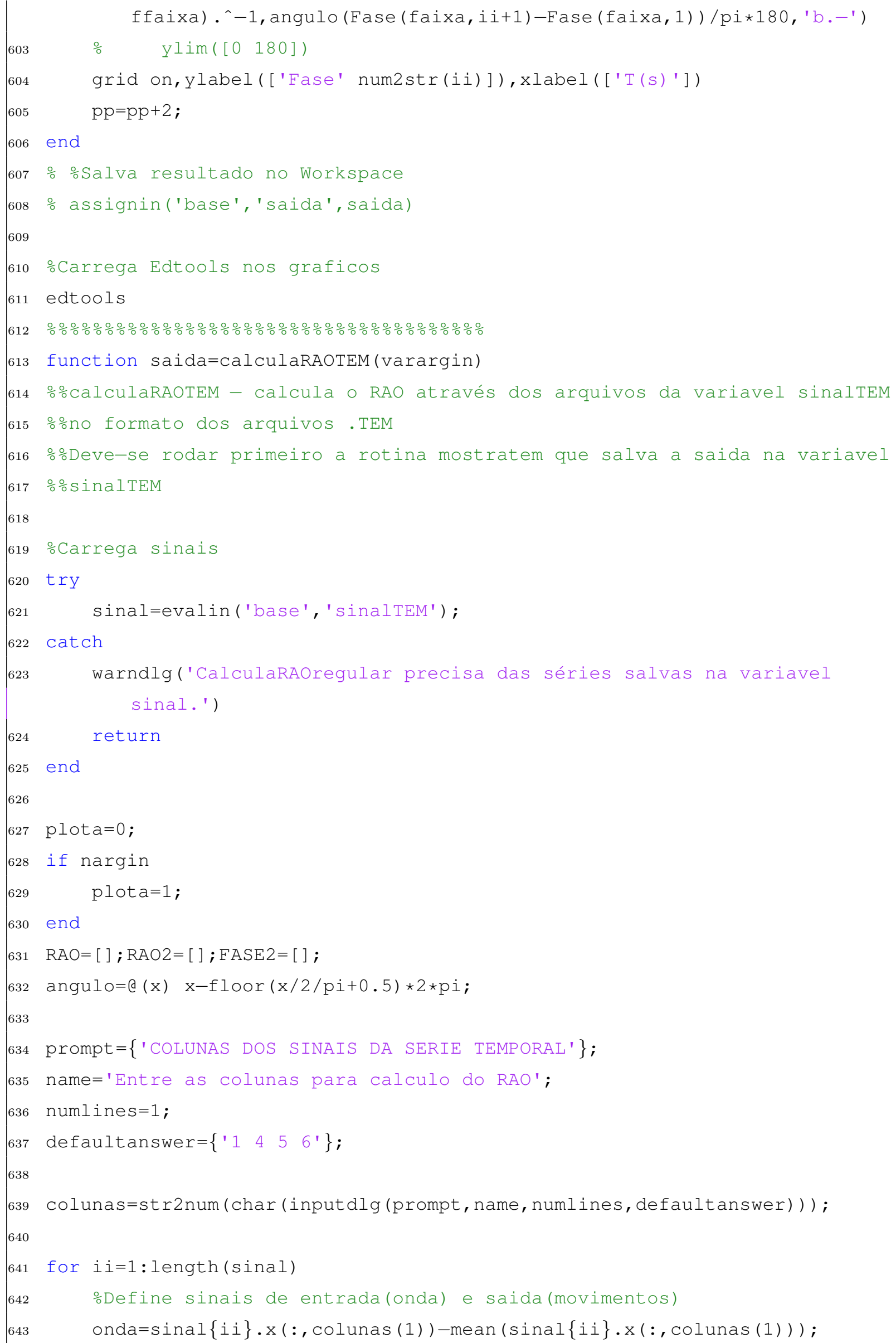




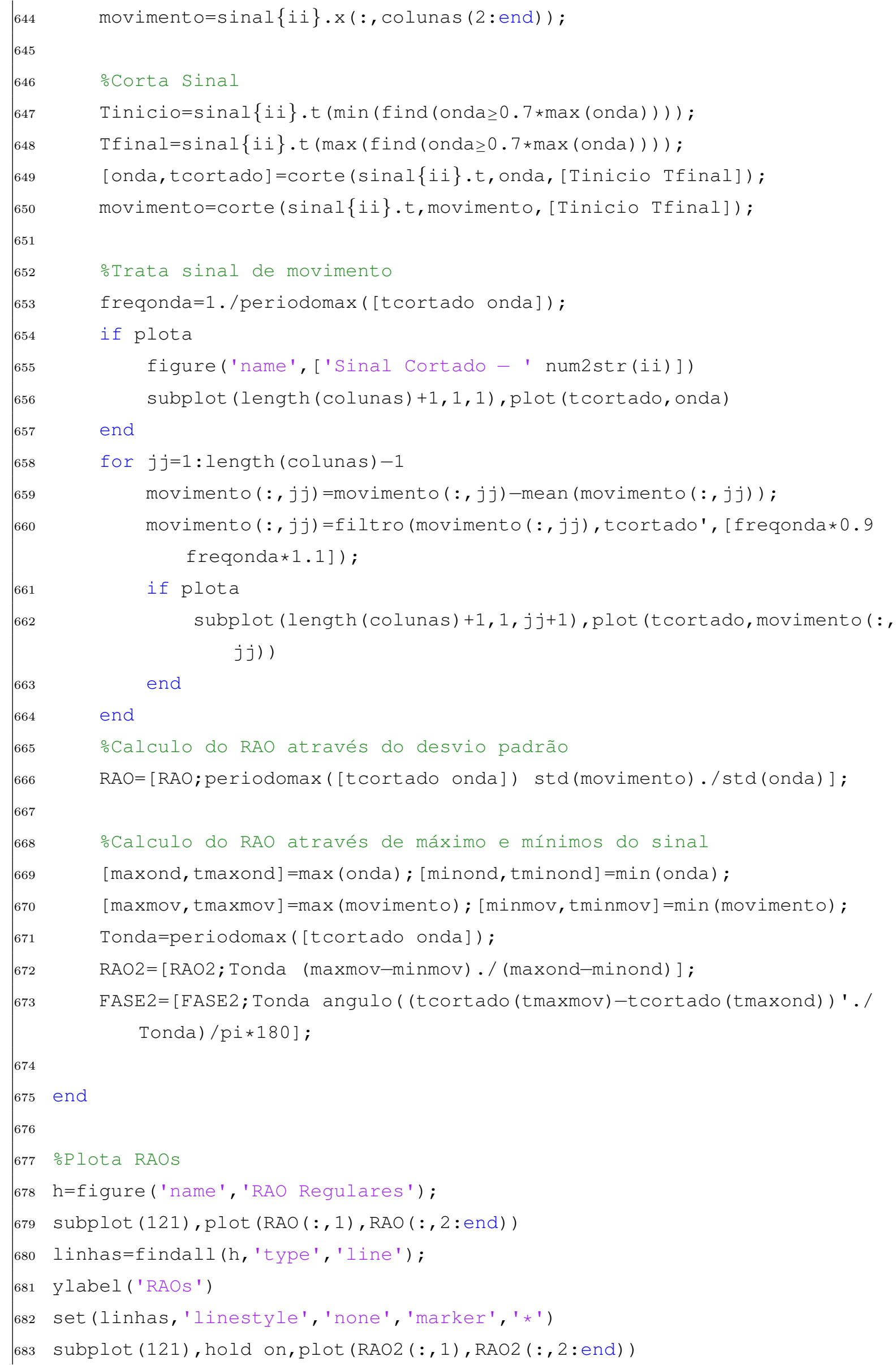




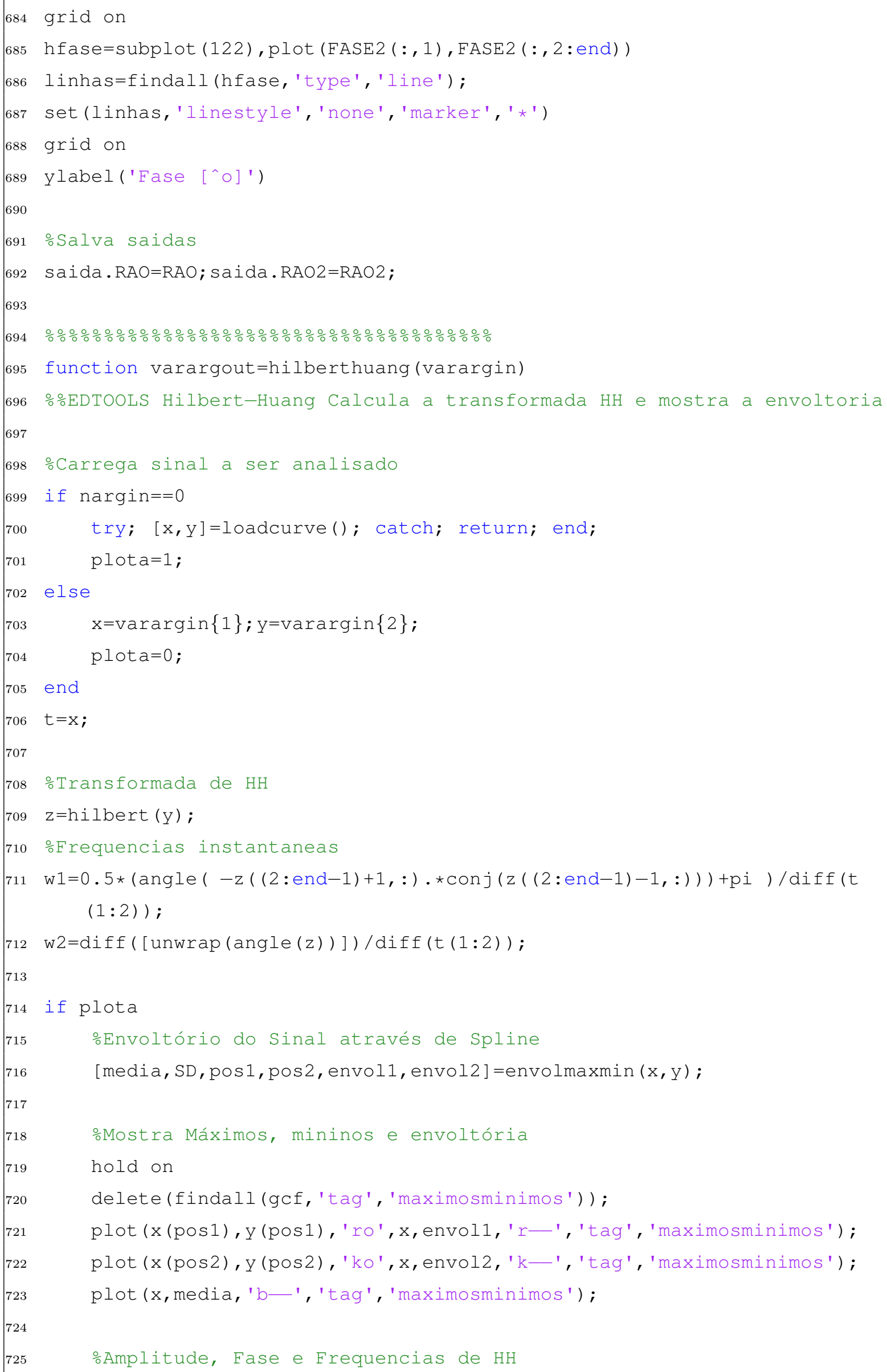




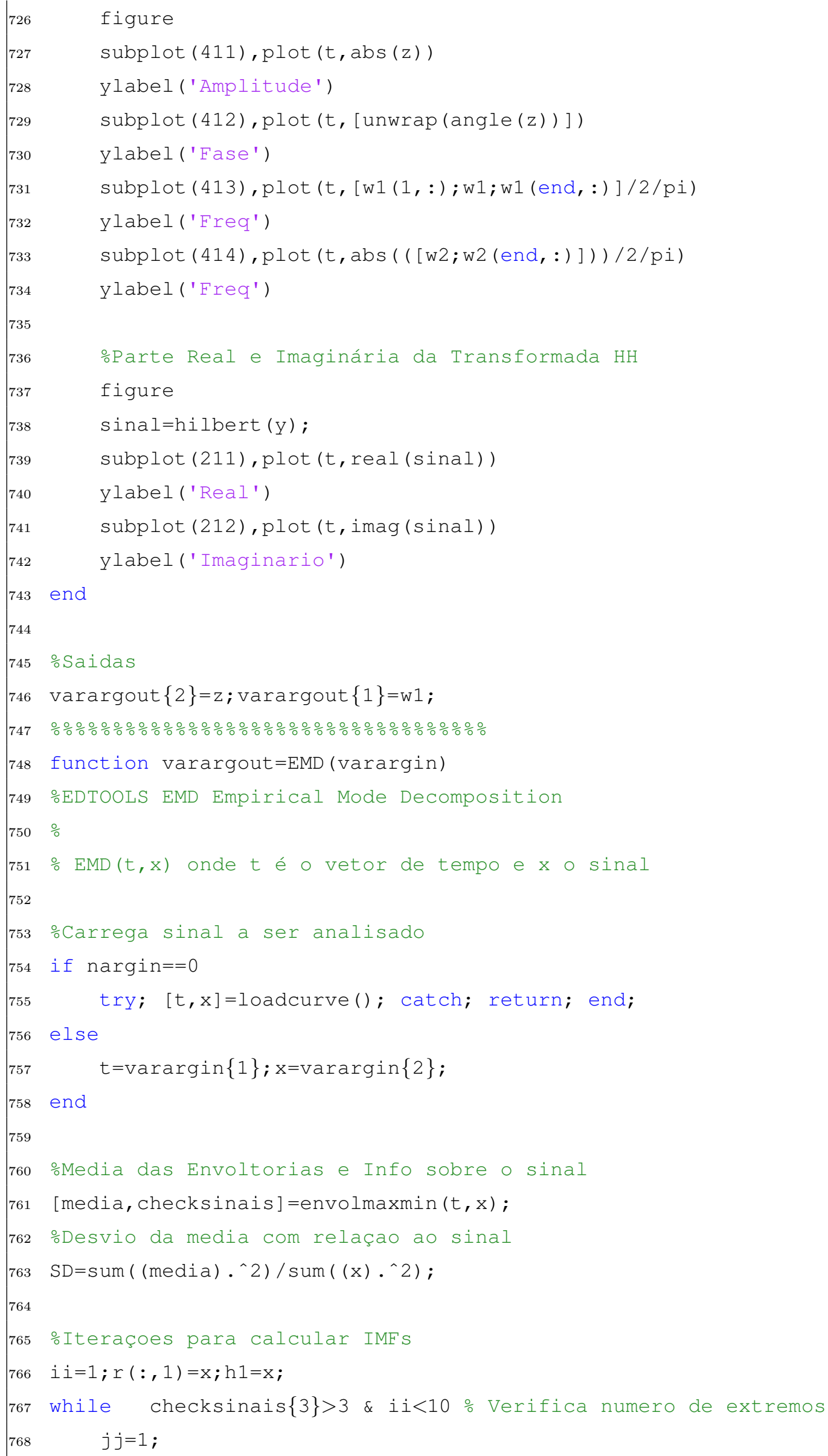




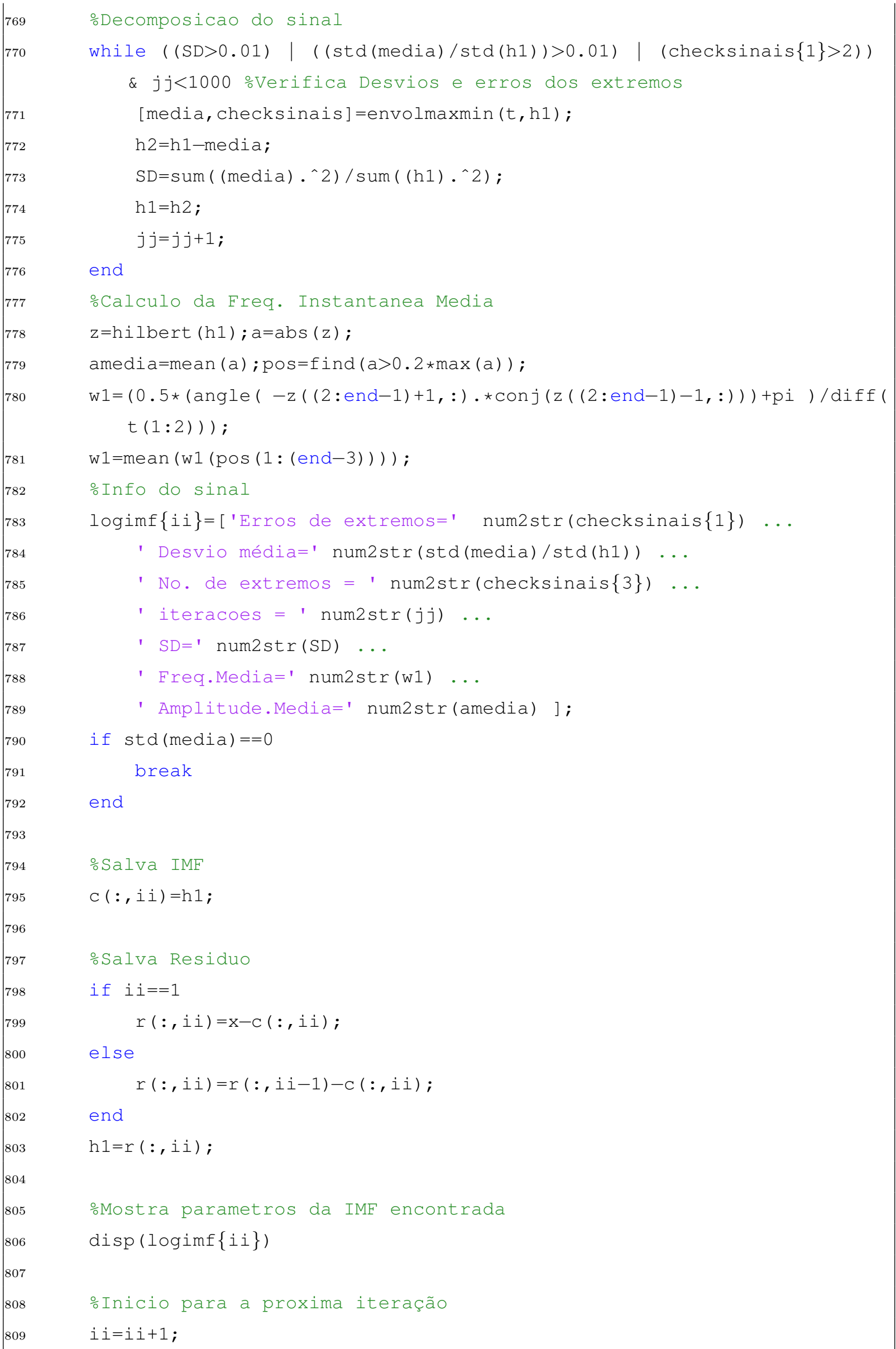




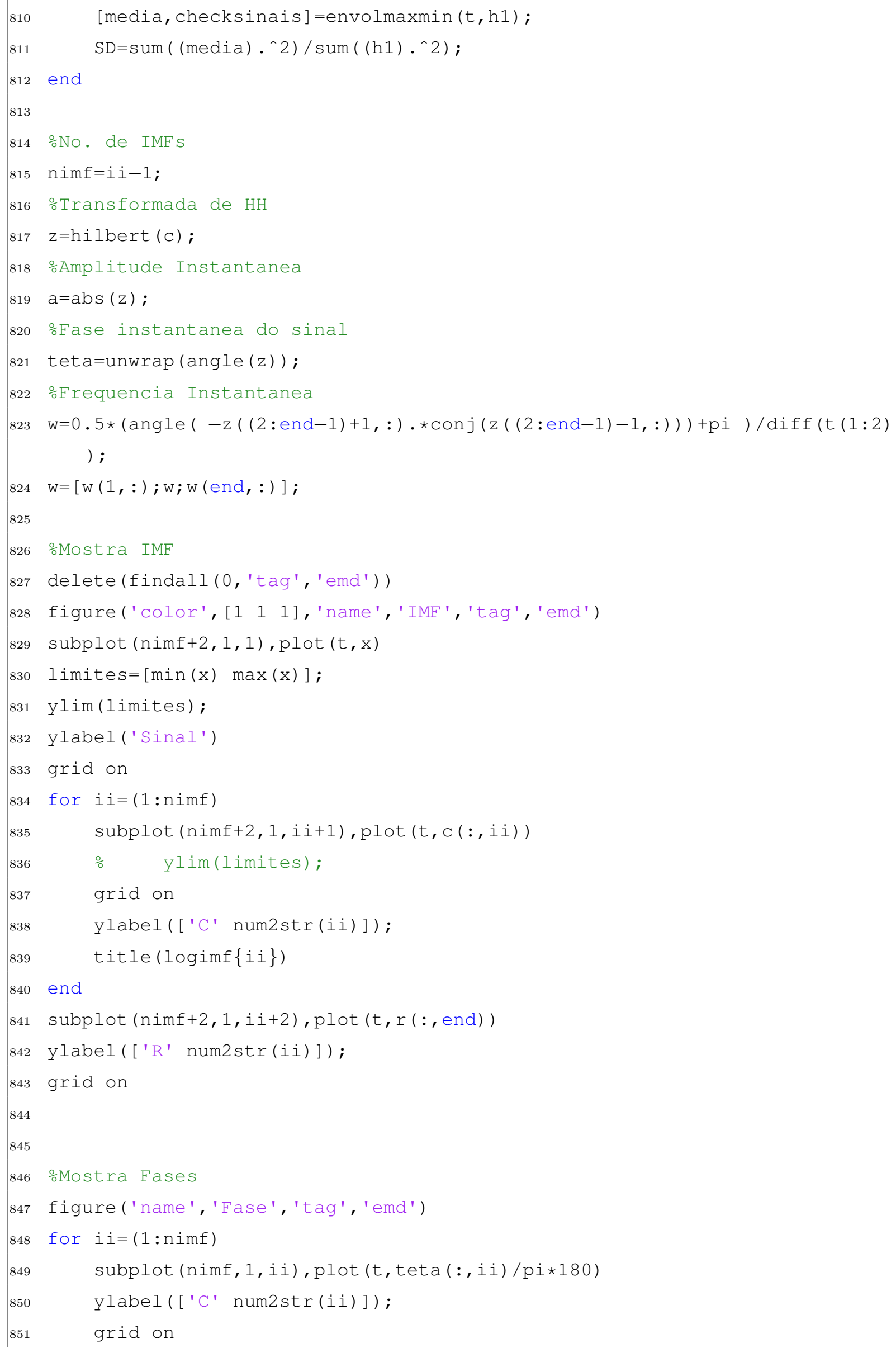




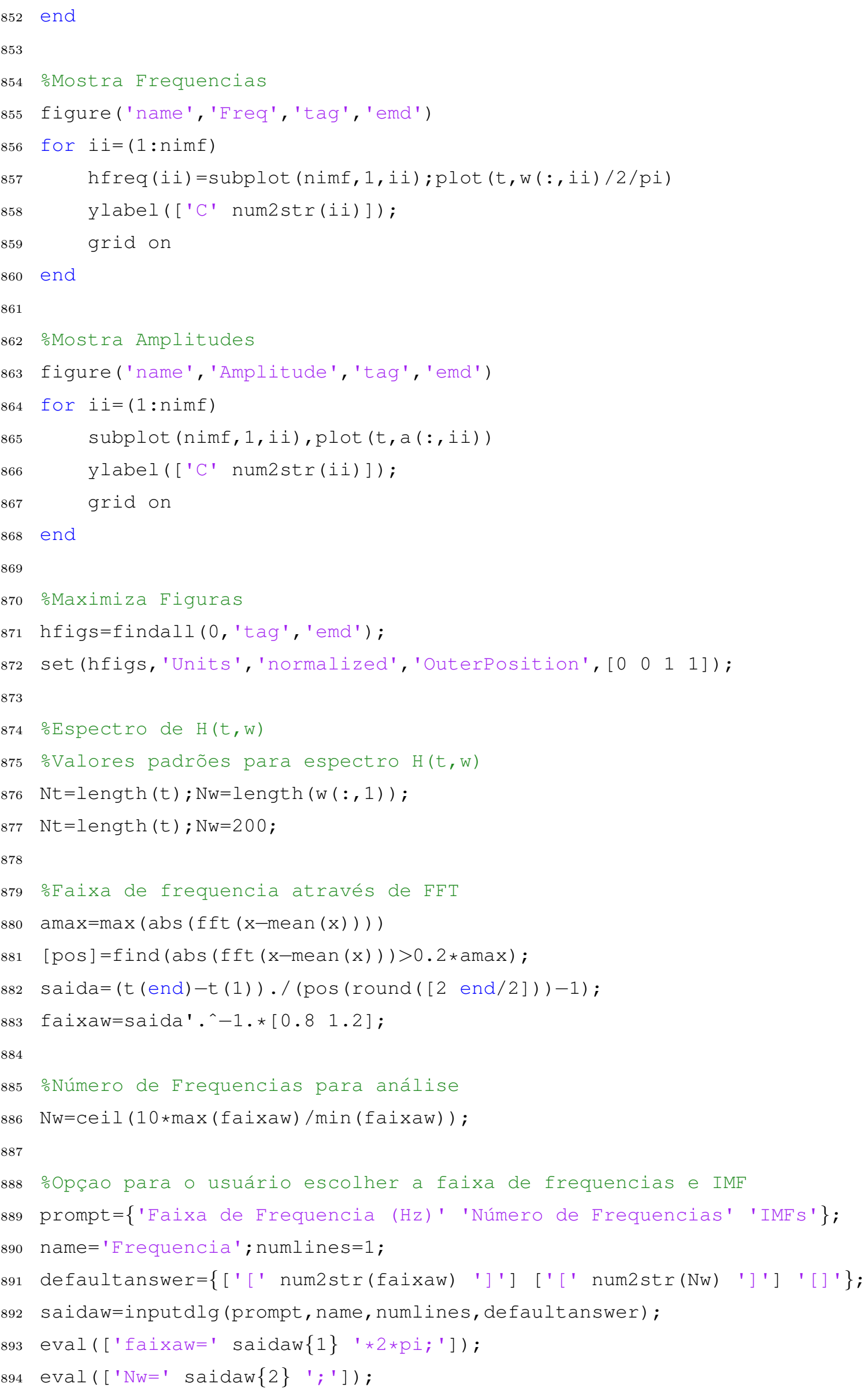




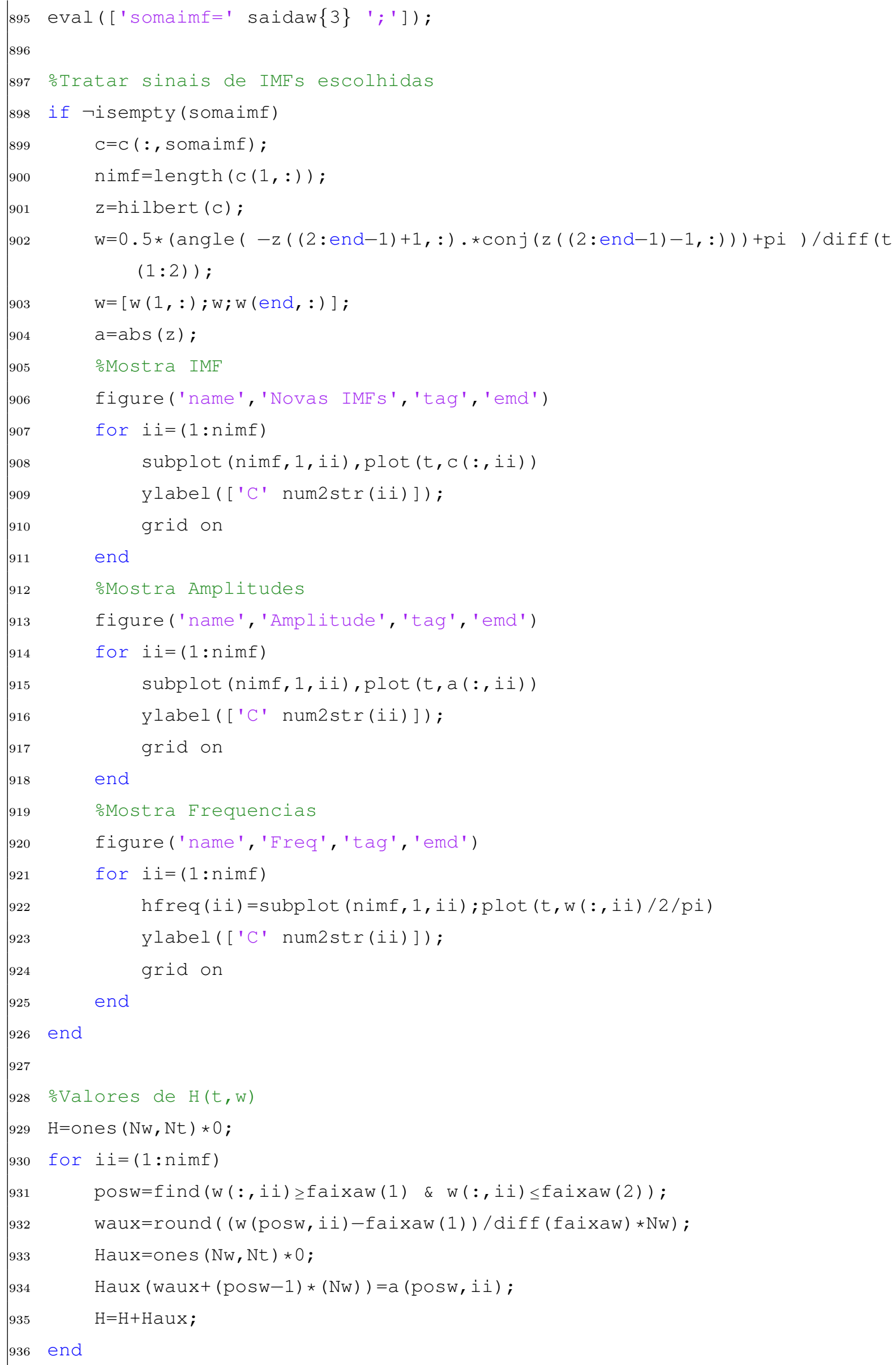




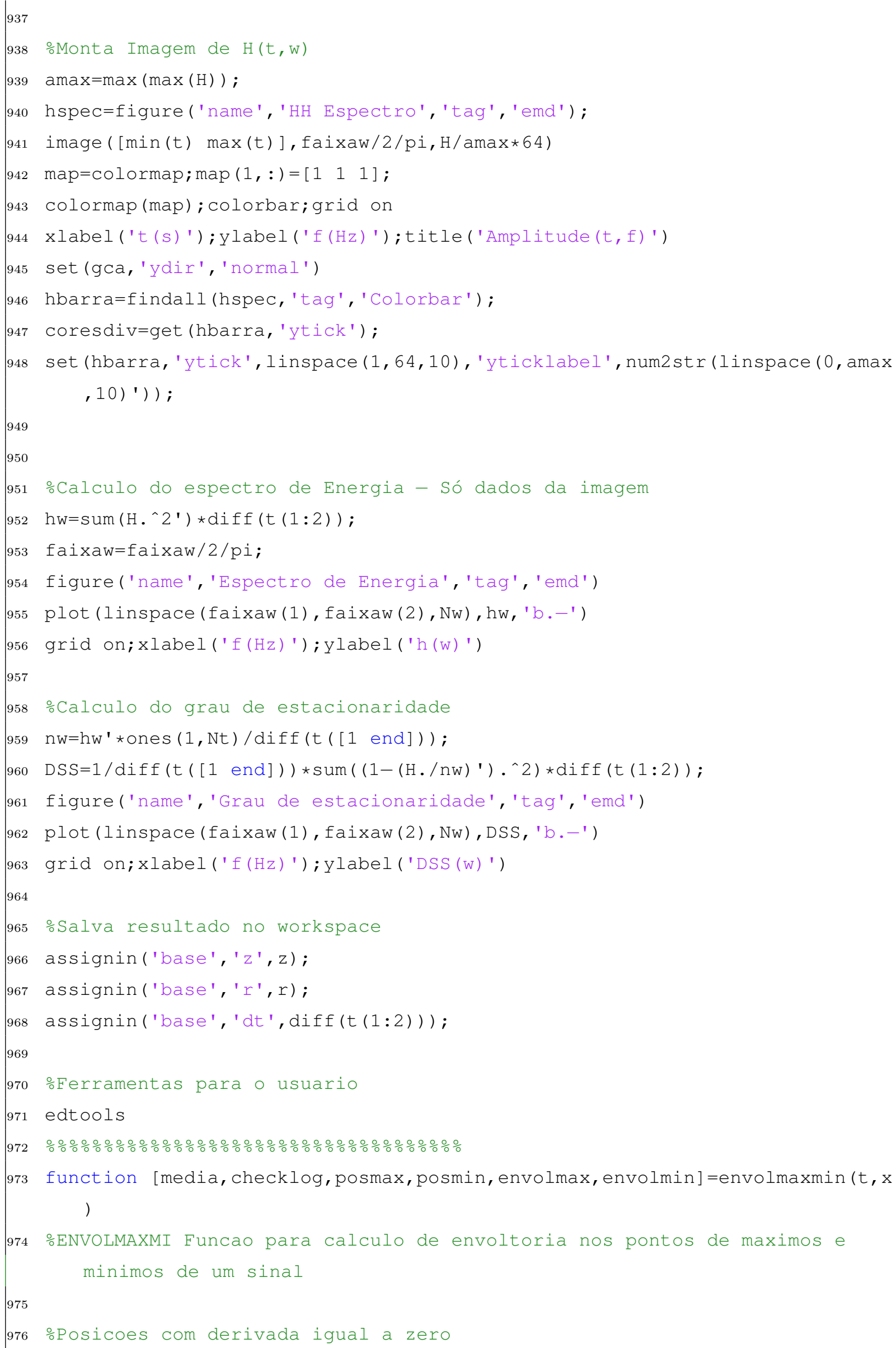




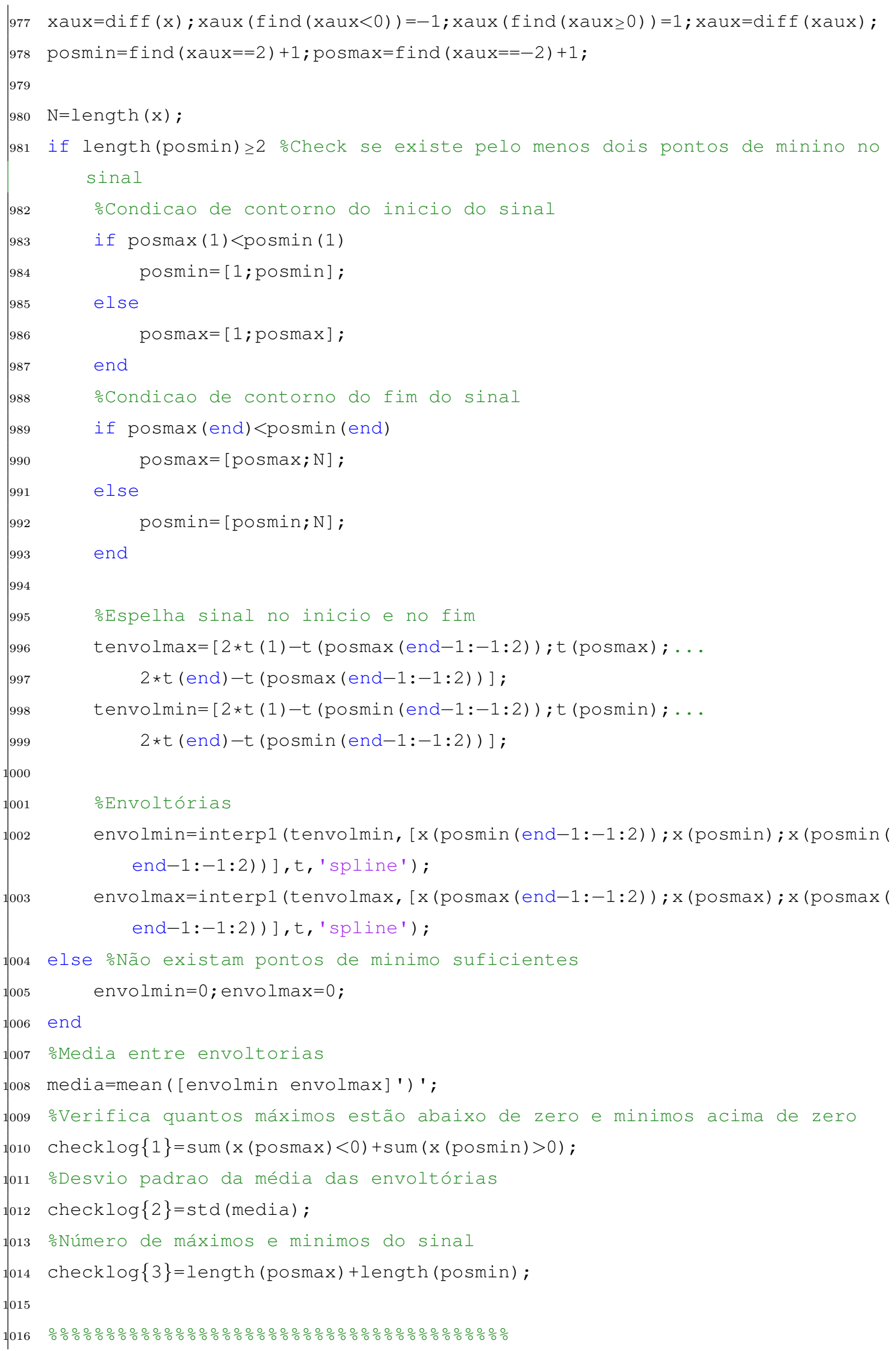




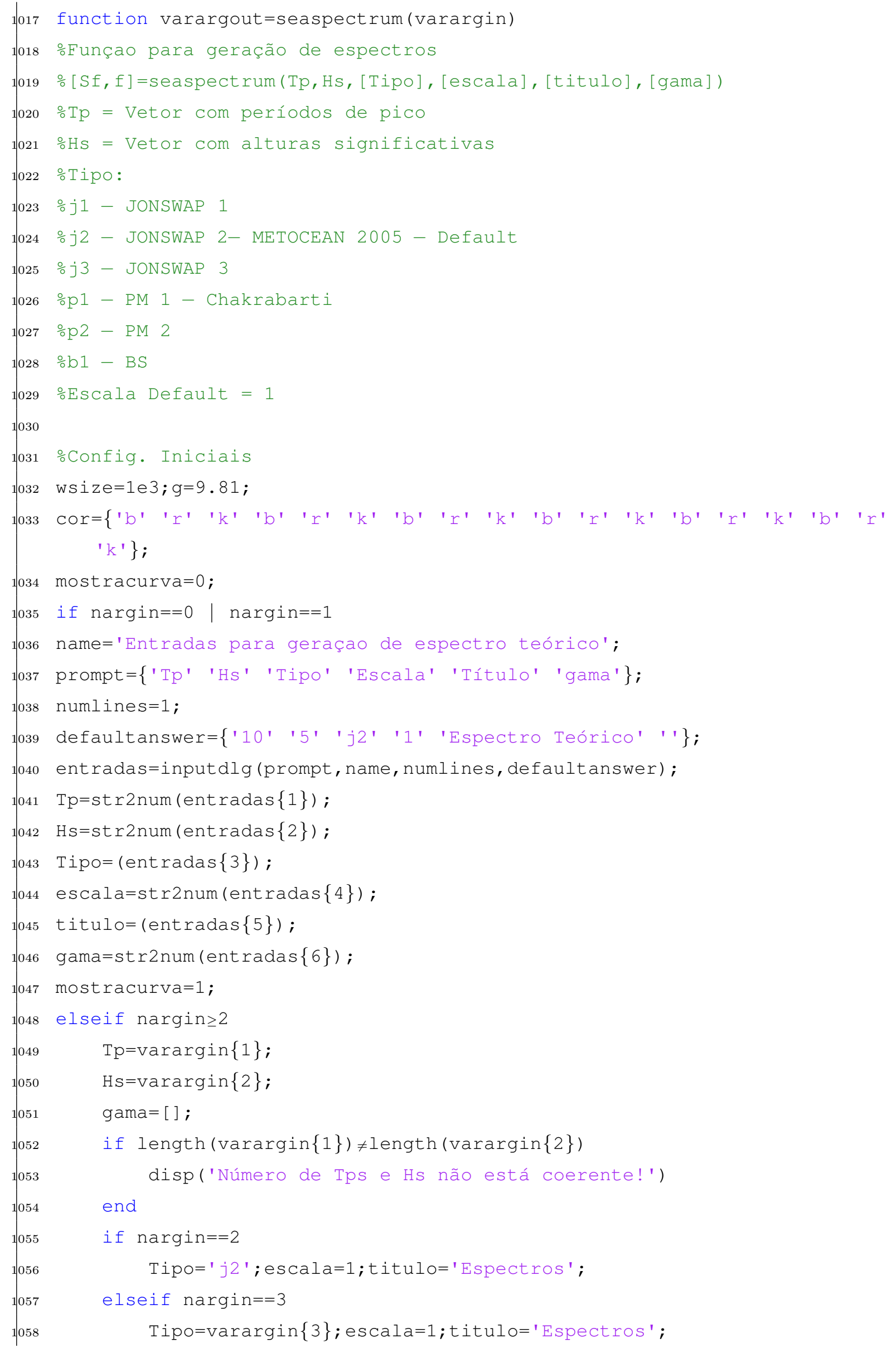




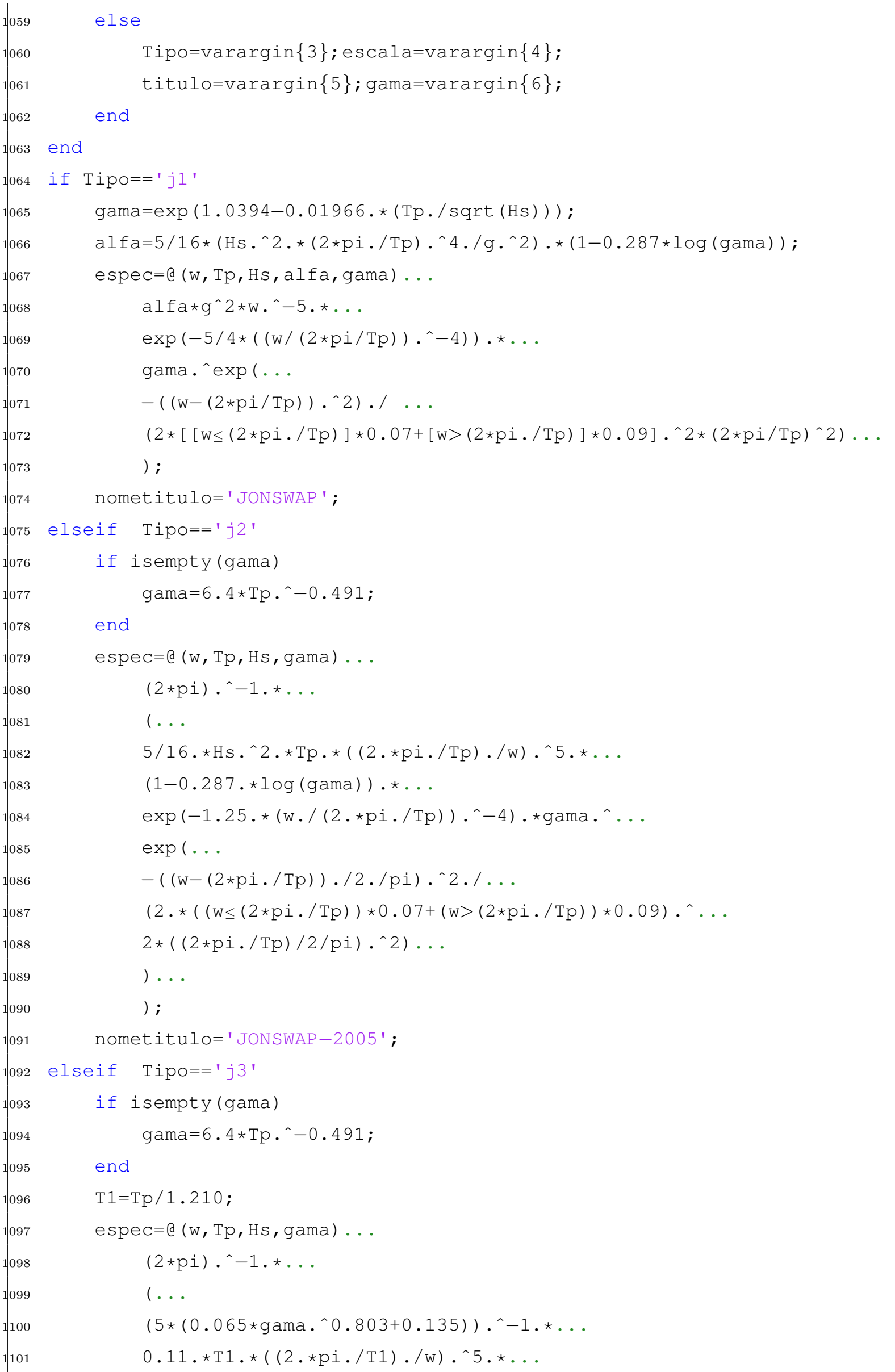




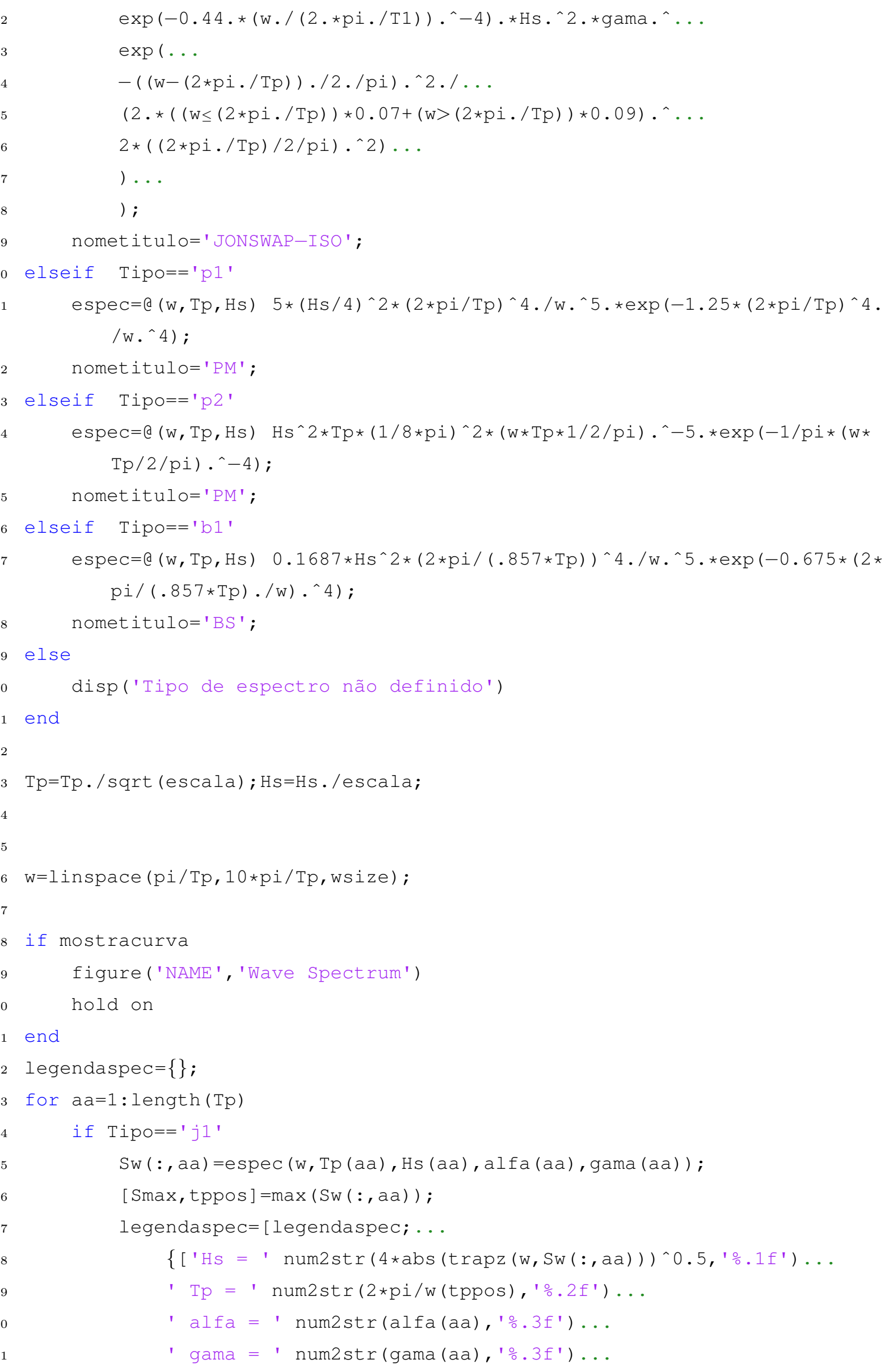




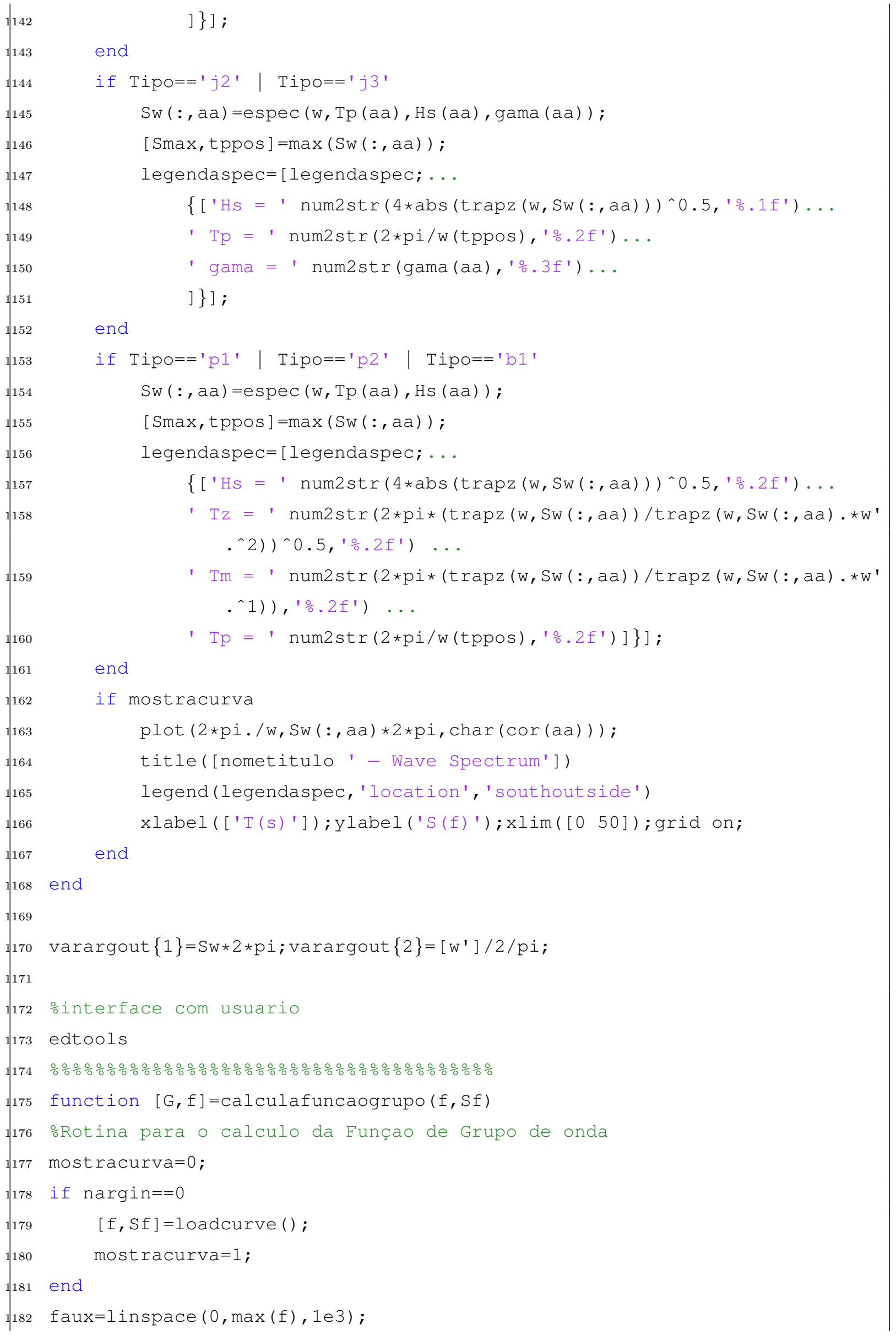




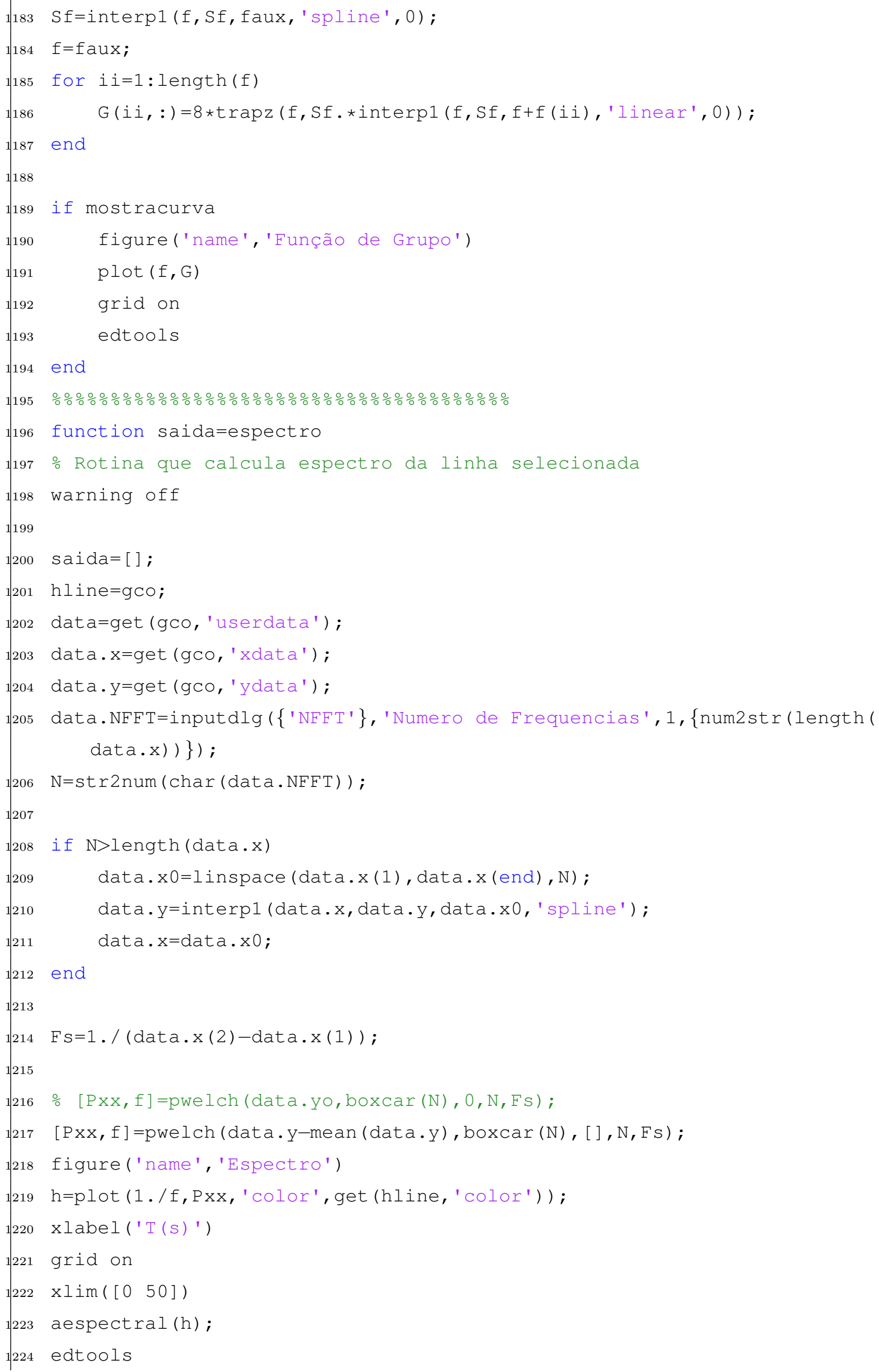




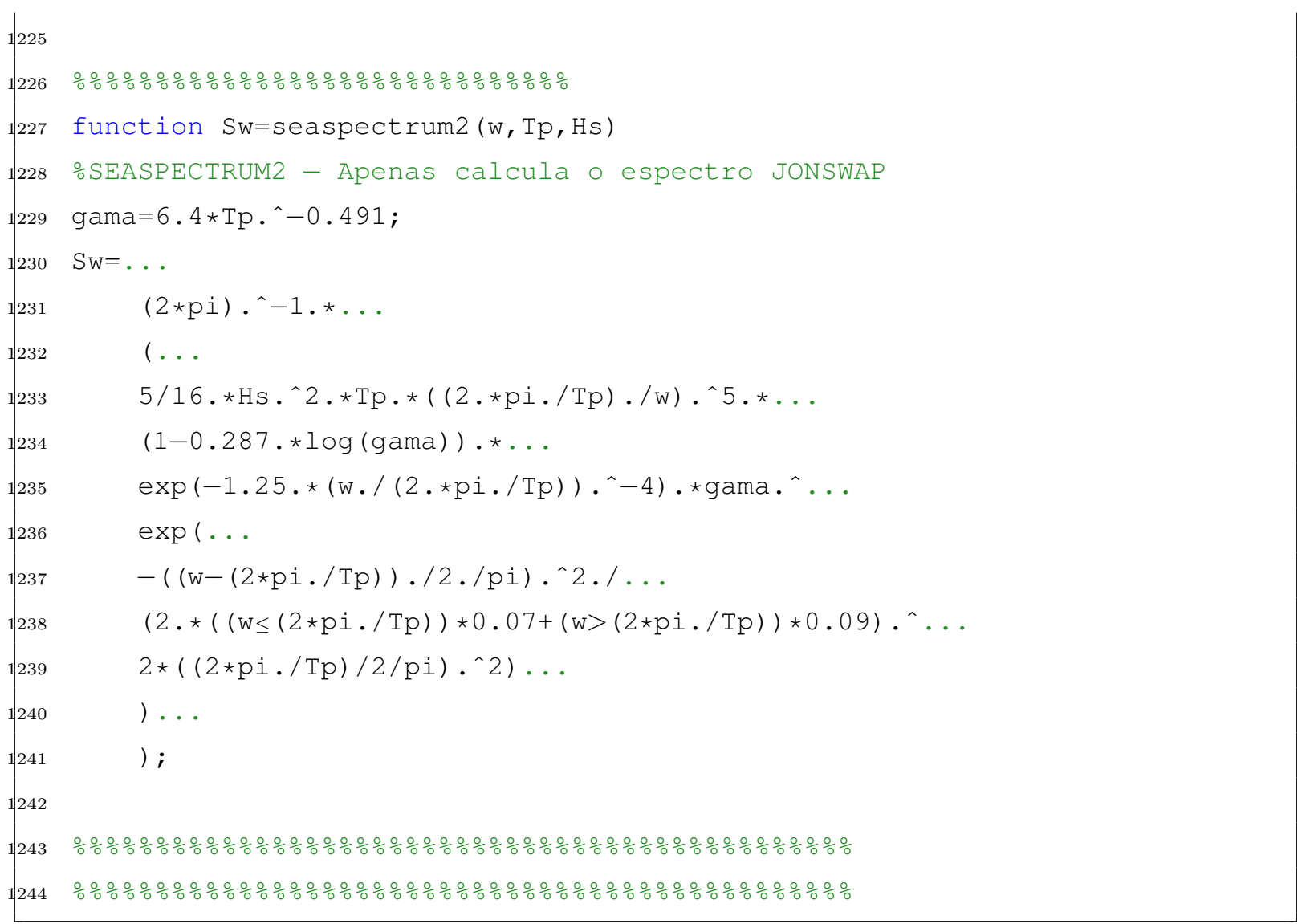

\section{VI.4 Rotinas de Documentação}

As rotinas de documentação auxiliam a salvar os dados do ensaio no formato de editores de texto, planilhas eletrônicas e apresentações. Assim as informações dos ensaios podem ser guardadas para avaliações e consultas futuras.

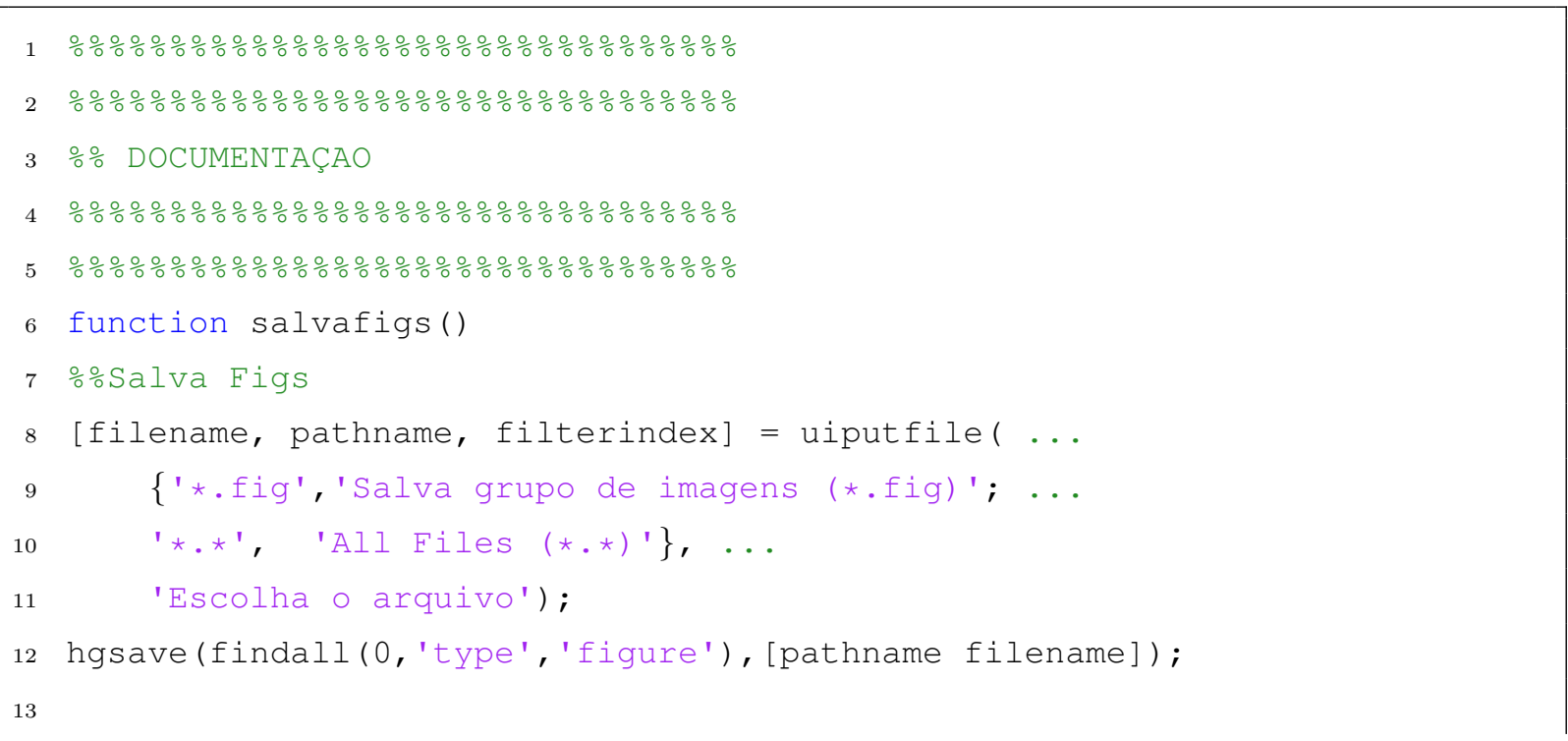




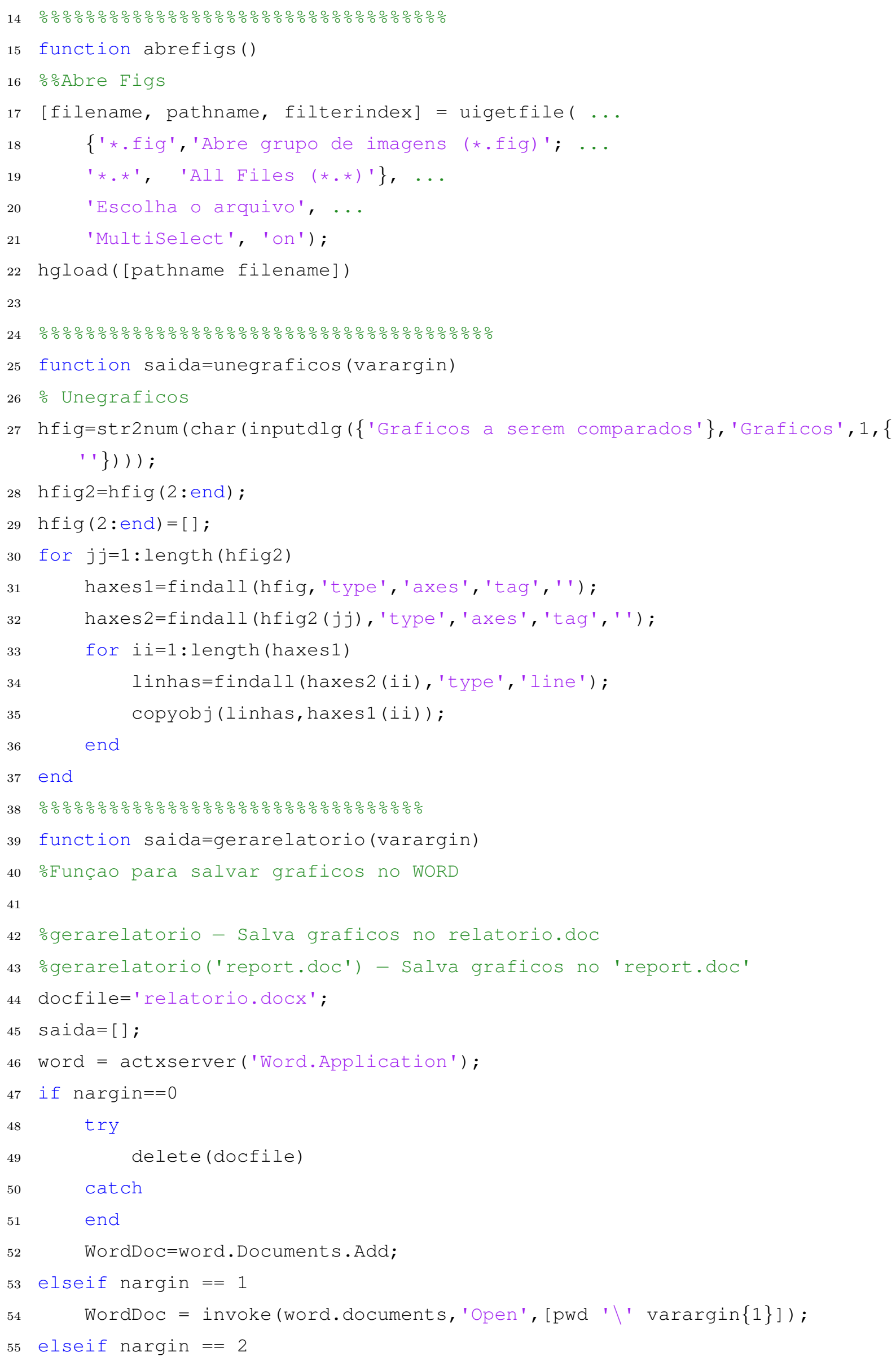




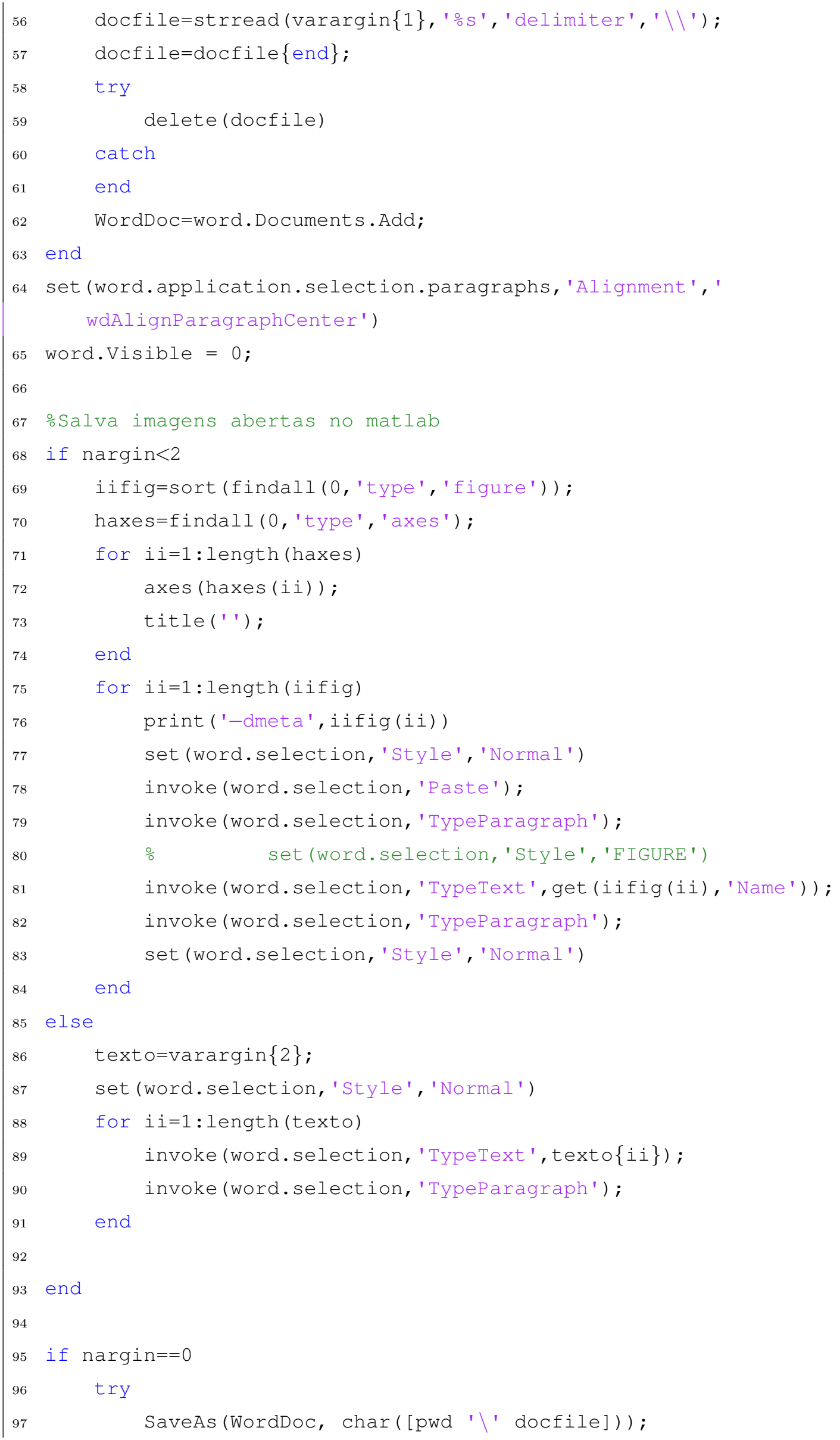




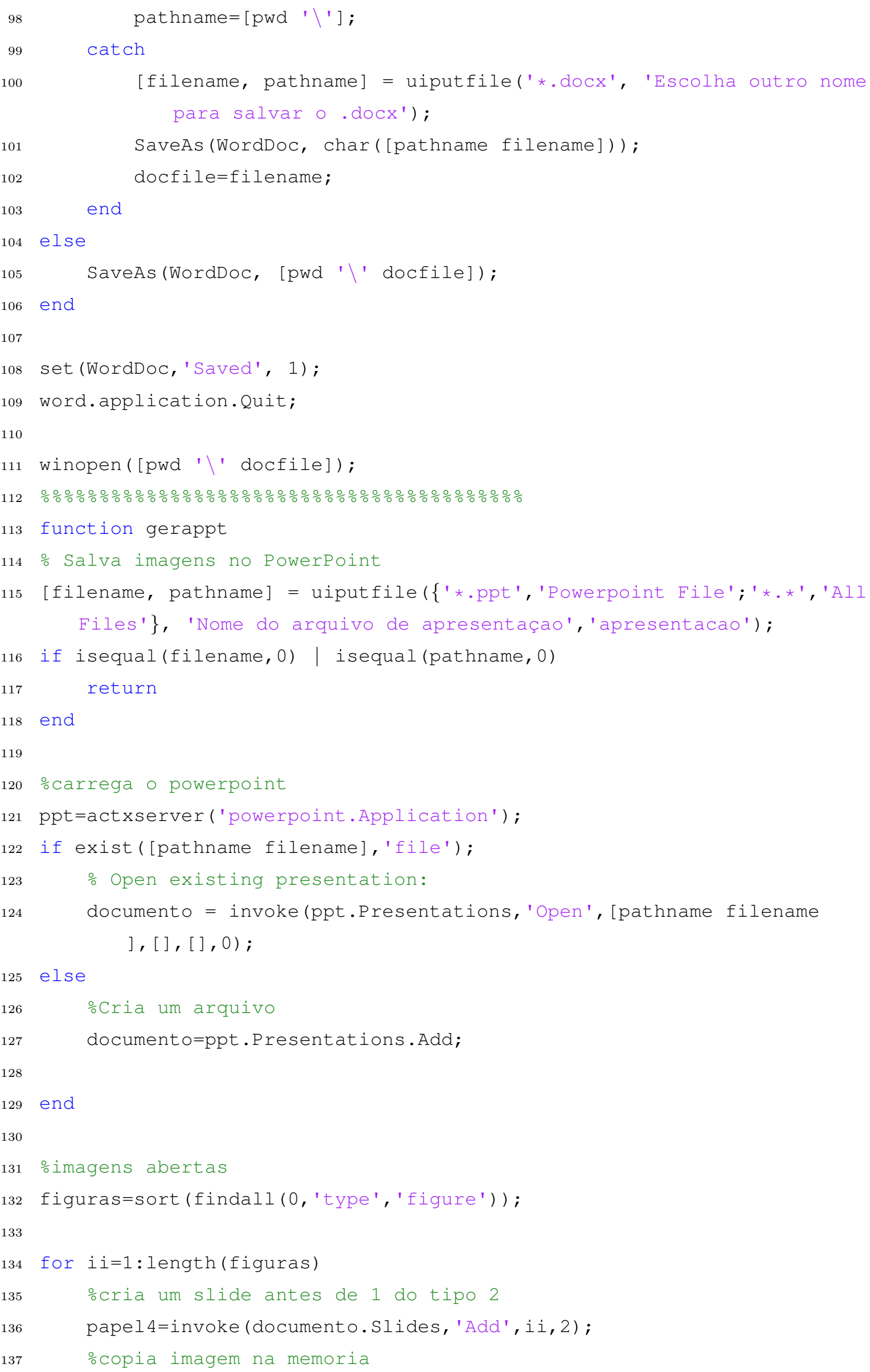




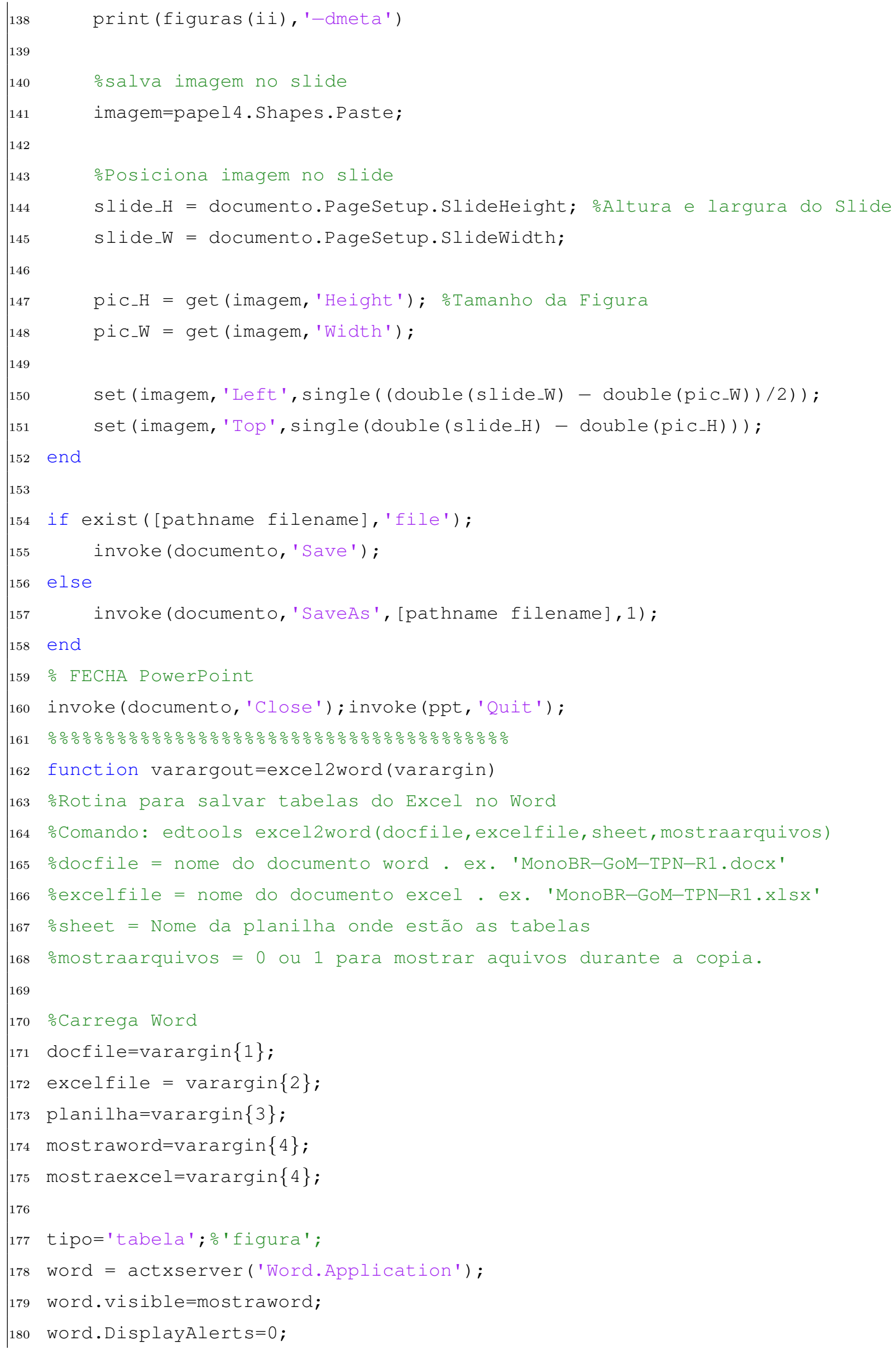




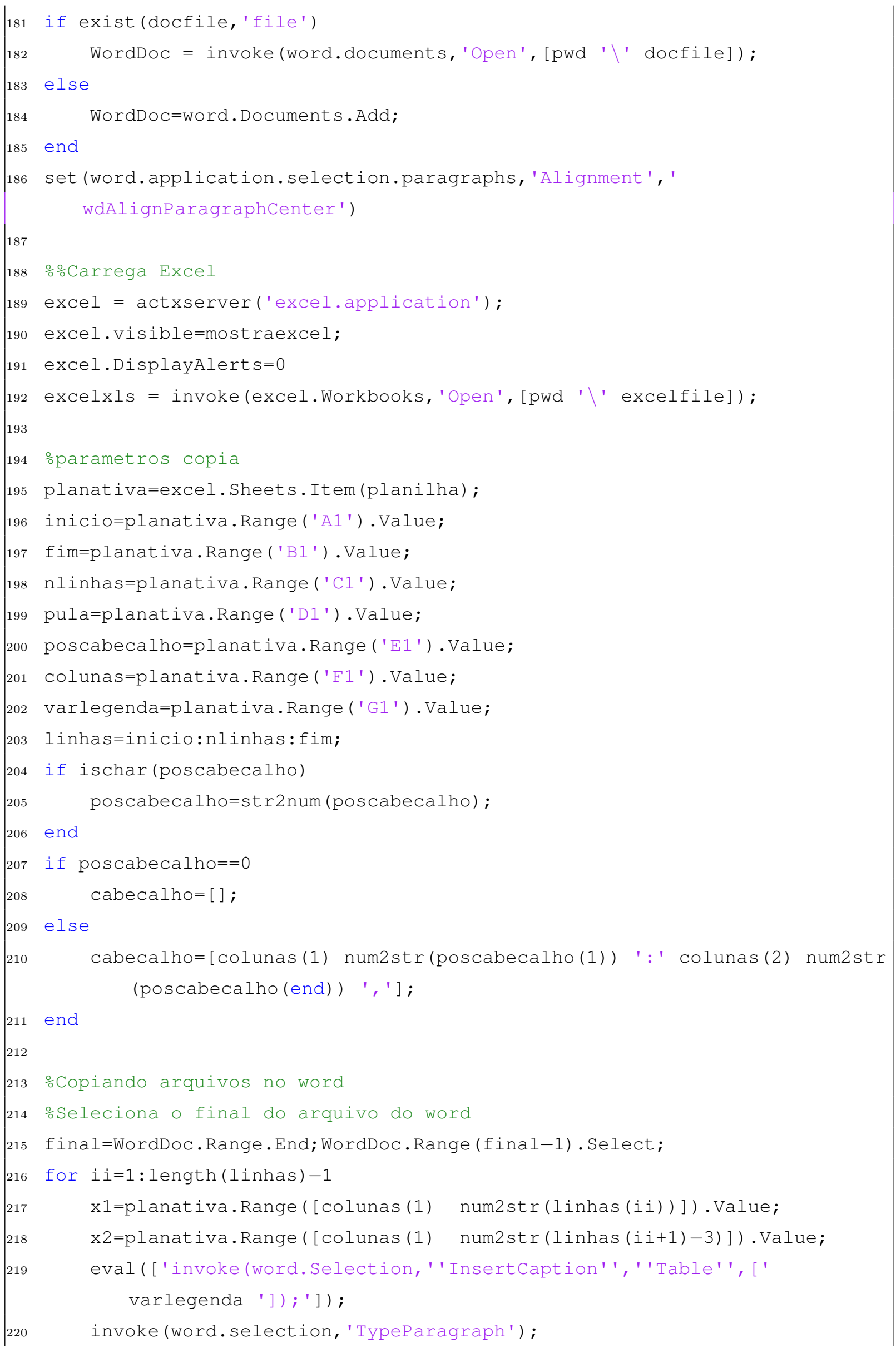




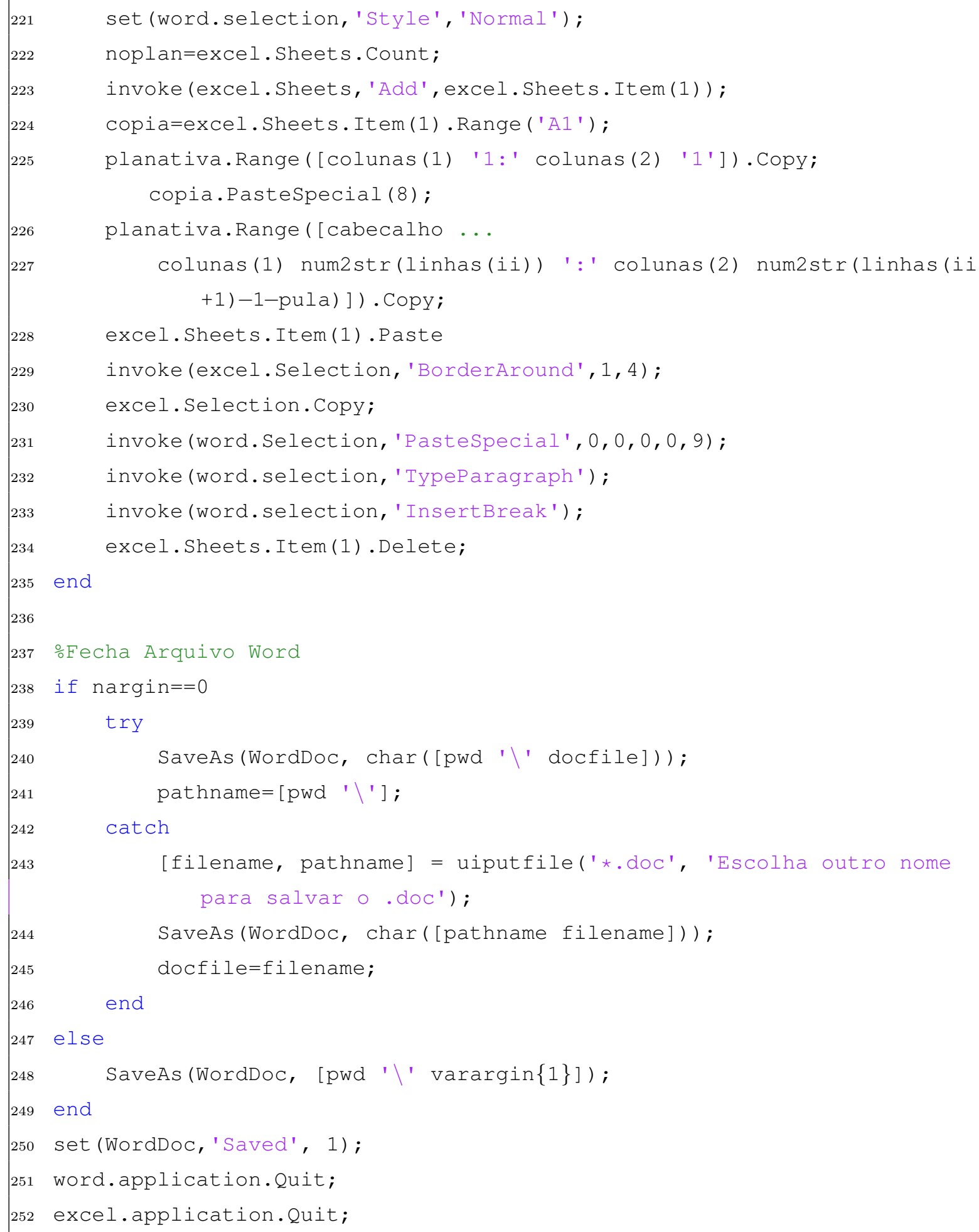




\section{Apêndice VII - Parâmetros em Escala}

Na Tabela VII.1 estão apresentadas qual a transformação entre os parâmetros na escala do modelo para a escala real. 
Tabela VII.1: Parâmetros em escala

\begin{tabular}{|c|c|c|}
\hline Variável & Unidade & Escala \\
\hline Comprimento & $\mathrm{m}$ & $\lambda$ \\
\hline Área & $\mathrm{m}^{2}$ & $\lambda^{2}$ \\
\hline Volume & $\mathrm{m}^{3}$ & $\lambda^{3}$ \\
\hline Tempo & $\mathrm{s}$ & $\lambda^{1 / 2}$ \\
\hline Posição & $\mathrm{m}$ & $\lambda$ \\
\hline Velocidade & $\mathrm{m} / \mathrm{s}$ & $\lambda^{1 / 2}$ \\
\hline Aceleração & $\mathrm{m} / \mathrm{s}^{2}$ & 1 \\
\hline Ângulo & graus & 1 \\
\hline Velocidade angular & graus/s & $\lambda^{1 / 2}$ \\
\hline Aceleração angular & graus $/ \mathrm{s}^{2}$ & $\lambda^{-1}$ \\
\hline Deslocamento & $\mathrm{kg}$ & $\lambda^{3}$ \\
\hline Inércia & $\mathrm{kg} \cdot \mathrm{m}^{2}$ & $\lambda^{5}$ \\
\hline Força & $\mathrm{N}$ & $\lambda^{3}$ \\
\hline Momento & N.m & $\lambda^{5}$ \\
\hline Amortecimento (surge, sway e heave) & $\mathrm{kg} / \mathrm{s}$ & $\lambda^{5 / 2}$ \\
\hline Amortecimento (roll, pitch e yaw ) & $\mathrm{kg} \cdot \mathrm{m} / \mathrm{s}$ & $\lambda^{7 / 2}$ \\
\hline Restauração (surge, sway e heave) & $\mathrm{N} / \mathrm{m}$ & $\lambda^{2}$ \\
\hline Restauração (roll, pitch e yaw ) & N.m & $\lambda^{4}$ \\
\hline
\end{tabular}




\section{Apêndice VIII - Propriedades de Alguns Sólidos}

Abaixo estão apresentadas as propriedades de alguns sólidos que auxiliam no ajuste da inércia dos modelos. As propriedades são os centros de massa, raios de giro e volumes.

Tabela VIII.1: Propriedades de alguns sólidos

\begin{tabular}{|c|c|c|c|c|}
\hline & Paralelepípedo & Cilindro & Semi-cilindro & Esfera \\
\hline$C_{x}$ & 0 & 0 & 0 & 0 \\
\hline$C_{y}$ & 0 & 0 & $-\frac{4 r}{3 \pi}$ & 0 \\
\hline$C_{z}$ & $\frac{L}{2}$ & $\frac{L}{2}$ & $\frac{L}{2}$ & 0 \\
\hline$K_{x x}$ & $\frac{\sqrt{3 a^{2}+3 L^{2}}}{6}$ & $\frac{\sqrt{9 r^{2}+3 L^{2}}}{6}$ & $\frac{\sqrt{9 r^{2}+12 L^{2}}}{6}$ & $\frac{10}{5} r$ \\
\hline$K_{y y}$ & $\frac{\sqrt{3 b^{2}+3 L^{2}}}{6}$ & $\frac{\sqrt{9 r^{2}+3 L^{2}}}{6}$ & $\frac{\sqrt{9 r^{2}+12 L^{2}}}{6}$ & $\frac{10}{5} r$ \\
\hline$K_{z z}$ & $\frac{\sqrt{3 a^{2}+3 b^{2}}}{6}$ & $\frac{\sqrt{2}}{2} r$ & $\frac{\sqrt{2}}{2} r$ & $\frac{10}{5} r$ \\
\hline$\nabla$ & $a b L$ & $\pi r^{2} L$ & $\frac{\pi r^{2} L}{2}$ & $\frac{4}{3} \pi r^{3}$ \\
\hline
\end{tabular}

Com as informações da Tabela VIII.1, a inércia das massas adicionadas ao modelo devem ser consideradas no balanço de inércia de acordo com as equações VIII.1, quando as massas estiverem rotacionadas com relação ao eixo de coordenadas global e seus eixos principais de inérica.

$$
\begin{aligned}
& \mathrm{I}_{x x}=\frac{I_{x x}+I_{y}}{2}+\frac{I_{x x}-I_{y}}{2} \cos (2 \theta) \\
& \mathrm{I}_{y y}=\frac{I_{x x}+I_{y}}{2}-\frac{I_{x x}-I_{y}}{2} \cos (2 \theta)
\end{aligned}
$$


Para determinar a inércia de transferência, as equações VIII.2 devem ser utilizadas.

$$
\begin{aligned}
& \mathrm{I}_{x x}=I_{x x}+m_{i}\left(x^{2}+z^{2}\right) \\
& \mathrm{I}_{y y}=I_{y y}+m_{i}\left(y^{2}+z^{2}\right)
\end{aligned}
$$

